University of South Florida

DIGITAL COMMONS

Digital Commons @ University of

@ UNIVERSITY OF SOUTH FLORIDA

South Florida

$5-19-2009$

\title{
An Empirical Examination of the Dark Side of Relationship Marketing within a Business to Business Context
}

Brent L. Baker

University of South Florida

Follow this and additional works at: https://digitalcommons.usf.edu/etd

Part of the American Studies Commons

\section{Scholar Commons Citation}

Baker, Brent L., "An Empirical Examination of the Dark Side of Relationship Marketing within a Business to Business Context" (2009). USF Tampa Graduate Theses and Dissertations.

https://digitalcommons.usf.edu/etd/1841

This Dissertation is brought to you for free and open access by the USF Graduate Theses and Dissertations at Digital Commons @ University of South Florida. It has been accepted for inclusion in USF Tampa Graduate Theses and Dissertations by an authorized administrator of Digital Commons @ University of South Florida. For more information, please contact digitalcommons@usf.edu. 
An Empirical Examination of the Dark Side of Relationship Marketing within a Business

to Business Context

by

\author{
Brent L. Baker \\ A dissertation submitted in partial fulfillment \\ Of the requirements for the degree of \\ Doctor of Philosophy \\ Department of Marketing \\ College of Business \\ University of South Florida \\ Co-Major Professor: Rajiv P. Dant, Ph.D. \\ Co-Major Professor: James R. Stock, Ph. D \\ Sajeev Varki, Ph. D. \\ James M. Curran Ph.D. \\ Michael L. Barnett Ph.D. \\ Michael D. Coovert Ph.D.
}

Date of Approval:

May 19, 2009

Keywords: trust, commitment, complacency, vulnerability, relational myopia

(C) Copyright 2009, Brent L. Baker 


\section{Dedication}

This dissertation and degree are dedicated to my loving wife Corinne, who said she'd come with me. 


\section{Acknowledgements}

I am indebted to several people who helped make this dissertation possible. I am grateful to Dr. Rajiv P. Dant at the University of Oklahoma, for agreeing to chair this dissertation. Dr. Dant has acted as a true mentor throughout my doctoral program. Dr. Dant believed in this research and spent countless hours reviewing my work in an effort to ensure I produced the best dissertation possible. I would like to thank Dr. Stock for agree to act as co-chair during the dissertation process. Dr. Stock's flexibility and understanding allowed for the completion of this dissertation in the most efficient and timely manner as possible. I also want to recognize the efforts of Dr. Curran who offered significant support in the form of advice and suggestions for my work. Dr. Curran was especially helpful during the analysis portion of this dissertation as he was always willing to listen and offer advice and solutions unavailable elsewhere. I also want to acknowledge the support of my other committee members. Dr. Sajeev Varki from the Marketing Department at the University of South Florida, Dr. Michael L. Barnett from the Management Department at the University of South Florida and Dr. Michael D. Coovert from the Department of Psychology at the University of South Florida. All of the above provided immeasurable help and support that made the completion of this dissertation possible. 
Table of Contents

List of Tables $\quad$ iv

List of Figures $\quad$ v

Abstract vi vi

Chapter One: Introduction 1

Chapter Two: The Dark Side of Relationship Marketing 10

Theoretical Development and Literature Review 12

Shared Values and the Dark Side of B2B Relationships 29

Shared Values $\quad 29$

Shared Values and Relational Myopia 34

Commitment and the Dark Side of RM 48

Commitment $\quad 48$

Commitment and Relational Myopia $\quad 52$

Commitment and Complacency $\quad 55$

Commitment and Vulnerability 61

Commitment and Suspicion $\quad 64$

$\begin{array}{ll}\text { Trust and the Dark Side of RM } & 68\end{array}$

Trust $\quad 68$

$\begin{array}{ll}\text { Trust and Relational Myopia } & 71\end{array}$

$\begin{array}{ll}\text { Trust and Complacency } & 75\end{array}$

$\begin{array}{ll}\text { Trust and Vulnerability } & 77\end{array}$

$\begin{array}{ll}\text { Trust and Suspicion } & 81\end{array}$

Satisfaction and the Dark Side of RM $\quad 83$

Satisfaction $\quad 83$

Satisfaction and Relational Myopia $\quad 86$

Satisfaction and Complacency $\quad 89$

Satisfaction and Vulnerability $\quad 92$

Satisfaction and Suspicion $\quad 93$

The Dark Side of RM Relationships' Influence on Relationship Strength 95

Relational Myopia and Relationship Strength 95

Complacency and Relationship Strength $\quad 97$

Vulnerability and Relationship Strength 99

Suspicion and Relationship Strength 101

Relationship Strength and Performance 103 
Chapter Three: Methodology 111

Research Setting $\quad 111$

$\begin{array}{ll}\text { Pre-Test } & 111\end{array}$

Data Collection Procedure $\quad 112$

Questionnaire 113

Relational Antecedent Measures $\quad 124$

Shared Values $\quad 124$

Commitment 124

Trust 126

Satisfaction 128

$\begin{array}{ll}\text { Dark Side Measures } & 129\end{array}$

Relational Myopia 130

Complacency 132

Vulnerability 132

Suspicion 133

Relationship Strength Measures 134

Performance Measures $\quad 135$

Time (Length of Relationship) Measure 136

Empirical Analysis 136

Rival Models 136

$\begin{array}{ll}\text { Chapter Four: Results } & 137\end{array}$

Pre-Test Results 137

Relational Antecedent Assessment (Pre-Test) 138

Pre-Test Reliability 138

Pre-Test Validity 141

Dark Side Assessment (Pre-Test) 145

Pre-Test Reliability $\quad 145$

Pre-Test Validity 147

Relationship Strength Assessment (Pre-Test) 149

$\begin{array}{ll}\text { Pre-Test Reliability } & 149\end{array}$

Pre-Test Validity 150

$\begin{array}{ll}\text { Performance Assessment (Pre-Test) } & 150\end{array}$

Pre-Test Reliability 150

Pre-Test Validity $\quad 150$

Main Study Results 151

Main Study Distribution Methods $\quad 152$

Non-Response Bias 154

Relational Antecedent Assessment (Main Study) 156

Main Study Reliability 156

Main Study Validity 157 
$\begin{array}{ll}\text { Dark Side Assessment (Main Study) } & 162\end{array}$

Main Study Reliability 162

Main Study Validity 163

Relationship Strength Assessment (Main Study) 166

Main Study Reliability 166

Main Study Validity 166

Performance Assessment (Main Study) 166

Main Study Reliability 166

Main Study Validity 167

$\begin{array}{ll}\text { Structural Model Assessment } & 167\end{array}$

$\begin{array}{ll}\text { Shared Values and Relational Myopia } & 170\end{array}$

$\begin{array}{lr}\text { Commitment and the Dark Side } & 170\end{array}$

$\begin{array}{ll}\text { Trust and the Dark Side } & 174\end{array}$

Satisfaction and the Dark Side 177

$\begin{array}{ll}\text { The Dark Side and Relationship Strength } & 179\end{array}$

Relationship Strength and Performance $\quad 181$

Chapter 5: Conclusion $\quad 193$

$\begin{array}{ll}\text { Summary } & 193\end{array}$

$\begin{array}{ll}\text { Theoretical Contributions } & 195\end{array}$

Managerial Implications $\quad 199$

$\begin{array}{lr}\text { Limitations } & 205\end{array}$

Future Research 206

$\begin{array}{lr}\text { References } & 210\end{array}$

Appendix 1: Pre-Test Survey 228

Appendix 2: Two Main Study Survey 246

Appendix 3: Three Survey Cover Letter 259

About the Author End Page 


\section{List of Tables}

Table $1 \quad$ Survey Sources, Reliability, Validity \& Items 116

Table 2 Pre-Test Reliability of Antecedent Relationship Constructs 139

$\begin{array}{lll}\text { Table } 3 & \text { Pre-Test CFA Results } & 141\end{array}$

Table 4 Pre-Test Discriminant Validity for Relational Antecedent Constructs 144

Table $5 \quad$ Reliability of Antecedent Relationship Constructs 145

Table $6 \quad$ Fit Indices for Dark Side Single Factor CFA 148

Table $7 \quad$ Dark Side Pre-Test Discriminant Validity 149

Table $8 \quad$ Number of Items Before and After Pre-Test 151

Table $9 \quad$ Reliability of Relational Antecedent Constructs 156

Table $10 \quad$ Main Study Relational Single Factor CFA Fit Indices 157

Table 11 Discriminant Validity for the Antecedent Measurement Model 162

Table 12 Reliability of Dark Side Constructs 163

Table 13 Fit Indices of Dark Side Constructs for Single Factor CFA 163

Table 14 Revised Dark Side Reliability and CFA Fit Indices 165

Table $15 \quad$ Dark Side Discriminant Validity Assessment 165

Table $16 \quad$ Antecedent-Dark Side Relationship Moderated by Time 169

Table 17 Relationships Between Relationship Strength and the Dark $\begin{array}{ll}\text { Side Constructs } & 179\end{array}$

Table 18 Dark Side-Relationship Strength Regression $\quad 180$

Table 19 Discriminant Analysis for the Dark Side and Relationship Strength 184 


\section{List of Figures}

Figure $1 \quad$ Dark Side Structural Model 9

$\begin{array}{lll}\text { Figure } 2 \quad \text { Dark Side Structural Model } & 28\end{array}$

Figure 3 Structural Model Illustrating Positive and Significant $\begin{array}{ll}\text { Path Coefficients } & 183\end{array}$

$\begin{array}{lll}\text { Figure } 4 & \text { Rival Model } 1 & 187\end{array}$

$\begin{array}{llr}\text { Figure } 5 & \text { Rival Model } 2 & 189\end{array}$

$\begin{array}{lll}\text { Figure } 6 & \text { Rival Model } 3 & 191\end{array}$ 
An Empirical Examination of the Dark Side of Relationship Marketing Within a Business to Business Context

Brent L. Baker

\begin{abstract}
A large number of empirical studies have illustrated the benefits of adopting and implementing a relational or relationship marketing strategy. However, there is an emergent stream of literature that suggests that despite the recognized benefits associated with this strategy there may also be a dark side that manifests itself between firms as a result of adopting a relationship marketing strategy. However, though this stream of literature recognizes the presence of the dark side, causal antecedents mediating the dark side constructs, or consequences of the dark side have yet to be theoretically derived, explained or empirically tested.

This dissertation constructs theoretical relationships between common relational constructs, such as trust and commitment and dark side symptoms such as relational myopia, complacency, vulnerability and suspicion. This dissertation also examines how these dark side symptoms, upon their onset, can yield negative consequences for the firms that have adopted the relationship marketing strategy. Data from a diverse set of business to business (B2B) relationships $(\mathrm{N}=305)$ was gathered to test the structural model implicit in the theoretical propositions presented in this dissertation. The results support the hypothesized notion of a dark side to B2B relationships as the relational
\end{abstract}


constructs of shared values, commitment, trust, and satisfaction were all found to have a positive, significant relationship with elements of the dark side. These results are discussed in detail within the chapters of this dissertation. 


\section{Chapter One: Introduction}

Relational marketing (RM) or the notions of relational exchange has assumed a predominant position within the marketing literature. Large numbers of empirical studies have illustrated the benefits of adopting a relational perspective for implementing and governing business to business (B2B) exchange relationships. However, there is a small body of emergent literature that suggests there might be negative consequences or a dark side to implementing the RM strategy. For example, in an effort to explain the limited effects of involvement and commitment on research use, Moorman, Zaltman, \& Deshphande (1992) suggest that members of a long term B2B relationship may lose their ability to objectively evaluate each other. They also suggest that the relationship may become stale and or boring which may inhibit new ideas. Grayson and Ambler (1999) empirically investigated Moorman, Zaltman, \& Desphande’s (1992) suggestions regarding long term $\mathrm{B} 2 \mathrm{~B}$ relationships and the proposed weakening of relational constructs in business relationships over time. Though Grayson and Ambler (1999) were able to support the weakening of certain relational constructs, interpreted as the existence and manifestation of the dark side, the authors were unable to offer an explanation for this manifestation. Other authors, such as Hibbard et al. (2001) and Pressey and Tzokas (2004) have directly investigated the existence of the dark side and have been consistent in their support for the phenomenon. However, the explanation for "why" B2B relationships often develop this down or negative side is not as well explained. 
Anderson and Jap (2005) recently provided anecdotal accounts of the dark side of B2B relationships. The authors suggest that such things as (1) immediate benefits, (2) interpersonal relationships between boundary spanners and (3) transaction specific investments all provide initial benefits for the firms involved but begin to yield negative effects with the passage of time. Also, though the authors do offer suggestions for avoiding or suppressing the dark side, the identification of the causal factors provoking its onset remains unclear.

The above review provides evidence of marketing's recognition of the dark side phenomenon. However, although scholars have mentioned the dark side, they have never discussed its operationalizations in a systemic manner. Figure one below illustrates the relationships between oft studied relational constructs such as trust, commitment, satisfaction et al. (c.f. Palmatier et al. 2006; Palmatier, Dant and Grewal 2007) and the dark side constructs of relational myopia, complacency, vulnerability and suspicion. The model also illustrates how these dark side constructs may be related to relationship strength as well as how the length of the relationship or time, as labeled in the model, will moderate the relationships between the relational constructs and the dark side constructs. The following dissertation theoretically develops and empirically investigates many of the common relational constructs familiar to the RM literature (c.f. Palmatier et al. 2006; Palmatier, Dant, and Grewal 2007), as potential antecedents to certain dark side symptoms. The dark side elements investigated in this dissertation consists of relational myopia, complacency, vulnerability and suspicion. Though perhaps counterintuitive this dissertation suggest that relational antecedents typically viewed as positive influences on B2B relationships may lead to these darks side constructs. 
After reviewing the relevant literature this dissertation explores the shared values construct, reviewing its various conceptualizations, operationalizations and definitions within the B2B context. This dissertation also explores how shared values may lead to a shared but narrowed view of the business environment labeled within this dissertation as relational or relationship myopia.

Following the shared values discussion, this dissertation discusses how commitment can lead to the onset of several dark side symptoms. Specifically, this dissertation examines how different components of commitment are related to such things as a narrowed or myopic view of the exchange relationship and complacent attitudes toward the relationship and the business environment. How these complacent and myopic views may constrict an organization's ability to take advantage of the opportunities presented to them via the business environment with which they operate is also discussed.

This dissertation also explores the dark side constructs of vulnerability and suspicion and how they relate to firms in a committed B2B relationship. Just as relational myopia and complacency can be provoked via relational constructs such as commitment, feelings of vulnerability and suspicion are also believed to manifest and can be directly attributable to relational constructs such as trust, satisfaction and commitment. For example, as firms become more integrated with their exchange partner(s) they allow themselves to become more transparent and this exposure will naturally lead to feelings of vulnerability and suspicion.

Trust and commitment are two of the more heavily studied relational constructs in the RM literature (Palmatier et al. 2006). The recent meta-analysis published by Palmatier et al. (2006), investigating the factors that influence RM effectiveness, found 146 and 96 
separate effects between trust and commitment respectively. By comparison, this same meta-analysis only found 36 effects between antecedents to relational mediators and relationship quality. Though often cited as one of the more important constructs needed for B2B relationship development (e.g. Dwyer Schurr and Oh 1987; Morgan and Hunt 1994) this dissertation suggest that trust may also act as an antecedent for all of the dark side symptoms mentioned above. For example, a focal firm may trust a distributor to deliver a high demand product vital for the focal firm's success. Without that product, the focal firm will not be able to deliver this product to their customers, which could cost the focal firm customers, profitability and damage to their reputation. As these negative consequences become a reality the focal firm will attribute the realization of these consequences to their distributor's inability to deliver as expected (and obviously as needed). It makes sense that in such a scenario, the focal firm will feel anger toward their partnering firm but also vulnerable upon realizing that the trust in their partnering firm left them exposed to their partnering firm's potential failure. In other words, instead of working to secure delivery themselves, the focal firm believes their partnering firm will deliver as promised. Delivery failure of course can be harmful to the focal firm but initially may not be something that is even considered. It is not until the partnering firm fails to deliver that the focal firm realizes it misplaced its trust as feelings of vulnerability are provoked. The above example illustrates how trust may lead to the onset of vulnerability.

Just as trust and commitment have been studied extensively within the B2B literature (Palmatier et al. 2006) satisfaction has also received a significant amount of attention (e.g. Garbarino and Johnson 1999; Kumar, Scheer, and Steenkamp 1995). Just as this 
dissertation explores how the seemingly positive relational constructs of shared values, trust and commitment can lead to negative effects or outcomes for the firms engaged in the relationship it also analyzes satisfaction and its relationships with the dark side. The proposition that firms that are satisfied with their exchange partners can be affected by the dark side may initially be counterintuitive but with a deeper analysis of these constructs the relationship to the dark side becomes more apparent. For instance, if a firm that is satisfied with the financial rewards associated with being involved in a certain business relationship is focused solely on these financial rewards with little to no attention on the relationship itself, then their view of the relationship is analogous to the myopic firm as originally proposed by Leavitt (1960). If an economically satisfied firm has not acknowledged the other aspects of the relationship then it is possible their narrow or shortsighted view is blinding the firm to issues that may need attention or relational opportunities that may further enhance relational performance. Regardless of what the firm is missing by having such a narrow focus toward the financial aspects of the relationship, the point remains that the firm's view toward the relationship is narrower than what it could be and thus the satisfied firm, as described in this example, is relationally myopic. This hypothetical example illustrates just one possibility of how satisfaction may hasten the onset of the dark side symptom of relational myopia. Satisfaction is believed to have the ability to also hasten the other dark side symptoms discussed in this dissertation. These relationships are theoretically derived and explored in more detail in Chapter two of this dissertation.

Alluded to above, is the idea that these dark side relationships become a destructive force for B2B relationships when they begin to hinder or in some other way inhibit 
relational performance. This runs counter to most of the current RM literature as the notion that employing an RM strategy yields positive benefits for the firm employing the strategy is fairly well supported (Palmatier et al. 2006). However, there is no consensus regarding which relational constructs influence performance the most or are most important for the success of the RM strategy (Palmatier et al. 2006). For instance, some researchers suggest that trust and commitment are most important (e.g. Morgan and Hunt 1994) while others believe trust by itself is most important (Doney and Cannon 1997). Still, others suggest commitment should be regarded as the most important relational construct. Yet, others believe that a more global measure, such as relationship quality, consisting of trust, commitment and satisfaction is the most appropriate way of measuring an RM strategy's influence on performance (e.g. Kumar, Scheer, and Steenkamp 1995).

This dissertation deviates significantly from this line of thinking by suggesting that not only can the dark side manifest in B2B relationships it can also influence the strength of the $\mathrm{B} 2 \mathrm{~B}$ relationship. This dissertation explores the relationships between relational constructs and the dark side as well as how these relationships influence relationship strength which is believed to influence perceptions of performance.

Finally, time is expected to moderate the relationships between the relational constructs and the dark side symptoms. Exactly how much time must pass before the dark side will set in is impossible to pinpoint as each B2B relationship will advance through the relationship development phases (c.f. Dwyer, Schurr, and Oh 1987) at differing rates, depending on such things as the industry, firm personnel and frequency of contact. However, regardless of industry, time will have to pass to let the B2B 
relationships develop to the point where the dark side can manifest. Although the amount of time needed may be shorter in one industry than in another, there is no denying the importance of time as a moderating variable on the relationships between the relational constructs and the dark side symptoms discussed in this dissertation.

An empirical study was conducted in an effort to test the hypothesized relationships proposed in this dissertation. As the relational constructs used in this dissertation have already received significant empirical attention, the items used to measure these relational constructs in this dark side study have been adapted from this existing body of work. However, the dark side constructs examined in this dissertation have yet to receive any empirical attention within the B2B literatures. Therefore, items have been adapted from several other disciplines and research settings. The appropriateness of each item is argued deductively and discussed in greater detail in chapter three of this dissertation. Given the exploratory nature of this study, a battery of items based on the constitutive definitions of these dark side constructs is also developed. These items are also discussed more fully in chapter three of this dissertation.

Six qualitative interviews were conducted prior to the empirical portion of the study. The interviews provide qualitative data that can be used to help theoretically derive relationships between constructs, as well as support hypothesized directionality, something that is difficult to do using only a cross sectional empirical study. Interviews were conducted with people from both sides of the relationship dyad. Three buyers and three sellers were asked to talk about their beliefs and experiences as it pertains to B2B relationships and the onset of dark side. B2B relationship managers on the buying side of the dyad produced 305 usable surveys used for the empirical examination of the dark 
side. The empirical results support the hypotheses that over time, shared values, commitment, trust, and satisfaction do have a significant relationship with three of the four dark side constructs introduced in this dissertation. The details of this empirical study, as well as a detailed interpretation of these results are discussed in chapters three and four of this dissertation.

Given the broad acceptance, support and implementation of the relational marketing paradigm, knowledge of its shortcomings will be invaluable insight to practitioners, firms and industries embracing the processes that the relational exchange paradigm promotes. Relationship marketing can be costly and demanding on a firm's resources. Insight into where and why relationships begin to fail should prove financially advantageous for firms investing in developing relational exchange norms and processes. These insights will also prove useful when evaluating a firm's long versus short term business relationships. The ability to spot potential causes of future dark side behaviors should provide firms the ability to stop these behaviors before they have had a chance to fully manifest resulting in destructive consequences. This ability will not only save the firm money, time and resources it may also provide the firm the ability to maintain profitable B2B relationships that may have otherwise disintegrated. In turn, it would allow firms objectivity needed to sever B2B relationships that have stopped being profitable or have otherwise become destructive. A more detailed discussion of these implications is presented in chapter five of this dissertation. This chapter thoroughly discusses the theoretical and managerial implications of the results of this dissertation. Limitations and suggestions for further research are also suggested in this final chapter. 
Figure 1: Dark Side Structural Model

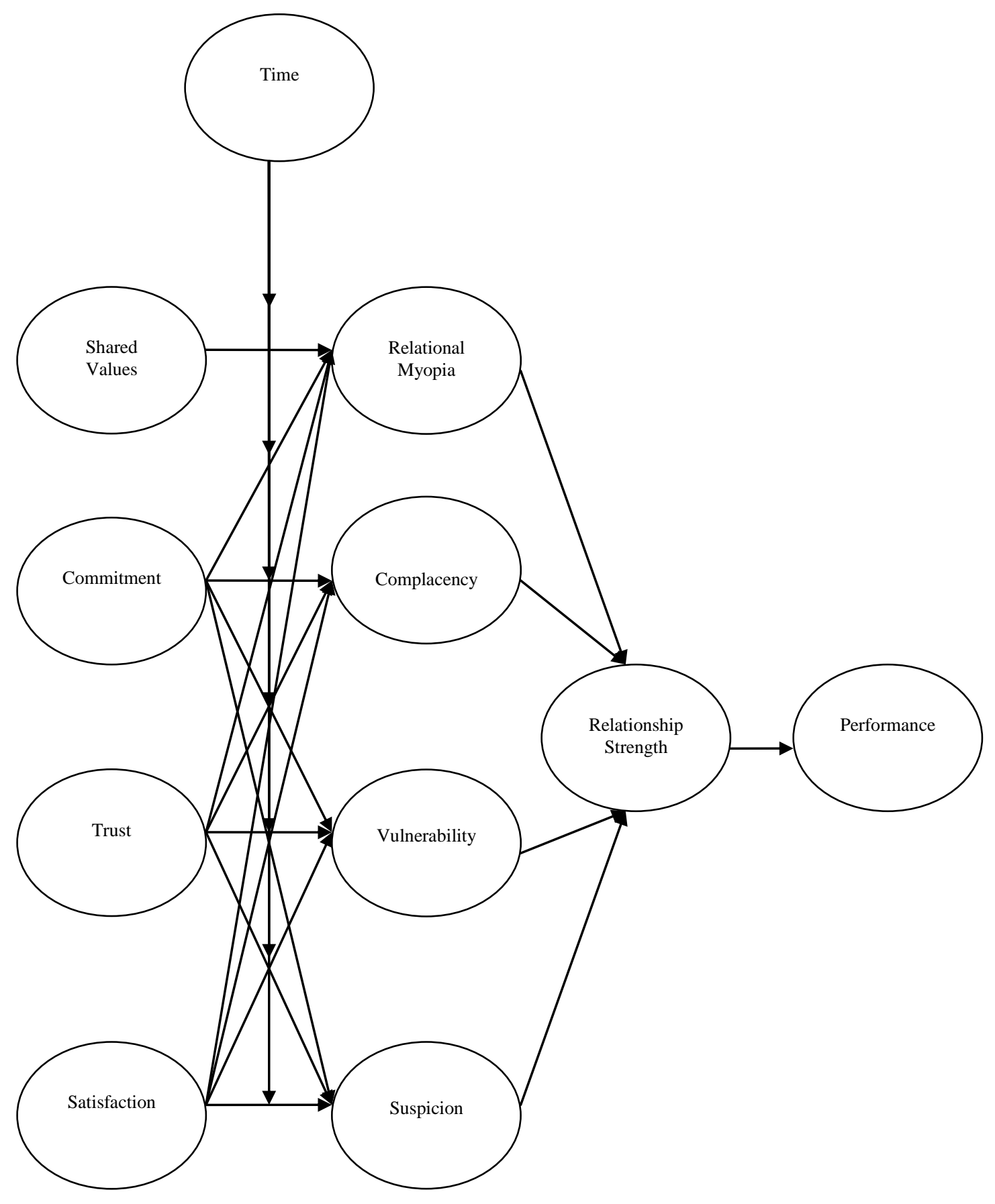




\section{Chapter 2: The Dark Side of Relationship Marketing}

Relationship marketing $(\mathrm{RM})$ has received considerable attention in both business and academic circles in recent years (Palmatier et al. 2006; Srinivasan and Moorman 2005). This considerable amount of attention is understandable given the positive outcomes generally associated with adopting a RM strategy. Specifically, successful B2B relationships have been recognized as a significant contributor to a firm's financial performance as well as increased efficiencies, expanded markets, reduced costs and greater innovation (Cannon and Homburg 2001; Palmatier, Dant and Grewal 2007; Rindfleisch and Moorman 2001). Other more relational benefits of a successful B2B relationship include: greater cooperation (Palmatier, Dant and Grewal 2007), reduced opportunism (Ganesan 1994) increased commitment (Verhoef, Franses, and Hoekstra 2002) and greater satisfaction (Geyskens, Steenkamp, and Kumar 1999).

Given all of the benefits of actively seeking out and maintaining B2B relationships, all of the academic and managerial attention RM has received certainly seems warranted. However, there is an emerging body of literature that suggests that RM isn't without its dark side and may even carry the seeds of its own destruction (Anderson and Jap 2005; Grayson and Ambler 1999; Hibbard et al. 2001; Pressey and Tzokas 2004). Some of the characteristics of this dark side include: the deterioration of relationship strength over time (Grayson and Ambler 1999; Hibbard et al. 2001; Moorman, Zaltman, and Desphande 1992), declining relationship interest over time (Bennett 1996) and firms, due 
to inertia, remaining in unprofitable or inefficient relationships long after they should have been terminated (Haytko 2004; Young, and Danize 1994).

This dark side of business to business relationships (B2B) should not be confused with implementing a RM strategy where one is not appropriate. For instance Rao and Perry (2002) conclude that such things as the type of product or service being marketed, the potential exchange partner's receptivity toward having a relationship, the firm's industry and internal organization are all factors that need to be considered when deciding whether or not implementing a RM strategy is appropriate. Given the expense associated with $\mathrm{RM}$ it is easy to see how if the above factors are not conducive to such implementation the strategy might yield negative and costly results (Rao and Perry 2002).

The dark side is also not to be confused with poor implementation of the relationship strategy (e.g. Colgate and Danaher 2000; Colgate and Lang 2005). Poor implementation isn't so much a strategic issue as it is a problem with execution. The dark side of B2B relationships is believed to lie within RM itself. That is, the adoption of a RM strategy is itself believed to lead to such dark side symptoms as complacency, relational myopia, vulnerability and suspicion regardless of the appropriateness of the strategy or how well the strategy is implemented.

The following discussion briefly reviews RM including its origin and how it has evolved into one of the dominant areas of interest within the marketing and B2B literature. The following discussion also provides a detailed and descriptive review of the relevant but limited dark side RM literatures. Drawing from this literature and several other areas within the marketing domain, a formal definition of the dark side is then presented. Using this definition as a guide this dissertation draws from several areas and 
theoretical domains such as management, social psychology and the marketing exchange literature to develop a nomological network illustrating several key relational constructs and their influence on several dark side symptoms. The relational constructs of commitment, trust, shared values, and satisfaction are discussed in relation to the dark side of B2B relationships. Specifically, how these relational constructs may provoke the onset of such dark side symptoms as complacency, myopia, vulnerability and suspicion as well as how the dark side subsequently influences relationship strength and performance. Finally, the moderating role of time is introduced as this variable is believed to be crucial in any investigation involving the dark side of B2B relationships in that it is the inexorable passage of time that is purported to convert a functional B2B relationship into a dysfunctional one. Drawing from this discussion, testable hypotheses relating these constructs to the dark side as well as the dark side to relationship strength and subsequently, performance are also presented.

\section{Theoretical Development and Literature Review}

Relationship marketing has its roots in social exchange theory. Social exchange theory is a psychological theory derived from the work of Thibaut and Kelley (1959), used for explaining human behavior within groups. The theory is rooted in the notions of reciprocal exchange. The reciprocal rule dictates that as one individual gives, another person returns, in some measure, what was given (Bothamley 1993; Thibaut and Kelley 1959). The balance of this exchange is not always equal however. Social exchange theory explains that how an individual feels about a relationship and the exchanges within the relationship are dependent on the individual's perceptions of (1) the difference between what is put into the relationship and exchange versus what is returned (2) the 
kind of relationship we feel we deserve and (3) the chances of having a better relationship with someone else or the attractiveness of alternatives (Thibaut and Kelley 1959).

Comparison level and a comparison level for alternatives are used for calculating what is fair regarding the outcomes of exchange (Kelley and Thibaut 1978). Anderson and Narus (1984) defined the comparison level in the channels of distribution context as (p. 63) “...a standard representing the quality of outcomes the distributor (manufacturer) has come to expect from a given kind of relationship, based upon present and past experience with similar relationships, and knowledge of other distributors' (manufacturers) similar relationships. The results of the exchange relationship are compared against this standard and determine the attractiveness of the relationship and of the exchange itself." The comparison level of alternatives can be defined, within the channels of distribution context as “.... a standard that represents the average quality of outcomes that are available from the best alternative exchange relationship" (Anderson and Narus p. 63). The comparison level of alternatives can be seen as a sort of zero point or the lowest level required for the comparison level standard to remain the most attractive choice. If the comparison level of alternatives is higher or rather the perceived benefits of an alternative relationship exceed those of the current relationship then exchange partners should be expected to switch to the more attractive relationship. Kelley and Thibaut (1978) do say however, that the emotional, social or legal costs associated with switching to the more rewarding relationship may simply be too restrictive to affect such a change.

Drawing from social exchange theory, many marketing researchers began to shift their emphases to the marketing relationship. For example, Bagozzi (1978) argued that 
relationships are the essence of marketing. Hunt (1983) echoed similar sentiments when he argued that the primary focus of marketing is the exchange relationship. Arndt (1979) believed that long term buyer seller relationships are important for the growth of domesticated markets. Other works in the marketing literature that illustrates the shift toward a relational focus in the marketing literature include (Ferber 1970; Kotler 1972; Kotler and Levy 1969).

It is with this focus on the relationship within the marketing context that the notion of RM was born. Many definitions of RM have been introduced (Hultman and Shaw 2003). However, many of these definitions fall short of defining all forms of relational exchange (Morgan and Hunt 1994). Many definitions stress the importance of the acquisition and retention of customers but neglect other aspects of relational exchange such as those between a focal firm and its stakeholders aside from customers, such as its employees, the government and suppliers among others (Hultman and Shaw 2003). For instance, Groonos (1991) explains that the establishment and maintenance of relationships is RM’s primary purpose. Barry (1983) defined RM as “Attracting, maintaining, and enhancing customer relationships". Jackson (1985) defined RM as "Marketing oriented toward strong, lasting relationships." (p. 2). In an effort to cover all forms of relational exchange, Morgan and Hunt (1994) proposed the following definition of RM "Relationship marketing refers to all marketing activities directed towards establishing, developing, and maintaining successful relational exchanges" (p 22).

Macneil (1980) categorizes types of commercial exchange on a continuum ranging from relational on one extreme to discrete on the other. Discrete transactions are those with very little to no relational behavior between the exchange partners (Macneil 1980). 
The classic example of a purely discrete transaction is the one time, out of town, cash purchase of unbranded gas from an independent gas station (Dwyer, Schurr and Oh 1987). The other side of the continuum is relational exchange or the long term continuous relationship in which the relationship is more important to the exchange partners than individual exchanges (Macneil 1980). Also important to note is that relational exchange occurs over time. With relational exchanges the relationship is said to begin at the end of the first transaction and implicitly carried on into the future (Dwyer, Schurr, and Oh 1987).

The way contracting norms manifest and subsequently govern the exchange relationship is another characteristic of relational exchange that differentiates it from discrete transactions that do not produce such norms (Kaufmann and Stern 1988). Macneil developed these relational norms as a way of explaining the principals that guide, control, and regulate proper relational exchange behavior (Ivens and Blois 2004). These norms include such sentiments as role integrity, reciprocity, flexibility and solidarity among others. Though a detailed discussion of each of Macneil's relational norms is outside the scope of this dissertation it should be noted that a large number of marketing researchers have utilized Macneil's notions of relationalism and relational norms when investigating RM and the governance of relational exchange (e.g. Bello and Gilliland 1997; Dant and Schul 1992; Heide 1994; Heide and John 1992; Kaufmann and Dant 1992; Kaufmann and Stern 1988).

As one may discern from the above discussion that RM is concerned with creating a series of sequential exchanges that are closer and long term orientated compared to individual discrete exchanges typical of a discrete orientation (Dwyer, Schurr and Oh 
1987; Hultman and Shaw 2003). More succinctly, tying the customer or exchange partner to the firm with a series of transactions following the establishment of the exchange relationship is the goal of RM (Ford 1980; Hultman and Shaw 2003), while discrete transactions or exchanges involve a single, short time exchange with a distinct beginning and end (Gundlach and Murphy 1993).

RM and relational exchange has received broad acceptance from marketing academics as well as marketing practitioners (Morgan and Hunt 1994; Palmatier et al. 2006; Rao and Perry 2002). Some view relational marketing as a paradigm shift or change in world view that essentially overturns most previous marketing thinking (Gronroos 1996; Sheth and Parvatiyar 1995) while others view relational marketing as a strategic focus ( $\mathrm{Li}$, Greenberg and Li 1997) or merely a tactic or strategy used while conducting marketing activities (Davis 1995; Larson 1997). All areas of marketing, from professional selling (e.g. Bejou 1994; Chonko and Tanner 1990; Crosby, Evans and Cowles 1990) to services marketing (Allen 1988; Berry 1983; Gronroos 1988) or from channels of distribution (Johnson 1999; Kumar, Scheer and Steenkamp 1995; Siguaw, Simpson and Baker 1998) to retailing (Reynolds and Beatty 1999; Srinivasan and Moorman 2005) have reportedly benefited from the adoption of the RM paradigm or more specifically, the adoption of business practices that are based on interactions within a network of relationships (Bejou 1997; Gummesson 2004). There have been numerous journal articles, special journal issues as well marketing conferences dedicated to RM topics and research (Rao and Perry 2002). Whether RM represents an actual paradigm shift in marketing thought or is merely a marketing strategy is still a matter of some debate (Rao and Perry 2002) 
The vast amount of attention RM has received should come as no surprise considering that the benefits of adopting a relational as opposed to a discrete approach toward marketing are very well documented. For example, when the relational variable of trust is high between two partners, higher profits are said to be realized as well as an increased ability to serve customers (Kumar 1996). Greater relationship satisfaction and anticipation of future contracts from customers have also been linked to an RM or relational exchange mindset (Anderson and Narus 1990; Doney and Cannon 1997). Also, RM approaches have been found to positively influence performance variables like profitability (Anderson and Weitz 1989; Lusch and Brown 1996) sales (Palmatier et al. 2006) or other financial metrics such as ROI (Iacobucci and Hibbard 1999).

However, in spite of the rather sizeable amount of literature extolling the virtues of $\mathrm{RM}$, some executives have been disappointed in the results of their RM efforts (Colgate and Danaher 2000; Palmatier 2007) while other researchers suggest there may be a dark side to implementing a RM strategy.

Of the limited amount of RM literature that discusses the dark side of B2B relationships, no piece is cited more than the 1992 work by Moorman, Zaltman and Desphande. The authors, using a sample of market research users and marketing research providers empirically investigated the role of trust between these knowledge users and knowledge providers. The authors found that trust and perceived quality of interaction contribute most significantly to research utilization, with trust having indirect effects through other relationship processes. However, the authors also found that involvement and commitment do not have much effect on research use. In an effort to explain why involvement and commitment do not influence the use of the information provided by the 
research provider the authors suggest that members of the long term relationship may lose their ability to be objective, which detracts from their effectiveness (p.323). Also, the relationship may become stale or the members of the relationship may become too much like each other which may breed boredom and subsequently inhibit new ideas (p.323). The authors suggest higher expectations between the members of the relationship as the relationship wears on (p.323). Finally, the authors suggest that opportunities for opportunistic behavior arise as the result of increased commitment and involvement (p.323). Though the authors do not formally declare these behaviors or attitudes toward the $\mathrm{B} 2 \mathrm{~B}$ relationship as the dark side, subsequent literature has referred to this article and specifically these behaviors and attitudes as the dark side.

Interestingly, these explanations were not empirically investigated in this work as this piece investigated the value of trust in the $\mathrm{B} 2 \mathrm{~B}$ relationship, not the manifestation of these dark side symptoms.

In 1999 Grayson and Ambler produced what is essentially the first empirical piece of research investigating the dark side of B2B relationships. This work, as far as can be discerned by the author of this dissertation, is the first work to utilize the phrase "dark side" regarding the potential hazards of implementing a RM strategy. Their work first sought to replicate the previous empirical work by Moorman, Zaltman, and Desphande (1992) and then extend their work by empirically investigating the aforementioned author's inability to support their hypothesized link between relational constructs and use of market knowledge provided by the knowledge provider. Grayson and Ambler (1999) used the propositions in the Moorman, Zaltman, and Desphande (1992) work to describe the dark side. More specifically, the suggestions proposed by Moorman, Zaltman, and 
Desphande (1992) that firms lose the ability to remain objective when evaluating exchange partners, increased opportunism in long term relationships, and increased expectations between exchange partners are the manifestations of the dark side put to test. Grayson and Ambler (1999) were unable to empirically support the notion that their dark side constructs, such as perceived opportunism, perceived loss of objectivity and rising expectations, mediate the relationships between trust and advertising use. In other words, though they found evidence to suggest that the effects of trust are dampened in long term relationships, they were unable to link this effect to the dark side constructs originally suggested by Moorman, Zaltman, and Desphande (1992).

Hibbard et al. (2001) took the investigation of the dark side of B2B relationships a step further than previous work when they empirically investigated the dark side phenomenon. Though the authors do not offer a definition of the dark side they do describe what can be inferred as the dark side by suggesting that over time the association between performance and certain relational variables will weaken:

"Specifically, it may be that attitudes and behaviors associated with a strong, close relationship (trust, commitment etc) become less important over time in terms of their impact on performance..." (p.30)

In this work the authors empirically investigated the relationship between relational constructs of trust, commitment, communication, shared values and mutual dependence and their influence on performance over time. The results were interesting in that the correlation between the relational variables and performance initially strengthened but over time began to diminish. The results of this study were consistent with Grayson and Ambler (1999) in showing that a dark side of B2B relationships does indeed exists. 
Though this article conceptually extended the limited understanding of the dark side of B2B relationships by empirically linking it to several relational variables, it does fail to operationalize any of the theoretical reasons for the onset or manifestation of the dark side of B2B relationships. Instead, the authors used time as a surrogate for the emergence of dark side sentiments and concluded that over time, the links between relational constructs and performance decline, implying that dark side symptoms must have developed. In other words, the actual emergent dark side sentiments have yet to be overtly measured in the extant literature.

Another work offering a significant contribution to the scant dark side literature is the piece by Pressey and Tzokas (2004). This paper looks at the dark side of long term relationships using a cross industry sample of UK exporters who are engaged in a relationship with a principal foreign customer. The authors draw from the previous literature on the topic to describe the dark side. Consistent with previous published works, the authors describe symptoms of the dark side as the loss of objectivity over time due to the high level of experience produced through extended and close B2B relationships (p. 696). The relationship may also become stale over time due to the perceptions of less added value (p. 696). Expectations also are said to increase over time (p. 696) and again, there may be a perception that one exchange partner is taking advantage of the other opportunistically (p. 696). Like Hibbard et al. (2001), Pressey and Tzokas (2004) use the passage of time as a surrogate for the onset of the dark side but do not directly operationalize the reasons for its onset. The authors found that there is indeed a dark side but it isn't as extensive or significant as some of the previous literature might suggest. More specifically, the authors found that there is some weakening of 
export relations over time in terms of level of commitment but as the authors state "if this can be described as a dark side then it surely must be surpassed by the importance placed in competence and the relative increase in performance" (p. 699). In effect, like Hibbard et al. (2001), Pressey and Tzokas (2004) too failed to directly operationalize the reasons for the emergence of dark side.

Anderson and Jap's qualitative article in the Sloan Management Review in 2005 uses a case study approach to examine, define and explain the dark side of B2B relationships. The authors describe the dark side of long term relationships between organizational partners as something that subtly undermine relationships in which parties are confident and optimistic about their collaboration and where both parties are receiving ongoing benefits. The authors are quick to point out that this dark side phenomenon is not the same thing as a B2B relationship that has soured and subsequently become dysfunctional and destructive. Rather, the authors interpret the dark side as a force that subtly undermines relationships that are believed by the exchange partners to be otherwise healthy. This article explains that close personal relationships can be a problem because it enables opportunism (p. 75). Also, offering immediate benefits seems to be a trade off between short-term and long-term gains and is a natural point of tension (p. 78). Finally, being unique may also be a problem since you are not motivated by the dynamics of the market since competition is minimized or eliminated altogether (p. 79).

Both Pressey and Tzokas (2004) and Anderson and Jap (2005) suggest that the variables that promote a good B2B relationship may also be the variables that eventually undermine the relationship. This dissertation expands this notion of the dark side of B2B relationships by claiming that it's the adoption of a RM strategy that eventually leads to 
the dark side of B2B relationships. More specifically, this dissertation suggests that such relational constructs as trust, dependence and even commitment may, over time, have a detrimental effect on the ability of a firm to achieve its organizational goals. Therefore, the dark side can be defined as the decrease in a firm's ability to obtain organizational goals resulting from the investment in B2B relationships.

The purpose of this dissertation is to explore potential boundaries of the RM strategy and its usefulness within the B2B context and how the continued investment in resources toward business relationships past the point of the relationship's ability to provide positive results might actually hurt a firm's ability to achieve its goals. This dissertation discusses the results of an empirical study designed to investigate the onset of dark side behaviors or symptoms within the B2B relationship context. The results of this study may be used to call into question the appropriateness of the relational exchange paradigm as well as contribute to the scant amount of literature that actually explores the down side of implementing a RM strategy.

The limited amount of literature discussed above should illustrate how new and in need of investigation this area of marketing and more specifically the dark side of relationship marketing or relational exchange actually is. However, the above cited works, though exhaustive as it pertains to the most relevant and up to date work that directly examines the dark side, it should not be confused as an exhaustive description of all the B2B and marketing literatures that have ever indirectly discussed or otherwise mentioned the dark side. Several works have indirectly investigated the dark side of B2B relationships (e.g. Colgate and Danaher 2000; Stewart and Durkin 1999) while others have casually mentioned the dark side and recognized the potential hazards of relational 
exchange strategies and that a relational exchange strategy is not always appropriate (e.g. Palmatier et al. 2006; Rao and Perry 2002). Much of this work will be referred to in the following discussion dedicated to the development of a conceptual taxonomy illustrating dark side behaviors and the antecedent conditions that lead to them.

To further clarify, a distinction should be made between marketing literature that has investigated bad B2B relationships and literature that has investigated the bad side of B2B relationships. In other words, there are several works that have found in their empirical investigations B2B relationships that were not performing according to the relational exchange paradigm. However, most of these works found that some key relational constructs, such as commitment, trust or dependence were not aligned with the basic tenets of relational exchange and thus produced B2B relationships that were less than optimal and perhaps ineffectual. For example, Stewart and Durkin (1999) examined the appropriateness of RM techniques in the Irish bank industry. They found considerable barriers toward a relational marketing strategy when Irish banks were trying to court students as new customers. Colgate and Danaher (2000) found that poor relationship implementation could actually lead to worse results in the New Zealand Banking industry, than banks that did not implement a relationship strategy at all. Colgate and Lang (2005) support Colgate and Danhaer's (2000) earlier findings in the New Zealand bank industry when their study found that greater customer satisfaction resulted from good relational implementation but that poor relational implementation resulted in poor customer satisfaction compared to banks that did not implement a RM strategy. 
The above literature review highlights the limited but key work that has discussed to some extent the dark side of adopting a RM strategy. Though the dark side has received little attention in the RM literature, it should be noted that other areas of study have also recognized the potential hazards associated with business relationships. For example, Spekmen et al. (1998), when discussing the rationale for strategic alliances, recognize that though there are benefits to alliance formation there are also potential hazards, or as in the authors words, a 'dark side' that may accompany these benefits. Specifically, the authors explain that though learning is often a motivating factor for alliance formation, opportunistic firms can use their position within the alliance to expropriate propriety technology at the expense of their cooperative alliance partner. Das and Teng (1999) discuss what they label relational risk in their work examining risk management in the strategic alliance context. The authors define relational risk as the potential for unsatisfactory interfirm cooperation. The probability that partner firms will lack commitment and engage in opportunistic behavior at the expense of an alliance partner is a chief premise of relational risk (Das and Teng 1999). Barringer and Harrison (2000) provide an overview of the interorganizational literature. This work examines several theoretical paradigms in an effort to help explain interorganizational relationship formation. Most germane to this dissertation is the author's recognition of potential problems that may arise between B2B relationships. Specifically, the article discusses the overly optimistic attitude firms will adopt when forming new relationships. These relationships may sour when their unrealistic expectations don't materialize. These alliance relationships are also difficult to manage due to the complexities of bringing together two competing corporate cultures (Barringer and Harrison 2000). Though this 
article does not thoroughly examine these issues or offer solutions for dealing with them, the recognition of such problems between cooperating firms is insight that should prove useful for those working in the RM context.

Other important insight to be gleamed from the interorganizational and alliance literature is the considerable failure rate of these types of B2B relationships. Researchers working in this area cite failure rates anywhere between 50 to $70 \%$ (e.g. Barringer and Harrison 2000; Bleeke and Ernst 1993; Levine and Byrne 1996; Spekman et al 1998). These alliance relationships are constituted differently than those typically examined in the RM setting but as the transactions between buyer and seller have become more relational and thus more like these alliance relationships, this large failure rate between these cooperative alliances should be of interest to those conducting RM research.

To this point, very little attention has been given to the theoretical justifications for the onset of the dark side. More specifically, very little if any theoretical reasoning is ever given in the extant literature as to why the dark side may manifest within B2B relationships. Since most of the above literature is rooted in the tenets of relational exchange, as derived from exchange theory, this lack of a theoretical foundation for the onset of the dark side makes sense. Exchange theory has typically been used as a theoretical foundation for why exchange relationships develop and subsequently prosper over time. Therefore, trying to apply exchange theory as a theoretical justification for why dark side symptoms as relational myopia, complacency, vulnerability or suspicion develop is difficult to conceptualize and arguably paradoxical.

Though, to this point, there has not been an established theoretical perspective used to explain the onset of the dark side, it is believed that there are perspectives both inside and 
outside of the marketing literatures which may prove useful in providing a theoretical foundation capable of supporting the hypothesized relationships between the relational and dark side constructs as well as the dark side constructs and their relationships to both relationship strength and performance. These theoretical perspectives will be discussed in the following chapter where they aid in the theoretical development of the hypothesized relationships explored in this dissertation.

Also, in an effort to support the directionality of the hypotheses proposed in this dissertation, six interviews were conducted with people within various industries who are active in the management of their firm's B2B relationships. Though the entire transcripts of these interviews are not included in this dissertation, the included portions of the interviews are representative of the general sentiment conveyed by the people who agreed to participate. These passages are included throughout this chapter, where appropriate, as is a brief description of the interview participants and the types of B2B relationships they manage.

To summarize, the aim of the following discussion is to further develop a theoretical foundation capable of accounting for the onset of the dark side. The following discussion will draw from the extant academic and practitioner literatures to help develop hypothesized relationships such relational variables as shared values, commitment, trust, and satisfaction and the dark side constructs being labeled here as relational myopia, complacency, vulnerability and suspicion. The following discussion will also draw from these same areas to develop the relationships between the aforementioned dark side constructs, relationship strength and performance while introducing time as a moderating influence on these relationships. Also, six interviews were conducted with individuals 
from varying industries. These individuals are all in some way heavily involved in the management of at least one of their firms B2B relationships. These interviews were conducted in an effort to supplement the theoretical justification of these hypothesized relationships and are referred to often throughout chapter two of this dissertation where appropriate. Figure two, on the following page, is the structural model illustrating the hypothesized relationships developed throughout the remainder of this chapter. 
Figure 2: Dark Side Structural Model

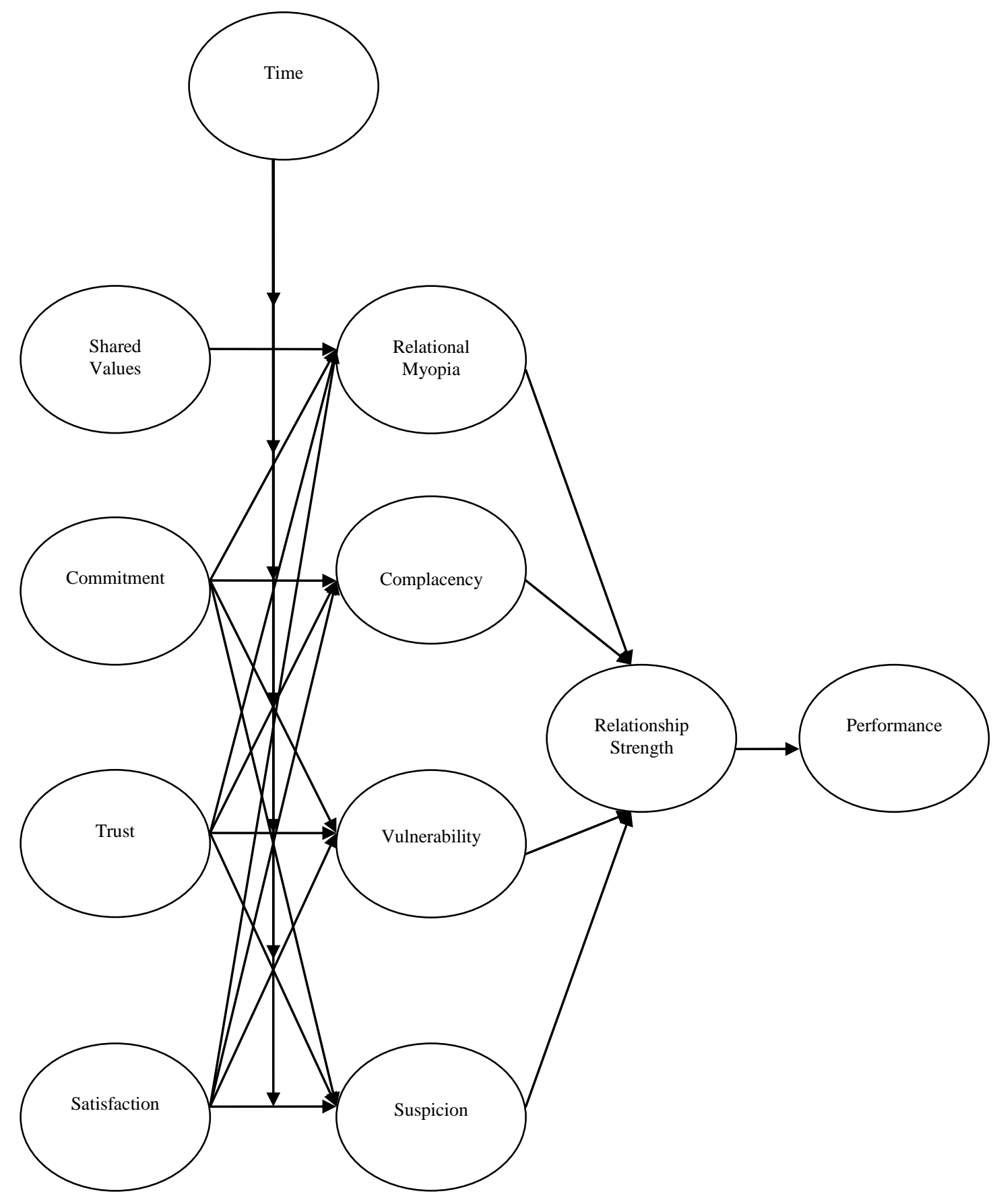




\section{Shared Values and the Dark Side of RM}

\section{Shared Values}

As with most of the relational constructs being utilized to examine relationships within the B2B setting, the shared values construct has been operationalized, conceptualized and defined in many different ways. For instance, some researchers have conceptualized shared values as a component construct made up of four facets (Barnes 2005). The first facet is the win-win facet, which describes partnering firms' recognition of the need for working together (Peck et al. 1999). The second facet is the affective component or the "good feelings" members of each firm have for each other (Barnes 1994). The third facet is the ownership component and describes how vertical integration is likely to have an impact on business relationships (Hakansson and Snehota 1995). Finally, the depth facet represents the amount of activities performed jointly by the members of the channel relationship (Ford, Hakansson, and Johanson 1986). Mukherjee and Nath (2003) also conceptualized the shared values construct as containing several components or facets rather than as one latent variable. Specifically, in the online banking context the authors describe shared values as the extent to which banks and their customers share common beliefs on things like ethics, security and privacy.

Scholars from other areas have related shared values to the construct or concept of culture. For instance, for application in the area of marketing management, Deshpande and Webster (1989) define organizational culture as “...the pattern of shared values and beliefs that helps people understand organizational functioning and thus provides norms for appropriate organizational behavior (p.4)". From the area of information technology Molla and Bhalla (2006) explain that "Organizations impose different values and beliefs 
(also commonly known as culture) on their members. Often, this defines both expected and accepted behavior modes, working relationships and communication patterns (p.38)."

When discussing the importance of shared values as an important antecedent for relationship commitment Voss and Voss (1997) discuss how shared values may be present at differing levels or degrees within a channel's relationship. For example, low pricing may be a shared value between a firm and its customers but this value is relatively shallow in scope compared to values about business philosophy, ethics and procedures that run deeper and encompass more of each of the partnering firms.

Though some scholars have used the term shared goals synonymously with shared values (e.g. Sin et. al. 2002) others have recognized a distinction between the two concepts. Wilson (1995 p. 9) writes "I define the concept of mutual goals as the degree to which partners share goals that can only be accomplished through joint action and the maintenance of the relationship... Although the wider concept of shared values has some appeal it seems too broad to be effectively operationalized." Though other researchers have clearly disagreed with Wilson's assertion concerning the operationalizing of the shared values construct, (e.g. Anderson and Weitz 1989; Morgan and Hunt 1994) this work provides evidence for the distinction between shared values and shared goals. Anderson and Weitz (1989) also recognize the difference between shared values and goals. The authors explain that differences in growth objectives are a difficult and pervasive problem in channels management. Cultural similarity is operationalized separately from the goal congruence construct and encapsulates such facet constructs as geography and culture. Referring to the cultural similarity construct Anderson and Weitz 
(1989 p. 314) explain, "The essence of the problem is lack of shared values and methods which manifests itself as differences in cognitive styles, operating methods and choices."

For the purposes of this dissertation, there will be a conceptual distinction between shared values and shared goals as the words and their meanings, though similar, connote very different things. For two organizations to have similar goals does not necessarily mean they share an entirety of values or vice versa. For example, two firms may share a similar goal of greater return on investment. However, one firm might value ethical and legal behavior and obtaining these goals legitimately while the other firm might have a "win at all costs" mentality and support underhanded, sneaky and potentially illegal behavior as valid means for obtaining these goals. In this scenario it is obvious that goals and values are referring to two very different things. However, this is not to say that the two constructs are in no way related. For instance, the shared goals between partnering firms are certainly things both firms value. Using this logic, and referring to the example and discussion above, it makes sense to conceive of shared goals as a component or facet of shared values. Therefore, though shared goals are valued by the partnering firms, goals are only a component of the much broader construct of shared values.

For the purposes of this dissertation, the definition of shared values offered by Morgan and Hunt (1994) shall be adopted. Morgan and Hunt (1994 p. 25) define shared values as the "extent to which partners have beliefs in common about what behaviors, goals and policies are important or unimportant, appropriate or inappropriate and right or wrong" This definition conceptualizes shared goals as a component or facet of shared values. This will allow for the distinction between the two constructs without discounting or ignoring the relevance shared goals has on the evaluation of shared values between 
partnering firms, as well as accounting for the influence these values have on the business relationship itself.

Drawing from this definition we can infer that channel relationships that are characterized by a substantial amount of shared values are made up of firms that are essentially "on the same page" regarding much of how business works, should work and how business practices and endeavors should be approached. In other words, these relationships might very well consist of firms that essentially think the same way or share a similar philosophy regarding how they conduct themselves within the channel and the market as a whole.

Shared values are often cited, within the RM literature as a necessary component for successful long term exchange relationships. For instance, Dwyer Schurr and Oh (1987), in their seminal article on the subject of relationship development recognized the importance of shared values. The authors, while explaining the benefits of relational exchange explain that partnering firms with highly divergent goals may invest a large amount of economic and psychic resources in conflict and haggling. In other words, relationships not based on shared goals may actually cost the firms more in terms of resources, time and energy than had they maintained a discrete transaction orientation with the partnering firm.

Tate (1996) using the marriage analogy, describes shared values as a necessary component for strong long-term orientated logistics relationships. The author explains: 
“Both parties must understand each other's needs, and must be compatible, with shared values. Like a marriage, a successful logistics partnership requires open communications, mutual commitment to the partnership, fairness and flexibility" (p. 7)

Other researchers have echoed the above sentiments while also providing empirical support for it in their research. For example, Morgan and Hunt (1994) found that shared values are an important antecedent to both trust and relationship commitment which in turn was found to influence important relational outcome variables such as cooperation and acquiescence. Mukherjee and Nath (2003) tested the influence of shared values on commitment and trust in the online banking context. The authors found that shared values is actually the most significant determinant of trust in the online banking context while they also significantly contributed to the commitment customers had for their online banking institution.

While conducting their qualitative investigation, Voss and Voss (1997) found that relationships based on shared values as well as governance structures lead to greater commitment or loyalty than relationships built solely on governance structures.

Fullerton (2003) using a longitudinal experimental design, manipulated his affective commitment by either eroding or enhancing the shared values between the customer and their service provider. The results suggest that affective commitment, which was based on the shared values between customers and their service providers, are more influential regarding the development of customer loyalty than is continuance commitment, which is based on switching costs and the lack of attractive alternatives. 


\section{Shared Values and Relational Myopia}

It is apparent that shared values are an important ingredient for the development and sustainability of B2B relationships. However, for the purposes of this research dissertation the contrary view that shared values, especially over time, might actually lead to potentially damaging side effects and dark side symptoms is developed. More specifically, shared values, recognized as one of the key ingredients for forming a sustainable long term business relationship (Anderson and Weitz 1989; Dwyer, Schurr and Oh 1987; Morgan and Hunt 1994), may actually lead to the dark side symptom labeled, in this dissertation, as Relational Myopia.

To illustrate, consider two firms engaged in a channels relationship characterized as high on shared values. Consistent with the definition of shared values presented above, this could mean that members of each firm view the environment with potentially the same knowledge, experience, attitude and bias as their channel partner. Though at times the similarity in point of view might enable the firms to quickly capitalize on any change in the environment that presents a market opportunity, it is also possible that these shared views might blind both firms to opportunities or environmental hazards that arise with the dynamics of the business environment.

This blinding effect could be the result of relational myopia which stems from two firms sharing a singular perspective regarding macro issues such as how the environment is viewed or how to act and react to outside influences that demand attention upon its recognition.

Marketing myopia was initially defined as a firm's shortsightedness or narrowness when it is attempting to define its business (Leavitt 1960). Other researchers have 
expanded upon this definition, labeling firms by the type of myopia with which they are plagued. For instance, Richard, Womack, and Allaway (1992) describe three types of myopia that may describe myopic firms. The first myopia described by the authors is the classic marketing myopia or the single industry single product orientation most closely resembling Leavitt's (1960) definition. Competitive myopic firms are slightly less handicapped by their lack of perspective than their classically myopic brethren in that they are willing to define their business orientation by their customers and not simply their product. However, from the business environment perspective they limit themselves by refusing to expand beyond their primary industry for solutions and opportunities. Finally, efficiency myopic firms are less restrained in their ability to venture into other industries but are somewhat restrained by their single product orientation. According to Richard, Womack and Allaway (1992), having a customer orientated firm that embraces a multi-industry perspective is the only way to truly have an innovative firm.

The concept of myopia becomes an especially relevant hazard for firms that share too much of the same view regarding how the firms act within the business environment. This is due to the shortsightedness or narrow perspective characteristic of myopia. In other words, firms that take too narrow a view toward things like their product, processes or customers are often guilty of myopia and subsequently suffer the consequences of their inability or unwillingness to embrace a larger and broader perspective.

Drawing from the above descriptions of myopia a description of relational myopia can be derived. Relational myopia can be described as two firms that due to their shared 
values have embraced too narrow a perspective regarding their relationship, its dynamics and how it should be governed as it maneuvers through the business environment.

If the firms had possessed differing perspectives toward their relationship and the environment with which it operates, instead of a myopic view of these things, the firms may have been able to identify problems or opportunities where the myopic firms didn't have the insight. In this case, it was the shared values that posed the problems, or at least stood in the way of the recognition of the problem or opportunity resulting in action not being taken at an early and still meaningful time.

Referring to the work of Starbuck, Barnett, and Baumard (2008) which explains and summarizes much of the work that supports the theoretical implications relating to the behavioral theory of the firm, we can draw a connection to relational myopia and this theoretical framework. Specifically, the authors report that firms will often deal with dynamic events in a standardized way and that firms due to standard operating procedures, will often act or react unreflectively and automatically. Of course this implies a lack of vision and complete disregard for the external environment where the firm operates. To further support the theoretical connection between relational myopia and Cyert and March's (1963) behavioral theory are the findings reported by Starbuck, Barnett, and Baumard (2008) that suggests that success actually plants the seeds for future failure. More specifically, as the firm operates it is argued that over time their success will lead to a more simplistic orientation rather than a more complicated one. The authors refer to this as strategic inertia and is said to lead to a narrower and specialized firm over time (Starbuck, Barnett, and Baumard 2008). The parallel to relational myopia is very striking as what Starbuck, Barnett, and Baumard (2008) 
describe at the firm level is analogous to relational myopia when applied to B2B relationships. It is not hard to believe that a firm that has allowed this narrow and simplistic mindset to develop at the firm level will also allow the mindset to govern their B2B relationships. It might actually be more difficult to envision a situation where the firms' attitude and vision regarding its own governance would really be that drastically different from how it manages its B2B relationships. If one accepts this connection than relational myopia's connection to the behavioral theory of the firm should be apparent.

Though scant, there is some practitioner and academic literature that either indirectly or anecdotally supports this notion. For example, Babicz (2000), in her piece discussing the elements of continuous improvement, recommends rotating auditors every so often so as not to develop close personal relationships and a myopic vision of the firm being audited. To quote one of her interview participants "As an auditor, you get comfortable with a procedure, process or system, you have confidence that you know their system, and you're not catching the nuances that change between visits" (p. 49). This passage illustrates the dangers of partnering firms sharing too similar a view.

Also in the auditor setting is Mirshekary, Yaftian and Cross' (2005) analysis of why one of Australia's top insurance companies failed. Their findings suggest that the auditors in charge of ensuring the firm's financial well being had too close of a relationship with the partnering firm. Therefore the auditors were not able to offer the necessary critical evaluation of the firm's financial state. This hastened the eventual collapse of the firm. Subsequent recommendations to the auditor industry include continuously rotating auditor personnel so as not to develop ties that are too close. Though close ties are not necessarily a form of relationship myopia, the evidence from 
this account suggests that the same shared values that allowed for the development of these close ties also led to the development of a myopic view of the relationship, thus hindering the auditor's ability to evaluate the firm critically. The auditors in this case, missed important issues that the partnering firm had also missed. Their shared perspective toward the partnering firm, as well as what was to be audited, effectively restricted the auditor's view which consequently led to the failure of the partnering firm.

Similarly, in the academic literature Boughton, Nowak, and Washburn (1996) concede that bringing in a fresh face to help with new advertising projects is required since established suppliers are not able to offer the "fresh look" needed when embarking on new business ventures. This inability is believed to be the result of advertising firms beginning to think alike which results in predictable non-creative or unimaginative solutions to new problems.

Moorman, Zaltman and Desphande (1992) suggest that it is commitment that breeds familiarity which may breed boredom and a desire for new ideas. However, since shared values has been shown as an important antecedent of both trust and commitment, an argument can be made that shared values in conjunction with commitment breeds boredom and familiarity. Conceptually, linking shared values to familiarity and thus boredom is intuitive since shared values hinge on partners essentially "looking alike". When two firms share values it can be said that they also share a view of the business environment. Thus this myopic or similar view may stifle creativity. Hindering the ability of the firms to adapt or change with the environment or recognize the environmental changes that require attention. In other words, the firms might not necessarily begin to look alike but they may begin to think alike and thus view the world 
alike, essentially reducing the benefits of engaging in a close integrated channels relationship.

At this point it is important to discuss the influence time is believed to have on the relationships between the relational variables and the dark side constructs discussed below. Time or length of the relationship is believed to moderate these relationships. This is because a certain amount of time must pass to allow for the manifestation of the dark side. Though at this point it is impossible to say exactly how much time must pass Hibbard et al. (2001) found that the link between relationship variables and performance begins to weaken after 160 months or just over 13 years. B2B relationships, according to Dwyer Schurr and Oh (1987) develop or evolve through a process. Firms must first recognize each other as viable exchange partners. Then, firms must decide to engage in a B2B relationship with a partnering firm. At this point firms are tentative as they often know very little about their new exchange partners. Firms in this phase of the relationship will keep up their guard and their vulnerabilities close and unexposed. It will take some time for firms to really become committed to their exchange partners. Through a series of exchanges over time, relationship norms and expectations will develop (Dwyer Schurr and Oh 1987). If the relationship is perceived as successful and the firms involved in the relationship are benefiting from participation, then over time firms will begin to "settle in" and become more committed to the relationship as well as their exchange partner. Firms will also let the reach of the relationship expand more into the firm itself. In other words, firms will begin to allow more exposure of themselves to their exchange partner as the firms become more integrated (c.f. Dwyer Schurr and Oh 1987). 
During these early phases of relationship development the dark side is unlikely to manifest with any serious consequence as firms, in these phases, are more vigilant regarding their exchange partner's behavior as well as more motivated to work toward meeting relational expectations. Should issues like complacency or suspicion develop it is likely that either one or both firms would simply terminate the relationship. However, in the later phases of the relationship, firms are more integrated as well as committed. Recognizing some of the dark side symptoms, such as myopia or complacency may be difficult as each firm in the relationship is no longer afforded the more objective view of their relationship and exchange partner afforded them in the beginning phases of the relationship. Other symptoms like suspicion or feelings of vulnerability may develop in the later stages simply because firms can no longer simply end an exchange relationship that in the beginning phases could easily have been walked away from. Referring back to the Dwyer Schurr and Oh's (1987) phase process of relationship development, it becomes clearer how important the passage of time is for the manifestation of the dark side. In the beginning phases firms still have the ability to leave a young relationship or simply not allow a potentially troublesome relationship begin in the first place. However, as time passes and B2B relationships evolve, firms will become more committed and integrated which makes the simple act of walking away much more difficult. In these phases, after enough time has passed it allows for the development of a fairly integrated and committed exchange relationship. The dark side is much more likely to manifest as firms in these more developed, older relationships have in many ways, due to the natural evolution of the exchange relationship, lost their ability to defend against it. 
Many studies within the marketing literature, as well as other business disciplines, have acknowledged time as an important variable that may have significant influence on business relationships (e.g. Davies and Prince 2005; Doney and Canon 1997; Hibbard et al. Lusch and Brown 1996; Verhoef, Franses, and Hoekstra 2002). The interesting and discrepant aspect of the summation of these studies is the inconsistent results they have produced. Some of these studies suggest that business relationships improve over time (e.g. Davies and Prince 2005; Deligonul et al. 2006; Verhoef, Franses and Hoekstra 2002) while others have failed to show the time variable rendering any significant influence on the quality of the business relationship at all (Doney and Canon 1997; Flavian, Guinaliu, and Torres 2005; Lusch and Brown 1996).

Though the above cited articles show time as either a positive influence on business relationships, or were unable to support the notion of a positive influence it is important to note that there is a growing body of literature that either theoretically suggests a negative relationship or empirically shows that business relationships do indeed sour over time. (e.g. Barnes 2005; Harris and Taylor 2003; Hibbard et al. 2001; Reinartz and Kumar 2000; Robinson 2005).

For instance, Barnes (2005) conducted a qualitative exploratory study that investigated the dynamics of B2B relationships over time. The results of this study found that there is often a high degree of optimism in the beginning phases of a relationship but when business relationships reach the mid point of their term a certain degree of complacency has a tendency to creep in. A degree of "comfort" is believed to emerge as evidenced by individuals paying less attention to their channel partners. 
Robinson (2005) is very specific in his piece aimed at practitioners and their partnering choices. In this piece, he states "However, once a successful partnership has been forged, there is a tendency for the client to not only neglect supplier relations, but also to become complacent about the contract itself." (p.18). This statement reflects the issues that may arise between firms after the relationship forging process has been completed.

Harris and Taylor (2003) conducted a qualitative study that discusses the limited role advertising agencies have on their client's development of an advertising budget. Through the use of qualitative interviews the authors are able to illustrate the influence time may have on the relationship between complacency and commitment. For example, on (p. 350) they state:

"However, as time goes on, agency/client roles begin to follow a well-worn path and thus, less involvement is necessary. Agencies may take their role for granted and become complacent, thus making themselves less valuable as a strategic partner..."

Reinartz and Kumar (2000) conducted a study on the profitability of long-life customers in a non-contractual setting. This study uncovered several results suggesting that long term relationships are actually more costly than short term relationships. The results of their study suggest that long term customers are not necessarily as profitable as shorter term customers, profits do not increase over time with long term customers and the costs of serving long term customers is actually more not less than short term customers. Finally, long life customers actually pay less rather than higher prices compared to short term customers. 
There are other authors that perhaps did not operationalize the time variable in their studies but have recognized its potential influence while interpreting their results (e.g. Grayson and Amber 1999; Moorman, Zaltman, and Desphande 1992; Pillai and Sharma 2003).

Moorman, Zaltman, and Desphande (1992), suggest that members of a long term business to business relationship may, over time, lose their ability to be objective, the relationship may become stale or the members of the relationship may become too much like each other. The implication here is that not only do relational norms lose their ability to yield positive relational outcomes; this inability is something of a time dependent variable. Grayson and Amber (1999) found similar decreases in benefits from relational constructs. Though they were unable to pinpoint the reasons for the dampened effects of trust in a long term relationship they were able to empirically support the notion that trust does indeed lose some of its positive effects, again, over time. The diminished correlation between relational variables and performance in Hibbard et al's (2001) study was also witnessed over time. Pressey and Tzokas (2004) in their empirical investigation of UK exporters also found that though there was an increase in performance, there was some relational diminishment surrounding the commitment construct. More relevant to this discussion however, is that this diminishment occurred over time.

Pillai and Sharma (2003) suggest that a lack of innovation is an issue that may transform a once relational business relationship into a more transactional one. Lack of innovation refers to the belief that supplier firms, over time, become unable to provide valued added services to the client or buying firm. That is to say, that the relationship becomes stale and thus, innovation becomes stymied or is unable to flourish in the 
relationship where it once had (Pillarli and Sharma 2003). The authors also suggest that dissatisfaction is a problem that builds up over time in mature relationships. The authors explain how though dissatisfaction isn't typically linked to any one incident or that there isn't "one thing" that leads to dissatisfaction the evidence does seem to point to more dissatisfaction in older relationships or rather the construct manifest within the relationship over a long period of time. Pillarli and Sharma (2003) also discuss how changes in the environment will have effects on channels relationships. As technology and communications evolve, over time, competitive pressures in the environment will manifest in ways not currently realized. These changes will force firms to evaluate the nature of their channels relationships to determine if the relationship is still viable in an environment that is different than the one where the relationship was forged.

It is important to recognize however that the passage of time itself isn't necessarily the factor that provokes the onset of these issues but it is the passage of time that allows for the development of these issues. For instance, Singh and Mitchell (1996) within the alliance context, discuss how successful alliances may fail when their environment changes over time. In this case it is not time that produced alliance failure but environmental changes. However, without the passage of time, environmental conditions would remain static and thus these successful alliances would never fail. Pilari and Sharma (2003) cite the lack of innovation as cause for business relationships to transform from a relational mindset into a transactional one. In this example, it is not the passage of time that leads to the transformation of the business relationship but the lack of innovation. Here again, however, it is recognized that without the passage of time, innovation would not decline and consequently these business relationships would remain 
relational as opposed to becoming transaction orientated. Finally Harris and Taylor (2003), discuss how over time advertising agency relationships begin to follow a well worn path which leads to complacency. This well worn path is the real issue not the passage of time but without the passage of time members of these agencies are not able to develop this 'well worn path' which is the true cause of the onset of complacency.

To expand upon this idea of time leading to the onset of dark side variables, the examination of how processes might be sped up should also be discussed. More specifically, Dwyer, Schurr, and Oh (1987) discuss that over time, through a series of exchanges, the relationship development process occurs. The authors do not however discuss exactly how much time needs to pass.

Time itself is not the issue per se but the passage of time allows for the development of issues. In other words, the development of these issues is time dependent. Therefore, when operationalizing the appropriate moderating variables, a researcher does not need to measure all the potential issues that may develop over the passage time as the time variable can act as a surrogate that adequately captures all these issues within one measure. More specifically, instead of measuring things like interaction frequency, transaction frequency, environmental changes, routine of process, personnel changes or any other dynamic that potentially could hasten the development of the dark side, as these issues, within the relationship context, are time dependent, using one time measurement will adequately capture the moderating influences these issues have on the relationships between the relational and dark side constructs.

The above discussion concerning the passage of time is intended to provide insight into how the passage of time is a necessary condition for the emergence of the dark side 
in general. However, though indirect, specific support for the relationship between shared values, relational myopia and time's moderating influence can be inferred from the Hibbard et al. (2001) piece that operationalized shared values and found a negative relationship between the relational construct and performance over time. The influence of time on the relationship between shared values and relational myopia stems from the assumption that firms will actually evaluate the nature of their channels relationships as Pillai and Sharma (2003) suggest they will.

One of the basic assumptions of exchange theory (Thibaut and Kelley 1959) is the notion of comparison level of alternatives. The comparison level of alternatives can be described as "the standard that represents the average quality of outcomes that are available from the best alternative exchange relationships (Anderson and Narus 1984, p. 63)". The idea is that firms will monitor their alternatives to make sure they are in the best; perhaps most profitable or efficient, relationship compared to whatever else is available. Therefore, the comparison level of alternatives represents the lowest level of outcomes a firm will accept to continue in the relationship (Anderson and Narus 1984). However, Thibaut and Kelley (1959) do concede that a firm may "remain in the present less rewarding relationship because the social, emotional, or legal costs entailed in moving to the better alternatives are too high" (p. 71). One could interpret these costs in moving as being subsumed in the costs of monitoring and continually searching for better relational partners. It is reasonable to think that firms, in an effort to avoid these costs, after having built their relational exchange relationships, may view further monitoring as an unneeded expense. In other words, if they already have a trusted partner with whom 
they share values; commitment etc. firms may view the monitoring of the environment or even the relationship as an unneeded and perhaps wasteful expenditure.

The qualitative data gathered during the interview process largely supports the relationship between shared values and relational myopia. When asked if she believes B2B partners share a vision regarding how their relationships run and if there is a down side or negative consequences to this shared vision, one interview participant, a 29 year old sales representative in charge of product sales said:

“...because things are going well with your relationship and it just runs on its own, you might not look out to see if there is a better way or process that could be more efficient or beneficial to either one of you"

This response is typical of those given by most of the interview participants and seems to support the idea of shared values between organizations, over time, leading to the onset of relational myopia.

Shared values have been linked to the development of both trust and commitment (Dwyer, Schurr, and Oh 1987; Morgan and Hunt 1994) both typically regarded as positive influences on the B2B relationship, over time, shared vales may help usher in the dark side symptom of relational myopia. This is due to the belief that over time, as the relationship continues to develop, shared values may limit each firm's ability to objectively evaluate the environment and to assess if each firm is still a good RM partner. The moderating effect of time on the relationship between shared values and relational myopia is rooted in this inability to continuously, over a long period of time, evaluate the environment and relationship due to a firm's myopic view of the exchange relationship. 
It is from the above discussion, pertaining to the description of shared values, relational myopia and the moderating influence of time that the following hypothesis is presented:

H1: Over time, there will be a positive relationship between shared values and relational myopia

Commitment and the Dark Side of RM

\section{Commitment}

Commitment, within the channels literature has been defined in many ways. When deriving their definition of commitment, Morgan and Hunt (1994) drew from such areas as social exchange, marriage and organizational behavior. The authors defined commitment as "An exchange partner believing that an ongoing relationship with another is so important as to warrant maximum efforts at maintaining it; that is, the committed party believes the relationship is worth working on to ensure that it endures indefinitely"(p. 23). Moorman, Zaltman and Desphande (1992) defined commitment as an enduring desire to maintain a valued relationship. Dwyer, Schurr and Oh (1987) conceptualize the commitment phase of relationship building as an implicit or explicit pledge or relational continuity between exchange partners. Leik and Leik (1977) defined commitment as the unwillingness to consider partners other than those in the current relationship. This definition is consistent with that of Gundlach, Arcrol, and Mentzer (1995) who defined commitment as the forsaking of alternative options. Though many of the above definitions are worded differently and perhaps carry slight differences in meaning, there does seem to be certain commonalities among all of them. The desire to stay involved and engaged in a relationship with other channel members is a consistent 
theme among all of the definitions discussed above, and serves as the primary conceptualization of the construct.

Parties engaged in B2B relationships view commitment as essential for achieving or obtaining positive outcomes among channel partners (Morgan and Hunt 1994). Therefore, relational partners, in order to maintain the realization of these positive outcomes, will work to maintain and foster commitment within the relationship and commitment is therefore recognized as one of the key ingredients of long term relationships (Dwyer, Schurr, and Oh 1987; Garbarino and Johnson 1999).

This conceptualization has provided guidance in many studies investigating the dynamics of relational exchange. For example, Priluck (2003) used this conceptualization of commitment when investigating the mitigating influence of RM during product and service failure. In his study, he found that consumers involved in relational exchange are more committed than consumers who are involved with discrete transactions. Tate (1996) in her qualitative investigation of the relationship between Kimberly -Clark Corporation and Tricor Warehouse relied upon this conceptualization to explain why commitment is vital when partnerships encounter rough times. Dorsch, Swanson, and Kelly (1998) used this conceptualization of commitment and found that the higher a vendor's status with the customer, the more committed customers are to that vendor.

However, researchers investigating the constructs germane to the relational exchange paradigm have begun to embrace commitment as a multi-faceted complex construct. Making it worthy of study and operationalization at deeper levels than just the onedimensional gist captured in the definitions discussed above. Specifically, some marketing researchers have borrowed the multi-component multi-faceted 
conceptualization of organizational commitment, developed by Allen and Meyer (1990) and applied it to the B2B setting. Works by Gruen, Summers, and Acito (2000) and Fullerton (2003) among others, have embraced the notion of commitment containing at least an affective, normative and continuance component.

The affective component is said to exist when channel partners identify with each other or are emotionally attached (Fullerton 2005). Feelings associated with "liking" and attachments are associated with affective commitment. Affectively committed relationships continue out of a sense of "wanting" or a desire to have the relationship continue. It should be noted that the more traditional view of commitment within the relational exchange and $\mathrm{B} 2 \mathrm{~B}$ literature is essentially the affective aspect of commitment (e.g. Dwyer, Schurr, and Oh 1987; Morgan and Hunt 1994; Moorman, Zaltman, and Desphande 1992)

Normative commitment has been defined as the "degree to which the membership is psychologically bonded to the organization on the basis of the perceived moral obligation to maintain the relationship with the organization" (Gruen, Summers, and Acito 2000 p.37). This form of commitment is rooted in a relational partner's sense of duty. Normative commitment is similar to affective commitment in that it is born out of an affective response rather than a more analytically or cognitively appraised sense of need. That is, normative commitment isn't necessarily born out of a sense of want but rather a sense obligation. Firms might not "want" to stay in certain channel relationships but feel a sense of duty to do so.

Finally, continuance commitment stems from a lack of attractive alternatives, high switching costs or amount of material sacrifice associated with terminating the 
relationship (Dwyer, Shurr, and Oh 1987; Fullerton 2005). Continuance commitment, it can be said, is derived more out of a sense of need rather than want (Fullerton 2003; Fullerton 2005; Gruen, Summers, and Acito 2000). If switching costs are excessive or the benefits of maintaining a relationship are not easily replaced should a firm decide to switch relational partners, then the firm is more likely to experience continuance commitment to the relationship (Dwyer, Shurr, and Oh 1987; Gundlach, Achrol, and Mentzer 1995). Commitment is also formed when one party takes actions that bind it to another party. Anderson and Weitz (1992) found that actions taken to limit freedom of choice such as contracts and service agreements also form continuance commitment. Finally, if one party perceives that they are dependent on the other in the exchange relationship then they are more likely to be committed to the relationship than if they don't (Anderson and Weitz 1992; Heide and John 1992).

This dissertation recognizes the benefit of making such operational distinctions regarding the facets or components of commitment. Much of the RM literature used to help develop the hypothesized relationships with the dark side operationalized commitment using the "affective" and "normative" component variables. Therefore, distinctions between affective and normative commitment will be made at the operationalization level of this dissertation and will be discussed further in Chapter three. Since this distinction is made at the operational level, the following discussion will use the more general construct label of "commitment" instead of the more specific "affective" and "normative" labels. The reasoning for making this distinction at the operational and not theoretical level stems from the complexity of the structural model 
and the belief that these dimensional differences recede in significance compared to the differences across other antecedent and mediating constructs.

\section{Commitment and Relational Myopia}

High levels of commitment may seem positive and a goal to strive for when engaging in a RM strategy. As mentioned above, there are positive benefits associated with high levels of commitment (Dwyer, Schurr, and Oh 1987; Garbarino and Johnson 1999; Morgan and Hunt 1994). However, it is also believed that it can be a danger that leads to partnering firms adopting too narrow a perspective regarding the relationship, its dynamics and how the relationship should be governed as it maneuvers through the environment. In other words, firms might become so committed to each other that their focus becomes narrowed through the good feelings between the firms. These good feelings about the relationship and the relational partner may be misinterpreted as the relationship yielding positive benefits and performance outcomes. This is consistent with the behavioral theory of the firm as it suggests that positive outcomes re-enforce behaviors even if better options are available to the firm (Ginsberg and Baum 1994). Applying this theoretical perspective to a B2B relationship suggests that one or both of the firms may become relationally myopic, over time, as they confuse good feelings for success or current success for future success. As the focus is drawn more and more toward the relationship, issues like monitoring of the economic or industrial environment are neglected as its necessity is effectively off the radar screens of the partnering firms. This can lead to several negative repercussions for the myopic firm. This myopic view is believed to impede their ability to adjust to the dynamics of their particular industry or 
other economic factors that may have a bearing on their ability to profitably conduct business.

It makes sense that when committed firms begin their relationship they are likely to see themselves as being "on the same page". Therefore, as their relationship progresses over time and the members of each firm realize efficiencies and perhaps some measure of success, the resulting confidence in the relationship will begin to discourage members from "looking for stuff" that might indicate the relationship is in need of repair or some other form of adjustment. This subjective view is undoubtedly narrowed and more shortsighted than an objective view and thus the onset of relational myopia.

Also, commitment might be enough to keep firms in a relationship but not necessarily enough to keep the relationship from becoming stale or rote. Committed firms will show persistence in their obligations without regard to environmental or other relational cues that may dictate a change of perspective (Weiner 1982). When firms are committed to their obligations but refuse to monitor the dynamics that surround those obligations it can then be said the firm has effectively narrowed its view or has adopted a myopic view of their exchange relationship.

One interview participant, a 43 year old software consultant, when asked about firm level group think and if this actually manifest between B2B partners, responded with the following:

“...I believe that once the relationship has settled there is an enormous amount of complacency that develops between the partners" 
The above passage serves as witness to the idea that complacency does develop in B2B relation ships over time. To further link the onset of complacency to sentiments of commitment we can draw once again from the 29 year old sales representative:

"I know in my experience that when I have become close to a customer and their processes, things would just flow without any issues. I would almost know what is expected of me because of having that experience with them. Unfortunately, that did not mean anything when a customer would get a better offer from someone else and then they would go with our competitor because they had something new and better for them."

It seems as if maintaining the relationship may not only allow for the onset of complacency but myopia as well. What is interesting about the above passage is that one can see an indirect relationship between the onset of complacency and feelings of vulnerability. In other words, it almost seems as if this sales rep is equating the onset of both myopia and complacency with an inability to offer anything new to the relationship which subsequently leads to loss sales which may provoke feelings of vulnerability.

Just as time is believed to have a moderating role on the relationship between shared values and relational myopia; it is also believed to have a similar moderating effect on the relationship between commitment and relational myopia. It is extremely unlikely that the relationship between commitment and relational myopia would occur at the outset or beginning of the relationship. A number of studies have cited commitment as a positive influence on B2B relationships (e.g. Dwyer, Schurr, and Oh 1987; Garbarino and Johnson 1999; Morgan and Hunt 1994). It therefore is not only counterintuitive but seemingly highly unlikely that commitment would display this sort of negative influence 
at the beginning of the relationship. However, as time goes by, it becomes more and more likely that partnering firms will adapt this myopic view of their environment and B2B relationship for the reasons discussed above. Drawing from this same line of logic is the idea that the performance of a focal firm is a function of how that firm's relational partner's strategies change or evolve over time (Singh and Mitchell 1996). Sing and Mitchell (1996) explain that the characteristics of partnering firms that help each firm, as well as the relationship, succeed in one phase of their relationship are the same characteristics that enable them to fail when their environment changes. This failure is contingent upon the relationship not allowing or rather not acknowledging the need to allow their strategies to evolve over time. This failure is consistent with the notions of relational myopia being described in this dissertation. It is from this logic that the following hypothesis is presented:

H2: Over time, there will be a positive relationship between commitment and relational myopia

\section{Commitment and Complacency}

Another dark side symptom believed to manifest within B2B relationships is the issue of complacency. Chowdhury and Lang (1996) published a qualitative exploratory study that investigated complacency and how it relates to small business failure. In this study they used the definition of complacency found in the Webster's Third New International Dictionary (1961) as "satisfaction or self-satisfaction accompanied by unawareness of actual dangers and deficiencies". The authors suggest that this definition has two possible implications. The first implication is that "unawareness" may be the result of poor problem sensing ability in a firm where management is content with the status quo. 
The second implication is the idea that what used to work for a firm no longer does. In other words, systems and process that used to be beneficial for the firm have begun to either yield less or stop yielding entirely the beneficial outcomes firm management has grown to expect. Complacency, in these cases, stems from the idea that firm management or key firm personnel are unable to recognize the deficiency in their once productive systems (Chowdhury and Lang 1996).

Shipley (1994) defines complacency as an internal unwillingness to change the status quo and suggests complacency as an organizational problem that keeps marketing personnel from being as effectual as possible within the firm. According to Austin (1991), complacency is the lack of consistency or a decrease in the level of service provided compared to that provided when the relationship was initially forged.

Regardless of the definition of complacency being utilized we can infer that complacency encompasses feelings of satisfaction and an unwillingness or inability to recognize the need for change. For example, two partnering firms that have met with some degree of success may be lulled into believing the relationship is infallible and without need of change. Firms begin to believe their success is the result of the channel partnership as is and changing the characteristics of the relationship or monitoring it in ways to guard against such things as complacency may seem redundant. An "If it ain't broke, don't fix it" mentality may develop. Theoretical justification for the onset of complacency again can be drawn from the behavioral theory of the firm. Miller (1990) found that firm success often leads to a sort of programmed, structured response to the environment which he describes as complacency and specialization. This is consistent 
with Cyert and March's generalizations which suggest that firms incorporate bias in their environmental assessments that favor their past success.

Complacency and its relationship with commitment is derived from firms assuming the "feel good" feeling they have toward the relationship and the results of the relationship is perpetual and therefore not requiring vigilance or maintenance to ensure its continuation. This is especially true if exchange partners have enjoyed some measure of success early in the B2B relationship (Bergquist 2006; Hagen 1999). Firms may become attached to their partnering firms and believe success is a given (Chowdhury and Lang 1996). Therefore, the idea of monitoring the specifics of the relationship or its environment becomes somewhat counterintuitive and perhaps a waste of time.

This inaction effectively locks the firms into a relationship that potentially should be terminated or in some other way redefined to better serve the partnering firms. However, their commitment to the relationship and all of its dynamics keeps these firms from taking the necessary steps to change the dimensions of their business relationship. The passage from Haytko (2004) works to illustrate how complacency can handicap an exchange relationship:

"Personal relationships do not always play a positive role in an organizational environment. For instance, personal relationships may be powerful enough to hold an interorganizational relationship together long after it should have been terminated..." (p.313)

Complacency here stems from the inability to recognize a need for action. So long as the firms are complacent toward the relationship they will not act against the relationship to which they are committed. Tan and Akhtar (1998) found indirect support for this link 
between commitment and complacency. Specifically, they found that high levels of commitment actually lead to mental exhaustion or "burnout" in the employer-employee context. Extrapolating those results into the B2B relationship context, we can infer that high levels of commitment between firms might lead to the firm level equivalent of relational burnout or exhaustion and subsequent complacency.

Other authors have found a connection between commitment and complacency. Specifically, Berquist (2006 p 17.) states:

“...Inertia caused by complacency, resistance to change and sheer size will be like anchors on sinking ships. Unbreakable supply chains and alliances will be like tethers. The perfect market will demand fluidity and agility, the ability to scale up or down in response to changes in demand and the ability to form and dissolve business relationships at a moment's notice..."

Other authors have echoed this same sentiment regarding the dangers of commitment and complacency. Hatzakis et al. (2005 p. 70) explains:

“...strong bonds with relationship managers led business and IT staff to a state of inertia and complacency towards activating direct bonds with each other. We argue that this may damage the prospects of business and IT colleagues to identify with each other and their capability to discover and share perspectives..."

These passages suggest that as the bonds become tighter inertia leads firms to stop looking at their relationship and the environment around them critically. Also important to note is that though not directly discussed the moderating influence time has on all of the above passages can be inferred. Haytko (2004) mentions relationships enduring long 
after they should have ended. The element of time presents itself when interpersonal relationships are strong enough to keep B2B relationships alive after their viable time has past. Berquist's (2006) notion of inertia implies the existence of relationships continuing after the environment has dictated change. Finally Hatzakis et al. (2005) echoes a similar sentiment of inertia blinding individuals within the firm. This inertia is the complacent view occurring over a period of time. A 55 year old male in charge of procurement for his government agency said:

"Also, we all tend t enjoy the comfort of dealing with people we know and have dealt with before but this comfort level can prevent us from exploring new options and ideas"

This above passage may be interpreted as an interpersonal inertia which influences the B2B relationship. This particular individual seems to recognize the potential for the desire to do the same things in the relationship, like work with the same people over and over again, to harm or hinder the organization's ability to obtain its goals.

Harris and Taylor (2003) also conducted a qualitative study that discusses the limited role advertising agencies have on their client's establishment of an advertising budget. Through the use of qualitative interviews the authors are able to illustrate the influence time is believed to have on the relationship between commitment and complacency. For example, the authors state:

"However, as time goes on, agency/client roles begin to follow a well-worn path and thus, less involvement is necessary. Agencies may take their role for granted and become complacent, thus making themselves less valuable as a strategic partner..." (p. 350) 
The above passage describes the relationship between commitment and complacency. The important point to recognize however, is that the influence commitment has on complacency occurs over time (Verhoef, Franses, and Hoekstra 2002). Drawing from the above discussion, describing how time influences the dark side the argument for the moderating role of time can be derived. Just as shared values are also typically viewed as a positive influence on a B2B relationship, commitment is also described as a positive influence on a B2B relationship (Dwyer, Schurr, and Oh 1987; Garbarino and Johnson 1999; Morgan and Hunt 1994). Firms are generally more apt to "put their best foot forward" at the beginning of a B2B relationship so through their increased vigilance the onset of complacency is less likely at the beginning of the relationship. However, as time goes by, and the B2B exchange partners get to know each other and the relationship becomes more comfortable it becomes more likely that $\mathrm{B} 2 \mathrm{~B}$ partners will begin to assume a level of stability that may lull them into complacency. Time as a moderating variable was also recognized in the interviews conducted for this dissertation. One respondent, a 38 year old male in charge of purchasing for his department in a large engineering firm said the following:

"My experience relates to the purchase of electronic equipment and traffic signal parts. I have noticed that over the years, certain manufacturers have let their quality fall to below acceptable levels..."

In this particular case it seems as if it took the passage of time in order for the dark side symptom to manifest. The preceding discussion details the potential reasons for the relationship between commitment and complacency as well as the moderating influence of time. Therefore, referring to the discussion above pertaining to how commitment may 
influence the onset of the dark side symptom of complacency over time, the following hypothesis is presented:

H3: Over Time there will be a positive relationship between commitment and complacency

\section{Commitment and Vulnerability}

When firms allow themselves to become committed to other firms they may potentially be creating a situation that allows for the onset of the dark side construct of vulnerability. Svensson (2004) defined the vulnerability construct as the gap between the focal firm's perceived dependence on another firm or customer and the focal firm's perceived trust in another firm or customer. Attridge, Berscheid, and Sprecher (1998) conceptualized a similar definition of vulnerability in the international joint venture context. These authors define vulnerability as a focal firm's concerns about the continuance of the alliance relationship and its partner's future provision of need satisfaction.

Halinen and Tahtinen's (2002) process theory of relationship ending offers insight into the onset of vulnerability. Specifically, the authors explain that predisposing factors may already exist when firms enter into a B2B relationship which makes it more vulnerable to breakdown. In other words, there may have been something about the structure or foundation of the relationship that was present from the beginning of the relationship that may ultimately lead to the failure of the relationship. Hailinen and Tahtinen (2002) also describe precipitating events that may change how a current relationship is structured and this change, according to them, may eventually lead to the end of the relationship. These events may be sudden and dramatic or a series of events which hasten action toward 
relationship ending. This dissertation argues that relationship ending may or may not be the result of the onset of the dark side but more importantly Halinen and Tahtinen's taxonomy offers insight into vulnerability and how it could manifest in B2B relationships. The process theory of relationship ending recognizes the likelihood of predisposing factors or precipitating events that may act to damage the B2B relationship. Using this framework, it is easy to see how otherwise functioning B2B relationships, characterized by high levels of trust, commitment etc. may all of a sudden find itself believing that their trust has been betrayed or that they are all of a sudden vulnerable to the actions of their B2B partners in a way they had previously not realized.

The link between commitment and vulnerability has also been alluded to in the business literature. Researchers investigating organizational commitment have found that increased feelings of insecurity or vulnerability influence an employee's commitment toward the employing organization negatively (e.g. Greenhalgh 1985; Mesner and Stebe 2004). These increased feelings may be the result of predisposing factors that trigger these feelings despite the good intentions of the B2B partners involved.

Other researchers in the B2B literature conceptualize commitment as encompassing vulnerability (e.g. Lacey 2007; Morgan and Hunt 1994; Wong and Sohal 2002). This suggests that firms in their commitment to other firms also accept or understand their increased vulnerability resulting from their commitment to another firm. Firms that are committed to another firm often make this commitment in lieu of other alternatives (Fullerton 2003; 2005). Therefore, exclusivity may then result binding the firms together with the "want" aspect of commitment acting as relational glue effectively holding the relationship together. Firms in such an exclusive agreement might then begin to feel 
vulnerable as they have effectively cut themselves off from other market opportunities. Becoming strongly committed may be a precipitating event leading to the onset of vulnerability as it was the act of becoming committed to their partnering firm that eventually leads to the realization that switching costs are too high and effectively leave one of the B2B firms incapable of taking advantage of other, perhaps better, market opportunities. Had the firm not embraced such commitment they may have remained in a position to take advantage of other opportunities and consequently would have no reason to feel vulnerable.

This logic holds true for firms that have never been the victim of an opportunistic or other harmful act by an exchange partner as well but almost certainly makes former victims feel even more vulnerable the more committed they become. This isn't to say that they do not trust their channel partners or are not committed but that firms engaged in committed B2B relationships are extremely cognizant or aware of the potential for opportunistic behavior at their expense and hence, the onset of the vulnerable feelings. The 29 year old sales rep said the following about feeling vulnerable in her B2B relationship.

"It bothered me when I did a lot for a customer and then they turn their back on me as soon as they got a better deal. It made me not want to do as much for the next customer because I didn't want to be taken advantage of."

Time is also expected to have a moderating influence on the relationship between commitment and vulnerability. It has been mentioned that over time relationships become more involved (Moorman, Zaltman, and Desphande 1992). Such involvement exposes firm vulnerabilities, providing partnering firms with more opportunity for 
opportunistic behavior (Garyson and Ambler 1999; Hibbard et al. 2001). It requires the passage of time for firms to become so integrated that they become willing to expose their vulnerabilities. In other words, though commitment is initially viewed as a good or positive influence on the B2B relationship, over time, commitment may encourage greater integration of partnering firms which then leads to each firm being more vulnerable to the actions of the other. Therefore, the passage of time may actually lead to the onset of feelings of vulnerability among committed B2B relationship partners. Using this logic, the following hypothesis is presented

H4: Over time there will be a positive relationship between commitment and vulnerability

\section{Commitment and Suspicion}

Suspicion was a common theme that arose often during the qualitative interviews.

The 38 year old purchasing manager said the following:

"It seems like over time firms start to take you for granted and when that happens they begin to feel like they can do whatever they want with you because you have an established relationship with them..."

Similar to the purchasing manager's statement is that of a 64 year old quasi-retired management consultant who has several years on both the buying and selling side of B2B dyads. The following comment, on the following page, is a portion of an experience he shared about an organizational buyer who used her powerful position with suppliers to extort such things as gifts and travel compensation: 
"In cases of bad management there won't be anybody monitoring the relationship. I have personal experience with one buyer who used her position to extort gifts and favors from her suppliers. Aside from the damage this does to the relationship and the company's name, it makes the sales rep suspicious when dealing with her company but other companies as well"

These sentiments should leave no doubt regarding the potential about suspicion developing over time in a B2B relationship. However, are these feelings always justified and do the justification of the dark side symptom even matter as it pertains to relational consequences and overall firm performance? Anderson and Jap (2005) warn against caving into what they label the spiral of suspicion, or the act of suspecting or believing an exchange partner is acting in a way contrary to either contractual or implied relational norms without having the necessary evidence to conclude such behavior. Anderson and Jap (2005) suggest that being overly guarded or suspicious of other exchange partners could be damaging to the relationship. That is to say, being too suspicious of exchange partner's behavior might actually lead to the behaviors a suspicious firm is trying to guard against.

For example, an exchange partner meeting with a rival firm or sending market scouts into an exchange partner's overseas territory isn't necessarily indicative of an exchange partner acting exploitive or otherwise opportunistically, as might be interpreted, but rather an exchange partner simply looking for market opportunities (Anderson and Jap 2005).

Given the above scenario, the advice offered by the aforementioned authors seems reasonable. However, suspicion is not always the product of a firm's managers overly 
developing a sense of vigilance. It is possible that being suspicious of a partnering firm may very well be warranted and appropriate. Given the transaction cost analysis (Williamson 1975) assertion of opportunism when the opportunity for opportunism presents itself, it makes sense that firms should at least have some sort of monitoring mechanisms to guard against members of partnering firms taking advantage of situations that might allow for opportunistic behavior. Of course opportunistic acts may be viewed as precipitating events which may lead to relationship ending or the onset of suspicion (c.f. Halinen and Tahtinen 2002). The above discussion refers to the increasingly integrated nature of today's B2B relationships. Increased levels of integration certainly expose focal firms to an increased chance of opportunistic behavior by members of partnering firms. Therefore, the onset of the dark side of suspicion might almost seem like a given in today's highly integrated B2B relationship.

As with the relationship between commitment and vulnerability, the crux of the relationship between commitment and suspicion relies on the increased integration, over time, between channel partners (Svensson 2004). Firms more highly integrated are generally going to be more open to such things as opportunistic behavior on the part of members of their partnering firms. Some qualitative evidence is given by the 64 year old quasi retired management consult who, when asked about the nature of today's integrated B2B relationships and the potential for problems with these arrangements said:

"Some firms are actually going away from relationships all together in an effort to keep the relationships from becoming personal. This is because companies feel that personal relationships may become the focus at the expense of company profitability" 
These comments support the notion that firms are suspicious of relationships because they recognize the potential for these relationships to harm the firm.

It makes sense that firms in committed relationships will typically have their guards down compared to firms in relationships that are not as committed. This commitment to the relationship implies a certain level of trust (Wetzels, Ruyter, and Birgelen 1998) or belief committed relationship partners will not willingly do things detrimental to the relationship. Therefore, in an effort to receive all the potential benefits of adopting a relational exchange strategy they allow their exchange partners access to their systems and methods. Consequently, the partnering firm finds itself more exposed and thus vulnerable to deleterious actions that can potentially be used by their exchange partner(s) to their detriment.

When firms find themselves overly exposed they may find themselves becoming somewhat hypersensitive to changes in the relational dynamic. For instance, if the partnering firm is not producing as much as they were projected or contracted too, not meeting delivery or payment deadlines or if the partnering firm engages in some other actions deemed inappropriate, it is sure to provoke suspicion between the focal firm and the firm with which they have entered into a committed relationship. Of course, partnering firms not delivering, producing or paying as expected will not become apparent in the initial phases of the relationship. Some amount of time will have to pass in order for these "suspicious" acts or actions to manifest in a way that creates suspicion for the focal partnering firm. For example, a focal firm may view late delivery or late payment in the initial stages of the relationship as an issue stemming from the "getting acquainted" or time when each relational partner is figuring out, not only each other, but 
also how the dynamics of the relationship are supposed to work. However, after some time, these "excuses" will no longer work as the seemingly innocent notion of "not knowing" how things are supposed to work is no longer viable. The focal partnering firm may begin to assume more deleterious reasons for the issues which will then lead to the onset of suspicion. Therefore, time as a moderating influence on a positive relationship between commitment and suspicion is proposed:

H5: Over time there will be a positive relationship between commitment and suspicion

Trust and the Dark Side of B2B Relationships

Trust

Much of the RM literature has concluded the importance of trust as a necessary ingredient for developing B2B relationships (e.g. Doney and Canon 1997; Dwyer, Schurr, and Oh 1987; Moorman, Zaltman, and Desphande 1992) and is generally viewed as a positive influence on the relationship itself. Bradach and Eccles (1989) suggest that trust is an expectation that helps alleviate the fear that a channel partner will act opportunistically. Trust is also required for the development of long term relationships since, in the short term, there are often inequities that exist between channel partners. Trust, therefore, acts as a sort of assurance mechanism that over the long term, short term inequities will be resolved (Anderson and Weitz 1989).

Dwyer, Schurr, and Oh (1987) explain that all contingencies between exchange partners are impossible to address with formal contracts. However, provided there is trust between the exchange partners, addressing all possible contingencies is not required for sustained cooperation between the partnering firms. The presence of trust also allows 
firms to serve customers better, is a more powerful governance mechanism than fear and generates better performance for partnering firms (Kumar 1996). Doney and Cannon (1997) describe trust as an "order qualifier" or a prerequisite to even be considered part of a potential exchange partner's consideration set. A number of empirical studies have shown trust as an important antecedent for the development of commitment to the relationship itself (e.g. Kwon and Suh 2005; Moorman, Zaltman, and Desphande 1992; Morgan and Hunt 1994; Verhoef, Franses, and Hoekstra 2002). Finally, in the alliance literature Gulati (1995), using prior alliances as a surrogate for trust, empirically shows that the number of prior alliances, or the greater the trust between firms, the less likely alliances were to be equity based. The implication is that trust between firms can act as a determinant of governance structure for future alliances.

Despite the surplus of evidence supporting the importance of trust as a relational construct it has been widely conceptualized and thus defined differently throughout the marketing, exchange, and relationship literatures (Wilson 1995). Despite the lack of consensus regarding the definition of trust most of these definitions have adopted either a behavioral or belief view of the construct (Moorman, Zaltman, and Desphande 1992; Ring and Van de Ven 1994).

The view of trust as a belief generally entails a sentiment or expectation about the trustee's trustworthiness. Trustworthiness is typically viewed as the result of an exchange partner's expertise, reliability or intentionality (Moorman, Zaltman, and Desphande 1992). Mayer, Davis, and Schoorman (1995) further explored these elements though they were labeled ability, benevolence, and integrity. Ability is recognized as "the group of skills, competencies, and characteristics that enable a party to have 
influence within some specific domain" (Mayer, Davis, and Schoorman 1995 p. 717). Benevolence is defined as the extent the trustee wants to do good by the trustor (Mayer, Davis, and Schoorman 1995). Benevolence can be said to encompass a positive affect between two trusting parties. The "good will" and genuine desire to help a partnering firm succeed and reach organizational and other objectives is encompassed in the benevolence aspect of trustworthiness. Integrity involves the trustor's belief that the trustee adheres to a set of guiding principals that the focal firm finds acceptable (Mayer, Davis, and Schoorman 1995). These elements of trustworthiness are believed to be useful in measuring the relationship between trust and the dark side and are thus discussed more thoroughly in chapter three or the operationalization section of this dissertation.

The behavioral view of trust stems from an exchange partner's willingness to be vulnerable (Coleman 1990; Moorman, Zaltman, and Desphande 1992). The behavioral aspect of trust as described here manifests when firms actually put themselves in a position of vulnerability, or perhaps, by the act of engaging in an exchange relationship, put themselves at risk. Proponents of this view of trust suggest that though an exchange partner might be trustworthy, without actually engaging in the relationship there is no risk and thus, no need for trust. It is the risk that stimulates the onset of trust between the firms not just their belief in their partnering firm's benevolence, ability or integrity.

Moorman, Zaltman, and Desphande (1992) defined trust as “A willingness to rely on an exchange partner in whom one has confidence" (p. 315). This definition encompasses both the belief and the behavioral views of trust. The willingness to rely implies an action or behavior on the part of the trustor while having confidence in the trustee speaks 
to the trustor's belief in the trustee. The authors argue that a definition of trust that encompasses both the belief and behavioral views is essential because without both views trust can not exist. A willingness to rely on an exchange partner does not by itself imply trust as power and control might be driving the reliance. Also, believing an exchange partner to be trustworthy without a willingness to rely on them inhibits trusts ability to manifest between the exchange partners (Moorman, Zaltman, and Desphande 1992). For the purposes of this dissertation, this conceptualization of trust, as defined by Moorman, Zaltman, and Deshpande (1992) will be utilized.

This is an appropriate definition for investigating trust and its relationship to the dark side of B2B relationships. This is because of the belief that a firm's willingness to become vulnerable to the actions of a partnering firm and these actions subsequently having unexpected negative consequences is where the dark side resides.

The following discussion will explore potential relationships between trust and how trust potentially influences the onset of the dark side of B2B relationships. Specifically, the following discussion will propose relationships between trust and how it might hasten the onset of the dark side symptoms between firms who have engaged in an exchange or other B2B relationship.

\section{Trust and Relational Myopia}

Though perhaps counterintuitive a focal firm that has a high level of trust in a partnering firm may influence the onset of the dark side symptom of relationship myopia. Consider a focal firm that engages in a long-term B2B relationship with another firm, specifically for the partnering firm's problem solving abilities. The partnering firm may have equipment, knowledge, problem specific experience or some other resources 
available that enable them to solve the focal firm's problems. The partnering firm probably also has a good reputation for treating their exchange partners well while delivering products or service without issue or hassle. Relational myopia may become a problem when conditions change in such a way that current specifics regarding the relationship require in some changes or updating. This is consistent with Cyert and March's (1963) generalizations regarding firm's perceptions and the incorporation of bias which can restrict or perhaps narrow their view of the environment.

If a focal firm trusts their partnering firm to deliver solutions a certain way they might not want their partnering firm to change their way of doing things even when these changes are really updates to such things as equipment and processes. Therefore, the partnering firm might resist the need to change or update how they deliver their solutions to the focal firm, potentially forgoing efficiency and cost savings realized by changing the method with which these solutions are delivered. Obviously, some amount of time will need to pass in order for conditions to change in such a way as to allow for the onset of relational myopia. More specifically, though the relationship may be ideally constructed to take advantage of the environment when the relationship is first forged, over time, the condition is likely to change which will require the firms in the relationship to reassess the details and dynamics that govern the B2B relationship. If this doesn't happen then the firms can be said to have adopted a myopic view of the relationship. In this scenario the environment must first change in a way that dictates action. This change can not happen without the passage of time and thus, the argument for the moderating role of time is derived. 
Relational myopia that is stimulated by the trust relational partners invest in each other may also develop when firms put their trust in their exchange partner's good intentions. As focal firms put their trust into their exchange partner to both deliver their product and or services as agreed and to make these deliveries with the focal firm's best interest in mind, the incentive to monitor both the relationship and relational partner wanes or disappears altogether. As long as things go according to expectations a narrow view of the relationship may develop and endure, over time, as there is nothing provoking a change in view toward the relationship. This might not initially appear to be a problem. So long as partnering firms are not taking advantage of the trust bestowed upon them there may not appear to be any real dark side issue. However, over time, narrowed views may not permit the type of evaluation of the relationship that could lead to such things as efficiency increases, cost cutting initiatives, and the recognition of better, more profitable exchange partners. In other words, as mentioned above, over time the relationship will change and if the firms involved in the relationship do not take steps to assess their needed reactions to the change in the environment, then it can be said that over time, the B2B relational partners have adopted a myopic view of their relationship.

Though predominately anecdotal and sparse there is some literature that indirectly alludes to these relationships between trust and relationship myopia. Merriden (1999) explains that fast growth companies often view the relationships they have with a typical type of consumer in one market the same way as they do in other markets. As firms move from one market to another they have developed a sense of trust in the customers they currently have. As a firm moves into the next market the myopic firm will allow this sense of trust in the customers from the preceding market to dictate the view the firm 
will have of the customers in the newer market. Though this is not directly analogous to the example described above it is a good illustration of how relationship myopia might, over time, be brought on by trust. To aid in the support of this relationship, specific questions were asked interview participants. The participants were asked about the long view of the relationship vs. the short view and how the adoption of a view is related to trust. The interview participants were also asked to discuss the good and bad sides of this relationship. The 29 year old sales rep said the following:

"I have clients that trust me to not give them things they don't want. They know I know what they want and I know I know what they want so the relationship is easier that way. It takes some time to get to this point though, you have to prove you know them well enough before they'll trust you like this."

It seems intuitive that if firms are focusing all of their attention on their competition then they have a very trusting relationship with their current relationship partners. Firms would not be able to focus all of their attention on just their competition if they did not trust in their partner's abilities and intentions to fulfill these obligations in a way deemed appropriate and acceptable to the focal firm. Therefore, these competitive myopic firms are probably also relationally myopic as a narrower focus on their competition leaves little room for a broad view of their exchange relationships. Trust in this situation is an enabling condition for the onset of relational myopia. It is from this discussion pertaining to trust, relational myopia and the moderating role of time that the following hypothesis is presented:

H6: Over time there will be a positive relationship between trust and relational myopia 


\section{Trust and Complacency}

It is easy to see how a focal firm that trusts its partnering firm will hasten the onset of complacency. The focal firm builds up confidence in their channel partner and subsequently stops looking for other perspective channel partners that can fulfill the needs of the focal firm. Relationship seeking and the subsequent building of the relationship can be an expensive and frustrating endeavor (Hibbard el al. 2001; Palmatier, Gopalakrishna and Houston 2006). It has been shown empirically that the greater the investments in the relationship, the less partners are apt to leave the relationship (Ranganathan, Seo and Babad 2006). Drawing from these results, it can be inferred that firm's will not typically have the incentive to keep looking for another partner after having found one capable of delivering what is needed. The amount of time and effort required to find a suitable partner precludes these efforts after a firm finds a suitable partner (Ranganathan, Seo, and Babad 2006). Therefore, so long as the partnering firm lives up to the focal firm's expectations about what is to be delivered, the focal firm will not keep scanning the environment for other opportunities and hence the onset of complacency. That is to say, the costs associated with relational partnering can be excessive. In an effort to safeguard the firm's assets, firms will stop investing in relationship building activities after they have found trustworthy exchange partners. Provided the focal firm trusts the partnering firm, the costs of relationship building essentially dictates a complacent attitude. However, if the firm does not trust their exchange partners then it is more likely that such a complacent attitude will not set in as the firm will continue to look for better alternatives outside their current exchange relationship as well as monitor their exchange partner's actions. 
The onset of complacency may also become an issue when a focal firm trusts in the goodwill and intentions of their partnering firm that the attitude they have toward their exchange relationship becomes complacent. This happens as firm's progress through a relationship without any detrimental issues occurring between the firms severe enough to damage the trust the firms have between each other. In other words, trust drifts into complacency. It's easy to see how a firm engaged in such a relationship might develop a complacent attitude toward the relationship when there are never any issues that call into question a partnering firm's goodwill or intentions. The relationship then might become stale over time (Doyle, Corstjens, and Michell 1980; Grayson and Ambler 1999; Moorman, Zaltman, and Deshpande 1992). Though the firms never lose faith in each other trust begins to morph into complacency as each firm begins to expect the status quo (Robinson 2005). Once firms have become complacent toward their relational partner(s) there is less effort and resources put toward the relationship in an effort to keep it vibrant and functional (Halinen 1997). In other words, trust not only allows for the onset of complacency but, as some authors suggest, actually becomes the complacent attitude between the firms (e.g. Bantu-Gomez and Bantu-Gomez 2007; Robinson 2005).

Of course, as with the other relationships between relational constructs and dark side sentiments discussed in this dissertation, the influence trust has on complacency is expected to occur over time. As mentioned above, trust is expected to morph into complacency (Robinson 2005). Obviously, in order for something to "morph" into something else, a certain amount of time must first elapse. This is an intuitively plausible assertion. Trust is typically thought of as a positive influence on B2B relationships and the development of the B2B relationship itself (Dwyer, Schurr, and Oh 1987; Moorman, 
Zaltman and Desphande 1992; Morgan and Hunt 1994). It does not make sense that trust induced complacency would manifest during the initial phases of the relationship. In the beginning firms will be more attentive and active in assuring the relationship is behaving and producing as expected. Complacency can not set in unless the relational partners have witnessed the types of behaviors expected from a trusted relational B2B partner. That is, the firms must first develop trust in their partners. This takes time. Then trust has to lull the partners into complacency. Again, this is expected to take time. Robinson (2005) supports this belief concerning the moderating influence time has on the relationship between trust and complacency. Specifically, he states "However, there is a danger that trust can drift into complacency and a lack of attention to the service being provided can result in a slipping of standards" (Robinson 2005, p. 18). The "drifting" from trust into complacency implies the necessary component of time. From the discussion above, regarding the relationship between trust and complacency, the following hypothesis is deduced:

\section{H7: Over time there will be a positive relationship between trust and}

\section{complacency}

\section{Trust and Vulnerability}

The relationship between trust and vulnerability can be drawn from the definition of trust being used in this dissertation as well as the many pieces of research that have recognized the link between the willingness to trust a relational partner and subsequently put oneself at risk (e.g. Barney and Hansen 1994; Bradach and Eccles 1989; Gambetta 1988; McEvily, Perrone, and Zaheer 2003; Moorman, Desphande, and Zaltman 1992). The link between vulnerability and trust is so fundamental that some researchers use 
vulnerability to help define trust. For example, Deutsch (1962) defined trust as "actions that increase one's vulnerability to another" while Banery and Hansen (1994) defined trust as "the mutual confidence that no party to an exchange will exploit another's vulnerabilities" (p. 176).

Moorman, Zaltman, and Desphande (1994) make the point that without vulnerability there would be no need for trust as the application of trust implies the importance of outcomes for the trustor. Therefore, based on the behavioral dimension of being willing to take risks by believing the trustee will act and do as expected automatically implies the positive link between trust and vulnerability.

As a focal firm places trust in the partnering firm they are not only believing the partnering firm can do what is expected of them, they are also assuming some risk by having a vested interest in the partnering firm actually fulfilling their obligations (Moorman, Zaltman, and Desphande 1992). If a focal firm places trust in a partnering firm they are making the firm vulnerable to some sort of consequence if the partnering firm does not actually possess the ability to do what the focal firm expects. The partnering firm may be incompetent regarding what is needed by the focal firm though the focal firm may trust they are fully capable of delivering. The focal firm may feel a sense of vulnerability when the partnering firm fails to deliver, perhaps due to loss of expert personnel, equipment damage or some other contingency. As time passes, the focal firm will begin to feel the loss associated with their partnering firm's inability to perform the contracted tasks.

This argument also speaks to the influence time has on the relationship between trust and vulnerability. A number of researchers have employed the passage of time as a 
variable that enhances the relational and long term orientation of firms in business to business relationships (Ganesan 1994; Lusch and Brown 1996). The primary argument for time's ability to enhance such relational variables as trust, communication, and satisfaction stems from the notion that as time goes by and the relationship develops, belief about the partnering firm(s) is replaced with experience. Specifically, as time goes on, information about the partnering firm is released or discovered (Park and Russo 1996). Assurances of mutual trust are either confirmed or denied as measures of such things as ability and trustworthiness can be assessed (Park and Russo 1996).

However, though some researchers have mentioned the possibility of firms not meeting expectations (e.g. Anderson and Weitz 1989; Davies and Prince 2005; Park and Russo 1996) most researches glance over the potential consequences of this relational failure, assuming that unsatisfactory relationships simply terminate (Anderson and Weitz 1989). Therefore, enduring relationships are by default functional, well run establishments.

It is the position of this dissertation that this is an unrealistic assumption. Many dysfunctional relationships endure, over time, simply out of need or lack of alternatives. If a firm invests in a B2B relationship simply to find out that the relationship is an underperformer, or worse the relational partner will exploit their vulnerabilities, it is assuredly cause for the termination of the B2B relationship. However, over time, and after such investments have been made, firms may no longer have the ability to seek out and develop another relationship with a different exchange partner. Also, the market may no longer be able to provide better relational options, effectively forcing firms to maintain less than optimal and/or desirable exchange relationships. A situation such as 
this seems likely to help usher in the dark side symptom of vulnerability. This is consistent with the dependence perspective of B2B relationship performance. This theoretical perspective suggests that $\mathrm{B} 2 \mathrm{~B}$ relationships that are asymmetrical typically adversely affect firm performance as there are no barriers to the use of coercive power (Palmatier, Dant, and Grewal 2007). As dependent firms realize they have exposed themselves and partnered with a partner that is unable or unwilling to meet relationship expectations and the focal firm does not have the ability to remedy the situation the focal firm may begin to feel as if their trust was misplaced and consequently begin to feel vulnerable.

It will take time for the focal firm to realize that they have partnered with a less than ideal exchange partner. Over time, as the focal firm realizes their partner isn't ideal, vulnerability may set in as the focal firm begins to wonder if their exchange partner is hurting such things as efficiencies, productivity and profitability. Perhaps questions about the viability of the exchange partner arise forcing the focal firm to wonder what will happen to them if their exchange partner goes out of business. More succinctly, as a focal firm realizes they have invested in a poor B2B relationship with a less than desirable exchange partner they may begin to feel vulnerable as they wonder what deleterious effects their poor relational choice is having on the viability of their firm. The passage of time is needed in this situation to allow for the ineptitude of the partnering firm to manifest and become apparent to the focal firm. Therefore:

H8: Over time there will be a positive relationship between trust and vulnerability 


\section{Trust and Suspicion}

From the above discussion on trust, it should become more apparent that engaging in a RM strategy entails a certain amount of risk which requires a certain amount of trust on the part of the partnering firms (c.f. Bradach and Eccles 1989; Coleman 1990; Moorman, Zaltman, and Desphande 1992). Firms have to be willing to trust that investments in the relationship will yield benefits not afforded to the firm by adopting a more discrete or transactional exchange philosophy. Firms, have to be willing to trust partnering firms to reciprocate investments to both build and maintain the relationship as a functioning entity that again yields benefits not otherwise provided by a different exchange philosophy. Finally, firms have to trust partnering firms not to take advantage of their exposed and vulnerable position regarding information, or the exploitation of dependence asymmetries that may have developed within the relationship.

Given the risk associated with entering trusting long term B2B relationships it becomes more intuitive as to how suspicion might become a problem between partnering firms over a period of time. It is certainly impossible to monitor the totality of a partnering firm's actions (Dwyer, Schurr, and Oh 1987). If this was possible then trust would not be an issue or a needed component for a successful relationship (Moorman, Zaltman, and Desphande 1992). Monitoring mechanisms would not need to be put in place to guard against any unforeseen actions or behaviors that the focal firm would like to avoid. However, this is not the case and thus opens the door for certain activities or actions to damage the strength of the relationship, including the trust between firms.

Such actions include opportunistic behavior (e.g. John 1984; Kwon and Suh 2005; Williamson 1975) destructive, abusive or punitive acts (e.g. Baker 2006; Hibbard, Kumar 
and Stern 2001; Kumar, Scheer, and Steenkamp 1998). These potentially harmful and destructive behaviors that occur between channel members speak mainly to the integrity of the partnering firm (e.g. opportunism) or benevolence of the partnering firm (e.g. destructive or punitive acts). However, a partnering firm that is not able to deliver what they say, or lack the equipment, expertise or resources to do what is expected are also real concerns that are linked directly to a focal firm's trust in a partnering firm (Mayer, Davis, and Schoorman 1995).

The manifestation of suspicion within the relationship is the product of one or both firms having believed it has endured some sort of act (rightly or wrongly) that damaged the trust between the firms. This is consistent with Halinen and Tahtinen's process theory of relationship ending where precipitating events lead to the eventual end of the relationship. Though this dissertation is not suggesting that every relationship which experiences such an event will end, it does suggest that there is a relational consequence when B2B relationships experience such events. For instance, as trust between firms decreases suspicion between firms will increase. Obviously, one potential course of action for dealing with a loss of trust is the ending or dissolution of the exchange relationship all together, as mentioned above and this remedy is logical provided the firm or firms can survive without each other.

However, in asymmetric relationships it may be that one partner is dependent on the other. In situations like this, offended firms may have no choice but to accept a loss of trust in their partners. Should such a situation arise the offended firms are likely to engage in behaviors symptomatic of the onset of suspicion. For instance, firms may have to re-arrange the business relationship and enact controls to safeguard against future 
destructive behaviors. A firm might decrease transaction specific investments, as well as move toward more transactional exchange in an effort to decrease some of the transparency of the firm. Communications may become less integrated in an effort to reduce exposure of vulnerabilities to the partnering firm. Keeping a more watchful eye, asking specific questions about the offending party's activities that weren't asked prior to the loss of trust, demanding clearer more specific accounts of the offending party's actions or just committing more time, personnel and resources toward guarding against behaviors of the offending firm are all potential manifestations of the new suspicious attitude of the offended exchange partner. It takes time for a focal firm to realize the types of behaviors described above that provoke feelings of suspicion. Again, this has to do with a partnering firm not having the ability to take advantage, invoke or levy any sort of destructive act on the focal firm in the initial phases of the relationship. It is only after the passage of time that firms will act destructively toward the relationship and relational partners. Therefore, the moderating role of time is believed to significantly influence the relationship between trust and suspicion.

H9: Over time there will be a positive relationship between Trust and Suspicion Satisfaction and the Dark Side of RM

\section{Satisfaction}

Satisfaction within the consumer literature has been conceptualized as either transaction specific satisfaction or cumulative satisfaction (Anderson, Fornell, and Lehmann 1994; Dant, Brown, and Bagozzi; Garbarino, and Johnson 1999). Transaction specific satisfaction entails a post choice evaluation of a specific purchase occasion (Anderson, Fornell, and Lehmann 1994). Cronin and Taylor (1992) embraced this 
conceptualization of satisfaction in their study investigating service quality and its relationships with consumer satisfaction, and purchase intentions. Wilson (1995) also embraced a similar conceptualization of satisfaction when developing his integrated model of buyer-seller relationships. Cumulative customer satisfaction can be viewed as an overall evaluation based on the totality of the purchase and consumption experience over time (Anderson, Fornell, and Lehman 1994).

However, within the marketing channels literature, satisfaction is most often conceived of as an overall evaluation and affective response toward one's exchange partner (Anderson and Narus 1984; Dant, Brown, and Bagozzi; Gaski, and Nevin 1985; Scheer and Stern 1992). This conceptualization of satisfaction is derived from an appraisal of all aspects of an exchange relationship one partner has with another (Anderson and Narus 1984). The adoption of this conceptualization of satisfaction seems most appropriate in a relational exchange context as evaluating outcomes and consequences according to each transaction runs counter to the relational exchange philosophy.

Using this conceptualization of satisfaction, Scheer and Stern (1992) were able to show that positively framed contingent rewards result in greater satisfaction than negatively framed contingent rewards or contingent penalties. Gaski and Nevin (1985) also used this conceptualization of satisfaction in their investigation of the effects of exercised and unexercised power within a channels setting. This study found that exercising coercive sources of power will have a more negative influence as compared to just the presence of these coercive sources. While exercising non-coercive sources of 
power will more positively influence satisfaction than the simple presence of these noncoercive (reward) sources of power.

Anderson and Narus (1990) found that trust has a positive influence on relationship satisfaction in the channels context while conflict influences satisfaction negatively. Also, in this study, the authors found that positive outcomes, compared to outcomes obtained from previous relationships or knowledge of similar relationships also had a positive influence on satisfaction.

Contrary to Anderson and Narus (1990) who found trust to be antecedent to satisfaction is Ganesan (1994) who found that satisfaction is actually antecedent to trust. Still, other researchers have satisfaction in conjunction with trust as a measure of relationship quality between two partnering firms (e.g. Crosby, Evans, and Cowles 1990; Leuthesser 1997).

Though this overall assessment of the exchange relationship has been the most widely utilized conceptualization of satisfaction within the channels and exchange literatures, Geyskens, Steenkamp, and Kumar (1999) make a distinction between economic and noneconomic satisfaction. Economic satisfaction is defined as a channel member's positive affective response to the economic rewards that flow from the relationship with its partner, such as sales volume and margins (Geyskens, Steenkamp, and Kumar 1999 p. 224). Noneconomic satisfaction is defined as "a channel member's positive affective response to the noneconomic, psychosocial aspects of its relationship, in that interactions with the exchange partner are fulfilling, gratifying, and easy" (Geyskens, Steenkamp, and Kumar 1999, p. 224). Noneconomic satisfaction, in contrast to economic satisfaction, is more concerned with the process and continues dynamics of the relationship and less on 
the tangible performance outcomes associated with economic satisfaction. Just as with the components of the relational constructs discussed above, this distinction within the satisfaction construct is further explored in the operationalization section or Chapter three of this dissertation.

Though this conceptualization of satisfaction is insightful it has not been widely adopted in the channels and exchange literatures; perhaps, because the above definition of satisfaction or the notion of "overall" satisfaction is said to subsume both economic and noneconomic satisfaction (Dant, Brown, and Bagozzi). As the majority of research investigating the satisfaction construct in the relational exchange context is concerned with the influence of all forms of satisfaction the adoption of this "overall" conceptualization seems appropriate and is the conceptualization adopted for this dissertation.

\section{Satisfaction and Relationship Myopia}

Perhaps the most evident of Cyert and March's (1963) application of the behavioral theory of the firm lies in the relationships between satisfaction, relational myopia and complacency. Cyert and March's generalizations for the firm explain that firms will routinize recurring processes as well incorporate biases that reflect past experience. Those generalizations also state that firms will continue to behave as they have until they perceive problems. In conjunction with these generalizations suggest so long as things are going well the firm will simply do as it always has and forgo any actions that may lead to any significant changes in the B2B relationship or its processes. Specifically, satisfaction may lead to relational myopia when a firm becomes too comfortable or satisfied with the results of the relationship itself. For instance, an economically satisfied 
firm that is deriving its satisfaction with the channels relationship primarily from the economic rewards resulting from the relationship might easily adopt a narrow focus of the relationship if it looks only at the economic aspects of their business relationship. Such firms might view their channel partners as a revenue producing agent and only a revenue producing agent. In such a situation the focal firm might not realize the shared values, be as committed or trust their partnering firm as much as another firm that embraces a more holistic view of their channel relationships. Relational myopia, therefore, is brought on by the primarily economic focus of the relationship. However, focusing only on the economic aspects of the relationship is definitely narrow or shortsighted as today's highly integrated channel relationships have a level of dynamics not common to most discrete relationships.

In a similar vein, firms that are non-economically satisfied may also become relationally myopic. Relationship myopia manifest when partnering firms become so consumed with this aspect of the relationship that they neglect the reason for the partnership in the first place. RM and relational exchange is, after all, a business strategy which has been cited many times as helping firms reach financial objectives (e.g. Allen 1988; Bejou 1997; Gummesson 1987; Priluck 2003). The myopic perspective is that firms can become so satisfied with the positive affect produced by the relationship that their commitment is more to this aspect of the relationship and not the attainment of firm or financial objectives. To be focused primarily on the positive affect of the relationship describes a shortsighted view of the relationship and thus, the relationship between noneconomic satisfaction and relational myopia: 
It is also believed that when firms are satisfied with all aspects of the relationship, both economic and non-economic, they can still adopt a myopic view of their exchange relationship. When firms are satisfied they may be lulled into a sort of comfort that doesn't necessarily preclude monitoring of the relationship but it also doesn't require it. If firms are satisfied with the results of their exchange relationship they may lack the incentive to stay vigilant about it. In such a scenario it is likely then that firms, seeing results that produce satisfaction, fail to see the opportunities for improvements. So long as they are satisfied they fail to see areas for improvement, cost cutting initiatives and potentially better relationship choices. So long as firms are this satisfied, they will not take the long view of the relationship which by default means the adoption of a short view which is indicative of the relational myopia construct being described here.

Finally, the influence the passage of time has on the relationship between satisfaction and relational myopia needs to be mentioned. Time is needed in order for satisfaction to manifest within the relationship. After exchange partners act in a way that is expected and is consistent with the contractual and behavioral demands of the other partner(s) within the relationship the focal firm then has reason to become satisfied. Likewise, time also needs to pass in order to have satisfaction influence the onset of relational myopia. Only after firms have become satisfied that they will begin to behave in the ways mentioned above that describe the onset of relational myopia, as influenced by satisfaction. This is due to the belief that it takes time for the lulling effects of satisfaction to set in and subsequently provoke the onset of relational myopia. The relationship between satisfaction and relational myopia over time is supported by the 
qualitative results collected during the interviews for this dissertation. The 64 year old quasi-retired management consultant responded with:

"It does seem as if companies, when they become satisfied with their business partners, will often start accepting everything their partners say. They just go along with their ideas because it seems to be working...."

This passage can be interpreted as supporting the relationship between relational myopia and complacency as it infers both a narrowed view of the relationship by one firm simply accepting their partner's view but it also implies complacency by that same partner by not putting forth the effort to know if their partner's view of the relationship is appropriate or not.

H10: Over time there is a positive relationship between satisfaction and relational myopia

\section{Satisfaction and Complacency}

As stated by many marketing scholars as well as marketing text books, a satisfied firm does not necessarily imply a loyal or happy partnering firm (e.g. Johnston and Marshall 2006; Torres and Kline 2006). Therefore, it stands to reason that satisfied firms might be nothing more than content in their current channel relationships (Skogland and Siguaw 2004). It is therefore no logical stretch to suggest that complacency may manifest in exchange relationships that can be characterized as nothing more than satisfied. Kumar Olshavsky and King (2001) found that levels of satisfaction influence loyalty. That is, the more satisfied the customer the more loyal they are said to be. Extrapolating these results to the $\mathrm{B} 2 \mathrm{~B}$ relationship context, it can be said that how satisfied a firm is with 
their exchange partner influences the probably of that partner becoming complacent versus staying vigilant and active in maintaining the relationship.

When satisfied firms are enjoying success they have no motivation to continue to monitor the environment in search of better alternatives or other business opportunities that might prove more beneficial to the focal firm (Hibbard et. al 2001). Just because firms begin to realize financial success, does not mean they could not realize more if they continue to monitor the environment and their relationship in search of such opportunities. However, satisfied firms don't necessarily embrace this incentive as they are realizing success which may act as a hindrance against this sort of behavior.

Ping (1993) found that firms that are satisfied in their exchange relationships are less apt to leave these relationships. Other researchers have found that the more satisfied a customer is the more committed they are to the salesperson or firm (Johnson, Barksdale, and Boles 2001). Hocutt (1998) found that the more satisfied a customer is with a salesperson the more committed to that salesperson the customer is. Finally, Priluck (2003) found that customers who are engaged in a relationship will be more satisfied with poor product performance than customers not engaged in a relationship.

All of these pieces describe scenarios that, on their face, look positive, but might actually breed the onset of complacency. The above mentioned literature describes customers that are willing to cope with less than optimal performance, or remain committed to a relationship simply out of their satisfaction with it. These pieces show the influence satisfaction has on "not" looking for other relationships and thus the onset of complacency. 
Another plausible scenario that links satisfaction to complacency can be constructed via the notion that depending on the amount of satisfaction, it may not be a strong enough influence to produce anything more than a non-negative evaluation of the exchange partner (Kumar, Olshavasky, and King 2001; Torres and Kline 2006). If the amount of satisfaction is low then it is plausible that the focal firm, though not unhappy with their current exchange partner, isn't necessarily overjoyed with the current state of the exchange relationship either. This may be due to any number of reasons; the current exchange partner is not the focal firm's first choice, the exchange partner is helping to meet objectives but not exceed them, there is nothing unique or special about the exchange partner and the service or products they provide but are suitable for the focal firms needs etc. If such a scenario exists then the focal firm may have what they need in an exchange partner but nothing more. The focal firm may not see the use in working to enhance this type of relationship or have the motivation to do so. Therefore, the onset of complacency becomes more probable.

Referring to the age of the relationship, though researchers have shown relationship age to positively influence satisfaction in the exchange relationship (Flavian, Guinaliu, and Torres 2005; Verhoef, Franses, and Hoekstra 2002), it is also believed that as time passes the more satisfied firms are likely to be with their exchange partners. The more satisfied firms are the less apt to look around for other alternatives, essentially "settling" on the exchange partners they have without consideration of potentially better exchange partners. A sort of "if it ain't broke don't fix it" attitude may develop keeping the firms from constantly seeking process improvements or other relational benefits and outcomes not being realized by the relationship in its present form. It is from this logic that the 
influence of time can be introduced as a moderating variable between satisfaction and complacency. Therefore:

H11: Over time there is a positive relationship between satisfaction and complacency

\section{Satisfaction and Vulnerability}

Satisfied firms may feel vulnerable because of their lack of touch regarding the rest of the alternative relationships possible. Also, such firms may not have their finger on the pulse of the dynamics of the channel or exchange relationship and therefore, over time, may lose their barometer of what is going on between the two firms. The sense of vulnerability stems from the notion that satisfied firms are aware of this lack of knowledge or involvement and though they are satisfied with the results and perhaps have no intention of becoming more relationally focused, over time, satisfied firms still feel vulnerable regarding its exchange relationship.

Obviously, for such firms the corrective action would be to get more involved with the relationship itself and move the relationship from a passive satisfaction where the firm is content to let things be, so long as the results are good, to a more active satisfaction where the firm, though satisfied with the current results, actively seeks ways for improvement. However, not all firms have the ability, resources or knowledge to do this while others are willing to accept the vulnerability in lieu of dedicating needed resources toward becoming more relationally focused. Therefore, such firms, as time goes by, are somewhat forced to accept the positive benefits of the relationship without ever having their finger on the pulse of the relationship; Hence the hastening of a sense of vulnerability for the satisfied firm. That is to say, firms may not have any issue with their 
lack of awareness concerning their B2B relationships initially, but over time are expected to develop feelings of vulnerability as they realize they have very little control or even understanding of their B2B relationships that are potentially significant contributors to the focal firm's viability, profitability and over all performance. It is intuitive that such feelings of vulnerability will manifest in firms like the ones described because firms will naturally want to have as much control as possible over the things that influence them the most. Satisfaction might lull firms into a "hands off" sort of attitude toward the governing of the relationship with their B2B partners but this attitude is believed to eventually lead to feelings of vulnerability as firms realize their satisfaction with the relationship has led them to a position of little or no control over the relationship and consequently left them vulnerable to the actions of their exchange partners. From this logic, the following hypothesis is presented:

\section{H12: Over time there is a positive relationship between satisfaction and} vulnerability

\section{Satisfaction and Suspicion}

Just as satisfied firms may feel vulnerable due to their lack of touch regarding the rest of their relationships they may also begin to feel suspicious of their exchange partners. The sense of suspicion stems from being satisfied without being engaged. Perhaps there are firms that for any number of reasons seek a passive relationship that focuses on results and not the dynamics of the exchange relationship. Therefore, so long as the results are as expected the firms remain satisfied but again, as with the relationship between satisfaction and vulnerability, discussed above, they remain out of touch and unaware. It then makes sense that though satisfaction with the results of the relationship 
may be the primary goal of the focal firm, not knowing what is stemming or producing these results may begin to breed feelings of both vulnerability and suspicion. Also, as with the relationship between satisfaction and vulnerability, time, is again expected to play a moderating influence on the relationship between satisfaction and suspicion. Just as above, time is required to lull firms into feelings of satisfaction and this "hands off" attitude toward the relationship. As time goes on and the firm becomes more and more detached from the relationship for the reasons described above, suspicion is expected to grow.

It might be argued that satisfaction is not the reason for the onset of suspicion in such a scenario but that other forces are at work, in conjunction with the onset of satisfaction that is the real catalyst of the dark side symptom(s). The counterargument to this line of thinking is that it was the satisfaction with the results of the relationship that lead to the disengagement or otherwise apathetic stance toward anything except the status quo regarding the results of the exchange relationship. So, from a relational perspective, it can be argued that if firms do not become satisfied with their exchange partners and relationships they will stay vigilant with regard to things like monitoring, actively pursuing improvement and making sure things are working the way they are supposed to. When firms become satisfied with things, the incentive to remain active may wane which thus, helps provoke the onset of both vulnerability and suspicion. Therefore, the succinct argument for this logic is that if firms do not allow for the onset of satisfaction then vulnerability and suspicion will not be able to develop and therefore:

H13: Over time there is a positive relationship between satisfaction and suspicion 


\section{The Dark Side of RM and its Influence on Relationship Strength}

Relationship strength can be described as a relational construct that embodies the overall depth and climate of a B2B relationship (Johnson 1999). The assessment of a B2B relationship is said to hinge on such things as how well each relational partner fulfills expectations, predictions, goals and the desires of the partnering firms (Jarvelin and Lehtinen, 1996) and these assessments are believed to manifest in a relationship partner's evaluation of the strength of the B2B relationship. It is believed that the dark side constructs, discussed above, will influence the strength of the relationship in much the same way they are believed to influence performance. A more detailed discussion of relationship strength and its relationship to the four dark side constructs is discussed below.

\section{Relational Myopia and Relationship Strength}

Relationship myopia will have the potential to hinder the decision making ability of two partnering firms effectively reducing their ability to take corrective action against market hazards. Relational myopia may also inhibit partnering firm's ability to take advantage of market opportunities. While accounting for these inabilities, it should be apparent that opportunity costs associated with missed opportunities represent a potential for significant financial loss for one or both of the partnering firms. The potentially more serious issue is the firms' inability to guard against market hazards. The manifestation of this issue may result in large financial outlays to compensate for an issue that was never addressed when it was still on the horizon. Typically, preventative action is less costly than corrective action. So again, relationship myopia may lead to a larger outlay of funds than had the relationship not become myopic. 
Stock (2002), when addressing the issue of myopia in the logistics context, warns practitioners and academics alike of the dangers of myopia as he alludes to its potential negative influence on performance. Specifically, he warns not to adopt too narrow a focus of the discipline as it may not realize its responsibilities to other areas of the firm as well as keep the discipline from reaching its full potential.

Anderson and Narus (1990) suggest that satisfaction with a business relationship can serve as an indicator of relationship success or relationship strength. This conceptualization of satisfaction is rooted in the partnering firms meeting each others' performance expectations (Anderson and Narus 1990; Johnson 1999). Using satisfaction as a measure of relationship strength might represent a significant opportunity costs due to performance expectations potentially falling short of performance potential. In other words, being satisfied with expectations might imply the dedication of just enough energy and resources to meet expectations but not enough energy and resources to meet performance potential. Though researchers have used satisfaction as a proxy for relationship strength (e.g. Anderson and Narus 1990; Johnson 1999; Mohr and Spekman 1994) what might be revealed is simply a firm obtaining a level of mediocrity that allows the relationship to continue. The narrow view of relationship strength is thus rooted in using satisfaction synonymously with strength. If the firms adopt a broader view of what is possible and what relationship strength is, aside from just the attainment of expectations, greater financial rewards might then be possible. However, as long as firms rely on the meeting of expectations as a measure of success, it can be argued that they are adopting a narrow or shortsighted view of relational success. This proposition can be theoretically justified by drawing from Cyert and March's behavioral theory of the firm 
and the generalization that suggests firms' perceptions have bias that reflect their past experience and future expectations. If firms have adopted such a narrow view of the firm it may have been from past success which the firm then focuses on. If the firm becomes focused on their past success and trying to recreate the conditions that provided for that success they may miss current market opportunities or market hazards. Also, myopic firms may believe their past success is an indicator of present conditions and believe that they, as well as their B2B relationships are strong, when in fact, they are not. This narrow view of relationship success is myopic and may lead the firm to believing that this narrow view is actually a sign that the relationship is strong, even though it may not be. The interviews conducted for this dissertation addressed this potential for confusion. The 55 year old government worker said:

"People think that since the relationship is basically on auto pilot that everything is going good..."

This statement clearly supports the logic that relationship myopia may in fact get confused for relationship strength. From this discussion a positive relationship between relational myopia and relationship strength can be presented

H18: There is a positive relationship between relational myopia and relationship strength

\section{Complacency and Relationship Strength}

Like relational myopia, complacency is also believed to have a positive relationship with relationship strength. This stems from potential confusion regarding relationship strength and relational inertia. It is easy to see how B2B relationships that have experienced a degree of success will transfer this success to the strength of their 
relationship. In other words, as goes the outcomes so goes the perception of relationship strength. There is a potential danger in this sentiment however. Miller (1990) found that the factors that helped a firm become successful, over time, leads the firm to become simpler and more narrowly focused. As the firm fails to receive or accept feedback that would deter them from this simpler point of view they may begin to believe that their past success is guaranteed and they have figured how to ensure this success.

Transferring this attitude to their relationships logically leads to the belief that the firm's relationships are also very strong. Danger arises when the environment changes and these changes demand adjustment to the B2B relationship. If firms who have become complacent, resting on past success, fail to see this need they may continue on without realizing they are in effect allowing the relationship to weaken even though the perception of the B2B relationship is that it is very strong.

This scenario implies a positive relationship between complacency and relationship strength. That is to say, firms who have allowed themselves to become complacent may confuse this complacent relationship with a strong one. Interview participants were able to support this hypothesized relationship between complacency and relationship strength. The 38 year old in charge of purchasing said:

"I definitely think companies will just assume success. I think it has to do with the investment in the relationship. If my company has been buying from a company for so many years and there are never any problems, it's almost as if they assume no problems means things are going well. They forget that all that really means is that things aren't going bad" 
Drawing from the content of the above interview, as well as the above discussion the following hypothesis is presented.

H19: There is a positive relationship between complacency and relationship strength

\section{Vulnerability and Relationship Strength}

It is contended that the greater the feelings of vulnerability for a focal firm, the more diminished the firm's perception of the strength of their relationship. This diminished perception of the relationship stems from the firm's dedication of resources toward alleviating feelings of vulnerability instead of dedicating these resources toward maximizing the efficiencies that might be realized through the relationship. In other words, instead of trying to be the best relational partner possible, which may provoke feelings of a strong relationship, firms that feel vulnerable might try to reduce these feelings of vulnerability by investing resources into eliminating exposures and monitoring their partnering firm(s) and the environment. These actions seem analogous to dependence balancing actions described by Heide and John (1988). Heide and John (1988) explain that firms are motivated to reduce their dependence on partnering firms and do so through offsetting investments. Both Ganesan (1994) and Inkpen and Beamish (1997) found support for these dependence balancing actions. If firms are motivated to monitor their exchange partner then it is probably that the relationship is not going to be as strong as the monitoring partner believes it can be or even should be.

At the time of this writing, there is no known $\mathrm{B} 2 \mathrm{~B}$ research that has directly investigated the relationship between feelings of vulnerability and its potential influence on relationship strength. However, El Ansary and Stern (1972) have shown that the more 
a firm depends on another firm to achieve its goals the less control the firm has over its own actions. This relationship suggests that the fewer alternatives a firm has (ergo, the less power it has) the more vulnerable it is (El Ansary and Stern 1972). Drawing from this argument, Boag and Dastmalchian (1988) suggests that the more vulnerable a firm, the less its ability to formulate and implement strategies for prosperity and survival. It follows then that firms will not feel as if they have a strong relationship if feelings of vulnerability are provoked as a result of being in the relationship itself. The relationship between vulnerability and relationship strength was explored during the interviews conducted for this dissertation. Not surprisingly, this relationship was overwhelmingly supported in the responses given to the question about the impact feelings of vulnerability have on the $\mathrm{B} 2 \mathrm{~B}$ relationship. Below is a representative response from the participants given by the 29 year old sales rep:

"When you trust someone or let things just run their course, all too often you might be making yourself open to things that you don't want like system changes, price changes, contract changes, and things like that. I think that when you are suspicious of your partner you might not ever be able to trust that they are going to do what is right for you and it ultimately hurts the relationship as a whole"

Though Hibbard, Kumar and Stern (2001) do not overtly explore the vulnerability construct in their work investigating destructive acts, it can be inferred that some of the responses to these acts are born out of feelings of vulnerability. Specifically, disengagement from and venting to a channel partner may occur out of feelings of necessity. A firm may realize that it was exposed to their channel partner and their partner took advantage of this exposure. It makes sense that if this is the case, 
disengagement or venting is done out of an effort to remove the exposure and the feelings of vulnerability. Whether the response to the destructive act is disengagement or venting, the response may be the result of the realization that they are vulnerable or that firms have taken advantage of that vulnerability. Consequently, such scenarios are believed to have a detrimental influence on the $\mathrm{B} 2 \mathrm{~B}$ relationship.

H20: There is a negative relationship between vulnerability and relationship strength

\section{Suspicion and Relationship Strength}

Similar to the relationship between vulnerability and relationship strength, the relationship between suspicion and relationship strength stems from a firm dedicating time, money and other resources to guard against what it is suspicious of. If the offended firm was not suspicious then these resources could be dedicated to something that would yield gains for the firm and the relationship instead of dedicating resources toward preventing a loss. Therefore suspicious firms, or relationships characterized as suspicious, will not be able to take advantage of the efficiencies provided by adopting a relationship marketing strategy. In other words, the more relational the firms, the more such things as costs are shared between firms, the more likely firms are to indicate a strong B2B relationship. As firms step back from relationalism to guard against unwanted behaviors they are then forced to bear more of the costs that were at one time shared as well as indicate a damaged B2B relationship. Firms will also spend money and invest resources to make up for the loss of efficiencies once realized when the firm was not suspicious of its exchange partner. In summary, the onset of suspicion, justified or 
not, inevitably costs firms engaged in the relationship in organizational performance as well as damaging relationship strength.

Like many of the other relationships discussed in this dissertation, the link between suspicion and relationship strength has not been thoroughly investigated in the channels, marketing or other B2B literatures. However, with the assumption that feelings of suspicion will occur for an offended firm upon the discovery of opportunistic behavior, it is possible to draw from the opportunism literature to help construct the theoretical negative relationship between suspicion and relationship strength.

Wathne and Heide (2000) explain that opportunism will affect value creation in different ways. Opportunistic behaviors that may arise between partnering firms are such things as engaging in behaviors that are prohibited or extracting concessions from a partnering firm (Wathne and Heide 2000). These opportunistic behaviors are overt and have the potential to damage the offended firm's perception of the relationship. Investments in monitoring the behaviors of the suspicious firm will be committed, subsequently damaging the firm's overall performance as well as relationship strength. Aside from the investment of time money and other resources the behavioral implications of suspicion also may damage a firm's perception of relationship strength. Specifically, upon becoming suspicious of a partnering firm, the offended firm alters its behavior to guard against suspicious activity. Instead of working to maximize the efforts of the relationship their behavior may be directed toward defense against suspicious activity. Instead of promoting increased integration between firms, the offended firm may retreat from their suspicious partner. The firms are then forced to transact with less transparency and with less integration. The potential results are less efficiency and increased 
transaction costs which will ultimately hurt their performance as well as the strength of the relationship.

Jap and Anderson (2003) found that confidence between two transacting individuals makes the relationship perform better in every respect. Though suspicion is not mentioned in this article, it is safe to assume that confidence in one's partner has an inverse relationship with suspicion in one's partner regarding such things as the functionality of the relationship. Zineldin and Dodourova (2005) also imply that the more suspicious one firm is of another, the more likely their alliance will end in failure. Therefore, it makes sense to assume that the greater the suspicion in the relationship the worse the relationship strength. Drawing from the discussion on suspicion and relationship strength, the following hypothesis is presented.

H21: There is a negative relationship between suspicion and relationship strength

\section{Relationship Strength and Performance}

\section{Performance}

Relationship marketing has long been viewed as an appropriate and effective tool for bolstering both firm and relationship performance (Morgan and Hunt 1994; Sheth and Parvatiyar 1995). This is intuitive as the motivation or incentive to enter into such relationships seems absent without the partnering firms benefiting in some way. That firms are motivated to enter into a B2B relationship in an effort to obtain some sort of benefit or increase in positive outcomes is not in question. However, just exactly what constitutes positive performance is still very much an unsettled matter within the 
relationship and B2B literatures (Ailawadi, Dant and Grewal 2004; Valos and Vocino 2006).

Valos and Vocino (2006) conducted a thorough review of how researchers have gauged channel performance. The authors identified several seemingly dichotomist choices researchers have made when investigating channel performance. For instance, non-financial vs. financial, frequent vs. infrequent, short term vs. long term, behavioral vs. output, subjective vs. objective, qualitative vs. quantitative, external vs. internal and strategic vs. tactical channel performance measures have all been utilized at some point to assess channel performance (Valos and Vocino 2006).

In the B2B context, some measure of objective financial performance (e.g. ROI, sales, profits) may intuitively seem the most appropriate measure of performance. However, though increased financial benefits are assuredly a motivation for a firm to enter into an exchange relationship, it might not be the primary reason. For example, a focal firm may be inefficient, in (say) logistics and supply chain management. In an effort to reconcile this deficiency the firm partners with a logistics firm that is tasked with increasing the efficiency of the focal firm. Though financial rewards will likely result should the focal firm improve its efficiencies, the primary reason for the relationship isn't increased financial rewards so much as it is the establishment of efficient logistical systems. The firm's financial rewards, in this example, are secondary while increased efficiencies are primary objectives. From this logic, it makes sense that the focal firm will measure relationship performance using efficiency metrics while financial metrics, if used at all, will serve as a secondary measure of resulting relationship benefits. In other words, the primary purpose of performance measurement is to provide feedback that will aid the 
firm in its efforts to realize specific firm goals, financial or otherwise (Kumar, Stern and Achrol 1992).

Certainly financial measures are an important element in assessing the return of a business relationship. It has been argued however that using financial measures of performance in isolation is myopic because they fail to measure the full complement of organizational goals associated with a B2B relationship (Chakravarthy 1986; Eccles 1991; Kaplan and Norton 1992). Coupled with the fact that researchers are often forced to develop perceptual measures of performance due to the fact that objective financial measures are often difficult to obtain (Ailawadi, Dant, and Grewal 2004), the reasoning for such a wide array of performance measures utilized in the B2B literature becomes more understandable.

In an effort to develop a reliable and valid measure of partnering firm performance Kumar, Stern, and Archol (1992) drew from Quinn and Rohrbaugh's (1983) work which identified four different models of organizational effectiveness. Kumar, Stern and Achrol (1992) assert that in order for a firm to maintain equilibrium and a continuance of the system, the firm must adequately meet the criteria for each of these performance models. The first of these models is the rational goal model which describes the firm's main objectives as productivity and efficiency or the maximization of outputs relative to pertinent conditions such as obstacles and costs (Quinn and Rohrbaugh 1983). The measurement of these objectives can be assessed through the evaluation of profits and sales (Kumar, Stern, and Achrol 1992). The rational goal model encompasses much of the objective financial measures often ascribed to performance measurement. The second model is the human relations model. This model focuses on cohesion and morale of 
organizational members (Quinn and Rohrbaugh's 1983). Within a B2B context, this model suggests that firms need to be concerned with the social aspects of its exchange relationships (Kumar, Stern, and Achrol 1983). The internal process model is the third model and stresses the notion of an organization as being the combination of interdependent parts (Kumar, Stern, and Achrol 1992). Key aspects of this model are firm loyalty and compliance. High levels of both loyalty and compliance are said to evoke coordinated actions between partnering firms and thus enable the attainment of organizational and relationship goals (Kumar, Stern, and Achrol 1992). Finally the fourth model is the open system model. This model views firms as openly pursuing such things as growth, learning and differentiation (Buckley 1967). Within a channels context, the open systems model can be viewed as a focus on growth and adaptation (Kumar, Stern and Achrol 1992).

The description of these four models illustrates the wide conceptualization of performance that encompasses more than just objective financial measures. Logically, the acceptance of these four areas or models of performance implies a belief that there is more to performance than just financial outcomes and hence the need for a performance instrument derived from a comparatively broad theoretical perspective.

Kumar, Stern, and Achrol's (1992) resulting performance measure is said to be more comprehensive than performance evaluations relying on a single sales measure or easily manipulated customer satisfaction measure (Kumar 1996). Though often not identical, many researchers have adopted a similar multi-faceted multi-dimensional perspective that incorporates many performance measures which encompass many conceptualizations of 
the performance construct (e.g. Hibbard, Kumar and Stern 2001; Lewis and Lambert 1991; Mohr and Spekman 1994).

For instance, Lewis and Lambert (1991) when investigating the relationships among performance, dependence and satisfaction within a franchising context, evaluated performance by assessing firm operations, organization, finance and development. Mohr and Spekman (1994) incorporated subjective measures of partnership satisfaction along with objective sales measures when evaluating partnership success. Hibbard, Kumar and Stern (2001) also evaluated performance using both subjective relational measures (competence, compliance, growth and satisfaction) along with subjective measures of objective performance like sales and profits when investigating the influence destructive acts have on B2B relationships. Johnson (1999), likewise, used a composite performance measure when evaluating the influence strategic integration on performance. Performance was measured by assessing both subjective relational indicators as well as gathering information on subjective perceptions of objective performance. Bello and Gilliland (1997) used measures of strategic, selling and economic performance to evaluate the influence output controls, process controls, and flexibility has on export channel performance.

Some researchers have evaluated performance from strictly a rational goal perspective (e.g. Archrol and Etzel 2003; Dant, Brown, and Bagozzi; Lado, Dant, and Tekleab 2008; Lusch and Brown 1996) while other researchers have integrated relational outcomes along with the economic and efficiency indicators of the rational goal model when discussing performance (e.g. Koza and Dant 2007; Robicheaux and Coleman 1994). 
In the absence of a universally recognized performance measure, the use of such a wide array of performance measures seems likely to continue. Understanding that performance encompasses such things as efficiency, organizational, relational and financial goals, trying to derive one universal performance measure is arguably inappropriate. Some economic performance measures may be negatively influenced through the adoption of a relationship strategy while some relational measures of performance may actually be enhanced through the adoption of a RM strategy. In fact, it could be argued that in some scenarios the manifestation of the dark side stems from the achievement of desired relational outcomes at the expense of needed economic outcomes.

Therefore, it is the position of this dissertation that performance should be evaluated from the rational goal model. The rational goal model subsumes many of the objective and perceptual economic and financial measures of performance (Kumar, Stern, and Achrol 1992). The rational goal model focuses on efficiency and productivity and contributes most to the understanding of a firm's bottom line. Consequently, the rational goal model is also believed to be the biggest indicator of a firm's viability in the market.

This is not to say that other areas of performance are not important and telling in their own right. However, firms need to achieve certain economic and financial outcomes in order to remain in business. Therefore, it can be argued that unless certain economic goals are reached, relational, organizational or other measures of performance become irrelevant since the firm may go out of business.

Reinartz and Kumar (2000) found some indirect support for this notion in their investigation of the profitability of long-term customers. The authors found that though many have suggested that relationship marketing is financially beneficial for a firm this 
notion does not hold up when tested empirically. More specifically, the authors found that long-term customers are not more profitable for a firm than short-term customers, profits from long-term customers do not increase over time, long-term customers do not actually pay higher prices than short term customers and the cost of serving long-term customers is actually higher than serving short term customers. Firms may have spent a lot of time and money developing relationships that are assumed to result in increased financial rewards but, at least according to Reinartz and Kumar (2000), this is not the case. This paper illustrates how adopting a relationship marketing strategy might actually be harmful to a firm in economic terms as well as illustrate the need to monitor the economic and financial performance of the relationship. Regardless of the success of a $\mathrm{B} 2 \mathrm{~B}$ relationship, as measured on any other metric, one has to assume that if a relationship is damaging the economic and financial health of the firm, the firm then will work to improve the economic results of the relationship or terminate it. Regardless of how good the relationship is, there is no motivation or incentive for a firm to maintain a B2B relationship without the necessary economic and financial benefits.

Using this logic, this dissertation will keep in the spirit of other B2B researchers who have investigated the performance construct from the rational goal model (e.g. Archrol and Etzel 2003; Dant, Brown, and Bagozzi; Lado, Dant, and Tekleab 2008; Lusch and Brown 1996) by utilizing this perspective of performance for this dissertation.

\section{Relationship Strength and Perceptual Performance}

As has been discussed above, it is believed that firms may transfer their perceptions of the relationship to the performance of the relationship and the firm's overall performance. That is to say, if a firm believes their relationship is strong they will also believe their 
relationship is performing well. If firms believe their firm is performing well it is believed that this belief will transfer to the perceptions of their firm level performance. To further illustrate the point, consider a scenario where a B2B relationship is perceived as strong. It is believed that this belief will first, obviously, translate into a perception about the beliefs of relationship performance which will also be poor. This makes sense if one considers a relationship where one relational partner has retreated from a relational posture in their B2B relationships in order to guard against such things as vulnerability and suspicion. It is highly likely that these firms will dedicate resources toward maintaining their guard and will be highly cognizant of these expenditures. If one realizes how much they are putting into not being taken advantage of they will most certainly realize that if they didn't have to guard against such things, they could put resources into relational performance which would certainly yield a better performing relationship. Since the relationship is normally a tool firms use to help achieve goals it makes sense that if the tool is working well they will realize this in the final outcomes as well. However, if the tool is not performing optimally it is difficult to see how someone would perceive the outcomes as being optimal. This scenario implies a direct relationship between relationship strength and performance. Therefore:

H22: There is a positive relationship between relationship strength and performance 


\section{Chapter Three: Methodology \\ Research Setting}

For this dissertation, the decision was made to recruit anybody managing a buyerseller relationship on the buying side of the dyad to participate in the dark side empirical study. This is not to imply that the person had to be in charge or carry the title of manager but they had to have substantial or significant influence in the management of the buyer-seller relationship. Although this is a wide criterion, the dark side, as described in this dissertation, is believed to manifest across industries and influence all kinds of $\mathrm{B} 2 \mathrm{~B}$ relationships.

\section{Pre-Test}

Most of the items used to derive the scales used to measure the dark side have been adopted from varying disciplines and context. Therefore, though the adaptation of these items is believed to be appropriate, it is not enough to rely on previous measures of reliability and validity to conclude the relational and dark side scales are both reliable and valid. Therefore, a pre-test comprising of $\mathrm{N}=100$ respondents was conducted. The pretest allows for a preliminary assessment of both reliability and validity. In all cases, more than 4 items per construct were included in the questionnaire to allow for pruning of items after the pretest. The results of the pre-test are discussed further in chapter four of this dissertation. 


\section{Data Collection Procedure}

Several data collection techniques were used to collect data for this empirical study. First, for the pre-test, a door-to-door method was utilized. This involved the author of this dissertation physically visiting each firm, making contact with management and firm employees in an effort to determine who the most appropriate individuals to complete the survey were. Appropriate respondents were those individuals that in some way help maintain the B2B relationships for their organization. After determining the appropriateness of each employee to act as a respondent an explanation of the author's affiliation, reasons for the study and a request for participation in the study was discussed. The author delivered the questionnaire in person together with a selfaddressed postage paid envelop to the prospective respondent so the respondent can place the completed survey in the mail. A business card with the author's name, phone number, email address and mailing address was also provided in case the respondent had questions or wanted the author to come and retrieve the questionnaire in person.

The firms initially approached were determined by such things as how far the author had to travel and how far each firm was from the next potential respondent. Also, firm specifics were be considered. More specifically, an effort was made to make sure a diverse group of firms were selected to participate in this study.

Several online versions of the survey were also constructed. A word document and a typeable PDF file were made available to aid in the distribution of the survey. Also, the use of an online survey hosting website was utilized again, to take advantage of the potentially good distribution made possible through online resources. These online versions of the survey were distributed through various online forums. Specifically, B2B 
forums were visited as well as utilizing online networking sites like Facebook and MySpace. Professional networking events were attended and finally undergraduate marketing students at a large southeastern university were given the opportunity to gain extra credit if they could produce complete and verifiable surveys from qualified respondents. The results of these data collection efforts are discussed in detail in chapter four of this dissertation.

\section{Questionnaire}

Since only one side of the dyad was sampled, common method bias was a concern. However, sampling from both sides of the dyad, though preferred, is not always feasible so one must devise other methods of dealing with the potential for common method bias (Podsakoff et al. 2003). One method of combating common method bias where data for the predictor and criterion variables can not be collected from different sources or at different times is to separate the predictor and criterion variables psychologically. As suggested by Podsakoff et al. (2003), one way of separating these variables psychologically is to create a cover story that makes it appear as if the measurement of the predictor variables are not connected with or related to the measurement of the criterion variables. Another method of combating common method bias is to guarantee participant anonymity (Podsakoff et al. 2003). Throughout the surveys used in this dissertation (i.e. pre-test and main study survey) as well as the cover letter accompanying the survey, participant anonymity was stressed. The predictor and criterion variables are also psychologically separated and a cover story created for the different surveys according to Podsakoff et al.’s (2003) recommendations. 
The first portion of the questionnaire (see appendix one) is intended to capture the relational sentiments of the respondents with one of the B2B exchange partners. That is, the beginning of the questionnaire poses questions designed to get a sense of the respondent's perception of how relational their partnership with their B2B partner actually is. This is accomplished by asking questions, adopted from the literature, that assess the respondents belief about the shared values, commitment, trust, and satisfaction constructs.

After inquiring about the respondents relational sentiments regarding the specific partnership with their B2B partner, in section two of the survey, respondents are asked to recall a specific issue that developed as the result of their B2B partner acting in a way that was not acceptable to the firm. The purpose of this line of questioning is to gauge sentiments of vulnerability and suspicion that may have developed along with the issues stemming from the incident. The respondents will be asked to briefly describe the issue, when it occurred or began to develop, how much or what was at stake and whether or not the issue is a reoccurring problem. It should be noted however that this dissertation did not employ the critical incident method often employed in a lot of B2B research (e.g. Bitner, Booms, and Tetreault 1990; Roos 2002). The critical incident methodology focuses on one very specific event. While any critical incident that may have provoked the onset of dark side sentiments should be recalled by the respondent, the purpose of this portion of the questionnaire is to cue the respondent to how negative issues stemming from the relationship itself may have developed over time. Following the questioning that asks the respondents to recall specific incidents that may have lead to specific issues 
within the relationship the respondents were asked several items designed to measure the onset of the dark side symptoms of suspicion and vulnerability.

Section three of the survey is designed to measure feelings of relational myopia and complacency. Respondents are first provided a brief set of instructions which are also meant to act as a "cueing" statement. The statement explains to the respondents that all relationships, including business relationships, change over time and that the following section seeks the respondent's opinion about the current state of their relationship with their B2B partner. The statement then instructs the respondents to please consider all the issues and events that have occurred between their establishment and their B2B partner. The respondents are then asked to respond to several items designed to measure sentiments of relational myopia and complacency.

Section four of the survey is designed to tap into the respondent's perception of how strong their relationship is with their B2B partner as well as how well they are performing. This is done by inquiring about perceptual measures of performance.

The final portion of the questionnaire asks basic demographic information about the respondent, their establishment and the length of time they have been in a relationship with the focal exchange partner. Table one below illustrates the origin of these scales, their reported reliability, whether or not measures of validity have been established as well as the items themselves. 
Table 1 Survey Sources, Reliability, Validity \& Items

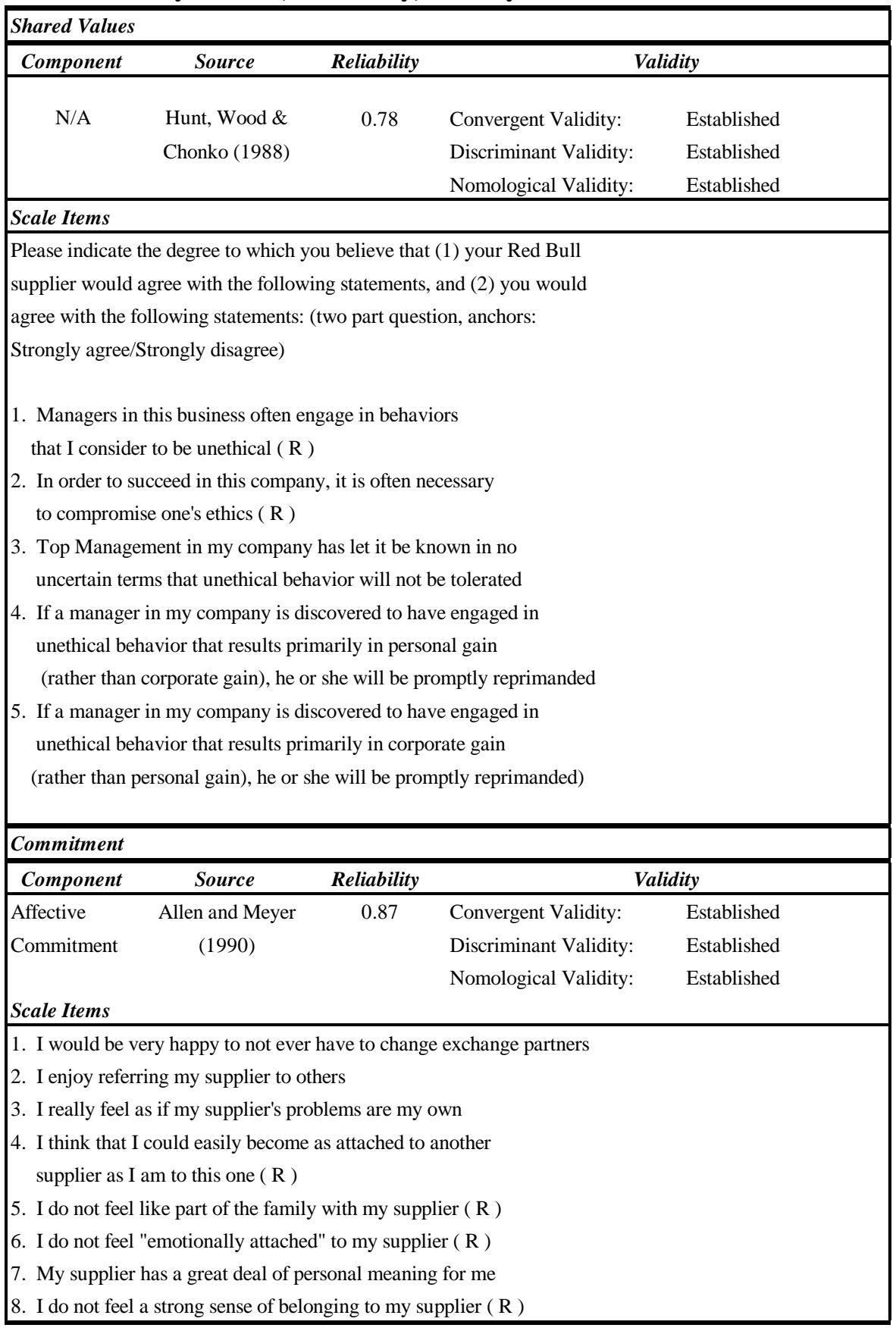


Table 1 continued

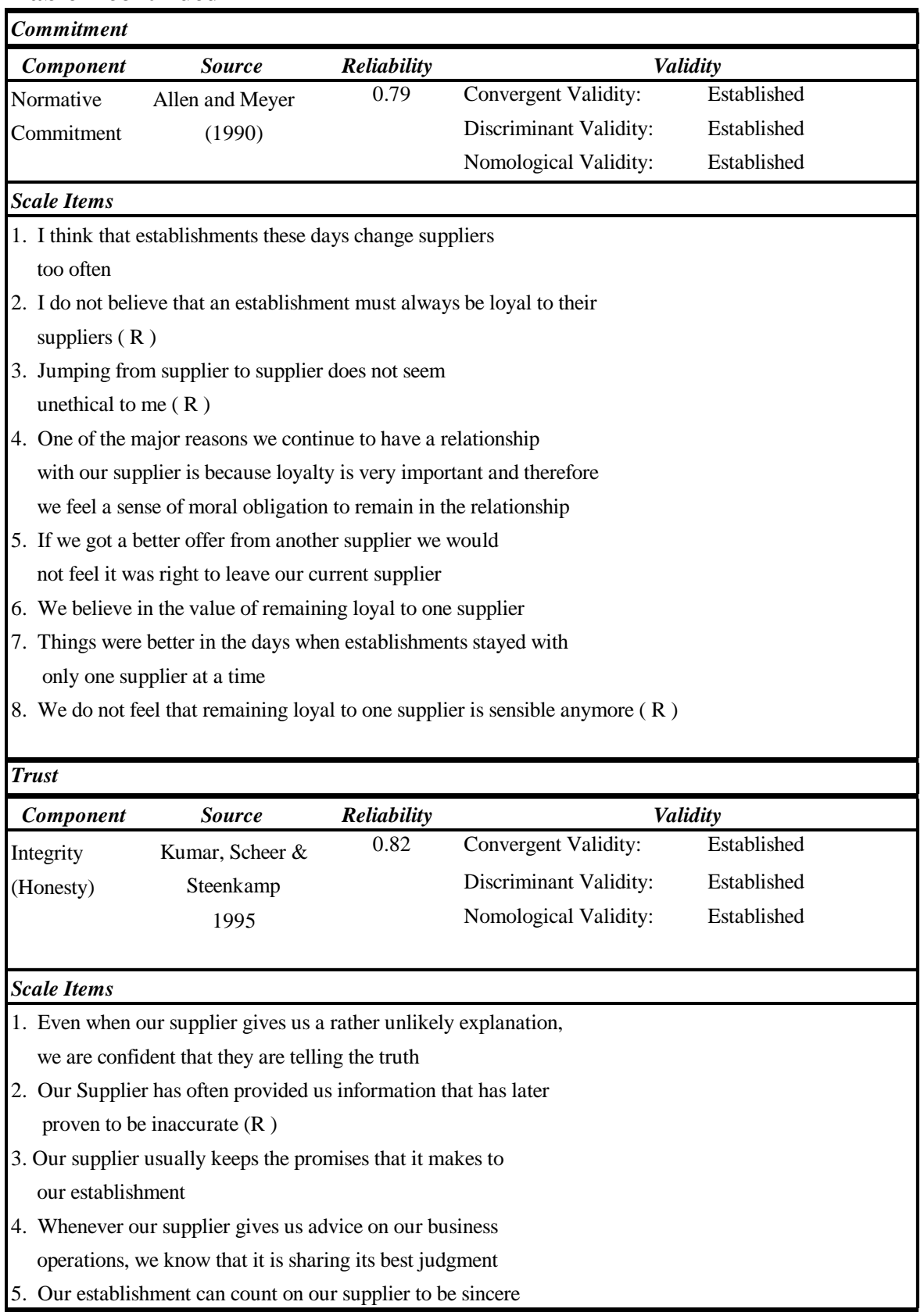


Table 1 Continued

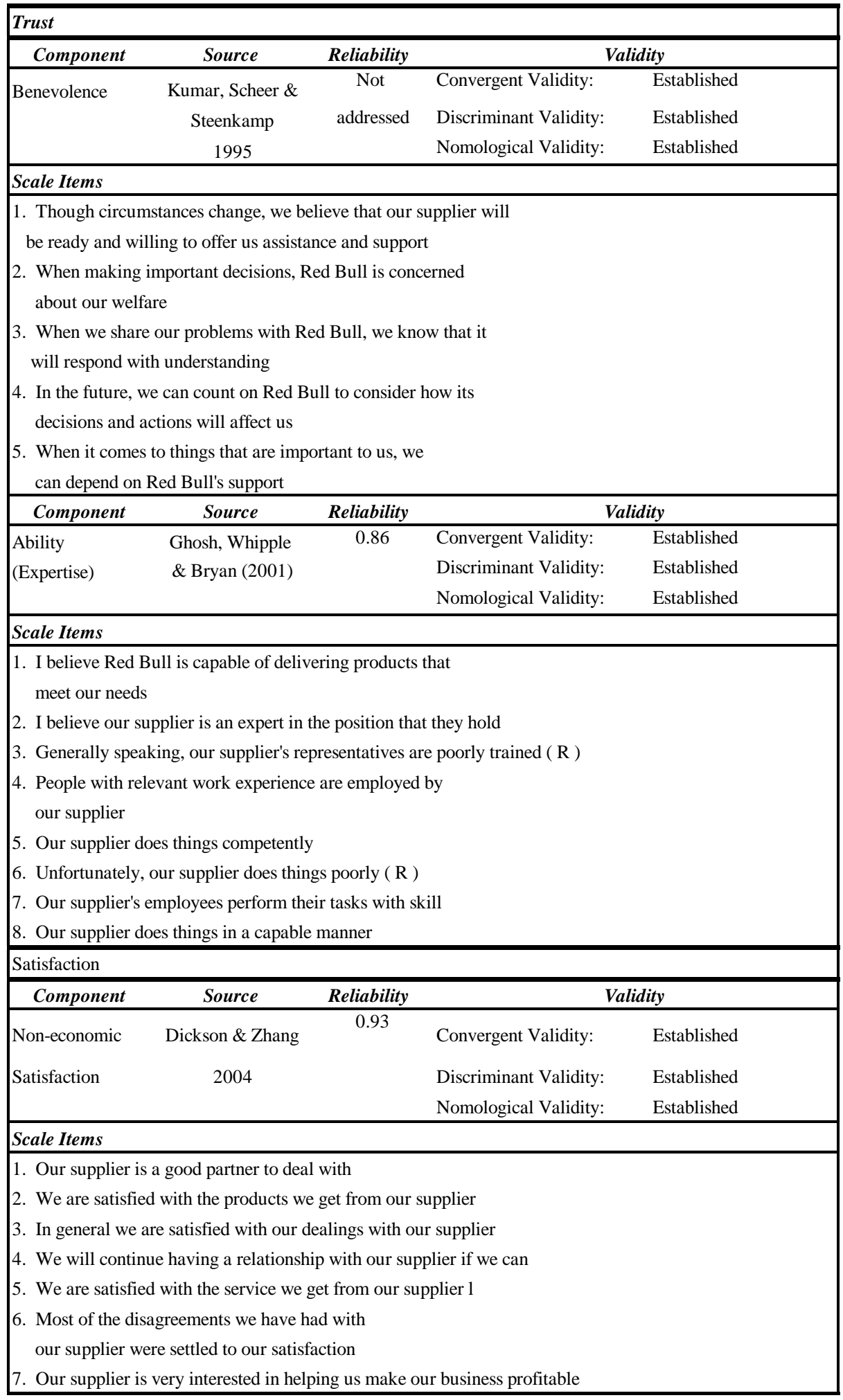


Table 1 Continued

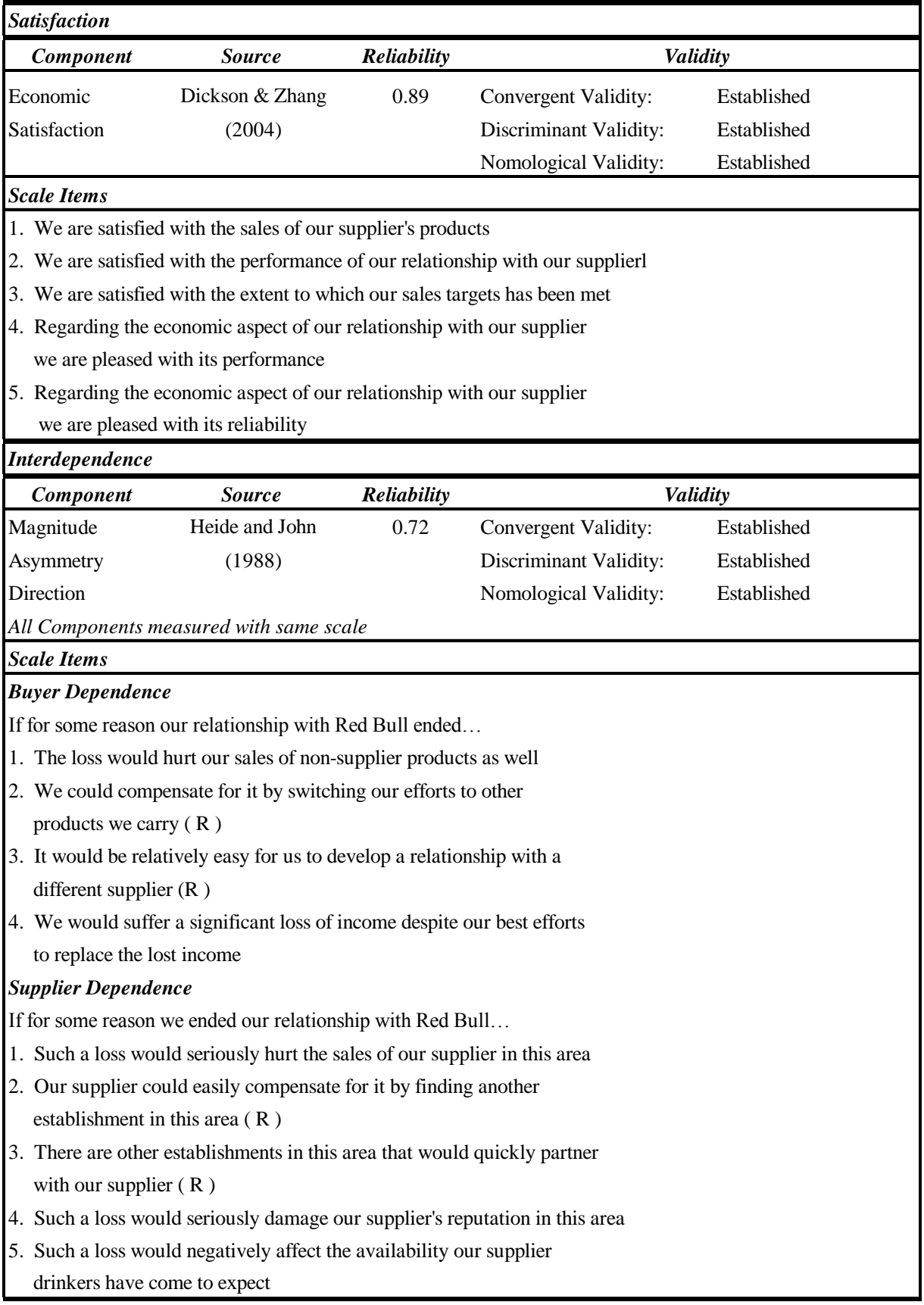


Table 1 Continued

Vulnerability

\begin{tabular}{cccll|}
\hline Component & Source & Reliability & \multicolumn{2}{c|}{ Validity } \\
\hline N/A & Perlin et al. & 0.79 & Convergent Validity: & Established \\
& $(1981)$ & & Discriminant Validity: & Established \\
& & & Nomological Validity: & Established \\
\hline
\end{tabular}

\section{Scale Items}

1. We have little control over the things that happen in our relationship with our supplier

2. There is really no way we can solve the problems in our relationship with our supplier

3. There is little we can do to change our relationship with our supplier

4. We often feel helpless when dealing with Red Bull

5. What happens to us is mostly dependent on us, not our supplier( $\mathrm{R}$ )

6. We can accomplish just about any goal our establishment sets out to ( R )

\begin{tabular}{|cccll|}
\hline Component & Source & Reliability & & \multicolumn{2}{c|}{ Validity } \\
\hline N/A & New Scales & Not & Convergent Validity: & Not established \\
& & Established & Discriminant Validity: & Not established \\
& & & Nomological Validity: & Not established \\
\hline Scale Items & & & & \\
\end{tabular}

7. Our supplier could act in a way that would hurt my establishment

8. Regarding how our supplier behaves in our relationship, they can get away with not doing what we expect of them

9. We do not have the ability to stop our supplier's behavior, even if it hurt our establishment

\begin{tabular}{|cccll|}
\hline Suspicion & & & & \\
\hline Component & Source & Reliability & & Validity \\
\hline N/A & Vitell, Rallapalli & 0.67 & Convergent Validity: & Established \\
& $\&$ Singhapakdi & & Discriminant Validity: & Established \\
& $(1993)$ & & Nomological Validity: & Established \\
\hline
\end{tabular}

\section{Scale Items}

1. I do not believe our supplier always adheres to

all applicable laws and regulations

2. I do not believe our supplier always accurately represents their credentials

3. I do not believe our supplier is always honest in serving us as a client

4. I believe our supplier would participate in a conflict of interest without prior notice to all parties involved

\begin{tabular}{|ccclc|}
\hline Component & Source & Reliability & \multicolumn{2}{c|}{ Validity } \\
\hline N/A & Levine \& & 0.70 & Convergent Validity: & Established \\
& McCornack & & Discriminant Validity: & Established \\
& (1991) & Nomological Validity: & Established \\
& & \\
5. I often feel as if our supplier is not completely & & \\
truthful with me & & & \\
6. Our supplier is basically honest ( R ) & & \\
7. Our supplier seldom lies to me ( R ) & & \\
8. Our supplier rarely tells us what they are thinking & & \\
\hline
\end{tabular}


Table 1 Continued

\begin{tabular}{|c|c|c|c|c|}
\hline \multicolumn{5}{|l|}{ Suspicion } \\
\hline \multirow{4}{*}{$\frac{\text { Component }}{\text { N/A }}$} & \multirow{4}{*}{$\frac{\text { Source }}{\text { New Scales }}$} & \multirow{4}{*}{$\begin{array}{c}\text { Reliability } \\
\text { Not } \\
\text { Established }\end{array}$} & \multicolumn{2}{|c|}{ Validity } \\
\hline & & & Convergent Validity: & Not established \\
\hline & & & Discriminant Validity: & Not established \\
\hline & & & Nomological Validity: & Not established \\
\hline \multicolumn{5}{|l|}{ Scale Items } \\
\hline \multicolumn{5}{|c|}{$\begin{array}{l}\text { 9. I do not believe our supplier always considers my } \\
\text { establishments best interest when acting }\end{array}$} \\
\hline \multicolumn{5}{|c|}{$\begin{array}{l}\text { 10. I believe our supplier at times, acts in ways that } \\
\text { could be harmful to our relationship }\end{array}$} \\
\hline \multicolumn{5}{|c|}{$\begin{array}{l}\text { 11. I believe our supplier, at times, acts in ways that could be } \\
\text { harmful to my establishment }\end{array}$} \\
\hline \multicolumn{5}{|c|}{$\begin{array}{l}\text { 12. I believe our supplier, at times, takes our } \\
\text { relationship for granted }\end{array}$} \\
\hline \multicolumn{5}{|c|}{$\begin{array}{l}\text { 13. I believe our supplier, at times, uses our relationship } \\
\text { against us for their own gain }\end{array}$} \\
\hline \multicolumn{5}{|c|}{ Relational Myopia } \\
\hline Component & Source & Reliability & \multicolumn{2}{|c|}{ Validity } \\
\hline \multirow[t]{3}{*}{ N/A } & Henard \& & 0.70 & Convergent Validity: & Established \\
\hline & Szymanski & & Discriminant Validity: & Established \\
\hline & $(2001)$ & & Nomological Validity: & Established \\
\hline \multicolumn{5}{|l|}{ Scale Items } \\
\hline \multicolumn{5}{|c|}{$\begin{array}{l}\text { 1. Our supplier uses flexible systems of delivery that have } \\
\text { been adapted for our establishment } \\
\text { 2. Our supplier has available novel distribution } \\
\text { systems (for example online ordering) for my establishment to use } \\
\text { 3. Our supplier offers my establishment a diversified product range } \\
\text { 4. Our supplier uses modern stock and control } \\
\text { systems when doing business with my establishment }\end{array}$} \\
\hline Component & Source & Reliability & & \\
\hline N/A & $\begin{array}{l}\text { Johannessen } \\
\text { Olsen } \\
\text { \& Lumpkin } \\
\quad(2001)\end{array}$ & $\begin{array}{c}\text { Established } \\
\text { but not } \\
\text { reported }\end{array}$ & $\begin{array}{l}\text { Convergent Validity: } \\
\text { Discriminant Validity: } \\
\text { Nomological Validity: }\end{array}$ & $\begin{array}{l}\text { Established } \\
\text { Established } \\
\text { Established }\end{array}$ \\
\hline \multicolumn{5}{|l|}{\begin{tabular}{|l} 
Scale Items \\
\end{tabular}} \\
\hline \multicolumn{5}{|c|}{$\begin{array}{l}\text { 5. Our supplier has offered our establishment new products } \\
\text { since the beginning of our relationship with them }\end{array}$} \\
\hline \multicolumn{5}{|c|}{$\begin{array}{l}\text { 7. Our supplier has offered our establishment new or updated } \\
\text { delivery methods since the beginning of our relationship with them }\end{array}$} \\
\hline \multicolumn{5}{|c|}{$\begin{array}{l}\text { 8. Our supplier has offered our establishment new or updated } \\
\text { ordering methods since the beginning of our relationship with them }\end{array}$} \\
\hline
\end{tabular}


Table 1 Continued

Relational Myopia

\begin{tabular}{|cccll|}
\hline Component & Source & Reliability & \multicolumn{2}{c|}{ Validity } \\
\hline N/A & Costa \& McCrae & 0.87 & Convergent Validity: & Established \\
& $(1985)$ & & Discriminant Validity: & Established \\
& & & Nomological Validity: & Established \\
\hline
\end{tabular}

Scale Items

9. When it comes to our relationships, we prefer variety to routine ( $\mathrm{R}$ )

10. When it comes to our relationships, we prefer to stick with things that we know

11. When it comes to our relationships, we dislike change

12. When it comes to how our relationships operate, we are attached to conventional ways of doing things

\begin{tabular}{|cccll|}
\hline Component & Source & Reliability & \multicolumn{2}{l|}{ Validity } \\
\hline N/A & New Scales & Not & Convergent Validity: & Not established \\
& & Established & Discriminant Validity: & Not established \\
& & Nomological Validity: & Not established \\
\hline & & & &
\end{tabular}

\section{Scale Items}

13. When it comes to our relationship we often find

new ways of doing things $(R$ )

14. The relationship we have with our supplierl lacks a long-range perspective

15. When it comes to the relationship my establishment has with our supplier, things normally happen the same way every time

\begin{tabular}{|cccll|}
\hline Complacency & & & & \\
\hline Component & Source & Reliability & & Validity \\
\hline N/A & Kahne (2005) & 0.67 & Convergent Validity: & Established \\
& & & Discriminant Validity: & Established \\
& & & Nomological Validity: & Established \\
\hline Scale Items & & & & \\
\hline
\end{tabular}

1. Our supplier does not waste time on change initiatives

2. Our supplier does not worry about the future of our relationship

3. Our supplier does not usually make any changes

4. Our supplier often makes major changes ( $R$ )

\begin{tabular}{|cccll|}
\hline Component & Source & Reliability & & \multicolumn{2}{c|}{ Validity } \\
\hline & New Scales & Not & Convergent Validity: & Not established \\
& & Established & Discriminant Validity: & Not established \\
& & Nomological Validity: & Not established \\
\hline & & & &
\end{tabular}

\section{Scale Items}

5. Regarding the relationship we have with our supplier we do not worry about future trouble in the relationship

6. Regarding the relationship we have with our supplier we are planning to make changes to how the relationship works ( $\mathrm{R}$ )

7. Regarding the relationship we have with our supplier I do not believe we would recognize the need to change anything if the need developed

8. I do not believe my establishment continues to look for other suppliers

9. I do not believe my establishment would recognize a better supplier if one was available 
Table 1 Continued

\begin{tabular}{|c|c|c|c|c|}
\hline \multicolumn{5}{|c|}{ Relationship Strength } \\
\hline \multirow{2}{*}{$\frac{\text { Component }}{\text { N/A }}$} & \multirow{3}{*}{$\begin{array}{r}\text { Source } \\
\text { Wong \& Sohal } \\
(2006)\end{array}$} & \multirow{2}{*}{$\frac{\text { Reliability }}{0.90}$} & \multicolumn{2}{|c|}{ Validity } \\
\hline & & & Convergent Validity: & Established \\
\hline & & & Discriminant Validity: & Established \\
\hline & & & Nomological Validity: & Established \\
\hline \multicolumn{5}{|l|}{ Scale Items } \\
\hline \multirow{2}{*}{\multicolumn{5}{|c|}{$\begin{array}{l}\text { 1. What is your oveall assessment of the strength of your } \\
\text { relationship with your supplier's sales rep }\end{array}$}} \\
\hline & & & & \\
\hline \multicolumn{5}{|c|}{ 2. How strong would you like the strength of your } \\
\hline \multicolumn{5}{|c|}{ relationship with your supplier's sales rep to be? } \\
\hline \multicolumn{5}{|c|}{ 3. What is your overall assessment of the strength of } \\
\hline \multicolumn{5}{|c|}{ your relationship with your supplier as a company? } \\
\hline \multirow{2}{*}{\multicolumn{5}{|c|}{$\begin{array}{l}\text { 4. How strong would you like the strength of your } \\
\text { relationship with your supplier as a company to be? }\end{array}$}} \\
\hline & & & & \\
\hline \multirow[t]{4}{*}{ Component } & Source & Reliability & \multicolumn{2}{|c|}{ Validity } \\
\hline & Herington, & Not & Convergent Validity: & Not established \\
\hline & Johnson & Established & Discriminant Validity: & Not established \\
\hline & $\&$ Scott (2007) & & Nomological Validity: & Not established \\
\hline
\end{tabular}

Scale Item

5. Over time I feel that the strength of my relationship with my supplier has become

Performance

\begin{tabular}{|cccll|}
\hline Component & Source & Reliability & \multicolumn{2}{c|}{ Validity } \\
\hline N/A & Lusch \& Brown & 0.916 & Convergent Validity: & Established \\
& 1996 & & Discriminant Validity: & Established \\
& & & Nomological Validity: & Established \\
\hline
\end{tabular}

\section{Scale Items}

In regard to other energy drink/establishment relationships in your

industry, how would you rate your relationship's performance with your

exchange partner in terms of

1. Sales growth

2. Profit growth

3. Overall profitability

4. Labor productivity

5. Cash Flow

\begin{tabular}{|c|c|c|c|c|}
\hline \multicolumn{5}{|l|}{ Time } \\
\hline Component & Source & Reliability & \multicolumn{2}{|c|}{ Validity } \\
\hline & Dark Side Study & Not & Convergent Validity: & Not established \\
\hline & & Established & Discriminant Validity: & Not established \\
\hline & & & Nomological Validity: & Not established \\
\hline \multicolumn{5}{|l|}{ Scale Items } \\
\hline \multicolumn{5}{|c|}{$\begin{array}{l}\text { 1. How long has your organization been involved in a relationship } \\
\text { with your exchange partner_____months_____years }\end{array}$} \\
\hline
\end{tabular}




\section{Relational Antecedent Measures}

All of the items used to measure the relational constructs in this dissertation have been obtained from previously established scales presented in the extant literature. All of these relational scales, adapted from the extant literature, have been subjected to psychometric assessment in the past. Below is a more detailed discussion regarding each scale used to assess the relational constructs operationalized within this dissertation.

\section{Shared Values}

Morgan and Hunt (1994) adopted the Corporate Ethical Values scale utilized in Hunt, Wood and Chonko (1989) to measure Shared Values. This scale follows Enz's (1989) two stage procedure for item measurement. That is, the survey items are asked in a two stage procedure. First, the respondents are asked to what degree they agree with a measurement item and second to what degree they believe their relational partner would agree with the statement. Morgan and Hunt (1994) then calculated shared values by subtracting the difference between the two responses.

This dissertation will follow this procedure by adopting the Corporate Ethical Values scale from Hunt, Wood and Chonko (1989).

\section{Commitment}

Commitment continues to gain acceptance as a multidimensional component construct consisting of an affective, normative and continuance component (Allen and Meyer 1990). Measures of affective and normative commitment are believed to be good but distinct measures of the more global commitment construct and are therefore discussed separately in more detail below. 
Affective commitment is rooted in the emotional attachment a channel partner has for another (Fullerton 2003). As mentioned above, the majority of marketing studies investigating this construct have operationalized the affective component (Fullerton 2003; Fullerton 2005). In fact, Morgan and Hunt (1994) adopted their scale for measuring commitment directly from the Allen and Meyer (1990) affective commitment scale. Considering the authors description of commitment or the enduring desire to maintain a valued relationship, this adoption of the affective commitment scale seems appropriate.

Normative commitment is rooted in the organizational behavior literature and was originally conceived of as the belief about an individual's responsibility to their organization (Allen and Meyer 1990). The roots of the operationalization of the normative component of commitment can be traced to Wiener and Verdi (1980) who proposed a three item scale measuring the normative sentiments of commitment. Respondents were asked to indicate if they feel a person should be "loyal to his organization, should make sacrifices on its behalf, and should not criticize it" (Wiener and Verdi 1980, p. 86). Though the normative component of commitment was originally operationalized in the organizational behavior literature it has received attention in the marketing and B2B literatures. For example, normative commitment has been found to positively influence bank employee's intention to stay with their employer while negatively influencing their complaining behavior (Bloemer and Odekerken-Schroder 2006). Gruen, Summers, and Acito (2000) found that normative commitment positively influenced members of professional association's coproduction or desire to be involved in the association's workload. 
This dissertation attempts to capture sentiments of both affective and normative commitment by incorporating both affective and normative commitment items into the scale used to measure commitment. In chapter four of this dissertation, a detailed discussion of the logic and methodology used to determine which items were most appropriate is given.

Trust

Mayer, Davis, and Schoorman (1995) describe the facets of trustworthiness; benevolence, ability, and integrity, as antecedents to trust and thus separate and distinct from trust. This is an interesting distinction that other researchers have also made (e.g. Barney and Hansen 1994; McEvily, Peroone, and Zaheer 2003). The basic notion is that if an exchange partner is trustworthy it means that they are worthy of having trust placed upon them (McEvily, Peroone, and Zaheer 2003). The reader can infer the distinction simply from the difference in the words. Being trustworthy means being able to be trusted or having trust placed upon you while trust itself derives its meaning from other descriptors.

Barney and Hansen (1994) also explain that the concept of trustworthiness refers to, in this context; the exchange partners to be trusted while trust refers to an element or attribute of the relationship between these exchange partners. That is to say, if exchange partners are trustworthy, the relationship can then have trust. However, though the distinction between trustworthiness and trust may be intuitively appealing it is not consistent with how many exchange and B2B researchers have defined the trust construct. 
Many researchers working in the B2B exchange context believe elements of trustworthiness are so vital to their concept of trust that they are either directly or indirectly referred to in their definitions. For example, Doney and Canon (1995) directly incorporate the concept of benevolence within their definition of trust (not trustworthiness). Other definitions are not so overt regarding their integration of these aspects into their definition but do seem to, at least indirectly, incorporate at least one of these elements into their definition. For example, the belief that another company will perform actions that will result in positive outcomes for the firm, from Anderson and Narus's (1990) definition, integrates the focal firm's trust in their partnering firm's ability to perform as well as the belief that the partnering firm will not take unexpected actions that would result in negative outcomes; refers to the integrity and benevolence aspects of trustworthiness.

There are some researchers who have integrated these aspects of trust into their definitions as well as operationalized them separately. For instance Kumar, Scheer, and Steenkamp (1995) recognized the distinction between these aspects of trust and conducted their investigation of how interdependence influences two of these aspects, benevolence and integrity (labeled honesty) separately. Also, Ghosh, Whipple, and Bryan (2001) recognized the ability aspect of trust when they investigated the aspect they labeled expertise.

This dissertation draws from these two works to develop measures of the three aspects of trust discussed here. Kumar, Scheer, and Steenkamp (1995) measured benevolence and integrity, this dissertation adapts these measures directly from this work. Though, Ghosh, Whipple, and Bryan's (2001) expertise or ability measure is used in the education 
context, the eight scale items are general enough that the measures can be adapted for use in the dark side context described in this dissertation. Thus, the trust scale used for this dissertation is derived from and made up of, previous measures of trust which capture the components of ability, integrity and benevolence.

\section{Satisfaction}

Many researchers investigating B2B issues have operationalized the satisfaction construct as a composite construct consisting of both economic and non-economic aspects. Economic satisfaction is primarily focused on the performance and productivity of the exchange relationship. Being economically satisfied can be described as the type of satisfaction focused on the outcomes of the process, not the process itself. If the exchange relationship is yielding positive outcomes regarding such things as sales, profitability and market share then the channel partners are more likely to be economically satisfied. On the other hand, channel partners enjoying a good functional channel or exchange relationship are more likely to indicate noneconomic satisfaction with the exchange relationship. Exchange partners that express non-economic satisfaction have recognized the benefits of improved processes, efficiencies, and/or the positive affects associated with their exchange partner and exchange relationship.

Geyskens, Steenkamp, and Kumar (1999) suggest that economic and noneconomic satisfactions are influenced differently by the antecedents that cause satisfaction as well as the consequences fostered by satisfaction. In their satisfaction meta-analysis, the authors are able to support this claim by providing evidence for the differential effects noneconomic satisfaction has on trust compared to economic satisfaction which was shown to have no influence on trust. Also, a channel partner's use of promises was 
shown to have a positive influence on economic satisfaction but a negative influence on noneconomic satisfaction.

Many, if not most, B2B researchers do seem to recognize the distinct importance of each facet of the construct as most continue to incorporate elements of economic and noneconomic satisfaction in varying proportions of their satisfaction measure (Dant, Brown, and Bagozzi)

This dissertation recognizes the conceptual differences between the two aspects of satisfaction and believes that measuring each element of satisfaction is not only warranted but also appropriate for this proposed research context. Therefore, this dissertation, like much of the research that has previously investigated satisfaction within the B2B setting (e.g. Dant, Brown, and Bagozzi; Gaski and Nevin 1985; Scheer and Stern) will incorporate elements of economic and noneconomic satisfaction into the overall satisfaction measure.

Dickson and Zhang (2004) also operationalized these two aspects of satisfaction in their study of supplier-retailer relationships in China's distribution channel for foreign brand apparel. The measures of both economic and noneconomic satisfaction have been adapted from this study (see Table one for scale items).

\section{Dark Side Measures}

As the measurement of the dark side constructs is new to the B2B context, established scales in the B2B literatures, to this point, do not exist. Therefore, some of the items have been adapted from various disciplines and research context while others have been derived from the constitutive definitions of each dark side construct. Therefore, though the scales used in this dissertation have all been adapted 
from previous literature, the adaptation is often indirect and out of context. Having said that, it is believed that though these scales are taken from different literatures investigating different phenomena within different contexts, that after adaptation, they are the most appropriate and suitable for investigating the dark side constructs described in this dissertation.

\section{Relational Myopia}

In spite of the plethora of marketing literature describing and discussing the issue of myopia, there is, at the time of this writing, no known literature that has operationalized and empirically studied the myopia construct. Therefore, the scale developed here to measure relational myopia was derived from various scales as well as a number of items derived from the constitutive definition of the relational myopia construct. Items were adapted from two separate innovation scales used elsewhere in the marketing literature. Four items from the Henard and Szymanski (2001) process innovation scale as well as four items from Johannessen, Olsen, and Lumpkin's (2001) innovation measure were adapted for use in this dark side context. These items were chosen from the belief that they capture the short-sightedness or narrow viewed sentiment of the myopia construct. This has to do with the notion of "newness" or the introduction of something new being synonymous with being innovative. That is, in relational terms, being innovative can be seen as the antithesis or opposite of myopic. Innovative relationships assuredly take time to work on new processes or improving existing ones. This sort of innovative nature can be viewed as taking the long view of the relationship as such innovation is only worth while to those who see opportunity in the long term and wish to make sure their relationship changes and evolves in a way that is best able to take advantages of 
opportunities as they are presented. The myopic relationship would not be as innovative as, by definition, they have adopted the "short view" of the relationship and therefore don't necessarily frown on innovation but their perspective doesn't allow for the recognition of the benefits innovative ideas may afford the B2B relationship. It is from this logic that items from these innovative scales are adapted for use in this context.

Items were also adapted from the IPIP - NEO personality inventory. Again, items originally developed to ascertain an individual's personality may not initially seem appropriate for measuring a firm's proclivity toward adopting a relationally myopic view of its relationships with other B2B partners. However, if one considers that firms are essentially the summation of individuals and throughout the RM literature firms are described as behaving like individuals and many of the constructs and theories used to explore interfirm behavior are derived from fields examining the individual, adapting items that measure the traits of individuals for the B2B context does not seem inappropriate.

The IPIP-NEO personality inventory, developed by Costa and McCrae (1985), is an operationalization of the "Big five" five factor model of personality. The big five consists of the Neuroticism, Extraversion, Openness, Agreeableness and Conscientiousness factors of personality. The items selected from this inventory to help assess relational myopia are used in the IPIP-NEO to help assess an individual's openness to experience. These items help evaluate an individual's preferences toward things like routine and their dislike of change. Adapting these items to the B2B context and then marrying them with the items from the supervisory control scale looks to produce a single scale capable of assessing a firm's tendencies to drift toward rote or 
routine processes and their inability to make changes to these processes as time passes and circumstances dictate such changes which are symptoms or characteristics of the relational myopia construct. Finally, three items were derived from the constitutive definition of the relational myopia construct. Please see table one for a complete lists of these items.

\section{Complacency}

As with the other dark side constructs, the scale used to measure complacency was drawn from work outside the B2B context, not investigating the issue of complacency. However, just as with the myopia construct, the work done by Kahne (2005) is believed to be useful, upon adaptation, for measuring the issue of complacency, or a complacent attitude toward one's relationship with an exchange partner. Kahne's (2005) work dealt primarily with developing a measure of an individual's sense of urgency. However, within this same work he found items that measure an individual's complacent attitude toward their organization. Adapting these measures to the $\mathrm{B} 2 \mathrm{~B}$ and dark side context provides a suitable scale for measuring the dark side construct of complacency.

Finally, relying heavily on the constitutive definition of the complacency construct within this dissertation, seven items were derived in an effort to provide a greater battery of items with which to construct the most appropriate complacency scale possible for measurement within the B2B context. These items are so labeled in Table one above.

\section{Vulnerability}

The vulnerability scale developed for this dissertation was derived by evaluating several scales, in many disciplines, that when adapted, are believed to best capture the vulnerability construct within a B2B context. Ultimately this dissertation adapted the 
seven items from Pearlin's Mastery Scale (Perlin et al. 1981). This scale was originally intended for measuring feelings of control or mastery over one's environment and life but has been adapted to help measure such things as job insecurity and powerlessness in the organizational behavior context (e.g. Ashford, Lee, and Bobko 1989). These items also help capture sentiments of vulnerability as it taps into such things as feelings of helplessness and control over one's environment. Feelings of helplessness and exposure are synonymous with vulnerability and are captured by the mastery scale. Therefore, it is the stance of this dissertation that after adaptation, the items in this scale, and the derived scale items, a good measure of vulnerability within the B2B context is formed. Please see table one for individual items.

\section{Suspicion}

Finally, as with all the other dark side constructs, the scale to measure suspicion is also derived from scales not originally intended to measure the notion of suspicion in the dark side context. However, that does not mean that the scales used to derive the dark side suspicion scale are inappropriate after adaptation to the B2B dark side context.

The general honesty and integrity scale is taken from work conducted by Vitell, Rallapalli, and Singhapakdi (1993). This scale uses items like "One should always adhere to all applicable laws and regulations" or "One should always accurately represent one's education, training, and experience". These items can be modified to capture feelings of suspicion by deductively linking suspicion as the opposite of honesty and integrity. That is, if a focal firm does not have faith in their exchange partner's honesty and integrity, it is likely that they do not feel as if this same exchange partner won't take advantage of vulnerabilities and other weaknesses. Therefore, modifying this scale to 
capture the opposite sentiments of honesty and integrity should help capture the notion of suspicion.

Four items from the Generalized Communication Suspicion Scale (Levine and McCornack 1991) are also adapted to help capture suspicious sentiments within the B2B setting. This scale was originally developed by Levine and McCornack (1991) to assess an individual's propensity to assume the deceptive intentions of others. As suspicion in the B2B context is concerned with the suspicious activity of exchange partners, the items in this scale, after adaptation, seem appropriate for use in this research. As with the other dark side sentiments, items were also derived from the constitutive definition of the construct to help form a more complete and appropriate suspicion scale for use in the B2B context. Please see table one above for a complete listing of the items used to measure suspicion in this dark side B2B context.

\section{Relationship Strength Measures}

Though there are many B2B studies that have examined the strength of the B2B relationship, finding a suitable scale, already accepted in the literatures and also appropriate for this research context, actually posed something of a challenge. This is because relationship strength has often been viewed as a higher order construct made up of several first order relational constructs (Dwyer and Oh 1987). Specifically, relationship strength has often been measured by first measuring other elements of the relationship such as trust, commitment and satisfaction (e.g. Donaldson and O'Toole 2000; Dwyer Schurr, and Oh 1987; Golicic and Mentzer 2006; Hausman 2001). The issue here is that these three constructs are all antecedent constructs included in this model. Using the most common measures of relationship strength, which are really 
measures of the second order antecedent relational constructs, implies a circular logic or reasoning that would make interpreting the results of the model, as they pertain to relationship strength, practically impossible. However, after a lengthy search several items not attached to these relational constructs have been published and utilized in the business to business literature. Wong and Sohal (2006) measured relationship strength with four items. Respondents, in their study were asked to evaluate how strong they think their relationship is with both their partnering firm and the partnering firm's representative. Respondents were also asked to indicate how close they would like the relationship with their partnering firm and firm representative to be. This allows for the assessment of the gap between where the relationship is and where respondents would like it to be. Finally, one global item from Herington, Johnson and Scott (2007) was used to assess how respondents view the overall strength of their relationship. Please refer to appendix one, Section II, items 31-35 to see these items in the pre-test and appendix two, Section II, items 13-17 to view these items in the main study survey.

\section{Performance Measures}

Perceptual measures of performance will be assessed. These measures are based on Lusch and Brown (1996) perceptual measures of performance. All but one item has been adapted for use in this dark side study. The item asking respondents to assess liquidity has been omitted as it is believed that this measure isn't pertinent to this relationship context and although many of the respondents will have a good idea about the liquidity of their establishment, they might not have a good idea about the liquidity of the relationship itself. Please see table one for the complete list of perceptual measures of performance used in this dissertation. 


\section{Time (Length of Relationship) Measure}

It is important that the time variables be scaled appropriately as to properly tease out the influence time has on this industry should there actually be a moderating effect. Therefore, for the purposes of this dissertation the time scale will be measured in years in order to provide an adequate scale capable of capturing the influence time has on the onset of the dark side. A single item asking how long the firm has been engaged (or was engaged) in the B2B relationship with their exchange partner will be asked.

\section{Empirical Analysis}

A detailed description of the empirical analysis follows in chapter four. Special attention is given to the empirical methods used to assess convergent and divergent validity as well as overall construct validity. The methods used to assess both the measurement and structural models are discussed along with the presentation of the empirical results.

\section{Rival Models}

As no structural equation model can claim to be completely correct an alternative model approach (Joreskog 1993) should be utilized to compare the theoretical model with potential rival models. A series of rival models were developed and compared to the proposed model with which this dissertation is based. A detailed description and discussion of how well these models compare to the proposed model follows in chapter four. 


\section{Chapter Four: Results}

$$
\text { Pre-Test Results }
$$

Two methods of data collection were used to collect the necessary one-hundred surveys needed to complete the pre-test analysis of the survey instrument. The first method involved the author of this dissertation utilizing a "door to door" approach where firms throughout the local metro area were visited in an attempt to get permission to leave the survey with a qualified potential respondent. As discussed in chapter three of this dissertation anybody who had significant influence in the management of a buyerseller relationship, on the buying side of the dyad, was considered qualified to fill out the survey. Given the length of the survey it was not feasible to wait for the survey to be completed on the spot. However, the participants were given two options for the delivery of the completed survey. The author could return to the establishment and pick it up or the participants could mail the completed survey directly to the author's office at the University. The participants were given a self-addressed postage paid reply envelope to aid in the latter method of delivery. The second method of data collection involved the use of students. Students in two undergraduate marketing sections were given the option of extra credit for each returned survey up to a pre-specified maximum number of points. As most of the undergraduate students were not qualified to fill out the survey themselves they were asked to have people they know and were qualified to fill out the survey complete the form. The students were asked to provide contact information of their 
respondents so that the surveys could be double-checked and validated. Fifteen surveys from the pool of student returned surveys $(\mathrm{N}=43)$ were drawn and the contact information on the surveys was utilized to contact the person who completed the survey and verify that they were indeed qualified to fill out the survey. They were also asked if they had any questions about the study. All of the contact information proved accurate and none of the student returned surveys had to be disqualified for validation reasons. For the pretest, the survey was constructed in a way to look like two separate surveys that had no relationship to each other. The participants were led to believe they were filling out two separate surveys for two separate research projects. Constructing the survey in this way is believed to separate the predictor and criterion variables in the respondent's mind which is supposed to guard against common method bias (Podsakoff et al. 2003).

Data collection for the first one hundred surveys used for the pre-test, took approximately five months. It is not believed that this amount of time between initial survey distribution and completion of survey collection would have any impact on the responses provided by the participants. The following are the results of the statistical analysis conducted to assess the reliability and validity of the items and constructs in the survey instrument used for this dissertation.

\section{Relational Antecedents Assessment (Pre-Test)}

\section{Pre-Test Reliability}

Reliability for all of the antecedent relational variables was determined by using two common methods of assessing item reliability in structural equation modeling; Chronbach's alpha and the composite or Jorsekog's reliability. Both Chronbach's alpha and the composite reliability show all the scales used to measure the antecedent relational 
constructs exceed the conventional 0.700 threshold of reliability see table two below for results.

Table 2 Pre-Test Reliability of Antecedent Relationship Constructs

\begin{tabular}{lcccc}
\hline & & & $\begin{array}{c}\text { Number of Items } \\
\text { before Pre-test } \\
\text { Analysis }\end{array}$ & $\begin{array}{c}\text { Number of Items } \\
\text { after Pre-Test } \\
\text { Analysis }\end{array}$ \\
\hline Shared Values & Chronbach's Alpha & Composite Reliability & 5 & 5 \\
Commitment & 0.781 & 0.828 & 16 & 12 \\
Trust & 0.794 & 0.787 & 18 & 15 \\
Satisfaction & 0.842 & 0.845 & 12 & 10 \\
\hline
\end{tabular}

The shared values items were adapted from the Corporate Ethical Values scale from Hunt, Wood and Chonko (1989). As mentioned in chapter three of this dissertation this scale follows Enz's (1988) two stage procedure for item measurement. More specifically, respondents were first asked to indicate to what degree they believed the supplier that they had decided to consider when completing the survey, would agree with the first statement. The second question was a repeat of the first with the exception of the respondent being asked how much they, themselves, would agree with the statement given. The difference of these items as well as the absolute value of the difference of these items was calculated and used for the pre-test analysis of the shared value constructs. Though there are ten items in the survey used to measure shared values (see Appendix one, section I, items 1 - 5), only the absolute value of the difference between the supplier response and respondent (buyer) was evaluated yielding what is essentially a five item scale. The pre-test analysis showed a reliable scale with the ten items given; therefore, the ten items used in the pre-test were retained for the subsequent main study. The two normative and affective facets of commitment both had eight items each on the pre-test survey that were derived from the Allen and Meyer scale (1990) of affective 
and normative commitment. After the data were collected and the analysis run it became apparent that dropping one item from the normative commitment scale and three items from the affective commitment scale would yield the most reliable and more parsimonious commitment scale. .

Both the benevolence and integrity facets of trust had five items each in the pre-test survey. The items used to measure both of trust facets derived from those used in Kumar, Scheer, and Steenkamp (1995). The ability facet of trust, derived from items used in Ghosch, Whipple, and Bryan (2001), had eight items in the pre-test survey. The pre-test analysis showed that trimming three items from the ability portion of the trust scale would yield a more reliable and again, more parsimonious scale for use in the main study. Therefore, the decision was made to drop the three items that did not add to the reliability of the scale. All of the benevolence and integrity items were maintained in the trust scale for use in the main study.

Satisfaction is made up of two facet components; non-economic and economic satisfaction. In the ongoing effort to use the most reliable and yet most parsimonious scales possible, two items were dropped from the seven item non-economic satisfaction portion of the scale used in the pre-test. These items were originally used in the work by Dickson and Zhang (2004). The added benefit of parsimony makes the decision to drop these items that much more intuitive provided the smaller scale is more reliable than the larger one, which is the case for the research context in this dissertation. However, economic satisfaction only has five items included in the pre-test survey. These five items were kept as they all appear to add to the reliability of the larger satisfaction scale. 


\section{Pre-Test Validity}

Convergent validity of the antecedent relational constructs was assessed by first conducting a single factor confirmatory factor analysis (CFA) for each of the relational constructs as well as a confirmatory factor analysis of the antecedent portion of the measurement model. The results of the single factor confirmatory factor analyses are listed in table three below.

Table 3 Pre-Test CFA Results

\begin{tabular}{lcccccc}
\multicolumn{1}{c}{$\begin{array}{c}\text { Chi }- \\
\text { Square }\end{array}$} & \begin{tabular}{c} 
Pr $>$ Chi- \\
\multicolumn{1}{c}{ Constructs } \\
Statistic
\end{tabular} & Square & RMR & RMSEA & CFI & NNFI \\
\hline Shared Values & 33.413 & $<0.0001$ & 0.009 & 0.040 & 0.998 & 0.990 \\
Commitment & 2629.86 & $<0.0001$ & 0.046 & 0.093 & 0.923 & 0.833 \\
Trust & 4330.719 & $<0.0001$ & 0.032 & 0.082 & 0.958 & 0.930 \\
Satisfaction & 3280.417 & $<0.0001$ & 0.048 & 0.148 & 0.963 & 0.888 \\
\hline
\end{tabular}

The chi-square statistic is a measure of overall fit. A large value of chi-square signifies that the observed and estimated matrices are considerably different. Low chisquare values are indications that the actual and predicted matrices are not statistically different. A non significant chi-square statistic is desired because the test is between actual and predicted matrices. The chi-square statistic for all of the antecedent relational variables is significantly large which indicates that the estimated and observed matrices are indeed different which indicates that each single factor CFA is indeed a poor fit. It should be noted however that the tendency of the chi-square to reject any specified model with a sufficiently large sample is quite high. In response or in an attempt to correct for this tendency researchers have begun to assess other fit indices. The RMR (root mean square residual) is the square root of the average of the residuals between the observed and estimated input matrices. Since this model uses correlations, the RMR is in terms of 
an average residual correlation. The RMR is useful for this model since it is using correlations instead of the covariance matrix. This is because the correlations are all on the same scale unlike covariances which may differ from variable to variable depending on the unit of measure (Hair et al. 1998). The RMSEA (or root mean square error of approximation) is the discrepancy per degree of freedom like the RMR; the difference is that discrepancy is measured in terms of the population, not just the sample used for estimation (Hair et al. 1998). The value is representative of the goodness-of fit that could be expected if the model were estimated in the population, not just the sample drawn for the estimation (Hair et al. 1998). According to Hair et al. (1998) values ranging from $.05-.08$ are acceptable while $\mathrm{Hu}$ and Bentler (1999) state that values of less than .06 for both the RMR and RMSEA indicate satisfactory model fit.

Bentler's Comparative Fit Index (CFI) represents a comparison between the estimated model and the null model. Larger values generally indicate a better fit. The NNFI index combines a measure of parsimony into a comparative index between the proposed and null models (Hair et al.1998). According to Hair et al. (1998) values for both the CFI and the NNFI should exceed 0.90 to indicate acceptable fit while Hu and Bentler (1999) recommend a stricter threshold of 0.95 .

The results shown in table three above reveal some potential issues with the relational constructs. Specifically, several of the fit indices fall well outside the accepted thresholds discussed above (e.g. the RMSEA for Satisfaction or the NNFI for Commitment). However, it is possible that $\mathrm{N}=100$ is not a large enough sample size to provide confidence in these CFA's. Although the power analysis for this dissertation, conducted according to the methodology prescribed by MacCallum, Browne, and Sugaware, 
indicate that a relevantly small sample is needed to run the structural model $(\mathrm{N}=20)$ proposed in this dissertation, other sources suggest that a larger sample is needed. Specifically, Hair et al. (1998) recommends that to ensure appropriate use of maximum likelihood estimation techniques that a minimum sample of $\mathrm{N}=200$ is needed as this is considered the critical sample size required to have confidence in the results. Also, Jackson (2001), in his article, which discussed the use of estimating sample size based on the number of estimated parameters vs. simply increasing the sample size all together found that sample sizes between 200-400 yielded the best results. Given the size of this pre-test model (i.e., $\mathrm{N}=100$ ) and the general consensus that a sample of at least 200 hundred is needed the argument can be made, though without certainty, that this smaller sample of only 100 might not be sufficient for producing interpretable results when running these CFA's. Therefore, though these results are cause for concern, the decision to proceed to the larger antecedent CFA model is made with the understanding that if subsequent analyses do not resolve these measurement issues, then the results produced while testing this model may be erroneous so interpretation of the results should take place with these issues in mind and with caution.

The next step in the pre-test analysis was to run a larger CFA including all of the antecedent constructs. The chi-square statistic is significant at 1039.056. The CFI and NNFI are 0.6197 and 0.5518 respectively. However, The RMR and RMSEA, though still outside the range of acceptable fit indices are slightly better at .0952 and 0.1268 respectively. These issues are again believed to be attributable to the small sample size.

However, in an effort to be as thorough and complete as possible the assessment of discriminant validity was also conducted. The method used to assess discriminant 
validity is the method originally suggested by Fornell and Larchker (1981) and is commonly referred to as the average variance extracted or AVE method for assessing discriminant validity. This method compares the squared correlations between two constructs to the average variance extracted for each of the constructs of interest. If the average variances extracted by the correlated latent variables are greater than the square of the correlation between the latent variables then discriminant validity is considered to be obtained.

Table 4 Pre-Test Discriminant Validity for Relational Antecedent Constructs

\begin{tabular}{|c|c|c|c|c|c|}
\hline Construct (a) & $\begin{array}{l}\text { Construct } \\
\text { (a) AVE }\end{array}$ & Construct (b) & $\begin{array}{l}\text { Construct } \\
\text { (b) AVE }\end{array}$ & $\begin{array}{c}\text { Correlation } \\
\text { estimate }\end{array}$ & $\begin{array}{c}\text { Squared } \\
\text { Correlation }\end{array}$ \\
\hline Shared Values & 0.428 & Commitment & 0.349 & -0.040 & 0.002 \\
\hline Shared Values & 0.428 & Trust & 0.551 & -0.139 & 0.019 \\
\hline Shared Values & 0.428 & Satisfaction & 0.600 & -0.150 & 0.023 \\
\hline Commitment & 0.349 & Trust & 0.551 & 0.144 & 0.021 \\
\hline Commitment & 0.349 & Satisfaction & 0.600 & 0.141 & 0.020 \\
\hline Trust & 0.551 & Satisfaction & 0.600 & 0.380 & 0.144 \\
\hline
\end{tabular}

As can be seen in the above table all the antecedent relational constructs have AVE figures that are higher than that of their squared correlations, indicating that discriminant validity has been achieved. However, the fact that there are AVE figures below 0.50 is troubling as this indicates that more than half of the variance in the items can be accounted for by something other than the items themselves. Under the worst possible interpretation, this could indicate that the items being used are not good measures of the constructs they are designed to measure, at least in this dissertation's context. However, after a larger, more appropriate sample size was obtained these issues were largely resolved. This resolution as well as the discussion of the dark side pre-test analysis follows below. 
Dark Side Assessment (Pre-Test)

Pre-Test Reliability

As with the antecedent relational constructs discussed above, reliability for the dark side constructs was assessed by figuring both the chronbach's alpha score for each construct as well as the composite reliability scores. Table six below lists these reliability scores for each of the dark side constructs.

Table 5 Reliability of Antecedent Relationship Constructs

\begin{tabular}{lcccc}
\hline \multicolumn{1}{c}{ Construct } & $\begin{array}{c}\text { Chronbach's } \\
\text { Alpha }\end{array}$ & $\begin{array}{c}\text { Composite } \\
\text { Reliability }\end{array}$ & $\begin{array}{c}\text { Number of Items } \\
\text { before Pre-test } \\
\text { Analysis }\end{array}$ & $\begin{array}{c}\text { Number of Items } \\
\text { after Pre-Test } \\
\text { Analysis }\end{array}$ \\
\hline Relational Myopia & 0.734 & 0.717 & 15 & 4 \\
Complacency & 0.891 & 0.877 & 9 & 4 \\
Vulnerability & 0.868 & 0.875 & 9 & 6 \\
Suspicion & 0.913 & 0.917 & 13 & 7 \\
\hline
\end{tabular}

As can be seen in the table, all of the dark side constructs have excellent reliability and exceed the commonly accepted threshold of 0.70 . What can also be ascertained from the table is the need to prune or drop some items from each dark side scale. relational myopia and complacency underwent the most radical changes after the pre-test reliability analysis but vulnerability and suspicion also presented measurement issues that required modifications of their respective scales.

Unlike the antecedent relational constructs discussed above, these dark side constructs do not have scales that are already well entrenched in the B2B literatures. Therefore, as mentioned in chapter three of this dissertation, the items for each scale had to be either adapted from unrelated social science disciplines or derived from the constitutive definition of each construct. Both of these methods were employed to derive each of these dark side scales. The scales being employed here do not exist for this B2B 
context so the high reliability scores are both surprising and encouraging. However, the changes to the scales are more significant than simply dropping items. Though this may appear radical at first, given the novelty and pioneering nature of this research it is not at all unexpected and supports the reasoning for the lengthy and substantial pre-test.

Of the original 15 items used to measure relationship myopia in the original pre-test survey only four were kept and used in the subsequent main study. The need for this significant pruning was revealed during the reliability analysis where, although other items helped produce a reliable scale, a deeper content analysis, which involved reevaluating the wording and phrasing of each item, showed that many of the items originally proposed as measures of relational myopia were in fact measuring something else. Therefore, the four items retained show good reliability and are believed to be the four best items for measuring relationship myopia. However two new items, derived from the constitutive definition of relationship myopia were added to the scale in an effort to adequately sample from relationship myopia domain. It is conceded that this addition of items to the main study survey without prior pre-testing was something of a gamble but content analysis of the subsequent items provided confidence that these new items are consistent with the four items previously retained which showed excellent reliability. Please see appendix two, section II items 11-12 for the additional relationship myopia items.

The complacency scale, like the relational myopia scale, underwent significant changes after the pre-test reliability analysis. Of the original nine items originally used to measure complacency, none were retained after the pre-test reliability analysis. However, as mentioned above, content analysis revealed that some of the relationship 
myopia items looked to be measuring something other than relational myopia. This argument was most apparent when looking at items five through eight (Appendix two, Section II, Items 7-12). These items asked about supplier behavior since the beginning of the relationship. In other words, has the supplier changed things as time has gone by or have they always done everything the same way? These four items are believed to be more appropriate for the measurement of complacency, not relationship myopia and thus, were moved and relabeled as complacency items. As can be seen in the table above, these items also show good reliability but, just as with relationship myopia, an effort must be made to sample from the entire complacency domain so again, two new items were added to the complacency scale to be used in the following main study survey. These items are shown in appendix two, section II numbers 2-3, with the rest of the main study survey.

Of the original nine vulnerability items used in the pre-test survey six were retained after the reliability analysis. Of the original 13 suspicion items used in the pre-test analysis, seven were kept for further analysis. These decisions were based on what items presented the most reliable set of measures of the vulnerability and suspicion construct. Pre-Test Validity

The next step, after the reliability assessment, is to evaluate the validity of each dark side construct. This validity assessment was done in three phrases. The first phase was an evaluation of the constructs at the construct level. That is, an evaluation of how well the items were measuring what they are supposed to be measuring. This was accomplished by conducting four single factor confirmatory factor analyses (CFA). The following phase meant measuring the entire dark side measurement model and the third 
phase involved the discriminant analysis of the dark side constructs. The results of these analyses are discussed below and the results of the single factor confirmatory analyses are listed in table six below.

Table 6 Fit Indicies for Dark Side Single Factor CFA

\begin{tabular}{lcccccc}
\multicolumn{1}{c}{ Chi-Square } & & & & & \\
\multicolumn{1}{c}{ Construct } & Statistic & Pr $>$ Chi-Square & RMR & RMSEA & CFI & NNFI \\
\hline Relational Myopia & 19.2665 & $<.0001$ & 0.0084 & 0.0427 & 0.9981 & 0.9885 \\
Complacency & 2.2997 & 0.0870 & 0.0014 & 0.0139 & 0.9999 & 0.9996 \\
Vulnerability & 67.8109 & $<.0001$ & 0.0098 & 0.0574 & 0.9977 & 0.9826 \\
Suspicion & 21.2042 & $<.0001$ & 0.0041 & 0.0450 & 0.9996 & 0.9914 \\
\hline
\end{tabular}

As can be seen in table six above, with the exception of the significant chi-square statistics, all of the single factor CFAs show excellent fit indices for the trimmed or pruned dark side scales. Coupled with the strong reliability number these fit indices lend support for the notion that these four scales are indeed measuring these new and novel constructs of interest.

After conducting these single factor CFAs the next step was to measure these four constructs at once in a single dark side CFA designed to assesses the usefulness of the dark side measurement model. The chi square statistic was significant at 14,918 $p<$ 0.0001. The RMR is 0.0539 , the RMSEA is 0.1043 , the CFI is 0.8942 and the NNFI is 0.8933. Though these numbers are, for the most part, close to the established thresholds they are still a little outside what is typically acceptable. These fit indices need to be interpreted with caution as the sample size used to derive these numbers may be too small for the assessment of a measurement model. However, with the strength of the reliability analysis and single factor CFA's the decision is made to move ahead to the discriminant validity portion of the pre-test analysis. 
The assessment of discriminant validity was done using the AVE method, detailed above. The results of the dark side pre-test assessment of discriminant validity are listed in table seven below.

Table 7 Dark Side Pre-Test Discriminant Validity

\begin{tabular}{|c|c|c|c|c|c|}
\hline Constructs (a) & $\begin{array}{c}\text { Construct (a) } \\
\text { AVE } \\
\end{array}$ & Construct (b) & $\begin{array}{c}\text { Construct (b) } \\
\text { AVE } \\
\end{array}$ & $\begin{array}{c}\text { Correlation } \\
\text { estimate }\end{array}$ & $\begin{array}{c}\text { Squared } \\
\text { Correlation }\end{array}$ \\
\hline Complacency & 0.690 & Relational Myopia & 0.475 & 0.395 & 0.156 \\
\hline Complacency & 0.690 & Vulnerability & 0.565 & 0.588 & 0.346 \\
\hline Complacency & 0.690 & Suspicion & 0.614 & 0.321 & 0.103 \\
\hline Relational Myopia & 0.475 & Vulnerability & 0.565 & 0.132 & 0.017 \\
\hline Relational Myopia & 0.475 & Suspicion & 0.614 & 0.230 & 0.053 \\
\hline Vulnerability & 0.565 & Suspicion & 0.614 & 0.605 & 0.366 \\
\hline
\end{tabular}

As can be seen in table seven above all of the AVE measures are above the squared correlation estimate between the constructs. These figures show that all of the constructs have obtained adequate discriminant validity. However, like the relational constructs discussed above, one of the constructs, namely relational myopia is close but still marginally below the 0.50 threshold. This indicates that more than half the variance affiliated with the items from this scale can be attributed to something other than the item itself. This is troublesome but given the AVE figure of 0.475 and its proximity to the accepted value of 0.50 and the relatively small sample size of 100 , the decision was made to move to the next phase of the analysis.

\section{Relationship Strength Assessment (Pre-Test)}

\section{Pre-Test Reliability}

The reliability of this five item relationship strength scale was only .676. It was believed that the addition of the global relationship strength measure would add reliability and validity to the smaller four item relationship strength scale. However, this 
proved not to be the case as a smaller four item relationship strength scale, without the global measure, yields a much stronger and reliable scale.

Pre-Test Validity

The Chronbach's alpha score for the four item relationship strength scale is 0.765 and the composite reliability score is 0.775 . The single factor CFA yielded a significant chisquare statistic $(\mathrm{p}>0.001,126.0525), \mathrm{RMR}=0.0246, \mathrm{RMSEA}=0.11, \mathrm{NNFI}=0.9485$ and a CFI of 0.9910. These CFA fit indices for the pre-test are promising though slightly outside accepted thresholds. Citing the above discussion regarding a larger sample size, the decision was made to keep these four items (without the global item) for the subsequent main study. The relationship strength construct is not run in a larger CFA as there is no theoretical correlating relationship between relationship strength and the other constructs in the model. Thus, the pre-test analysis of the relationship strength construct at this point, is complete.

\section{Performance Assessment (Pre-Test)}

\section{Pre-Test Reliability}

The reliability for the five item performance scale was extremely high on both measures of reliability. Both the Chronbach's alpha score and the composite reliability score were .919 accounting for rounding error. Given the strength of the reliability figures, enough confidence in the reliability of the performance measure exists to shift the analysis toward the validity assessment.

\section{Pre-Test Validity}

The single factor performance CFA did have a significant chi square at 41.625 ( $p$ > 0.001) but the RMR, RMSEA, CFI and NNFI were all well within acceptable thresholds 
(0.005, 0.046, 0.999 and 0.997 respectively). As with relationship strength, there is no theoretical correlating relationship between performance and any other construct within the structural model. Thus, performance was not subjected to discriminant analysis. At this point, the pre-test analysis of performance is complete. Since Time is a single item construct it is not subjected to the pre-test assessments of reliability or validity.

\section{Main Study Results}

The pre-test analysis showed that the survey could be pruned or shortened for the main study portion of this research project. A slightly shortened survey was constructed and distributed via several data collection methods for this main study. Table eight below shows how many items were in the original pre-test survey and how many were removed after the pre-test analysis. This substantial pruning saved a considerable amount of space and fewer items is believed to have helped guard against respondent fatigue.

Table 8 Number of Items Before and After Pre-Test

\begin{tabular}{lcc}
\hline Construct & $\begin{array}{c}\text { Number of } \\
\text { Items before } \\
\text { Pre-test } \\
\text { Analysis }\end{array}$ & $\begin{array}{c}\text { Number of } \\
\text { Items after } \\
\text { Pre-Test } \\
\text { Analysis }\end{array}$ \\
\hline Shared Values & 5 & 5 \\
Commitment & 16 & 12 \\
Trust & 18 & 15 \\
Satisfaction & 12 & 10 \\
Relational Myopia & 15 & 4 \\
Complacency & 9 & 4 \\
Vulnerability & 9 & 6 \\
Suspicion & 13 & 7
\end{tabular}

A total of 305 usable surveys were collected and used for the main study analysis.

These surveys were collected with various data collection methods. These distribution methods are discussed in the section below. 


\section{Main Study Distribution Methods}

Several online versions of the smaller survey were constructed. A word document and a typeable PDF file were put together and the use of the online survey hosting site Survey Monkey was also employed. These online versions of the survey were distributed through several online forums. Specifically, B2B message boards were frequented in an attempt to solicit respondents but this effort yielded zero complete responses. Online networking environments such as Facebook and MySpace were also employed. Bulletins were posted on the Facebook and MySpace pages of two of this dissertation's author's friends and family asking if qualified respondents would be willing to take the time to fill out the survey. This effort was able to produce 55 complete surveys from qualified respondents. Based on the, age, education and known vocations of the people contacted directly via these forum it is believed that this method produced a response rate well over $50 \%$ as approximately 250 people would have been made aware of the survey but of those people, it is believed that anywhere between $75-90$ people were actually qualified to complete the survey. Also, an email blast was sent to a network of management consultants which consists of approximately 3,500 people worldwide though only 17 of the 305 responses were from outside the U.S. Of the approximately 3,500 management respondents that received the email asking for participation, only 27 qualified respondents returned a completed survey. It should be noted however, that it is believed that a relatively small number of these 3,500 are actually qualified to complete the survey as the majority of these people have a background in the selling side of B2B relationships, not the buying side. The author of this dissertation also attended networking events and fairs in an effort to find qualified respondents willing to complete 
the survey. At these events hard copies of the survey were distributed but mention of the online surveys was also made in an effort to make things as easy for the respondents, or potential respondents as possible. This effort was able to produce 23 complete surveys from qualified respondents. Approximately 15-20 people typically attend these events. The author of this dissertation attended four of these events which would yield a response rate of approximately $28 \%$ if everyone attending was qualified to fill out the survey. However, not everyone attending these events was qualified to complete the survey so estimating a response rate for this method of collection at something greater than $30 \%$ seems reasonable.

Finally, two undergraduate marketing sections were afforded extra credit for every survey they returned complete from a qualified respondent. These sections were initially given hardcopies of the survey with a self addressed postage paid envelope and a cover letter briefly explaining the affiliation of this dissertation's author and purpose of the study. These students were also given the option of downloading one of the internet versions of the survey or directing respondents to the Survey Monkey website where an online version of the survey was being hosted. These student returned surveys required contact information for the respondents so that the author of this dissertation could confirm the responses and respondents were legitimate. It is important to note that all respondents were reassured that their personal information would be kept confidential but in order for the students to receive extra credit the contact information had to be provided. The extra credit was also contingent upon actual confirmation of the respondents. The author of this dissertation randomly selected 25 student returned surveys and contacted the respondents listed on the survey in an effort to confirm the 
legitimacy of the survey. All 25 surveys proved legitimate and no further action was taken to confirm the legitimacy of the student returned surveys. The students in the two undergraduate marketing sections, approximately 100 students, were able to produce 200 returned surveys. It is impossible to know the exact response rate for the student administered surveys as they had access to online versions of the survey that could be distributed without the author's knowledge. However, it is also reasonable to believe that the majority of the time, the majority of students would not administer a survey unless they were fairly sure the survey would get completed by a qualified respondent. The students were given instructions not to go to places that they did not know or talk to people with whom they were not familiar. The extra credit was explained as a method for them to take advantage of their current relationships. Respondents, who already have a relationship with the student, are incentivized by the opportunity to help the student, which is often a much greater incentive than anything offered by many B2B researchers, so it is reasonable to believe that this method produced a response rate above $50 \%$. The 25 contacted respondents represent approximately $7.5 \%$ of the student returned surveys.

\section{Non Response Bias}

Some of the distribution techniques discussed above utilized what can be described as a "blast" or a technique where several hundred to several thousand people received some form of electronic notification (e.g. email, post, bulletin notification) asking for participation. It is believed that using these sorts of techniques are good, efficient ways to get the survey instrument in front of large numbers of qualified people in a quick, cost effective manner. The down side of these methods is that it is impossible to track, with 
$100 \%$ accuracy, how many qualified potential respondents actually see the survey and have the opportunity to respond but don't. However, the number of potential respondents who received the hard copy of the survey was tracked more carefully. Four hundred and fifty hard copies of the survey were distributed. Of these surveys, 135 surveys were returned. Thirteen surveys however had to be disqualified due to various reasons such as incompleteness, the respondent not being qualified or not having enough information to fill out the survey. This leaves a total of 122 complete surveys from qualified respondents for a hard copy response rate of $27 \%$. This number is consistent with many B2B research projects of a similar nature (e.g. Rauyruen and Miller 2007; Palmatier et al. 2008). Coupled with the potential response rates discussed above it is reasonable to believe that, even though it is impossible to know for sure, the response rate for this dissertation is consistent with other, similar B2B research project. This, of course means that the study response rate is something significantly less than $50 \%$ which necessitates the need for an evaluation of non-response bias.

In order to assess the non-response bias, eight non-demographic questions and two demographic questions from the original survey were put into a small one page nonresponse survey. Roughly one item per construct was selected at random and the two demographic questions were also selected at random. This one page, ten question survey was designed to take only a couple of minutes and would be used to statistically evaluate the differences, if any, between respondents and non-respondents. Since a detailed list was kept of everyone who was handed an actual hard copy of the survey the author of the study went back to several non-respondents and asked for participation in the smaller one page study. After receiving thirty $(\mathrm{N}=30)$ complete, non-respondent surveys a 
multivariate analysis of variance was conducted (MANOVA) across all variables to see if there were differences between respondents and non-respondents. The results indicated no significant differences across any of the non-demographic or demographic variables $(\mathrm{F}=2.457 \mathrm{p}>0.05)$ between respondents and non-respondents. With no significant differences between the respondents and non-respondents being discovered the analysis of the main study could commence with confidence in the generalizablity of this research project's results.

As with the pre-test, the analysis of the measurement model was broken up into three different parts. First the reliability and validity of the antecedent relational variables was assessed. This is followed by the reliability and validity assessment of the dark side constructs and finally the reliability and validity of the relationship strength and performance constructs individually. Again, the time measurement is a single item and not subjected to these measurement model analyses. After these measurement model analyses are conducted the assessment of the structural model takes place. The results of these analyses are discussed below.

\section{Relational Antecedent Assessment (Main Study)}

\section{Main Study Reliability}

The results of the reliability assessment of the antecedent relational constructs can be seen in table ten below.

Table 9 Reliability of Relational Antecedent Constructs

\begin{tabular}{lccc}
\hline & Chronbach's Alpha & $\begin{array}{c}\text { Composite } \\
\text { Reliability }\end{array}$ & Number of Items \\
\hline Shared Values & 0.803 & 0.813 & 5 \\
Commitment & 0.802 & 0.805 & 12 \\
Trust & 0.931 & 0.945 & 15 \\
Satisfaction & 0.952 & 0.953 & 10 \\
\hline
\end{tabular}


As can be seen in the table, all of the antecedent relational constructs show good reliability using either the chronbach's alpha score or the composite reliability score. These scores allowed the analysis to move forward to the next step in the relational antecedent assessment.

Main Study Validity

With confidence in the reliability of the items the next step in the analysis of the antecedent portion of the measurement model was to assess the single factor structures through the use of single factor confirmatory factor analyses (CFA). The results of these single factor CFAs are shown in table ten below.

Table 10 Main Study Relational Single Factor CFA Fit Indicies

\begin{tabular}{lcccccc} 
& Chi-Square & Pr $>$ Chi-Square & RMR & RMSEA & CFI & NNFI \\
\hline Shared Values & 10.840 & 0.001 & 0.010 & 0.031 & 0.956 & 0.995 \\
Commitment & 170.920 & $<.0001$ & 0.135 & 0.075 & 0.994 & 0.996 \\
Trust & 531.765 & $<.0001$ & 0.013 & 0.163 & 0.995 & 0.795 \\
Satisfaction & 223.095 & $<.0001$ & 0.026 & 0.032 & 0.999 & 0.998 \\
\hline
\end{tabular}

Aside from the significant chi-square statistics, the only fit indices outside their accepted thresholds are the RMSEA for trust and the NNFI for trust. All of the other fit indices produced during the single factor CFA's all look to be very close, or well within conventional thresholds. Having said this, the fit indices for trust that fall outside their accepted thresholds are troubling. However, given the strength of the other fit indices and the proximity of these fit indices to their accepted thresholds the decision was made to continue with these constructs in the hope that the remaining measurement model analyses would provide enough evidence to guide the proper action regarding these scales. For instance, the remaining measurement model analyses may have suggested 
dropping certain items or the continuation with the analysis of the structural portion of the model with the measurement model left as is. However, any results produced during the analysis of the structural model that are concerned with these constructs would have to be interpreted with caution if no further action had been taken regarding these items and scales.

After the single factor CFA's the next step was to run the larger CFA consisting of the entire antecedent measurement model. The CFA run with all the above listed constructs produced the following fit indices: The chi-square was significant at 32310.425 ( $p$ > 0.001) with an RMR of 0.042, an RMSEA of 0.073. The CFI is 0.895 while the NNFI is 0.845. Two of the fit indices for the larger CFA are troubling enough to warrant a deeper investigation and re-evaluation of the items being used to measure the four antecedent relational constructs. Specifically, the CFI and NNFI are far enough out of their acceptable thresholds that moving forward without first addressing these issues would leave the interpretability of the results difficult and in doubt. In an effort to resolve these issues the decision was made to go back and re-evaluate the relational constructs at the item level. This involved an item by item evaluation of the standardized loadings and their contribution to the constructs average variance extracted. These tools, used in conjunction with a content analysis of each item, as they relate to the underlying theoretical foundations supporting this dissertation, helped determined which items were contributing the greatest utility regarding the measurement of each relational construct and which items should be dropped from the analysis.

This re-evaluation showed that the first two shared values items were not contributing to the usefulness of the shared values scale as their standardized loadings were low 
compared to the other three items. The decision was made to drop these first two shared values items from the scale and to proceed with the analysis using only a three item shared values scale. Since shared values became only a three item scale and thus modified from its original five item scale an effort was made to go back and re-evalute the scale at the single factor level. Since the shared values scale is now only three items a single factor CFA is not possible. This is one of the draw backs of using such a limited number of items to measure any one given construct. However, this handicap is more than overcome by the strength of the full antecedent measurement mode. A reliability assessment is possible however and was conducted for the revised three item scale. The revised chronbach's alpha score is 0.835 and the revised composite reliability score is 0.839. The revised three item scale also accounts for more than $60 \%$ of the variance extracted.

The scales used to measure commitment also had its share of measurement issues. The twelve item scale was unable to extract more than $50 \%$ of the variance which is a troublesome figure as this means more than half of the variance can be accounted for by something other than the scale. An exploratory factor analysis was conducted and although the EFA supports a two factor structure, which is consistent with the dimensions of commitment being measured in this dissertation (e.g. normative and affective) the true usefulness of the EFA was its revealing several items which were handicapping the commitment scale. Specifically, the affective portion of the commitment scale had five items to this point. The decision was made to drop the first two items as the rotated factor matrix and the standardized loadings show that these first two items contribute very little to the measurement of commitment. Similar results were revealed for the 
normative portion of the commitment scale. For similar reasons, the decision was made to drop the first, second, fourth and sixth items. Though the rotated factor matrix does support a two factor structure the six items retained have enough cross loadings to support continuing the analysis with commitment being measured as a single construct capturing elements of both normative and affective commitment. The revised single factor CFA for the smaller six item commitment scale resulted in a chi-square statistic of 311.688 an RMR of .029 an RMSEA of .071 a CFI of .996 and a NNFI of .947. The revised reliability scores were 0.753 and 0.746 for the chronbach alpha score and composite reliability score respectively.

An exploratory factor analysis was also conducted for trust. Similar to commitment, the EFA revealed a two factor structure. Also like commitment however, is the large number of cross loadings for several items between the two factors. A second EFA was run where the factor structure was constrained to only one factor. As expected, most of the items which showed high loadings for the previous two factor structure also loaded high on the single factor. In an effort to isolate the items that were contributing most to the measurement of trust a close examination of the item's standardized loadings along with the results of the EFA was conducted. Using these two methods together it became apparent that the most useful and parsimonious trust scale would be produced by retaining the third and fifth item from the integrity scale, the first and fifth item from the benevolence scale and the third and fifth item from the ability scale. Together these six items produced a trust scale capable of accounting for more than $50 \%$ of the variance extracted as well converging onto one single factor. The fit indices for the smaller six item trust scale were also very good. The chi-square was significant at 1245.157 but the 
RMR and RMSEA were both acceptable at 0.032 and 0.073 respectively. The CFI and the NNFI were also acceptable at 0.986 and 0.959 respectively. The chronbach alpha score for reliability was 0.879 while the composite reliability was 0.924 .

The EFA for satisfaction included the items for both non-economic satisfaction and economic satisfaction. Interestingly, these two scales do not diverge as only one factor was extracted. An examination of the single factor structure and the item's standardized loadings showed that the first three non-economic satisfaction items and the second and fourth economic satisfaction items worked best together to produced one satisfaction scale that converges capable of capturing elements of both non-economic and economic satisfaction. The revised satisfaction CFA yielded a chi-square statistic of 1345.567. The RMR and RMSEA were within or close to acceptable thresholds at 0.017 and 0.098 respectively while the CFI and NNFI were both well within acceptable thresholds at 0.987 and 0.957 respectively. The revised reliability scores were also promising at .094 for the chronbach alpha score and 0.96 for the composite reliability score.

With renewed confidence in the smaller, more parsimonious scales a revised CFA was run for the entire antecedent measurement model. The chi-square was significant at $7160.642 p<0.0001$. Aside from the chi square, all other fit indices were either close to within acceptable thresholds. The RMR was 0.035 while the RMSEA was 0.080 . The CFI and NNFI were 0.947 and 0.917 respectively. The above reliability and fit indices provide enough evidence of convergent validity for the antecedent constructs and antecedent measurement model that moving forward to the next step in the analysis was done with confidence. The next step in the analysis of the antecedent measurement model is the assessment of discriminant validity. 
The method used to assess discriminant validity for the entire antecedent measurement model is again the AVE method suggested by Fornell and Larcker (1981). The results of this analysis are on the following page, in table 11.

Table 11 Discriminant Validity for the Antecedent Measurement Model

\begin{tabular}{|c|c|c|c|c|c|}
\hline Construct (a) & $\begin{array}{c}\text { Construct } \\
\text { (a) AVE }\end{array}$ & Construct (b) & $\begin{array}{l}\text { Construct } \\
\text { (b) AVE }\end{array}$ & $\begin{array}{c}\text { Correlation } \\
\text { estimate }\end{array}$ & $\begin{array}{c}\text { Squared } \\
\text { Correlation }\end{array}$ \\
\hline Shared Values & 0.634 & Commitment & 0.516 & 0.417 & 0.174 \\
\hline Shared Values & 0.634 & Trust & 0.676 & 0.315 & 0.099 \\
\hline Shared Values & 0.634 & Satisfaction & 0.765 & 0.317 & 0.100 \\
\hline Commitment & 0.516 & Trust & 0.676 & 0.621 & 0.386 \\
\hline Commitment & 0.516 & Satisfaction & 0.765 & 0.615 & 0.378 \\
\hline Trust & 0.676 & Satisfaction & 0.765 & 0.642 & 0.412 \\
\hline
\end{tabular}

As can be seen in the preceding table, discriminant validity has been achieved for the antecedent relational measurement model. At this point, confidence in the antecedent measurement model is obtained so moving on to assessment of the dark side measurement model is now appropriate.

\section{Dark Side Assessment (Main Study)}

\section{Main Study Reliability}

As with all the other constructs evaluated to this point, the mediating dark side constructs were evaluated by calculating the chronbach's alpha score as well as the composite reliability score and seeing how these scores compare to the established thresholds pertaining to these scores. The initial reliability scores for the dark side constructs are promising with the exception of complacency which at 0.678 was not able to exceed the 0.70 threshold. This promoted a re-evaluation of the complacency construct. It should be noted that this construct had two additional items added after the pre-test evaluation. A look at the standardized loadings for each item of the complacency 
scale revealed the two additional items were loading quite poorly. Another reliability analysis, run with the four items held over from the pre-test analysis was conducted. The results showed that these two items were indeed hurting the reliability of this scale as the new, four item scale, showed a chronbach's alpha of .831 and a composite reliability score of .832. The results of the reliability analysis are shown below in table 12 .

Table 12 Reliability of DarkSide Constructs

\begin{tabular}{|lrrr|}
\hline \multicolumn{1}{|c}{ Construct } & $\begin{array}{c}\text { Chronbach's } \\
\text { Alpha }\end{array}$ & $\begin{array}{c}\text { Composite } \\
\text { Reliability }\end{array}$ & $\begin{array}{c}\text { Number of } \\
\text { Items }\end{array}$ \\
\hline Relational Myopia & 0.793 & 0.852 & 6 \\
Complacency & 0.831 & 0.832 & 4 \\
Vulnerability & 0.908 & 0.909 & 6 \\
Suspicion & 0.935 & 0.936 & 7 \\
\hline
\end{tabular}

\section{Main Study Validity}

The results of the revised reliability analysis provide confidence that the dark side scales are reliable enough to move forward to the validity analysis of these same dark side constructs. The next step in the main study analysis is the assessment of both convergent and divergent validity for the dark side constructs. This is accomplished by first evaluating the single factor structure via single factor confirmatory analyses. The results of the initial single factor confirmatory factor analyses are shown in table 13 below.

Table 13 Fit Indicies of Dark Side Constructs for Single Factor CFAs

\begin{tabular}{|c|c|c|c|c|c|c|}
\hline Construct & Chi-Square & $\begin{array}{c}\text { Pr }>\text { Chi- } \\
\text { Square }\end{array}$ & $\begin{array}{c}\text { Root Mean } \\
\text { Square } \\
\text { Residual } \\
\text { (RMR) }\end{array}$ & $\begin{array}{l}\text { RMSEA } \\
\text { Estimate }\end{array}$ & $\begin{array}{c}\text { Bentler's } \\
\text { Comparativ } \\
\text { e Fit Index }\end{array}$ & $\begin{array}{c}\text { Bentler \& } \\
\text { Bonett's } \\
\text { (1980) Non- } \\
\text { normed Index }\end{array}$ \\
\hline Relational Myopia & 117.565 & $<.0001$ & 0.018 & 0.092 & 0.9929 & 0.8934 \\
\hline Complacency & 155.838 & $<.0001$ & 0.016 & 0.122 & 0.9903 & 0.9418 \\
\hline Vulnerability & 526.214 & $<.0001$ & 0.017 & 0.135 & 0.9954 & 0.9317 \\
\hline Suspicion & 58.431 & $<.0001$ & 0.010 & 0.080 & 0.9908 & 0.9724 \\
\hline
\end{tabular}


The results of the single factor CFA's are, for the most part, promising. However, the RMSEA estimates are slightly out of convention for both complacency and vulnerability. However, based on the strength of the other fit indices, and the exploratory nature of this research, the decision is made to relax, slightly, the fit index criterion for the above indices. This relaxation of the fit indices should be interpreted as a slight relaxation in that if an index is only slightly above or below accepted thresholds, it will not hinder the progress of this research project. It should not be interpreted as all of the indices being given a wider birth regarding their acceptability.

The chi-square statistic for the initial dark side CFA was significant at 10643.5425 (p > 0.0001) with an RMR of 0.0542, a RMSEA of 0.0778 a CFI of 0.9201 and a NNFI of 0.8832. These fit indices represent marginal fit at best given the low NNFI. However the other fit indices are encouraging and the argument could be made to proceed with the analysis with the dark side portion of the structural model being left as is. However, an examination of the standardized loadings of each item show that not all items are loading adequately and, if dropped, might help bolster the strength of the dark side model as well as provide dark side scales that will account for a greater share of the variance extracted. It is with this logic that another dark side CFA analysis was conducted. The second analysis was done without the weaker items believed to be hurting the overall dark side measurement model fit. Relationship Myopia dropped its fourth and fifth item while vulnerability dropped only its fifth item and suspicion dropped only its first item. This analysis produced a chi-square statistic of $6814.8917(p>0.0001)$ while the RMR and RMSEA are 0.062 and 0.075 respectively. The CFI and NNFI were both improved by dropping these weaker items. The CFI is now 0.938 and the NNFI is 0.917 . On the 
strength of these new findings, the decision is made to proceed with the analysis with the four complacency items, four relational myopia items, five vulnerability items and six suspicion items. Before the analysis can continue however, a revised assessment of the reliability and CFA statistics for the new, slimmer scales should take place. These revised reliability and single factor CFA results are shown in the table below.

Table 14 Revised Dark Side Reliability \& CFA Fit Indices

\begin{tabular}{lcccc}
\hline Indicies & Complacency & Relational Myopia & Vulnerability & Suspicion \\
\hline Number of Items & 4 & 4 & 5 & 6 \\
Chronbach's Alpha & 0.796 & 0.760 & 0.883 & 0.921 \\
Composite Reliability & 0.802 & 0.764 & 0.886 & 0.929 \\
Chi -Square Statistic & 167.150 & 195.680 & 38.999 & 44.134 \\
RMR & 0.020 & 0.024 & 0.010 & 0.006 \\
RMSEA & 0.129 & 0.030 & 0.062 & 0.046 \\
CFI & 0.988 & 0.990 & 0.999 & 0.999 \\
NNFI & 0.9262 & 0.9794 & 0.9860 & 0.9929 \\
\hline
\end{tabular}

All of the revised single factor dark side constructs show fit indices well within the accepted thresholds, less the chi-square statistic. Based on the larger dark side CFA and the strength of these revised single factor CFA's the decision is made to proceed to the assessment of discriminant validity. Discriminant validity is again assessed by using the AVE method of discriminant validity. The results of this analysis are shown in table 24 on the following page of this dissertation.

Table 15 Dark Side Discriminant Validity Assessment

\begin{tabular}{|c|c|c|c|c|c|}
\hline \multicolumn{3}{|c|}{ Construct (a) } & \multirow{2}{*}{$\begin{array}{c}\text { Construct } \\
\text { (b) AVE }\end{array}$} & \multirow{2}{*}{$\begin{array}{c}\text { Correlation } \\
\text { estimate }\end{array}$} & \multirow{2}{*}{$\begin{array}{c}\text { Squared } \\
\text { Correlation }\end{array}$} \\
\hline Construct (a) & AVE & Construct (b) & & & \\
\hline Complacency & 0.504 & Relational Myopia & 0.587 & 0.079 & 0.156 \\
\hline Complacency & 0.504 & Vulnerability & 0.609 & -0.342 & 0.346 \\
\hline Complacency & 0.504 & Suspicion & 0.687 & -0.364 & 0.103 \\
\hline Relational Myopia & 0.587 & Vulnerability & 0.609 & 0.015 & 0.017 \\
\hline Relational Myopia & 0.587 & Suspicion & 0.687 & -0.039 & 0.053 \\
\hline Vulnerability & 0.609 & Suspicion & 0.687 & 0.552 & 0.366 \\
\hline
\end{tabular}


The results of the assessment of discriminant validity are encouraging as they show that not only do all of the dark side constructs diverge they all also account for more than $50 \%$ of the variance extracted. This analysis provides enough evidence of the strength of the dark side measurement mode. The following analysis evaluated the reliability of the relationship strength construct

\section{Relationship Strength Assessment (Main Study)}

Main Study Reliability

The reliability of this construct proved adequate at 0.776 for the chronbach's alpha and .7948 for the composite reliability score. These figures are enough to move the analysis to the validity portion of the assessment.

\section{Main Study Validity}

The single factor CFA also proved good as the chi-square statistic is significant at $87.284(p>0.0001)$ the RMR is 0.038 , the RMSEA is 0.078 , the CFI is 0.9996 and the NNFI is 0.9796 . These fit indices provide enough confidence in the relationship strength items to move forward to the assessment of the performance construct.

\section{Performance Assessment (Main Study)}

\section{Main Study Reliability}

The reliability of performance is at 0.917 for the Chronbach's alpha and 0.919 for the composite reliability score. These figures, as with the reliability figures for performance in the pre-test, are very strong, providing confidence in the measure and the ability to move the assessment to the validity portion of the main study performance assessment. 


\section{Main Study Validity}

The single factor CFA proved good as the chi-square statistic is significant at 99.123 ( $p>0.0001$ ) the RMR is 0.015 , the RMSEA is 0.043 , the CFI is 0.995 and the NNFI is 0.948. Since time is a single item constructs, it is again, not subjected to these assessments of reliability and validity. At this point the analysis will move forward to the assessment of the structural model.

\section{Structural Model Assessment}

Hypothesis 1-17 propose relationships among antecedent relational constructs and mediating dark side constructs that are moderated by time. Moderation in this SEM context was tested using the method proposed by Little, Bovaird and Widman (2006). Little, Bovaird and Widman suggest orthogonalizing powered and product terms for use in moderation testing in the SEM context. Orthogonalizing or residual centering is accomplished by first creating a product term from the antecedent construct and the proposed moderating construct. For this dissertation, this means multiplying the items for each antecedent relational construct with the single item time variable. For example, this dissertation has three shared values indicators and one time indicator, measured in years. Multiplying the single item time variable and the three shared values items produces three product terms. These product terms, are then regressed onto the firstorder effect indicators for both shared values and time. For instance, if the first shared values indicator (SV1) is multiplied by the only time indicator (T) the resulting product term is labeled SV1T. The regression equation is as follows:

$$
\mathrm{SV} 1 \mathrm{~T}=\mathrm{b}_{\mathrm{o}}+\mathrm{b}_{1} \mathrm{SV} 1+\mathrm{b}_{2} \mathrm{SV} 2+\mathrm{b}_{3} \mathrm{SV} 3+\mathrm{b}_{4} \mathrm{~T}
$$


The residuals for this regression equation then become indicators for the moderating variable in the structural equation model. This process is then repeated for each of the remaining two shared values * time product terms. The residuals for the three product terms are the three indicators for the newly created shared values/time latent construct. The remaining regression equations used to derive these indicators are below:

$$
\begin{aligned}
& \text { SV2T }=b_{o}+b_{1} S V 1+b_{2} S V 2+b_{3} S V 3+b_{4} T \\
& S V 3 T=b_{o}+b_{1} S V 1+b_{2} S V 2+b_{3} S V 3+b_{4} T
\end{aligned}
$$

This new latent construct represents the moderating effect time has on the relationships between shared values and the dark side constructs. This orthogonalizing or residual centering procedure is repeated for each of the antecedent relational constructs that are hypothesized to have a positive relationship with the four dark side constructs over time. After all of the residuals have been calculated they are then entered into the larger structural equation model which was designed to analyze the relationships among relationship strength and perceived measures of performance, the dark side constructs and relationship strength as well as the time moderated relationships among the antecedent relational constructs and the four dark side constructs. Although this structural model was run all at once, the results are presented below in three separate sections in an effort to present results that are clearer and more easily understood. The first of the three sections, presented in table 16 below are the results from the portion of the structural model concerned with the time moderated relationships between the antecedent relational constructs and the dark side constructs followed by a discussion interpreting these results. 
Table 16 Antecedent-Dark Side Relationships Moderated by Time

Independent Antecedent Relational Constructs

\begin{tabular}{|c|c|c|c|c|}
\hline $\begin{array}{c}\text { Dependent Dark } \\
\text { Side Construct }\end{array}$ & Shared Values & Commitment & Trust & Satisfaction \\
\hline \multicolumn{5}{|l|}{ Relational } \\
\hline \multicolumn{5}{|l|}{ Myopia } \\
\hline Hypothesis & $\mathrm{H}_{1} * * *$ & $\mathrm{H}_{2} * * *$ & $\mathrm{H}_{6} * * *$ & $\mathrm{H}_{10} * * *$ \\
\hline Std Loading & 1.406 & 1.127 & 0.424 & 0.141 \\
\hline UnStd Loading & 2.103 & 0.889 & 0.741 & 0.390 \\
\hline Std Error & 0.1669 & 0.180 & 0.180 & 0.148 \\
\hline $\mathrm{t}$ value & $11.02 * *$ & $4.952 * *$ & $4.108 * *$ & $2.638 * *$ \\
\hline \multicolumn{5}{|l|}{ Complacency } \\
\hline Hypothesis & & $\mathrm{H}_{3} * * *$ & $\mathrm{H}_{7} * * *$ & $\mathrm{H}_{11} * * *$ \\
\hline Std Loading & & 15.163 & 5.627 & 1.934 \\
\hline UnStd Loading & Not & 2.650 & 2.158 & 1.172 \\
\hline Std Error & Hypotheized & 0.094 & 0.320 & 0.368 \\
\hline $\mathrm{t}$ value & & $28.341 * *$ & $6.738 * *$ & $3.1874 * *$ \\
\hline \multicolumn{5}{|l|}{ Vulnerability } \\
\hline Hypothesis & & $\mathrm{H}_{4}$ & $\mathrm{H}_{8}$ & $\mathrm{H}_{12}$ \\
\hline Std Loading & & -4.883 & -1.789 & -0.617 \\
\hline UnStd Loading & Not & -2.392 & -1.936 & -1.060 \\
\hline Std Error & Hypotheized & 0.131 & 0.334 & 0.314 \\
\hline $\mathrm{t}$ value & & -18.2990 & -5.804 & -3.3816 \\
\hline \multicolumn{5}{|l|}{ Suspicion } \\
\hline Hypothesis & & $\mathrm{H}_{5} * * *$ & $\mathrm{H}_{9} * * *$ & $\mathrm{H}_{13} * * *$ \\
\hline Std Loading & & 2.517 & 1.648 & 1.448 \\
\hline UnStd Loading & Not & 2.400 & 1.924 & 1.047 \\
\hline Std Error & Hypotheized & 0.138 & 0.332 & 0.313 \\
\hline $\mathrm{t}$ value & & $17.354 * *$ & $5.793 * *$ & $3.350 * *$ \\
\hline
\end{tabular}




\section{Shared Values and Relational Myopia}

Hypothesis one proposes a time moderated positive relationship between shared values and relational myopia. The results of this dissertation support this hypothesis, providing evidence to support the notion that over time, B2B partners who have similar values may become relationally myopic. More specifically, these data suggest that firms, as time passes, may develop a form of "group think" that permeates throughout the relationship. Relational myopia may manifest as a firm's inability or unwillingness to continually monitor their environment objectively and relying on behaviors that support the status quo. In other words, firms may become so rooted in the process and conventions that govern their B2B relationships that they lose the ability to adapt or change their relationships as the environment dictates.

The consequences of relational myopia may manifest in greater opportunity costs as firms fail to take advantage of better B2B relationship opportunities that afford such things as greater efficiency and market opportunity. Relationally myopic firms fall into what can be described as a relational rut and although effort is still expended toward relationship maintenance relational myopia keeps firms from critically evaluating relational processes and supports the acceptance of the status quo. Consequently, the relationally myopic firm does not recognize opportunities for such things as streamlined processes, better relational partners or other market opportunities.

\section{Commitment and the Dark Side}

$\mathrm{H}_{2}$ suggests a time moderated relationship between commitment and relational myopia. This hypothesis was supported commitment showed a significant, timemoderated relationship with relational myopia. The scale used to measure commitment 
incorporated items to capture sentiments of both affective and normative commitment. The significant relationship between commitment and relational myopia then suggests that both normative and affective commitment positively influence the onset of relational myopia over time.

The relationship between affective commitment and relational myopia is most probably the result of the good feelings B2B partners have for one another. The affectively committed firms won't be looking for ways to improve on something that they feel is already doing well. If affectively committed firms in a B2B relationship stop critically evaluating their relationships and their processes because they don't want to betray the good feelings they have about the relationship, then the argument is that over time, as B2B partners feel better about their relationship, the less critical of it they become.

Normatively committed firms are committed to their B2B relationships more out of a sense of duty than from positive affect as is the case with affectively committed firms. If a firm is doing something out of a sense of obligation they may lack the incentive to stay abreast on the details that govern relationship dynamics.

Normatively committed firms may lack the ability, desire or incentive to take a more active role in the governing of the B2B relationship. It makes sense that in these normatively committed relationships the normatively committed firm will simply allow their relationship partner to do most of the work regarding how the relationship will be run and the normatively committed firm will simply adopt this vision as their own. This shared vision of the relationship is of course narrower in scope than if both firms brought 
their different and unique experiences together and is an example of how normative commitment can, over time, lead to the onset of relational myopia.

$\mathrm{H}_{3}$ shows that there is indeed a time moderated relationship between commitment and complacency. This suggests that firms who are committed to their B2B partners will, over time, become more complacent toward the relationship itself. The onset of complacency suggests a sort of comfort which may lull the affectively committed firm into the perpetual acceptance of the status quo. This may happen as firms who feel good about the relationship won't want to do things to upset what is providing such positive feelings about the relationship. Firm managers may believe the relationship is performing well or in some other way, make firm mangers feel good and have confidence in how the relationship is set up and being run. Though this may not appear like a bad thing, problems may emerge as the environment changes. For example, a committed firm may have developed such an attachment to their relational partner, perhaps from stellar performance at the beginning of the relationship, that over time, the firm begins to assume these results are given and therefore does not recognize the need to take action when something happens. In this situation it is not unrealistic to think that the good feelings one firm has for another has led them to believe that their partners are not only superior but will always be superior and therefore, have become complacent toward the governing and monitoring of their B2B relationship.

As discussed in chapter two of this dissertation researchers in the B2B literatures have conceptualized commitment as a relational construct that actually encompasses feelings of vulnerability (e.g. Lacey 2007; Morgan and Hunt 1994; Wing and Sohal 2002). As firms become more committed they expose themselves to their relational partner's which 
implies a sort of relational risk that that can only be described as vulnerability. The results of this dissertation do not support this hypothesis (H4) for committed firms. This suggests that as firms become more committed they fail to recognize their vulnerable position within the B2B relationship. This is understandable given the good feelings that characterize the committed relationship. It might be that firms that recognize their vulnerability are not going to be as committed to their B2B partners because of the anxiety and potential tension that feelings of vulnerability may produce. In other words, it might be that firms that feel vulnerable toward their B2B relationship partners are incapable of feeling high levels of commitment because of the negative feelings the recognition of vulnerability provoke.

$\mathrm{H}_{5}$ proposes a time moderated relationship between suspicion and commitment. The results of this dissertation support this hypothesis. Commitment does show a significant and positive relationship with suspicion over time. It seems as if, over time, relational partners who are committed to their B2B partners will not start to feel vulnerable but do become suspicious of their B2B partners. This may have to do with events or issues that develop in the B2B relationship that, although resolved, may leave the B2B partner wondering about what their exchange partner is actually doing or if they are capable of doing what is expected of them. For example, a committed firm may have to deal with late shipments from their B2B partner. If the buying firm in the dyad is large enough and has enough suppliers one supplier may not be enough to provoke feelings of vulnerability. However, this situation does not excuse the late shipment and thus provokes feelings of suspicion. 
The link between commitment and suspicion may also stem from one relational partner allowing the relationship to develop to a point where their partner takes the goodwill and good nature of the relationship for granted or abuses the good feelings by believing they are no longer responsible for meeting contractual obligations. If a member of the relationship dyad begins to believe the positive affect or good feelings within the relationship is a cue for lax relationship norms then they might start to believe that such things as ridged deadlines, formal rules and regulations are really flexible guidelines to be used for mere guidance but not strict adherence. If this behavior manifest then it makes sense that the other side of the dyad might become suspicious of the relationship partner.

\section{Trust and the Dark Side}

The relationship between trust and relational myopia is proposed in $\mathrm{H}_{6}$ of this dissertation. The results for this hypothesis are supported in this dissertation as the relationship between trust and relational myopia was shown to have a significant and positive relationship over time.

Trust, in this B2B context is concerned with the trust one relational partner has in their partner's propensity to act in the best interest of their partner and the relationship as a whole as well as their ability to complete contractually assigned tasks. The significant, time moderated relationship between trust and relational myopia is intuitive as it suggests that over time, if one relational partner believes that their partner is continually acting in the best interest of the relationship they will continue to do so until given a reason not to. A relational partner might think to themselves, "They are doing things well and the results are good, therefore, I'll let them keep doing things the way they do them now". Though this attitude may seem appropriate it really implies the onset of relational myopia 
as the relational partners sort of assume a similar, narrow vision of the relationship. In contrast, an attitude that says "Our relationship partner is doing things well but I wonder how we can do things better" implies the exact opposite of relational myopia but this attitude may be more difficult to adapt and apply in the B2B context. It is probably much easier to just let things function as they always have after people have become accustomed to routines and processes. Also, constantly questioning what seems to be a good system may send the message that trust is an issue and by suggesting improvements a firm in a B2B relationship runs the risk of offending their exchange partner. In this context, it makes sense that adopting a myopic view of the firm may be the path of least resistance as well as a conflict avoidance strategy.

The results for $\mathrm{H}_{7}$ are supported as the results of this dissertation show a positive and significant relationship between trust and complacency over time. This positive relationship suggests that as time passes firms who believe in their relational partner's abilities, as well as their good intentions, are more likely to allow for the onset of complacency. This may seem intuitive firms who believe in their relational partner's ability to execute assigned tasks as well as their good intentions may lose the incentive to remain vigilant toward the monitoring of the $\mathrm{B} 2 \mathrm{~B}$ relationship. The focal firm may begin to believe their relational partner(s) will carry most of the load regarding relationship processes and performance. In other words, as time passes and the capable relationship partner continues to perform, it is possible that the other member of the B2B relationship will simply sit back and allow their relationship partner to do most of the work. A "stay out of the way and let them do it" attitude may manifest which is really indicative of complacency. 
$\mathrm{H}_{8}$ was not supported as the relationship between vulnerability and trust showed a significant but negative relationship over time. These results are surprising given the implied relationship between trust and the willingness to be vulnerable. Having said that however, the author of this dissertation, while distributing the surveys and conducting the qualitative interviews, found that respondents consistently failed to acknowledge any sort of dependence or interdependence with their exchange partners. Sentiments such as "I don't need anyone" or "You can always go with someone else" kept reemerging. This is important in recognizing the potential explanation for why there failed to be a positive relationship between trust and vulnerability. B2B relationship managers who fail to acknowledge dependence may not see the behaviors of their B2B partners as something that can significantly influence their firm. The fact that they recognize they have other relational options and don't perceive switching costs or other obstacles getting in the way of a simple relational switch may mean that they won't allow themselves to become exposed to the point of feeling vulnerable. Another potential explanation is that any B2B relationship of any duration demands exposures but that does not mean the B2B managers recognize or acknowledge these exposures and subsequent vulnerabilities. Whether it be sense making or an objective evaluation of their position in the B2B relationship, it became apparent during the data collection phase of this dissertation that B2B managers do not recognize or accept their own vulnerabilities as they pertain to their B2B relationships, regardless of the amount of trust they may or may not have had in their B2B relationship partners.

The proposed relationship between suspicion and trust is captured in $\mathrm{H}_{9}$. This hypothesis was supported as there is a positive and significant relationship between trust 
and suspicion that appears to manifest over time. Though a relational partner may not feel vulnerable regarding their position in a B2B relationship, they may still feel suspicious of their relational partner's behaviors and actions. It is intuitive that over time B2B partners will be forced to act in ways that are outside their norms. Relational partners may not know why or what is causing these behavioral changes and though they might be benign and not motivated through deleterious pursuits, the fact that they are different may be enough to provoke suspicion.

\section{Satisfaction and the Dark Side}

$\mathrm{H}_{10}-\mathrm{H}_{13}$ hypothesizes positive, time moderated relationships between satisfaction and the four dark side constructs. Three of the four relationships showed significant positive relationships that manifest over time. The positive relationships between satisfaction and relational myopia and complacency may seem fairly intuitive. Satisfaction does not typically bring with it motivation for change and this lack of motivation is believed to really be the catalyst for the onset of both relational myopia and complacency. The results of this dissertation support this statement as the relationships between these two dark side constructs and satisfaction were significant.

The relationship between suspicion and satisfaction is a little less intuitive as it is a positive relationship over time. If a firm is satisfied with their B2B relationship they may lose incentive to stay engaged in the governing of the relationship itself. As this speaks to the onset of complacency, the lack of engagement may have side effects as well. If a firm relaxes how involved it is with its B2B relationship, over time, the realization may emerge that they have let their guard down as well as relinquished control of the relationship. This realization may then lead to feelings of suspicion toward the focal 
firm's relationship partners. The relationship partners may not be guilty of any wrong doing, it is simply the partnering firm's realization that they have engaged in a hands off or mostly hands off approach toward the governance of the B2B relationship that leaves them feeling suspicious of their B2B partner's behaviors.

The relationship between satisfaction and vulnerability showed significance but in the opposite of the direction hypothesized. The onset of vulnerability implies dissatisfaction with the relationship. In keeping with this logic it does not make sense that firms who are satisfied with their relationship will also feel vulnerable at the same time. Dissatisfaction may have to manifest before firms will admit to feeling vulnerable in their B2B relationships. This criterion does not need to apply to suspicion as firms may still be satisfied with their relationship only it's tempered by feelings of suspicion. It would all depend on the specific situation but it is not unreasonable to think that a firm can be satisfied with their B2B relationship but at the same time suspicious of it. However, being satisfied with the B2B relationship and allowing for the onset of vulnerability may be a little more difficult for firms involved in a B2B relationship to reconcile.

Since all of the proposed moderated relationships showed significance in either the positive or negative direction, there is no need to consider any main effect relationships. The focus now turns to the relationships between the dark side constructs and relationship strength. Below, in table 17 are the results from the structural analysis that pertain directly to this portion of the structural model. 
Table 17 Relationships Between Relationship Strength and the Dark Side Constructs

\begin{tabular}{llcccc}
\hline Dependent Construct & Complacency & $\begin{array}{c}\text { Relational } \\
\text { Myopia }\end{array}$ & Vulnerability & Suspicion \\
\hline Relationship Strength & & & & \\
& Hypothesis & $\mathrm{H}_{18} * * *$ & $\mathrm{H}_{19}$ & $\mathrm{H}_{20}$ & $\mathrm{H}_{21}$ \\
& Std Loading & 0.373 & -0.413 & 1.350 & -1.110 \\
& UnStd Loadin & 2.459 & -0.118 & 0.374 & -0.432 \\
& Std Error & 0.111 & 0.080 & 0.573 & 0.343 \\
& t value & $22.143^{* *}$ & -1.478 & 0.6515 & -1.263 \\
\hline
\end{tabular}

**p $<0.01$

****provides support for hypothesis

The Dark Side and Relationship Strength

$\mathrm{H}_{18}-\mathrm{H}_{21}$ propose relationships between the dark side and relationship strength. $\mathrm{H}_{18}$ and $\mathrm{H}_{19}$ suggest positive relationships between relational myopia and complacency while $\mathrm{H}_{20}$ and $\mathrm{H}_{21}$ propose negative relationships between relationship strength and vulnerability and relationship strength and suspicion respectively. As expected the relationship between relational myopia and relationship strength showed significance in the positive direction.

What is surprising is that the other three dark side constructs failed to show a significant relationship between themselves and relationship strength. This may be because these other dark side constructs don't influence a B2B manager's perception of the strength of their relationship in quite the same way as relational myopia or this specific research setting was not conducive for teasing out any influence these dark side constructs had on the B2B manager's perceptions regarding their B2B relationship. Another possibility is the relationship strength measure used for this dissertation. The scale used for this dissertation was not consistent with typical relationship strength measures due to relationship strength often being a second order construct comprised of lower order constructs such as trust and commitment. Since these relational constructs 
were used in the antecedent portion of the structural model a combined trust and commitment scale could not then be put in the outcome portion of the structural model, thus the need for the less cited relationship strength scales used in this dissertation.

However, though these combined trust and commitment scales could not be used in the structural model, a combined scale, comprised of trust and commitment, was constructed and regressed against the dark side constructs. The results of the regression analysis are in table 18 below.

Table 18. Dark Side-Relationship Strength Regression

\begin{tabular}{lccc}
\hline & Beta Coefficient & T-value & Significance \\
\hline Relational Myopia & 0.121 & 8.967 & 0.000 \\
Complacency & 0.303 & 2.981 & 0.000 \\
Vulnerability & -0.039 & -1.042 & 0.298 \\
Suspicion & -0.294 & -7.814 & 0.000 \\
\hline
\end{tabular}

The results of the regression analysis are not surprising. The results support the relationship between complacency and relational myopia. This might mean that firms who have allowed for the onset of this dark side construct may be confusing relationship strength with relational myopia and complacency. In other words, it may be that when firms have become comfortable in their relationship, as they have grown to believe relational processes are at a point that is beyond improvement, they subsequently rest on the status quo. Firms may believe they are at a point where their relationship is at a point of absolute strength. In other words, as firms become comfortable they believe this comfort is actually a sign of strength which may then feed deeper levels relational myopia and complacency.

The results support a negative relationship between suspicion and relationship strength and although not significant, the relationship between vulnerability and relationship strength is trending negative. If firms have realized the onset of these dark side 
symptoms they undoubtly will be perceived as damaging to their B2B relationships. Vulnerability and suspicion are not comfortable feelings and not something that is typically accepted in any relationship. Vulnerability and suspicion can be seen as things that work against relationship strength as any firm that has recognized these symptoms are feeling them because their relationship is not as strong as they previously believed. The idea that a firm feels vulnerable in their B2B relationship may mean that they feel their relationship is not that strong and potentially ending. If the firm is the more dependent firm then they maybe troubled by the potential for relationship ending. If firms are suspicious it is because firms believe their B2B partners are working or behaving in ways that are contrary to accepted and perhaps expected relational norms. Adherence to these norms undoubtedly contributes to relationship strength so it makes sense that behaviors that are contrary to these norms may provoke suspicion. It also explains the negative relationship between suspicion and relationship strength as the two almost assuredly manifest according to a shared inverse relationship.

\section{Relationship Strength and Performance}

The last hypotheses, $\mathrm{H}_{22}$ suggest a positive relationship between relationship strength and performance. The results indicate that this hypothesis is supported. The standardized loading is 0.186 and the unstandardized loading is .4543 . The standard error is 0.085 and the $t$ value is 5.305 . The idea of there being a positive relationship between relationship strength and performance is not something new (e.g. Crosby, Evans and Cowles 1990; Kumar, Hibbard and Stern 1994; Kumar, Scheer and Steenkamp 1995) and again, not something that is conceptually difficult to accept. If a firm believes they are performing well they will also believe their relationships are performing well which 
logically implies strength in the B2B relationship. Likewise, a firm that believes their relationships are functioning well will transfer these beliefs regarding the relationship onto their overall firm level performance. It is possible for firms who believe their performance is poor to still indicate strong B2B relationships. These firms may attribute their poor performance to such things as the economy or issues within their own firm. However, it is more likely that in situations where performance depends on combined efforts the relationship must also function well in order for performance goals to be obtained. Firms do not typically enter into B2B relationships unless they need an exchange partner to obtain organizational goals it then follows that in most B2B relationships relational partners will first have to believe their B2B relationships are functioning well before they will believe their firm level performance is maximized.

To this point, the results pertaining to all of the areas of the structural model have been discussed except for the overall model itself. Below, in figure three is a representation of the entire structural model illustrating the significant and positive paths. 
Figure 3: Structural Model Illustrating Significant Path Coefficients

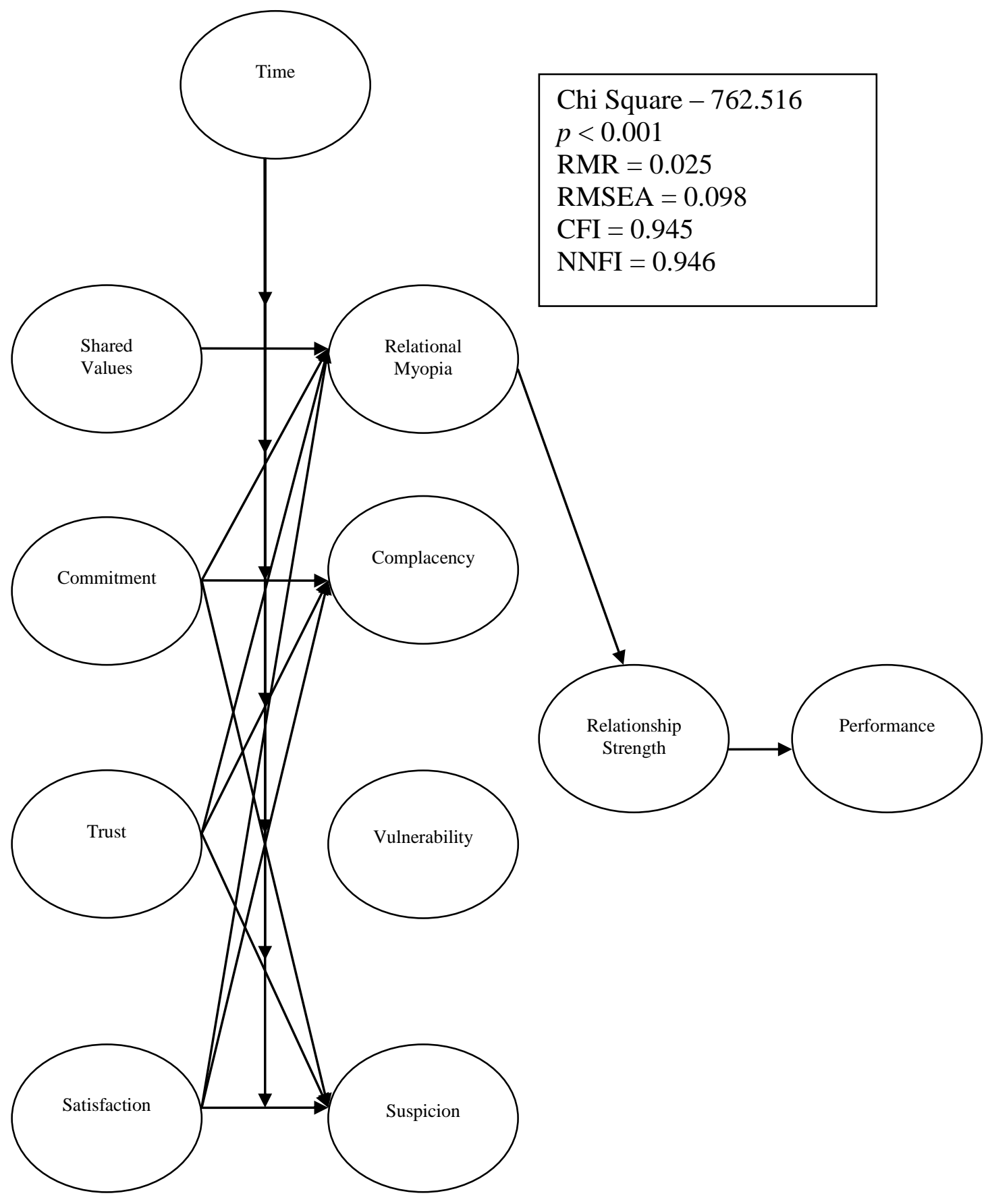


As can be seen from the fit indices, listed in figure three, on the proceeding page, the model shows reasonably good fit. The RMSEA is slightly higher than accepted thresholds but only slightly. The same is true of the CFI and NNFI. These two fit indices are slightly lower than the more strict thresholds prescribed by Hu and Bentler (1999) but are within the acceptable thresholds prescribed by Hair et al. (1998). Given the exploratory nature of this dissertation it is not unreasonable to relax the thresholds of acceptability for these fit indices slightly to account for the expected increased variances which commonly accompany the use of new and untested scales and the exploration of new constructs. Therefore, the above fit indices reveal what is by all measures a useful dark side model which, through the process of this dissertation, has contributed to and insightful knowledge regarding the dynamics and nuances of B2B relationships and the implementation of a RM strategy.

The non-significant results regarding the relationships between relationship strength pose opportunities for further supplemental analyses which may provide insight into why these relationships failed to yield significant results. A discriminant analysis was conducted with relationship strength as the dependent or grouping variable with the dark side constructs entered as the independent variables. The results were interesting and are listed in table 19 below.

Table 19 Discriminant Analysis for the Dark Side and Relationship Strength

\begin{tabular}{lcccc}
\hline & $\begin{array}{c}\text { Strong } \\
\text { Relationship } \\
\text { Mean }\end{array}$ & $\begin{array}{c}\text { Weak } \\
\text { Relationship } \\
\text { Mean }\end{array}$ & F-Test & Significance \\
\hline Relational Myopia & 4.440 & 4.150 & 1.865 & 0.173 \\
Complacency & 3.090 & 4.530 & 33.027 & 0.000 \\
Vulnerability & 3.200 & 4.350 & 16.461 & 0.000 \\
Suspicion & 3.340 & 5.030 & 38.463 & 0.000 \\
\hline
\end{tabular}


As can be seen in table 19 above, the only construct not to show significant differences between the strong versus weak relationship strength groups was relational myopia. Of course this is the one variable that showed a significant and positive relationship with relationship strength during the analysis of the structural model. The other three variables show significant differences between the strong and weak relationship strength groups. This means that the respondents who were reflecting upon what they view as a weak relationship were more likely to indicate the onset of complacency, vulnerability, and suspicion. This is consistent with the results of the structural model assessment. The belief is that the differing effect sizes across the strong and weak relationship strength groups may be enough to cancel out the actual effect the dark side sentiments have on the weaker relationships. More specifically, since the strong relationships are less likely to indicate the onset of the dark side compared to the weak relationships, it then makes sense that taken together, a significant dark side influence would not result during the assessment of the structural model. However, since the mean for relational myopia was sufficiently high for both the strong and weak relationship strength groups, it then makes sense that this effect showed a significant influence on relational myopia during the assessment of the structural model.

The final stage of the structural model assessment is to compare the hypothesized model to a series of competing models, which act as alternative explanations to the proposed model (Hair et al.1998). Comparing the proposed model to competing models provides insight into whether or not the proposed model is acceptable, regardless of overall fit, because no other similarly formulated model can achieve a better fit (Hair et al. 1998). Below is the first rival model that examines the relationships between the 
antecedent constructs and only two of the dark side constructs, relational myopia and complacency. These two are examined together because it can be argued that these two are the more relational of the dark side constructs. That is, these two constructs are believed to manifest in $\mathrm{B} 2 \mathrm{~B}$ relationships where the relationship, for the most part, has proceeded well. More specifically, the dark side is believed to be able to occur in relationships where the partners think everything is going as good as can be expected. The dark side doesn't necessarily need to be presented in deleterious actions conducted on the part of a B2B relational partner. The dark side may manifest where things go so well that B2B partners fail to recognize that these "good behaviors" are actually a manifestation of the dark side itself. That is, a "we like the way things are going so we are going to leave them as is" attitude develops. This attitude of course fails to account for things like changing regulations, technology developments or economic ebb and flows. This scenario develops a dark side model that is solely based on B2B partners believing that their relationship is the pillar of relationship strength and this belief, consequently, leading to a shortsighted and complacent view of the B2B relationship.

Also, relationship strength was also taken out of the model as a theoretical argument for the direct relationship between the dark side and performance can be made. That is, relationship strength might not be a mediating influence between the dark side and performance. This first rival model thus represents a theoretically derived, yet more parsimonious dark side model. 
Figure 4. Rival Model 1

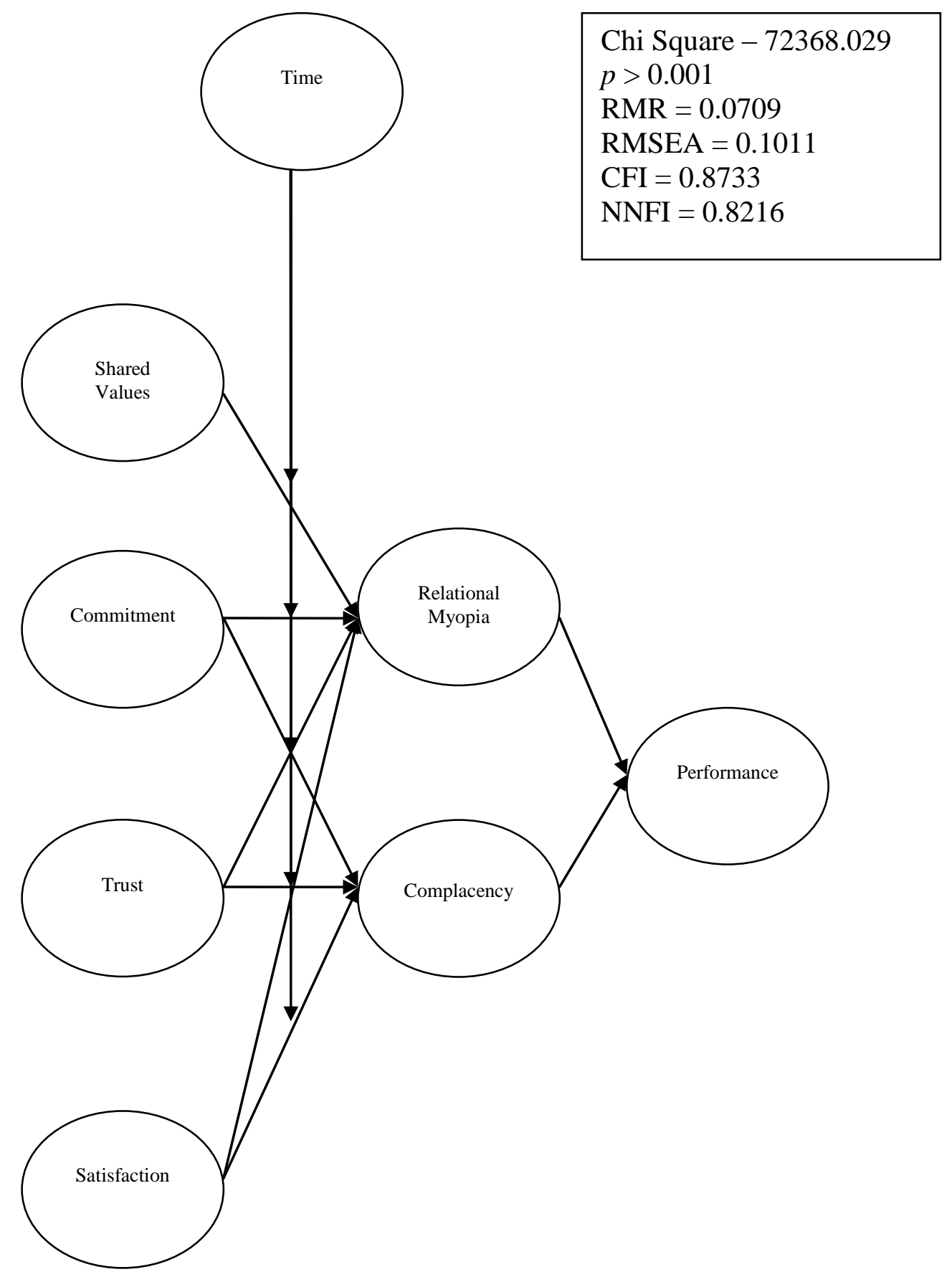


The above rival model does have a smaller though still very significant chi-square as well as a slightly better RMR estimate than the proposed model. However, the proposed model shows a better RMSEA, CFI and NNFI. Aside from the significant chi square the fit indices between the two models are also very close regardless of which is better for each model. At this point, it would appear that accepting the proposed model over the first rival model is acceptable due to the inability of the rival model to clearly establish itself as a clearly superior model when compared to the proposed model.

The second rival model is similar to the first with the exception of having vulnerability and suspicion as the two dark side constructs as opposed to relational myopia and complacency. These two constructs are conceptually similar in that they are both believed to manifest more in $\mathrm{B} 2 \mathrm{~B}$ relationships where events that have negatively influenced the relationship have occurred or in relationships where the relational sentiment between the B2B partners has been deteriorating for one reason or another. Also, the shared values construct is removed from this rival model as there are no hypothesized relationships between shard values and vulnerability and suspicion. The fit indices for this second rival model as well as a diagram illustrating this modified rival model are illustrated below in figure five. 
Figure 5. Rival Model 2

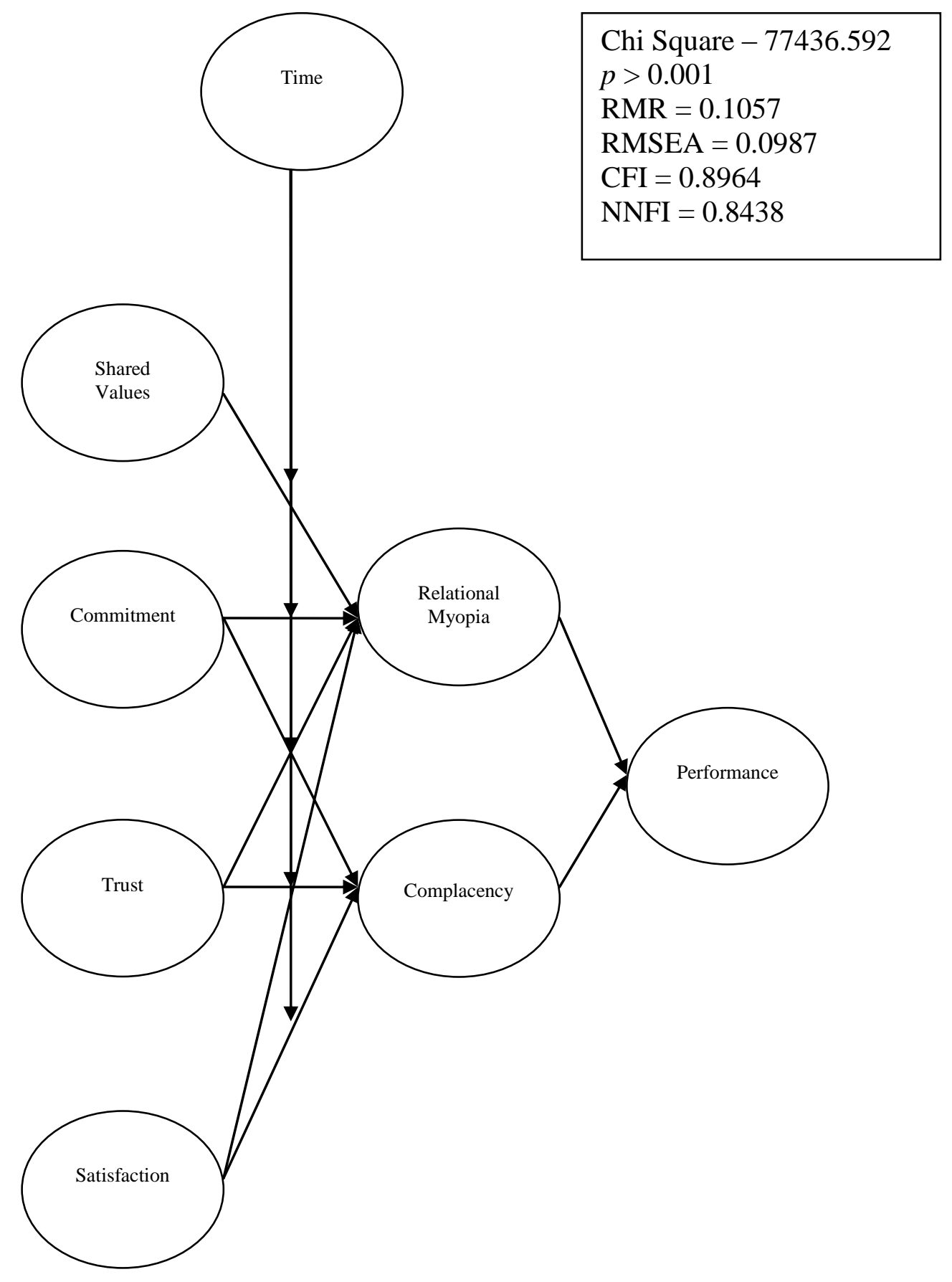


Rival model two looks to be a better model than rival model one. Like the proposed model, the chi square is significant but the RMR is also higher than both the proposed model and the first rival model. The RMSEA is comparable to the proposed model and slightly lower than that of rival model one. The real strength of the second rival model is the CFI and NNFI which are better than both the proposed and first rival model.

However, as with the first model, the second rival model fails to clearly distinguish itself from the other models discussed and again, acceptance of the proposed model is perfectly reasonable given its fit relative to the other two rival models.

The third and final rival model removes the moderating time variable that is in all of the other models. Figure six illustrates this modified structural model as well as listing the relevant fit indices. 
Figure 6: Rival Model

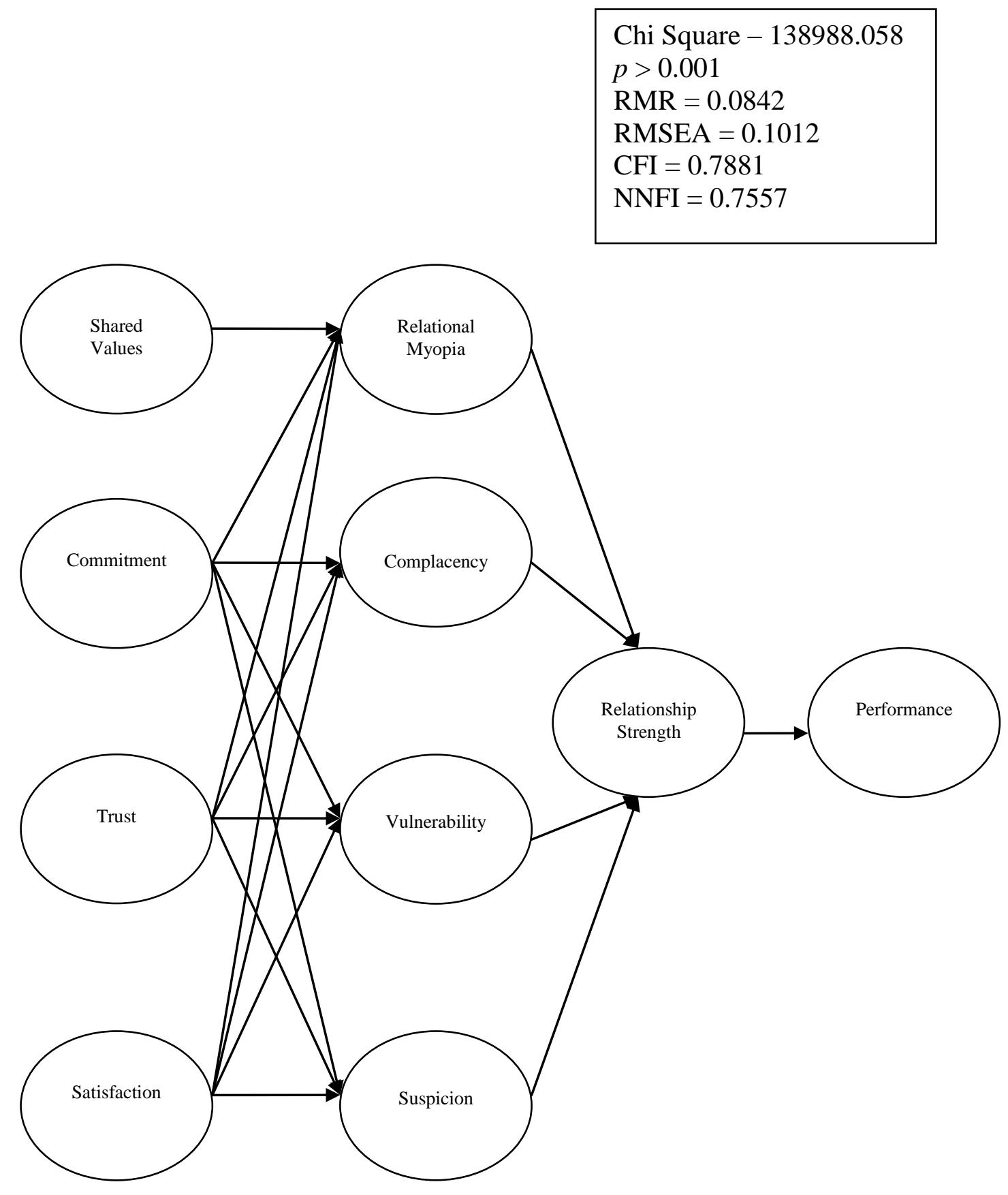


This final rival model looks to be the worst fitting model of all. None of the fit indices for this model are better than those of the proposed model which is very similar to this third rival model with the exception of the moderating variable of time. The results of the rival models compared to those of the proposed model suggest that the proposed model is acceptable, as none of the other rival models were able to clearly support itself as a superior model to the one that was proposed. The acceptance of the proposed model should be done with caution however as many of the fit indices failed to exceed their recommended thresholds. Future research should consider adding additional constructs, refining construct measures or reevaluating and perhaps re-specifying casual relationships within the structural model (Hair et al. 1998). 


\section{Chapter Five: Conclusion}

\section{Summary}

Though sparse, there is some B2B literature that recognizes that there is a dark side to relationship marketing (e.g. Grayson and Ambler 1999; Hibbard et al. 2001; Moorman, Zaltman, and Desphande 1992;). Given the plethora of studies that have investigated the various aspects of relationship marketing it is surprising that there has not been more work dedicated to investigating this dark side. This negligence has been recognized however. Palmatier (2008) in his recent monograph dedicated to the exposition of relationship marketing states "More effort is needed to understand how RM can negatively affect performance through inefficiencies, cognitive rigidity, and seller-side relationship effects (price erosion)" (p. 95). This dissertation represents an effort to contribute to this largely untouched and unknown area of relationship marketing. What makes this work important isn't solely that it offers new knowledge relevant to the marketing literatures (though that contribution shouldn't be underestimated), the impact value of the work presented in this dissertation stems from the contrarian stance taken against some of the most fundamental and entrenched conventions governing relationship marketing. Since researchers investigating the effects of relationship marketing have focused almost exclusively on relationship benefits and the positive effects relationship marketing has on the firm, the idea that closely-bonded B2B relationships may actually have negative effects seems to have received very little consideration and even less 
empirical investigation. Given the expanse of the relationship marketing literature and all the areas that have been influenced by this stream (e.g. Allen 1988; Bejou 1994; Scheer and Steenkamp 1995) identifying and examining this relational dark side is a task that we consider to be of immediate and considerable importance.

The belief in the importance of gaining this dark side insight motivated this dissertation. Through the support of several of the hypothesized relationships, this dissertation is able to empirically support the more global notion that relationship constructs such as shared values, trust, commitment, and satisfaction can have a direct influence on the onset of such dark side symptoms as relational myopia, complacency, vulnerability and suspicion. These results would be considered heretical within main stream RM literature as these relational constructs have typically been linked to positive outcomes for the firm (c.f. Palmatier, Dant, and Grewal 2008).

This dissertation should be seen as a first step toward developing a deeper understanding of RM that will not only provide insight into how engaging in B2B relationships can benefit the firm but also how engaging in these relationships can also be harmful. More specifically, this dissertation is a move to shift the focus of RM research away from the benefits of a RM strategy as these benefits are already well established within the RM literature (e.g. Morgan and Hunt 1994; Palmatier et al. 2006; Rao and Perry 2002) and toward the recognition of the dark side so that its causes and its effects can be more deeply understood. From this knowledge, appropriate coping and defense mechanisms can be developed so firms can both enjoy the benefits of a RM strategy as well as guard against the onset of its dark side. 


\section{Theoretical Contributions}

This dissertation contributes a theoretical perspective that integrates a sunset clause into the dominant theoretical perspectives currently guiding the majority of RM research. More specifically, the results of this dissertation found that several key RM constructs, generally accepted as having a positive influence on B2B relationships can, over time, lead to negative effects or what is described in this dissertation as dark side symptoms. This stands in direct contrast to the dominant theoretical perspectives currently guiding much of the current RM research. Specifically, theoretical perspectives, such as the commitment-trust perspective, dependence perspective, transaction cost perspective and relational norms perspective have all been applied within the RM literature as tools that offer theoretical explanations for how and why relational constructs positively influence B2B relationships. Though these perspectives have proven useful when examining the positive benefits and outcomes associated with RM, they have not yet accounted for the eventual manifestation of the dark side as it is described in this dissertation. This sunset clause provides the missing theoretical justification for the diminished returns and eventual onset of dark side symptoms associated with continued investment in a RM strategy.

To help clarify, consider the commitment-trust perspective, which suggests that it is the trust and commitment relationship partners feel for each other that are the ultimate drivers of relationship performance (Palmatier, Dant, and Grewal 2007). Since trust and commitment drive relationship performance, it would then stand to reason that the more resources firms invest in these relational constructs the greater the relational return. The 
relational norms perspective, (MacNeil 1980; Kaufmann and Dant 1992) explains that relational norms like solidarity and mutuality positively influence relational performance. Like the commitment trust perspective, the relational norms perspective implies that firms should continue to invest in the development of these relational norms. What is not provided in these perspectives is the recognition of decreased returns from greater and greater investments over time. In other words, continued investment in the development of relational sentiments does not produce greater returns in perpetuity. Simply put, there is a limit to how much these relational investments will return. After this limit is exceeded, continued investment may lead to these dark side symptoms.

This dissertation hypothesized and found partial support for the moderating influence time has on the relationships between shared values, commitment, trust, satisfaction, and the dark side constructs of relational myopia, complacency, vulnerability and suspicion. As a practical interpretation these results empirically support the presence of this limit and provide support for the notion that increased relational investment, over time, may begin to yield negative or deleterious effects.

The TCE perspective (Williamson 1975), also a dominant theoretical perspective guiding RM research, is similar to the perspectives discussed above in that it does not predict the time moderated relationships between relational constructs and dark side constructs. The TCE perspective recognizes the potential for opportunistic behavior. The belief that a partner is acting opportunistically may provoke feelings of vulnerability and or suspicion. These feelings are undesirable so firms will take action to somehow alleviate these symptoms. In order to do this it is likely that firms are going to need to dedicate time and resources toward this goal which ultimately will negatively influence 
relationship performance. Though this sounds consistent with the onset of the dark side, the TCE perspective does not link the onset of opportunism to the relational constructs studied in this dissertation. In other words, though the TCE perspective theoretically predicts impediments of relational performance, and is useful for predicting such occurrences, it does not link these impediments to continuous relational investments over time which is what the results of this dissertation suggests is happening.

This dissertation provides and tests a rich repertoire of constructs as they relate to the dark side symptoms and the moderating influence of time. Including as many relational constructs as possible into the sunset perspective will provide a greater understanding of how the positive linkages between B2B relationships and positive outcomes changes over time and starts yielding negative results.

The three theoretical perspectives discussed above are generally regarded as three of the more dominant perspectives that have guided much of the RM research for the better part of thirty years (Palmatier 2008). However, discussed throughout this dissertation is Cyert and March's (1963) behavioral theory of the firm which warrants further discussion here as it relates to the dark side. This perspective does seem to have a limited ability to offer an established theoretical framework capable of explaining the onset of some of the dark side constructs. Specifically, this theory explains, from an organizational learning perspective, that firms will learn from their past experience and work to provide an environment that promotes and re-enforces positive results. Of course, firms will try to control their environment but no firm, regardless of size, can exert that kind of control over the environmental landscape. Thus, firms often adopt a narrowed view of their firm as the environment changes but firm level managers, through their myopic view of the 
firm, fail to make the adjustments needed for the firm to function optimally. Applying this theoretical perspective to the $\mathrm{B} 2 \mathrm{~B}$ relationship is logical as organizational learning certainly is influenced by the past success and failure of organizational relationships. Thus, firms that have myopic views of their firms most certainly have myopic views of their B2B relationships and hence, the connection of the onset of the dark side to this organizational behavioral theory.

Though the perspective offered by Cyert and March (1963) provides some explanatory power and predictability regarding the onset of elements of the dark side, the sunset perspective being offered in this dissertation is believed to offer more as it includes a greater number of constructs and directly links the onset of the dark side to continued relational investments over time.

As Palmatier (2008) recognizes, most RM research has been focused on the benefits of the relationship. It makes sense that if researchers have been too narrowly focused on the benefits of RM then the theoretical perspectives used to guide their research will also be narrowly constructed and only account for the benefits and not the potential hazards of adopting a RM strategy. This narrowly focused view of RM research means that RM researchers have not given attention to the potential hazards of adopting an RM strategy despite the growing amount of evidence, published in the practitioner literature, that these hazards exist (e.g. Dowsett 2007; Merriden 1999; Shipley 1994).

This dissertation serves as the much needed first step toward the development of a broader and more complete theoretical perspective capable of explaining both the benefits and hazards associated with the adoption of a RM strategy. In other words, the results of this dissertation provide evidence that relational variables can and do lead to a 
dark side. These dark side or deleterious effects can manifest in several ways. For example, as discussed in chapter two of this dissertation, B2B partners may develop such a level of familiarity that they are no longer able to evaluate one another objectively (Moorman, Zaltman, and Desphande 1992), A "what have you done for me lately" attitude may develop (Gruen, Summers, and Acito 2000) or B2B firms may begin to think that their B2B partners are taking them for granted or otherwise abusing their relationship (Grayson and Ambler 1999; Baker 2006). Of course these potential problems represent only a small amount of the seemingly infinite number of potential issues that may develop as the result of continued relational investment over time.

The sunset clause perspective developed throughout this dissertation is a theoretical perspective that accounts for the relationships between the relational and dark side constructs. By attaching a sunset clause to the notion that relational constructs are positive influences on relationships allows for their benefits to wane and potentially disappear over time. More specifically, by accounting for the diminished benefits relational constructs have on relational performance over time, RM researchers are able to theoretically justify the initial positive influence of these relational constructs while also accounting for the development of the dark side symptoms. This sunset clause perspective provides RM researchers a deeper and clearer understanding of $\mathrm{B} 2 \mathrm{~B}$ relationships and the influence these relationships have on the firms who engage in them.

\section{Managerial Implications}

The results of this dissertation may be interpreted as a reminder that though B2B relationships often yield positive results for the firm engaged in the relationship (e.g. Cannon and Homburg 2001; Palmatier, Dant and Grewal 2007; Morgan and Hunt 1994), 
entering into them should be tempered with caution as these relationships do pose hazards for those not actively engaged in the monitoring of their B2B relationships. Palmatier (2008), draws from several previously offered definitions of relationship marketing to derive an integrated and consistent definition of RM, "Relationship marketing (RM) is the process of identifying, developing, maintaining, and terminating relational exchanges for the purpose of enhancing performance". Businesses enter into B2B relationships in an effort to reach organizational goals not obtainable on their own. However, though managers are encouraged to enter into B2B relationships when appropriate they are also encouraged to do so with the understanding that over time, the positive effects that the B2B relationship has provided may begin to wane or even provoke more serious issues and consequences. For example, as discussed in this dissertation, firms who become so entwined in their relationship may begin to, over time, drift into a relational myopia where everything runs on auto pilot. Though this may sound attractive to managers because it implies fewer resources toward relationship maintenance, it may prove costly as processes and systems become dated and inefficient.

Managers are reminded to stay vigilante regarding their relational processes. Though a certain amount of automation regarding systems and processes may be desirable, the attainment of this sought after automation should not lull firm managers into believing they are "where they need to be". The environment is very dynamic and ever changing, relational myopia may be disguised as increased efficiencies and process automation but as the environment changes, managers must take stock of their B2B relationships to make sure they are operating as efficiently and appropriately as possible relative to their business environment. 
Managers are encouraged to stay active and critical in the evaluation of their B2B relationships. It is easy to see how firms that reflect similar thoughts or otherwise share in the same values are attractive relational partners. Though this may make establishing a new relationship easier the results presented here suggest that this can also handicap the vision of those involved in the relationship. Specifically, firms may adopt too similar a view of the relationship which effectively prevents the emergence of diversified ideas and creative problem solving. It may be wise to remain cognizant of this possibility in an effort to prevent the onset of relational myopia.

In other words, the most obvious solutions to the relational problems may not be the best ones. If firm manages demand solutions from several sources or at least demand the evaluation of several potential solutions they can be sure they have, as thoroughly as possible, evaluated as many potential options from as many different perspectives as possible. This sort of exercise may be more time consuming but it does provide insurance against the onset of relational myopia.

This dissertation is not suggesting that becoming committed to a B2B partner is a bad thing. It is suggesting that firm managers remain aware of the potential hazards that may accompany the emergence of commitment over time. Affective commitment was found to be significantly related to relational myopia, complacency and suspicion while normative commitment is significantly related to relational myopia and vulnerability over time. It is tough to imagine relational myopia or complacency becoming a problem if firms are constantly evaluating relationship processes as well as relationship partners. This may not sound like a good strategy for developing strong, lasting B2B relationships but it believed that if these evaluation programs are administered as a function of policy 
from the beginning of the relationship, it will not hinder the evolution of a strong efficient relationship. In other words, just because firms are committed to remaining vigilant it does not mean they are not also committed to their B2B relationships. It means that firms will routinely take stock of how their B2B relationship is functioning in an effort to make sure that relationship potential is being realized. Firms will still be focused on the long term but through their routine evaluations of their B2B relationships will have a safeguard against the relationship becoming too comfortable which lull firms and managers into complacency and relational myopia.

Also, if firms are aware of their options as they pertain to relational partners there is really no reason to feel vulnerable or suspicious toward the B2B partner's behavior. The ability to engage in another relationship or at least the knowledge of knowing there are other B2B partners available may be enough to prevent the onset of these dark side symptoms. Of course maintaining this knowledge will require firms keeping an active scan of the horizon to see who and what is available.

Of course trust is important in any B2B relationship (e.g. Doney and Cannon 1999; Moorman, Zaltman and Desphande 1992) but consistent with this more global recommendation of this dissertation, trust needs to be tempered with vigilance. It is believed that firms that remain active in the scanning of the horizon and the evaluation of their B2B relationships will not only not allow the onset of these dark side symptoms; their relationship may even become stronger. As time passes it makes sense that firms that are constantly evaluating their environment and its B2B relationships, will learn that they either need to switch relational partners or that their current partner's are the best ones to help them achieve their relationship and organizational goals. This isn't to imply 
that firms should be ready to take an immediate turn toward a discrete transaction but that remaining observant doesn't mean you don't trust your B2B partner, it simply means you are guarding against the onset of these dark side symptoms. Put another way, it means that though you trust your B2B partner to work as best they can with your best interest in mind, you don't trust the combination of the dynamic environment and a positive trusting relationship to be able to guard against the onset of these dark side symptoms. So, instead of allowing the relationship to run itself, the firm and its managers must to an active role in relationship management despite the feelings of trust that characterize the relationship.

Satisfaction was found to be positively related to relational myopia, complacency and suspicion over time. To guard against satisfaction leading to the onset of these dark side symptoms it is recommended that firms follow the advice prescribed above to guard against other relational constructs leading to the onset of the dark side which is to remain vigilant regarding the environment and the $\mathrm{B} 2 \mathrm{~B}$ relationships they are in. Remaining vigilant and engaged in the relationship simply means to keep monitoring the relationship and its progress in an effort to ensure maximum efficiencies and proper fit among relational partners. Some things that may aid in this effort include organizational buyers routinely examining competitor bids to take stock of their relational partner's current level of pricing. Firm management should take an active role in the development and management of the relationships as well its monitoring. Do not leave B2B relationship governance solely in the hands of subordinates. It is important to remember that B2B relationships are at the firm, not the individual, level. Rotating people in at different times may aid in the prevention of the dark side as it prevents interpersonal relationships 
from developing to the point where interpersonal interests supersede the interests of the firm. Finally, compare progress and status reports to other B2B relationships. Metrics of particular interests include price, service, and other intangibles not expressed in the contract.

It is important not to confuse satisfaction with success or as signs they have the relationship figured out or so finely tuned the relationship can now run itself. There is nothing wrong with being satisfied with one's B2B relationship, the danger manifests when this satisfaction acts as evidence that it can't get any better and a firm subsequently "lets down their guard".

Firms should also realize that when they are in a position of dependence it is still in their best interest to cater to their relationships as well as working to alleviate their dependent position. Dependent firms should not sit back and let the less dependent firm run the relationship on their own simply because the more dependent firm feels they have no input. Taking an active role in the governing of the B2B relationship will build confidence and allow for the firms to both grow and contribute to the relationship. The same can be said for less dependent firms. It is tempting to allow the more dependent firm to do all the work since they need the relationship more than the less dependent firm. This is really symptomatic of complacency, and even for firms that are less dependent, can eventually lead to the onset of such things as vulnerability and feelings of suspicion.

Finally, firms need to be sure not to confuse dark side sentiments with relationship strength. As discussed above, it is logical to believe firms may perceive the onset of relational myopia and complacency as sign of relationship strength. This makes sense as firms may reach a point where they no longer put as many resources toward the B2B 
relationship as they once did and figure that the relationship, if left alone, will always run the way it currently is. This is fine provided the relationship is running in a manner appropriate for the current business environment. However, as the environment changes the need to modify relational processes will emerge. If a firm is complacent and myopic toward how its relationship runs it may miss these signs believing that the relationship is strong and not in need of adjustment. Provided firms stay active in monitoring how these relational process are performing and make changes when needed then there is no reason to believe these dark side constructs should ever become an issue, despite the evidence in this dissertation, suggesting that they do.

\section{Limitations}

The empirical investigation for this dissertation was done without dyadic data. This provides a limitation as it only provides the insight of one side of the relationship. In this case it is the buying, not the supplying side that contributed information with which this dissertation is based. Though this dissertation made every effort to combat the issues associated with common method bias by ensuring participant anonymity and psychologically separating the predictor and criterion variables (e.g. Podsakoff et al. 2003) these data should be interpreted with these limitations in mind.

The fit indices provide another limitation that should be recognized. Though the fit indices for the proposed model were better than any of the rival models they still fell short of reaching several of the commonly accepted thresholds (c.f. Hu and Bentler 1999). This is not unexpected given the exploratory and novel nature of this research but it still is cause for caution. When interpreting these results, this limitation needs to be kept in mind as these results suggest there is a better, yet still unproposed, structural 
model that can better capture the nature of the dark side and its relationship to the constructs inherent in relationship marketing.

Though an initial attempt was made to expand the data collection efforts to include foreign buyers this effort fell well short of where it needed to be to do an appropriate comparison and subsequent analysis of international buyers and their dark side effects. Therefore this dissertation relies on a domestic sample. This means the model should not be extended to foreign cultures without additional testing. Finally, the cross-sectional nature of this empirical study limits causal inferences. Though qualitative data were included in this dissertation, in an effort to support the directionality of the hypothesized relationships, longitudinal data, though difficult to obtain, would be better for evaluating how the dark side of relationship marketing manifests and changes over time.

\section{Future Research}

This dissertation presents a new theoretical sunset clause that predicts the positive benefits associated with adopting a RM strategy as well as the eventual manifestation of dark side. Specifically, this sunset clause recognizes the important moderating influence of time and its influence on the relationships between relational constructs and the eventual manifestation of dark side symptoms. However, as discussed in chapter two, time is really a surrogate for other moderating issues that are the real culprit as far as the onset of the dark side is concerned. Future research should focus on replacing time as the moderating variable with something more descriptive and exact regarding the relational constructs and the true moderating catalyst of the dark side. One potential issue is the levying of punitive, abusive or other destructive acts. Interpersonal friendships that develop to the point where the interpersonal relationship trumps the firm level goals may 
also become a problem when individuals behave according to this mindset. Also, the unwillingness to acknowledge better relational partners can become problematic in a rapidly changing economic and business environment. This may become a problem when firms become so comfortable that dedicating resources to monitoring exchange partner alternatives may seem like a waste of money. An investigation in how this sentiment develops and to what extent it is a problem should be of particular interest to the firm. Finally, closely related to the previous, is the idea that firms will mistake adequate for optimal. Again, how this develops and why should be of particular interest to researchers and practitioners alike.

For example, the results of this dissertation found that the ability component of trust is positively related to complacency over time. Of course it's not simply the passage of time that is provoking this relationship. It is more likely that partnering firms, as time passes are realizing their B2B partners are capable of meeting their contractual obligations and completing their assigned tasks. As time passes, and partnering firms continue to perform as expected, partnering firms are lulled into complacency knowing that they do not need to monitor their relational partner as previous behavior has led them to believe they will continue to perform as expected.

Of course, it is the partnering firms pleasing behavior, not simply the passage of time that is provoking the onset of complacency. Future research should investigate this relationship between complacency and ability but with expected repetitive behavior as the moderator, not time. There is a potentially infinite number of moderators that may be influencing these relationships between the relational variables and the onset of the dark 
side. Researchers may want to spend time investigating these moderators in an effort to isolate those that are most influential and most common.

There are emerging theoretical perspectives within RM that may prove useful in explaining the onset of the dark side. The resource based view of the firm is an integrated perspective that suggests that relationship marketing's impact on relational performance is influenced by relational constructs such as trust and commitment as well as relational investments like training and communication (Palmatier 2008). Future research may investigate how these investments may lead to the dark side and what dark side sentiments are provoked as a result of these relationship specific investments. Elements of evolutionary psychology have also been utilized in the RM context (e.g. Eyuboglu and Buja 2007). Instinctual feelings like gratitude, guilt and norms of reciprocity are believed to influence B2B relationship behavior (Palmatier 2008). How these intrapersonal constructs influence B2B relationships may be of particular interest from an evolutionary perspective. It begs the question about control over behavior and if firms have any choice or have the ability to put safeguards in place that can guard against the dark side or if natural instinct prevents the recognition of the dark side. Future research should investigate these potentialities to see if these evolutionary psychology sentiments really do have a place in an RM context, and if they do, to what extent do they influence the onset of the dark side.

Future research should also investigate how to devise tools and strategies to help guard against the dark side. The benefits of relationship marketing and the realization of its dark side present an interesting paradox for marketing researchers to study. The idea of looking for RM failures will provide marketers with a better understanding of their 
$\mathrm{B} 2 \mathrm{~B}$ relationships as well as provide the tools needed to better manage and govern these relationships. This will also help marketers make a clear distinction between the dynamics and nuances of interpersonal relationship and those of B2B relationships. A distinction, through the emergence of relationship marketing, can be argued to have been very much blurred.

From an operational perspective, future research can be expanded by gathering data from the supplying or selling side of a B2B relationship to evaluate the effects of the dark side on this side of the relationship. Gathering data from both sides of the relational dyad will help eliminate any concern associated with common method bias (Podsakoff et al. 2003) as well as provide a broader understanding of the dark side and its influence on the relationship as a whole, not just one side of it. Future research should expand this research outside the United States. Given the increasingly integrated global economy (Keegan and Greene 2004) it is likely that the dark side manifests itself in other countries and cultures as well. Especially interesting are the dark side implications in some of the emerging economies such as those in India, Brazil and China. All of these countries have vastly different cultures from the U.S. so the dark side may manifest itself completely differently or not at all in those foreign business cultures.

Future research should also consider adding other constructs such as fear, loyalty and vigilance to these models. It will be interesting to see if firms that remain vigilant and open to change regarding their $\mathrm{B} 2 \mathrm{~B}$ relationships will indicate relationships that are just as strong as those relationships where firms become so committed to their partners that they are willing to sacrifice organizational goals in order to preserve the $\mathrm{B} 2 \mathrm{~B}$ relationship. 


\section{References}

Achrol, Ravi S. and Michael J. Etzel (2003), "The Structure of Reseller Goals and Performance in Marketing Channels," Journal of the Academy of Marketing Science, 31 (2), 146-163.

Ailawadi, Kusum L., Rajiv P. Dant, and Dhruv Grewal (2004), "The Difference Between Perceptual and Objective Performance Measures: An Empirical Analysis," Marketing Science Institute Working Paper Series.

Allen, Michael (1988), "Strategic Management of Consumer Services," Long Range Planning, 21, 20-25.

Allen, Natalie J. and John P. Meyer (1990), "The Measurement and Antecedents of Affective, Continuance and Normative Commitment to the Organization," Journal of Occupational Psychology, 63, 1-18.

Anderson, Erin and Sandy D. Jap (2005), "The Dark Side of Close Relationships," MIT Sloan Management Review, 43 (3), 75-82.

Anderson, Erin and Barton Weitz (1989), "Determinants of Continuity in Conventional Industrial Channel Dyads," Marketing Science, 8 (4), 310-323.

---- (1992), "The Use of Pledges to Build and Sustain Commitment in Distribution Channels," Journal of Marketing Research, 29 (1), 18-34.

Anderson, Eugene W., Claes Fornell, and Donald R. Lehmann (1994), "Customer Satisfaction, Market Share, and Profitability: Findings from Sweden," Journal of Marketing, 58 (3), 53-66.

Anderson, James C. and James A. Narus (1990), "A Model of Distributor Firm and Manufacturer Firm Working Relationships," Journal of Marketing, 54 (1), 42-58.

---- (1984), "A Model of the Distributor's Perspective of Distributor-Manufacturer Working Relationships," Journal of Marketing, 48 (4), 62-74.

Arndt, J. (1979), "Toward A Concept of Domesticated Markets," Journal of Marketing, $43,69-75$. 
Ashford, Susan J., Cynthia Lee, and Philip Bobko (1989), "Content, Causes, and Consequences of Job Insecurity: A Theory-Based Measure and Substantive Test," The Academy of Management Journal, 32 (4), 803-829.

Attridge, Mark, Ellen Berscheid, and Susan Sprecher (1998), "Dependency and Insecurity in Romantic Relationships: Development and validation of Two Companion Scales," Personal Relationships, 5 (1), 31-58.

Austin, Jon R. (1991), "An Exploratory Examination of the Development of Marketing Research Service Relationships: An Assessment of Exchange Evaluation dimensions," in AMA Summer Educators' Conference Proceedings. Chicago: American Marketing Association.

Babicz, Gillian (2000), "Don't Wait, Ask Questions," Quality, 39 (11), 48-50.

Bagozzi, Richard P. (1978), "Marketing as an Exchange: A Theory of Transactions in the Marketplace," American Behavioral Scientists, 21 (March - April), 535-55.

Baker, Brent (2006), "Punitive Acts, Destructive Acts and Abusive Acts in Channels of Distribution: Conceptual Clarity and Demarcation," in AMA Educators' Proceedings: Enhancing Knowledge Development in Marketing, Dhruv Grewal and Michael Levy and R. Krishnan (Eds.) Vol. 17. Chicago: American Marketing Association.

Banutu-Gomez, Michael Ba and Shandra M.T. Banutu-Gomez (2007), "Leadership and Organizational Change In a Competitive Environment," Business Renaissance Quarterly, 2 (2), 69-.

Barringer, Bruce R., Jeffrey S. Harrison (2000), "Walking a Tightrope: Creating Value Through Interorganizational Relationships," Journal of Management, 26 (3) 367403)

Barnes, Bradley R. (2005), "Is the Seven-Year Hitch Premature in Industrial Markets?," European Journal of Marketing, 39 (5/6), 560 - 84.

Barnes, James G. (1994), "Close to the Customer: But is it really a Relationship?," Journal of Marketing Management, 10 (7), 561-70.

Barney, Jay B. and Mark H. Hansen (1994), "Trustworthiness as a Source of Competitive Advantage," Strategic Management Journal, 15 (Winter), 175-190.

Bejou, David (1997), "Relationship Marketing: Evolution, Present State, and Future," Psychology \& Marketing, 14 (18), 727-736. 
---- (1994), "Relationship Selling Trajectories: A Conceptual Model and Empirical Investigation," Published Dissertation, University of Memphis.

Bello, Daniel C. and David I. Gilliland (1997), "The Effect of Output Controls, Process Controls, and Flexibility on Export Channel Performance," Journal of Marketing, $61(1), 22-38$.

Bennett, Roger (1996), "Relationship Formation and Governance in Consumer Markets: Transactional Analysis versus the Behaviorurist Approach," Journal of Marketing Management, 12, 417-436.

Bergquist, Scott C. (2006), "The Perfect Market - and Strategies to Survive it," The Journal of Business Strategy, 27 (2), 11-20.

Berry, Leonard L. (1983), "Relationship Marketing," in Emerging Perspectives on Services Marketing, Leonard L. Berry and G. L. Shostack and G. D. Upah (Eds.): UT: American Marketing Association.

Bitner, Mary Jo, Bernard H. Booms, and Mary Stanfield Tetreault (1990), "The Service Encounter: Diagnosing Favorable and Unfavorable Incidents," Journal of Marketing, 54 (1), 71-84.

Bloemer, Josee and Gaby Odekerken-Schroder (2006), "The Role of Employee Relationship Proneness in Creating Employee Loyalty," International Journal of Bank Marketing, 24 (4), 252-264.

Boag, David A. and Ali Dastmalchian (1988), "Market Vulnerability and the Design and Management of the Marketing Function in Small Firms," Journal of Small Business Management, 26 (4), 37-43.

Bothamley, Jennifer (1993), Dictionary of Theories. London: Gale Research International Ltd.

Boughton, Paul D., Linda Nowak, and Judith Washburn (1996), "A Decision Model for Marketing Research Relationship Choices," Journal of Services Marketing, 10 (1), 56-67.

Bradach, Jeffrey L. and Robert G. Eccles (1989), "Price, Authority, and Trust: From Ideal Types to Plural Forms," Annual Review of Sociology, 15 (1989), 97-118.

Buckley, Walter (1967), Sociology and Modern Systems Theory. Englewood Cliffs: Prentice Hall.

Cannon, Joseph P and Christian Homburg (2001), "Buyers-supplier relationships and customer firm costs," Journal of Marketing, 65 (1), 29-43. 
Chakravarthy, Balaji S. (1986), "Measuring Strategic Performance," Strategic Management Journal, 7 (5), 437-458.

Chonko, Lawerence B. and John F. Tanner (1990), "Relationship Selling at Trade Shows," Review of Business, 12 (1), 13-18.

Chowdhury, Shamsud D. and James R. Lang (1996), "The Decline of Small Firms: A Preliminary Investigation into the Concept of Complacency," Canadian Journal of Administrative Sciences, 13 (4), 321-331.

Coleman, James S. (1990), Foundations of Social Theory. Cambridge: The Belknap Press.

Colgate, Mark and Bodo Lang (2005), "Positive and Negative Consequences of a Relationship Manager Strategy: New Zealand Banks and their Small Business Customers," Journal of Business Research, 58 (1), 195-204.

Colgate, Mark R. and Peter J. Danaher (2000), "Implementing a Customer Relationship Strategy: The Asymmetric Impact of Poor Versus Excellent Execution," Journal of the Academy of Marketing Science, 28 (3), 375-387.

Costa, Paul T. Jr. and Robert R. McCrae (1985), The NEO Personality Inventory. Odessa: Psychological Assessment Resources.

Cronin, J. Joseph, Jr. and Steven A. Taylor (1992), "Measuring Service Quality: A Reexamination and Extension," Journal of Marketing, 56 (3), 55-68.

Crosby, Lawrence A., Kenneth R. Evans, and Deborah Cowles (1990), "Relationship Quality in Services Selling: An Interpersonal Influence Perspective," Journal of Marketing, 54 (2), 68-81.

Cyert, Richard M., James G. March (1963) A Behavioral Theory of the Firm. PrenticeHall, Englewood Cliffs, NJ

Dant, Rajiv P., James R. Brown, and Richard P. Bagozzi , "Unraveling the Causal Links Amongst Trust, Commitment, Satisfaction, Conflict and Performance in Channels of Distribution," Working Paper .

Dant, Rajiv P. and Patrick L. Schul (1992), "Conflict Resolution Processes in Contractual Channels of Distribution," Journal of Marketing, 56 (1), 38-54.

Das, T.K., Bing-Sheng Teng (1999) "Managing Risks in Strategic alliances," The Academy of Management Executive, 13 (4), 50-62 
Davies, Mark and Melvin Prince (2005), "Dynamics of Trust Between clients and Their Advertising Agencies: Advances in Performance Theory," Academy of Marketing Science Review, 11, 1-32.

Davis, J. (1995), "Dependence, Self-interest, and Relationship Marketing: A View of the Nature of Exchange," Journal of Marketing Theory and Practice, 3 (Fall), 18-23.

Deligonul, Seyda, Daekwan Kim, Anthony S. Roath, and Erin Cavusgil (2006), "The Achilles 'Heel of an Enduring Relationship: Appropriation of Rents Between a Manufacturer and its Foreign Distributor," Journal of Business Research, 59 (7), 802-810.

Deshpande, Rohit and Fredrick E. Webster Jr. (1989), "Organizational Culture and Marketing: Defining the Research Agenda," Journal of Marketing, 53 (1), 3-15.

Deutsch, Morton (1962), "Cooperation and Trust: Some Theoretical Notes.," in Nebraska symposium on motivation, M.R. Jones (Ed.): University of Nebraska Press.

Dickson, Marsha A. and Li Zhang (2004), "Supplier-Retailer Relationships in China's Distribution Channel for Foreign Brand Apparel," Journal of Fashion Marketing and Management, 8 (2), 201-220.

Doney, Patricia M. and Joseph P. Cannon (1997), "An Examination of the Nature of Trust in Buyer-Seller Relationships," Journal of Marketing, 61 (2), 35-51.

Dorsch, Michael J., Scott R. Swanson, and Scott W. Kelly (1998), "The Role of Relationship Quality in the Stratification of Vendors as Perceived by Customers," Journal of the Academy of Marketing Science, 26 (2), 128-142.

Dowsett, Christopher (2007), "How Good Companies Go Bad," Strategic Finance, 89 (5), 15-17.

Doyle, Peter, Marcel Corstjens, and Paul Michell (1980), "Signals of Vulnerability in Agency-Client Relations," Journal of Marketing, 44 (4), 18-23.

Dwyer, Robert F., Paul. H. Schurr, and Sejo Oh (1987), "Developing Buyer-Seller Relationships," Journal of Marketing, 51, 79-89.

Dwyer, Robert F. and Orville C. Walker (1981), "Bargaining in an Asymmetrical Power Structure," Journal of marketing, 45 (1), 104-117.

Eccles, Robert G. (1991), "The Performance Measurement Manifesto," Harvard Business Review, 69 (1), 131-137. 
El-Ansary, Adel I. and Louis W. Stern (1972), "Power Measurement in the distribution Channel," Journal of Marketing Research, 51 (9), 59-74.

Emerson, Richard M. (1962), "Power-Dependence Relations," American Sociological Review, 27 (1), 31-41.

Enz, Cathy A. (1989), "The Measurement of Perceived Interorganizational Power: A Multi-Respondent Perspective," Organization Studies, 10 (2), 241-251.

Ferber, Robert (1970), "The Expanding Role of Marketing," Journal of Marketing, 34 (1), 29-30.

Flavian, Carlos, Miguel Guinaliu, and Eduardo Torres (2005), "The Influence of Corporate Image on Consumer Trust: A Comparative Analysis in Traditional Versus Internet Banking," Internet Research, 15 (4), 447-470.

Ford, David I. (1980), "The Development of Buyer-Seller Relationships in Industrial Markets," European Journal of Marketing, 14 (5/6), 339-353.

Ford, David I., Hakan Hakansson, and Jan Johanson (1996), "How do Companies Interact?," Industrial Marketing and Purchasing, 1 (1), 26-41.

Fornell, Claes, David F. Larcker (1981) Evaluating Structural Equation Models with Unobservable Variables and Measurement Error" Journal of Marketing Research, 18 (February), 39-50

Fullerton, Gordon (2005), "How Commitment Both Enables and Undermines Marketing Relationships," European Journal of Marketing, 39 (11/12), 1372-88.

---- (2003), "When Does Commitment Lead to Loyalty?," Journal of Service Research, 5 (4), 333-344.

Gambetta, Diego (ed) (1988), Trust: Making and Breaking Cooperative Relations. Oxford: Basil Blackwell.

Ganesan, Shankar (1994), "Determinants of Long-Term Orientation in Buyer-Seller Relationships," Journal of Marketing, 58 (2), 1.

Garbarino, Ellen and Mark S. Johnson (1999), "The Different Roles of Satisfaction, Trust, and Commitment in Customer Relationships," Journal of Marketing, 63 (2), 70-87.

Gaski, John F. and John R. Nevin (1985), "The Differential Effects of Exercised and Unexercised Power Sources in a Marketing Channel," Journal of Marketing Research, 22 (2), 130-142. 
Geyskens, Inge, Jan-Benedict Steenkamp E.M., and Nirmalya Kumar (1999), "A MetaAnalysis of Satisfaction in Marketing Channel Relationships," Journal of Marketing Research, 36 (2), 223-238.

Ghosh, Amit K., Thomas W. Whipple, and Glenn A. Bryan (2001), "Student Strust and Its Antecedents in Higher Education," The Journal of Higher Education, 72 (3), 322-340.

Grayson, Kent and Tim Ambler (1999), "The Dark Side of Long-Term Relationships in Marketing Services," Journal of Marketing Research, 36 (1), 132-41.

Greenhalgh, Leonard (1985), "Job Insecurity and Dissinvolvement: Field Research on the Survivors of the Layoff," in National Academy of Management Meetings. San Diego CA.

Gronroos, Christian (1988), "New Competition in the Service Economy: The Five Rules of Service," International Journal of Production and Management, 8 (3), 9-19.

Gronroos, Christrian (1996), "Relationship Marketing: The Strategy Continuum," Journal of the Academy of Marketing Science, 4 (1), 7-18.

Gruen, Thomas W., John O. Summers, and Frank Acito (2000), "Relationship Marketing Activities, Commitment, and Membership Behaviors in Professional Associations," Journal of Marketing, 64 (2), 34-49.

Gulati, Ranjay (1995), Does Familiarity Breed Trust? The Implications of Repeated Ties for Contractual Choice in Alliances," Academy of Management Journal, 38 (1), 85-112.

Gummesson, Evert (1987), "The New Marketing - Developing Long Term Interactive Relationships," Long Range Planning, 20 (4), 10-20.

---- (2004), "Return on Relationships (ROR): The Value of Relationship Marketing and CRM in Business-to Business Contexts," The Journal of Business \& Industrial Marketing, 19 (2), 136-148.

Gundlach, G and P Murphy (1993), "Ethical and Legal Foundations of Relational Marketing Exchanges," Journal of Marketing, 57 (4), 35-46.

Gundlach, Gregory T., Ravi S. Achrol, and John T. Mentzer (1995), "The Structure of Commitment in Exchange," Journal of Marketing, 59 (1), 78-92. 
Hagen, Mark R. (1999), "Complacency - The Enemy of Quality," Quality Progress, 32 (10), 32-44.

Hair, Joseph F. Jr., Rolph E. Anderson, Ronald L. Tatham, William C. Black, (1998) Multivariate Data Analysis. Upper Saddle River: Prentice Hall

Hakansson, Hakan and Ivan J. Snehota (1995), Developing Relationships in Business Networks. London: Routledge.

Halinen, Aino (1997), Relationship Marketing in Professional Services: A Study of Agency-client Dynamics in the Advertising Sector. London: Routledge.

Halinen, Aino, Jaana Tabtinen (2002). "A ProcessTheory of Relationship Ending," International Journal of Service Industry Management, 13(2), 163-180.

Harris, Judy and Kimberly A. Taylor (2003), "The Case for Greater Agency Involvement in Strategic Partnerships," Journal of Advertising Research (4), 346-352.

Hatzakis, Tally, Mark Lycett, Robert D. Macredie, and Valerie A. Martin (2005), "Towards the Development of a Social Capital Approach to Evaluating Change Management Interventions," European Journal of Information Systems, 14 (14), 60-74.

Haytko, Diana L. (2004), "Firm-to-Firm and Interpersonal Relationships: Perspectives from Advertising Agency Account Managers," Journal of the Academy of Marketing Science, 32 (3), 312-328.

Heide, Jan B (1994), "Interorganizational governance in marketing channels," Journal of Marketing, 58 (1), 71.

Heide, Jan B. and George John (1992), "Do Norms Matter in Marketing Relationships?," Journal of Marketing, 56 (2), 32-44.

---- (1988), "The Role of Dependence Balancing in Safeguarding Transaction-Specific Assets in Conventional Channels," Journal of Marketing, 52, 20-35.

Henard, David H. and David M. Szymanski (2001), "Why Some New Products Are More Successful Thank Others," Journal of Marketing Research, 38 (3), 362-375.

Hibbard, Jonathan D., Frederic F. Brunel, Rajiv P. Dant, and Dawn Iacobucci (2001), "Does Relationship Marketing Age Well?," Business Strategy Review, 12 (4), 2935. 
Hibbard, Jonathan D., Nirmalya Kumar, and Louis W. Stern (2001), "Examining the Impact of Destructive Acts in Marketing Channel Relationships," Journal of Marketing Research, 38 (1), 45-61.

Hultman, Claes M and Eleanor Shaw (2003), "The Interface Between Transactional and Relational Orientation in Small Service Firm's Marketing Behaviour: A Study of Scottish and Swedish Small Firms in the Service Sector," Journal of Marketing Theory and Practice, 11 (1), 36-51.

Hunt, Shelby D. (1983), "General Theories and the Fundamental Explananda of Marketing," Journal of Marketing, 47 (4), 9-17.

Hunt, Shelby D., Van R. Wood, and Lawrence B. Chonko (1989), "Corporate Ethical Values and Organizational Commitment in Marketing," Journal of Marketing, 53 (3), 79-90.

Iacobucci, Dawn and Jonathan D. Hibbard (1999), "Toward An Encompassing Theory of Business Marketing Relationships (BMRS) and Interpersonal Commercial Relationships (ICRS): An Empirical Generalization," Journal of Interactive Marketing, 13 (3), 13-33.

Inkpen, Andrew C. and Paul W. Beamish (1997), "Knowledge, Bargaining Power, and the Instability of International Joint Ventures," Academy of Management Review, 22 (1), 177-202.

Ivens, Bjoern S. and Keith J. Blois (2004), "Relational Exchange Norms in Marketing: A Critical Review of Macneil's Contribution," Marketing Theory, 4 (3), 239-263.

Jackson, Barbara B. (1985), "Building Customer Relationships that Last," Harvard Business Review, 63, 120-28.

Jackson, Dennis L. (2001), "Sample Size and number of Parameter Estimates in Maximum Likelihood Confirmatory Factor Analysis: A Monte Carlo Investigation," Structural Equation Modeling: A Multidisciplinary Journal

Jap, Sandy D. and Erin Anderson (2003), "Safeguarding Interorganizational Performance and Continuity Under Ex Post Opportunism," Management Science, 49 (12), 1684-1701.

Johannessen, Jon-Arild, Bjorn Olsen, and G.T. Lumpkin (2001), "Innovation as Newness: What is New, How New, and New to Whom?," European Journal of Innovation Management, 4 (1), 20-31. 
Johnson, Jean L. (1999), "Strategic Integration in Industrial Distribution Channels: Managing the interfirm Relationship as a Strategic Asset," Journal of the Academy of Marketing Science, 27 (1), 4-18.

Johnson, Julie T., Hiram C. Jr. Barksdale, and James S. Boles (2001), "The Strategic Role of the Salesperson in Reducing Customer Defection in Business Relationships," Journal of Personal Selling and Sales Management, 21 (2), 123 134.

Johnston, Mark W. and Greg W. Marshall (2006), Relationship Selling (2nd ed.). Boston: McGraw-Hill.

Joreskog, K. G. (1993), "Testing Structural Equation Models" in K.A. Bollen \& J.S. Long (eds.), Testing Structural Equation Models (pp. 294-316). Newbury Park: Sage Publications

Kahne, Jeffrey D. (2005), "Measuring Organizational "Sense of Urgency:" A Leadership Challenge," Our Lady of the Lake University.

Kaplan, Robert S. and David P. Norton (1992), "The Balanced Scorecard - Measures That Drive Performance," Harvard Business Review, 70 (1), 71-79.

Kaufmann, Patrick J. and Rajiv P. Dant (1992), "The Dimensions of Commercial Exchange," Marketing Letters, 3 (2), 171-185.

Kaufmann, Patrick J. and Louis W. Stern (1988), "Relational Exchange Norms, Perceptions of Unfairness, and Retained Hostility in Commercial Litigation," Journal of Conflict Resolution, 32 (3), 534-552.

Kelley, Harold H. and John W. Thibaut (1978), Interpersonal relations: A theory of interdependence. New York: Wiley.

Kotler, Phil and Sidney J. Levy (1969), "Broadening the Concept of Marketing," Journal of Marketing, 33 (1), 10-15.

Kotler, Philip (1972), "A Generic Concept of Marketing," Journal of Marketing, 36 (2), 46-54.

Koza, Karen L. and Rajiv P. Dant (2007), "Effects of Relationship Climate, Control Mechanism, and Communications on Conflict Resolution Behavior and Performance Outcomes," Journal of Retailing, 83 (3), 279-296.

Kumar, Anand, Richard W. Olshavsky, and Maryon F. King (2001), "Exploring Alternative Antecedents of Customer Delight," Journal of Consumer Satisfaction, Dissatisfaction and Complaining Behavior, 14, 14-26. 
Kumar, Nirmalya (1996), "The Power of Trust in Manufacturer-Retailer Relationships," Harvard Business Review, 74 (6), 92-106.

Kumar, Nirmalya, Lisa K Scheer, and Jan-Benedict E. M. Steenkamp (1998), "Interdependence, Punitive Capability, and the Reciprocation of Punitive Actions in Channel Relationships," Journal of Marketing Research, 35 (2), 225-235.

Kumar, Nirmalya, Louis W. Stern, and Ravi S. Achrol (1992), "Assessing Reseller Performance from the Perspective of the Supplier," Journal of Marketing Research, 29 (2), 238-253.

Kwon, Ik-Whan G. and Taewon Suh (2005), "Trust, Commitment and Relationships in Supply Chain Management: A Path Analysis," Supply Chain Management, 10 (1), 26-33.

Lacey, Russell (2007), "Relationship Drivers of Customer Commitment," Journal of Marketing Theory and Practice, 15 (4), 315-333.

Lado, Augustine A., Rajiv P. Dant, and Amanuel G. Tekleab (2008), "Trust-Opportunism Paradox, Relationalism, and Performance in Interfirm Relationships: Evidence from the Retail Industry," Strategic Management Journal 4 (1), 401-423.

Larson, B. (1997), "An Examination of Relational Cohesion Theory," in American Marketing Association Educator's Proceedings: Marketing Theory and Applications, D LeClair and M. Hartline and M. P. Gordon and B. Kellerman (Eds.).

Leavitt, Theodore (1960), "Marketing Myopia," Harvard Business Review, 38 (4), 45-56.

Leik, Robert K. and Sheila A. Leik (1977), "Transition to Interpersonal Commitment," in Behavioral Theory in Sociology: Essays in Honor of George C. Homans, Robert L. Hamblin and John H. Kunkel, Eds.: Transaction.

Leuthesser, Lance (1997), "Supplier Relational Behavior: An Empirical Assessment," Industrial Marketing Management, 26 (2), 245-54.

Levine, Timothy R., Steven A. McCormack (1991), "The Dark Side of Trust: Conceptualizing and Measuring Types of Communicative Suspicion," 39 (4), 325-340

Lewis, M. Christine and Douglas M. Lambert (1991), "A Model of channel member Performance, Dependence, and Satisfaction," Journal of Retailing, 67 (2), 205-21. 
Li, Fan, Barnett A. Greenberg, and Tiger Li (1997), "Towards a General Definition of Relationship Marketing," in American Marketing Association Educator's Proceedings-Enhancing Knowledge Development in Marketing, W. Pride and G. Hult (Eds.).

Little, Todd D., James A. Bovaird, Keith F. Widaman (2006) "On the Merits of Orthogonalizing Powered and Product Terms: Implications for Modeling Interactions Among Latent Variables," Structural Equation Modeling: A Multidisciplinary Journal, 13(4) 497-519.

Lusch, Robert F. and James R. Brown (1996), "Interdependency, Contracting, and Relational Behavior in Marketing Channels," Journal of Marketing, 3 (60), 19-38.

MacCallum, Robert C., Michael W. Browne, Hazuki M. Sugaware (1996) "Power Analysis and Determination of Sample Size for Covariance Structure Modeling" Psychological Methods, 1 (2), 130-149

MacNeil, I.R. (1980), The New Social Contract,. New Haven, CT: Yale University Press.

Mayer, Roger C., James H. Davis, and F. David Shorrman (1995), "An Integrative Model of Organizational Trust," The Academy of Management Review, 20 (3), 709-34.

McEvily, Bill, Vincenzo Perrone, and Akbar Zaheer (2003), "Trust as an Organizing Principle," Organization Science, 14 (1), 91-103.

Merriden, Trevor (1999), "The Challenges of Hypergrowth," Management Review, 88 (10), 34-38.

Mirshekary, Soheila, Ali M. Yaftian, and Damien Cross (2005), "Australian Corporate Collapse: The Case of HIH Insurance," Journal of Financial Services Marketing, 9 (3), 249-258.

Mohr, Jakki and Robert Spekman (1994), "Characteristics of Partnership Attributes, Communication Behavior, and Conflict Resolution Techniques," Strategic Management Journal, 15 (2), 135-152.

Molla, Alemayehu and Arjun Bhalla (2006), "Business Transformation Through ERP: A Case Study of an Asian Company," Journal of Information Technology Case and Application Research 2006, 8 (1), 34-54.

Moorman, Christine, Gerald Zaltman, and Rohit Deshpande (1992), "Relationships Between Providers and Users of Market Research: The Dynamics of Trust Within and Between Organizations," Journal of Marketing Research, 29 (3), 314328. 
Morgan, Robert M. and Shelby D. Hunt (1994), "The Commitment-Trust Theory of Relationship Marketing," Journal of Marketing, 58 (3), 20-38.

Mukherjee, Avinandan and Prithwiraj Nath (2003), "A Model of Trust in Online Relationship Banking," The International Journal of Bank Marketing, 21 (1), 515.

Palmatier, Robert W. (2008) Relationship Marketing. Marketing Science Institute, Cambridge Massachuesetts

Palmatier, Robert W, Rajiv P Dant, and Dhruv Grewal (2007), "A Comparative Longitudinal Analysis of Theoretical Perspectives of Interorganizational Relationship Performance," Journal of Marketing, 71 (4), 172-194.

Palmatier, Robert W, Rajiv P Dant, Dhruv Grewal, and Kenneth R Evans (2006), "Factors Influencing the Effectiveness of Relationship Marketing: A Meta Analysis," Journal of Marketing, 70 (4), 136-153.

Palmatier, Robert W., Srinath Gopalakrishna, and Mark B. Houston (2006), "Returns on Business-to Business Relationship Marketing Investments: Strategies for Leveraging Profits," Marketing Science, 25 (5), 477-493.

Park, Seung Ho and Michael V. Russo (1996), "When Competition Eclipses Cooperation: An Event History Analysis of Joint Venture Failure," Management Science, 42 (6), 875-890.

Pearlin, Leonard I., Morton A. Lieberman, Elizabeth G. Menaghan, and Joseph T. Mullan (1981), "The Stress Process," Journal of Health and Social Behavior, 22 (1981), 337-356.

Peck, Helen, Adrian Payne, Martin Christopher, and Moia Clark (1999), Relationship Marketing Strategy and Implementation. Oxford: Butterworth-Heineman.

Pillai, Kishore Gopalakrishna and Arun Sharma (2003), "Mature Relationships: Why Does Relational Orientation Turn Into Transaction Orientation?," Industrial Marketing Management, 32 (December), 643-651.

Ping, Robert A. (1993), "The Effects of Satisfaction and Structural Constraints on Retailer Exiting, Voice, Loyalty, Opportunism, and Neglect," Journal of Retailing, 69 (3), 320-52.

Pressey, Andrew and Nikolaos Tzokas (2004), "Lighting Up the "Dark Side" of International Export/Import Relationships: Evidence from UK Reporters," Management Decision, 42 (5/6), 694-708. 
Priluck, Randi (2003), "Relationship Marketing Can Mitigate Product and Service Failures," The Journal of Services Marketing, 17 (1), 37-52.

Quinn, Robert E. and John Rohrbaugh (1983), "A Spatial Model of Effectiveness Criteria: Towards a Competing Values Approach to Organizational Analysis," Management Science, 29 (3), 363-377.

Ranganathan, C., DongBack Seo, and Yair Babad (2006), "Switching Behavior of Mobile Users: Do Users' Relational Investments and Demographics Matter?," European Journal of Information Systems, 15 (3), 269-276.

Rao, Sally and Chad Perry (2002), "Thinking About Relationship Marketing: Where Are We Now?," The Journal of Business \& Industrial Marketing, 17 (7), 598-614.

Reinartz, Werner J. and V. Kumar (2000), "On the Profitability of Long-Life Customers in a Noncontractual Setting: An Empirical Investigation and Implications for Marketing," Journal of Marketing, 64 (4), 17-35.

Reynolds, Kristy E. and Sharon E. Beatty (1999), "Customer Benefits and Company Consequences of Customer-Salesperson Relationships in Retailing," Journal of Retailing, 75 (1), 11-32.

Richard, Michael D., James A. Womack, and Arthur W. Allaway (1992), "An Integrated View of Marketing Myopia," The Journal of Consumer Marketing, 9 (3), 65-71.

Rindfleisch, Aric and Christine Moorman (2001), "The Acquisition and Utilization of Information in New Product Alliances: A Strength-of-Ties Perspective," Journal of Marketing, 65 (2), 1-18.

Ring, Peter Smith and Andrew H. Van de Ven (1994), "Developmental Processes of Cooperative Interorganizational Relationships," The Academy of Management Review, 19 (1), 90-118.

Robicheaux, Robert A. and James E. Coleman (1994), "The Structure of Marketing Channel Relationships," Journal of the Academy of Marketing Science, 22 (1), 38-51.

Robinson, Mike (2005), "So...You Think You Have Partnering Sorted?," The British Journal of Administrative Management (August/September), 18-19.

Roos, Inger (2002), "Methods of Investigating Critical Incidents: A Comparative Review," Journal of Service Research, 4 (3), 193-204. 
Scheer, Lisa K. and Louis W. Stern (1992), "The Effect of Influence Type and Performance Outcomes on Attitude Toward the Influencer," Journal of Marketing Research, 29 (1), 128-142.

Sheth, Jagdish N and Atul Parvatiyar (1995), "The Evolution of Relationship Marketing," International Business Review, 4 (4), 397-419.

Shipley, David (1994), "Achieving Cross-Functional Co-ordination for Marketing Implementation," Management Decision, 32 (8), 17-20.

Siguaw, Judy A., Penny M. Simpson, and Thomas L. Baker (1998), "Effects of Suppler Market Orientation on Distributor Market Orientation and the Channel Relationship: The Distributor Perspective," Journal of Marketing, 62 (3), 99-111.

Sin, Leo Y.M., Alan C.B. Tse, Oliver H.M. Yau, Jenny S.Y. Lee, and Raymond Chow (2002), "The Effect of Relationship Marketing Orientation on Business Performance in a Service-Oriented Economy," The Journal of Services Marketing, 16 (7), 656-676.

Singh, Kulwant, Will Mitchell (1996), "Precarious Collaboration: Business Survival After Partners Shurt Down or Form New Partnerships," Strategic Management Journal, 17(Special Issue), 99-115

Skogland, Iselin and Judy A. Siguaw (2004), "Are your Satisfied Customers Loyal?," Cornell Hotel and Restaurant Administration Quaarterly, 45 (3), 221-234.

Spekman, Robert E., Theodore M. Forbes, III, Lynn A. Isabella Thomas C. MacAvoy (1998) "alliance Management: A View From the Past and a Look to the Future," Journal of Management Studies, 35 (6), 747-772

Srinivasan, Raji and Christine Moorman (2005), "Strategic Firm Commitments and Rewards to Customer Relationship Management Investments in Online Retailing," Journal of Marketing, 69 (3), 193-200.

Starbuck, William H., Michael L. Barnett, Philippe Baumard (2008) "Payoffs and Pitfalls of Strategic Learning" Journal of Economic Behavior \& Organization, 66, 7-21

Stewart, Kate and Mark Durkin (1999), "Bank Relationships with Students," Irish Marketing Review, 12 (2), 37-47.

Stock, James R. (2002), "Marketing Myopia Revisited: Lessons for Logistics," International Journal of Physical Distribution and Logistics Management, 32 $(1 / 2), 12-22$. 
Svensson, Goran (2004), "Vulnerability in Business Relationships: The Gap Between Dependence and Trust," The Journal of Business \& Industrial Marketing, 19 (7), 469-483.

Tan, Doreen S. D. (Syed Akhtar), "Organizational Commitment and Experienced Burnout: An Exploratory Study from a Chinese Cultural Perspective," International Journal of Organizational Analysis, 6 (4), 310-328.

Tate, Karen (1996), "The Elements of a Successful Logistics Partnership," International Journal of Physical Distribution \& Logistics, 26 (3), 7-13.

Thibaut, John W. and Harold H. Kelly (1959), The Social Psychology of Groups. New York: Wiley.

Torres, Edwin N. and Sheryl Kline (2006), "From Satisfaction to Delight: A Model for the Hotel Industry," International Journal of Contemporary Hospitality Management, 18 (4), 290-301.

Valos, Michael J. and Andrea Vocino (2006), "An Integrative Marketing Channel Performance Measurement Framework," Journal of Database Marketing \& Customer Strategy Management, 14 (1), 17-28.

Verhoef, Peter C., Philip Hans Franses, and Janny C. Hoekstra (2002), "The Effect of Relational Constructs on Customer Referrals and Number of Services Purchases From a Multiservice Provider: Does Age of Relationship Matter?," Journal of the Academy of Marketing Science, 30 (3), 202-216.

Vitell, Scott J., Kumar C. Rallapalli, and Anusorm Singhapakdi (1993), "Marketing Norms: The Influence of Personal Moral Philosophies and Organizational Ethical Culture," Journal of the Academy of Marketing Science, 21 (Fall), 331-338.

Voss, Glenn B. and Giraud Zannie Voss (1997), "Implementing a Relationship Marketing Program: A Case Study and Managerial Implications," Journal of Services Marketing, 11 (4), 278-293.

Wathne, Kenneth H. and Jan B. Heide (2000), "Opportunism in Interfirm Relationships: Forms, Outcomes, and Solutions," Journal of Marketing, 64 (4), 36-51.

Wetzels, Martin, Ko de Ruyter, and Marcel van Birgelen (1998), "Marketing Service Relationships: The Role of Commitment," The Journal of Business and Industrial Marketing, 13 (4/5), 406-519.

Wiener, Yoash and Yoav Vardi (1980), "Relationships Between Job, Organization, and Career Commitments and Work Outcomes: An Integrative Approach," Organizational Behavior and Human Performance, 26 (1), 81-96. 
Williamson, Oliver E. (1975), Markets and Hierarchies, Analysis and Antitrust Implications. New York,: The Free Press.

Wilson, David T. (1995), "An Integrated Model of Buyer-Seller Relationships," Journal of the Academy of Marketing Science, 23 (4), 335-345.

Wong, Amy and Amrik Sohal (2002), "An Examination of the Relationship Between Trust, Commitment and Relationship Quality," International Journal of Retail and Distribution Management, 30 (1), 34-50.

Young, L. and S. Danize (1994), "Super-glued Relationships: The Nature of Bonds Between Professional Service Suppliers and Buyers," in IMP Conference.

Zineldin, Mosad and Mariana Dodourova (2005), "Motivation, Achievements and Failure of Strategic Alliances: The Case of Swedish Auto-Manufacturers In Russia," European Business Review, 17 (5), 460-470. 
Appendices 
Appendix 1: Pre-Test Survey

\author{
University of South Florida
}

Retail Outlet \& Business Relationship Pre-Test Survey 2008

Dear Retail Outlet Agent:

As someone who keeps in contact with your establishment's vendors or suppliers you are in a unique position to gauge the quality of the relationship you and your establishment has with these partnering firms.

The following survey is for two research projects on business to business relationships. These studies are designed to gauge the quality of business to business relationships and how your vendors or suppliers handle issues of conflict. It is believed that the results of these surveys will provide a deeper understanding of how business to business relationships evolve and change over time and consequently provide a deeper understanding of how best to manage and govern these business relationships.

Your participation in this survey is completely voluntary and your individual responses will remain strictly confidential. No names will ever be revealed to any supplier. All reports based on this survey will only present combined data. Also, please keep in mind that the authors of this survey are only affiliated with the University of South Florida and the University of Oklahoma and have no affiliation with any of the suppliers. Therefore, we have no reason to consult with any of the suppliers about the results of this study. So, please be completely honest and as frank as possible.

Thank you in advance for your cooperation.

P.S. These surveys should take about 20 - 25 minutes to complete.

Survey I:

Section I: Relationship with Focal Supplier

This section seeks your opinion about the quality of the relationship you currently have with one of your focal suppliers. We ask that you identify a supplier that your establishment has been able to conduct a significant amount of business with. Please review the following statements, and provide your evaluations by checking the appropriate box. All questions refer to the focal supplier you've identified and not the individual representatives of the supplier.

Please identify a focal supplier that your retail establishment has conducted a significant amount of business with
Name of Supplier:

To the best of your knowledge

The amount of time your establishment has

Conducted business with this focal supplier
Months:

Years: 


\section{Appendix 1 (Continued)}

\begin{tabular}{|c|c|c|c|c|c|c|c|c|}
\hline & $\begin{array}{l}\text { The below items } \\
\text { need to be answered } \\
\text { in } 2 \text { parts. Please } \\
\text { indicate the degree to } \\
\text { which you believe } \\
\text { that (1) your supplier } \\
\text { would agree with the } \\
\text { following statements, } \\
\text { and (2) you would } \\
\text { agree with the } \\
\text { following statements: }\end{array}$ & $\begin{array}{l}\text { Strongly } \\
\text { Disagree }\end{array}$ & $\begin{array}{l}\text { Disagre } \\
\mathbf{e}\end{array}$ & $\begin{array}{c}\text { Moderatel } \\
\mathbf{y} \\
\text { Disagree }\end{array}$ & $\begin{array}{l}\text { Neither } \\
\text { Agree nor } \\
\text { Disagree }\end{array}$ & $\begin{array}{c}\text { Moderately } \\
\text { Agree }\end{array}$ & Agree & $\begin{array}{c}\text { Strongly } \\
\text { Agree }\end{array}$ \\
\hline $1 \mathrm{a}$ & $\begin{array}{l}\text { Managers in this } \\
\text { business often engage } \\
\text { in behaviors that I } \\
\text { consider to be } \\
\text { unethical. (Supplier's } \\
\text { Response) }\end{array}$ & 1 & 2 & 3 & 4 & 5 & 6 & 7 \\
\hline $1 \mathrm{~b}$ & $\begin{array}{l}\text { Managers in this } \\
\text { business often engage } \\
\text { in behaviors that I } \\
\text { consider to be } \\
\text { unethical. (Your } \\
\text { Response) }\end{array}$ & 1 & 2 & 3 & 4 & 5 & 6 & 7 \\
\hline $2 a$ & $\begin{array}{l}\text { In order to succeed in } \\
\text { this company, it is } \\
\text { often necessary to } \\
\text { compromise one's } \\
\text { ethics. (Supplier's } \\
\text { Response) }\end{array}$ & 1 & 2 & 3 & 4 & 5 & 6 & 7 \\
\hline $2 b$ & $\begin{array}{l}\text { In order to succeed in } \\
\text { this company, it is } \\
\text { often necessary to } \\
\text { compromise one's } \\
\text { ethics. (Your } \\
\text { Response) }\end{array}$ & 1 & 2 & 3 & 4 & 5 & 6 & 7 \\
\hline $3 a$ & $\begin{array}{l}\text { Top Management in } \\
\text { my company has let it } \\
\text { be known in no } \\
\text { uncertain terms that } \\
\text { unethical behavior } \\
\text { will not be tolerated. } \\
\text { (Supplier's Response) }\end{array}$ & 1 & 2 & 3 & 4 & 5 & 6 & 7 \\
\hline $3 b$ & $\begin{array}{l}\text { Top Management in } \\
\text { my company has let it } \\
\text { be known in no } \\
\text { uncertain terms that } \\
\text { unethical behavior } \\
\text { will not be tolerated. } \\
\text { (Your Response) }\end{array}$ & 1 & 2 & 3 & 4 & 5 & 6 & 7 \\
\hline $4 a$ & $\begin{array}{l}\text { If a manager in my } \\
\text { company is discovered } \\
\text { to have engaged in } \\
\text { unethical behavior that } \\
\text { results primarily in } \\
\text { personal gain (rather } \\
\text { than corporate gain), } \\
\text { he or she will be } \\
\text { promptly } \\
\text { reprimanded. } \\
\text { (Supplier's Response) }\end{array}$ & 1 & 2 & 3 & 4 & 5 & 6 & 7 \\
\hline
\end{tabular}




\section{Appendix 1 (Continued)}

\begin{tabular}{|c|c|c|c|c|c|c|c|c|}
\hline $4 b$ & $\begin{array}{l}\text { If a manager in my } \\
\text { company is discovered } \\
\text { to have engaged in } \\
\text { unethical behavior that } \\
\text { results primarily in } \\
\text { personal gain (rather } \\
\text { than corporate gain), } \\
\text { he or she will be } \\
\text { promptly } \\
\text { reprimanded. (Your } \\
\text { Response) }\end{array}$ & 1 & 2 & 3 & 4 & 5 & 6 & 7 \\
\hline $5 a$ & $\begin{array}{l}\text { If a manager in my } \\
\text { company is discovered } \\
\text { to have engaged in } \\
\text { unethical behavior that } \\
\text { results primarily in } \\
\text { corporate gain (rather } \\
\text { than personal gain), he } \\
\text { or she will be } \\
\text { promptly } \\
\text { reprimanded. } \\
\text { (Supplier's Response) }\end{array}$ & 1 & 2 & 3 & 4 & 5 & 6 & 7 \\
\hline $5 b$ & $\begin{array}{l}\text { If a manager in my } \\
\text { company is discovered } \\
\text { to have engaged in } \\
\text { unethical behavior that } \\
\text { results primarily in } \\
\text { corporate gain (rather } \\
\text { than personal gain), he } \\
\text { or she will be } \\
\text { promptly } \\
\text { reprimanded. (Your } \\
\text { Response) }\end{array}$ & 1 & 2 & 3 & 4 & 5 & 6 & 7 \\
\hline & $\begin{array}{l}\text { Please indicate how } \\
\text { much you either } \\
\text { agree or disagree } \\
\text { with the items below. }\end{array}$ & $\begin{array}{l}\text { Strongly } \\
\text { Disagree }\end{array}$ & $\begin{array}{c}\text { Disagre } \\
\text { e }\end{array}$ & $\begin{array}{c}\text { Moderatel } \\
\mathbf{y} \\
\text { Disagree }\end{array}$ & $\begin{array}{c}\text { Neither } \\
\text { Agree nor } \\
\text { Disagree }\end{array}$ & $\begin{array}{l}\text { Moderately } \\
\text { Agree }\end{array}$ & Agree & $\begin{array}{c}\text { Strongly } \\
\text { Agree }\end{array}$ \\
\hline 1 & $\begin{array}{l}\text { I would be very happy } \\
\text { to not ever have to } \\
\text { change partners. }\end{array}$ & 1 & 2 & 3 & 4 & 5 & 6 & 7 \\
\hline 2 & $\begin{array}{l}\text { I enjoy referring my } \\
\text { supplier to others. }\end{array}$ & 1 & 2 & 3 & 4 & 5 & 6 & 7 \\
\hline 3 & $\begin{array}{l}\text { I really feel as if my } \\
\text { supplier's problems } \\
\text { are my own. }\end{array}$ & 1 & 2 & 3 & 4 & 5 & 6 & 7 \\
\hline 4 & $\begin{array}{l}\text { I think that I could } \\
\text { easily become as } \\
\text { attached to another } \\
\text { supplier as I am to this } \\
\text { one. }\end{array}$ & 1 & 2 & 3 & 4 & 5 & 6 & 7 \\
\hline 5 & $\begin{array}{l}\text { I do not feel like part } \\
\text { of the family with my } \\
\text { supplier. }\end{array}$ & 1 & 2 & 3 & 4 & 5 & 6 & 7 \\
\hline 6 & $\begin{array}{l}\text { I do not feel } \\
\text { "emotionally } \\
\text { attached" my supplier. }\end{array}$ & 1 & 2 & 3 & 4 & 5 & 6 & 7 \\
\hline 7 & $\begin{array}{l}\text { My supplier has a } \\
\text { great deal of personal } \\
\text { meaning for me. }\end{array}$ & 1 & 2 & 3 & 4 & 5 & 6 & 7 \\
\hline 8 & $\begin{array}{l}\text { I do not feel a strong } \\
\text { sense of belonging to } \\
\text { this supplier }\end{array}$ & 1 & 2 & 3 & 4 & 5 & 6 & 7 \\
\hline
\end{tabular}




\section{Appendix 1 (Continued)}

\begin{tabular}{|c|c|c|c|c|c|c|c|c|}
\hline 9 & $\begin{array}{l}\text { I think that } \\
\text { establishments these } \\
\text { days change suppliers } \\
\text { too often. }\end{array}$ & 1 & 2 & 3 & 4 & 5 & 6 & 7 \\
\hline 10 & $\begin{array}{l}\text { I do not believe that } \\
\text { an establishment must } \\
\text { always be loyal to } \\
\text { their suppliers. }\end{array}$ & 1 & 2 & 3 & 4 & 5 & 6 & 7 \\
\hline \multirow[t]{2}{*}{11} & $\begin{array}{l}\text { Jumping from supplier } \\
\text { to supplier does not } \\
\text { seem unethical to me. }\end{array}$ & 1 & 2 & 3 & 4 & 5 & 6 & 7 \\
\hline & & $\begin{array}{l}\text { Strongly } \\
\text { Disagree }\end{array}$ & $\begin{array}{c}\text { Disagre } \\
\mathbf{e}\end{array}$ & $\begin{array}{c}\text { Moderatel } \\
\mathbf{y} \\
\text { Disagree }\end{array}$ & $\begin{array}{c}\text { Neither } \\
\text { Agree nor } \\
\text { Disagree }\end{array}$ & $\begin{array}{c}\text { Moderately } \\
\text { Agree }\end{array}$ & Agree & $\begin{array}{c}\text { Strongly } \\
\text { Agree }\end{array}$ \\
\hline 12 & $\begin{array}{l}\text { One of the major } \\
\text { reasons we continue to } \\
\text { have a relationship } \\
\text { with this supplier is } \\
\text { that loyalty is very } \\
\text { important and } \\
\text { therefore we feel a } \\
\text { sense of moral } \\
\text { obligation to remain in } \\
\text { the relationship. }\end{array}$ & 1 & 2 & 3 & 4 & 5 & 6 & 7 \\
\hline 13 & $\begin{array}{l}\text { If we got a better offer } \\
\text { from another supplier } \\
\text { we would not feel it } \\
\text { was right to leave our } \\
\text { current supplier. }\end{array}$ & 1 & 2 & 3 & 4 & 5 & 6 & 7 \\
\hline 14 & $\begin{array}{l}\text { We believe in the } \\
\text { value of remaining } \\
\text { loyal to one supplier. }\end{array}$ & 1 & 2 & 3 & 4 & 5 & 6 & 7 \\
\hline 15 & $\begin{array}{l}\text { Things were better in } \\
\text { the days when } \\
\text { establishments stayed } \\
\text { with only one supplier } \\
\text { at a time. }\end{array}$ & 1 & 2 & 3 & 4 & 5 & 6 & 7 \\
\hline 16 & $\begin{array}{l}\text { We do not feel that } \\
\text { remaining loyal to one } \\
\text { supplier is sensible } \\
\text { anymore. }\end{array}$ & 1 & 2 & 3 & 4 & 5 & 6 & 7 \\
\hline 17 & $\begin{array}{l}\text { Even when our } \\
\text { supplier gives us a } \\
\text { rather unlikely } \\
\text { explanation, we are } \\
\text { confident that they are } \\
\text { telling the truth. }\end{array}$ & 1 & 2 & 3 & 4 & 5 & 6 & 7 \\
\hline 18 & $\begin{array}{l}\text { Our supplier has often } \\
\text { provided us } \\
\text { information that has } \\
\text { later proven to be } \\
\text { inaccurate. }\end{array}$ & 1 & 2 & 3 & 4 & 5 & 6 & 7 \\
\hline 19 & $\begin{array}{l}\text { Our supplier usually } \\
\text { keeps the promises } \\
\text { that it makes to our } \\
\text { establishment. }\end{array}$ & 1 & 2 & 3 & 4 & 5 & 6 & 7 \\
\hline
\end{tabular}




\section{Appendix 1 (Continued)}

\begin{tabular}{|c|c|c|c|c|c|c|c|c|}
\hline 20 & $\begin{array}{l}\text { Whenever our supplier } \\
\text { gives us advice on our } \\
\text { business operations, } \\
\text { we know that it is } \\
\text { sharing its best } \\
\text { judgment. }\end{array}$ & 1 & 2 & 3 & 4 & 5 & 6 & 7 \\
\hline 21 & $\begin{array}{l}\text { Our establishment can } \\
\text { count on our supplier } \\
\text { to be sincere. }\end{array}$ & 1 & 2 & 3 & 4 & 5 & 6 & 7 \\
\hline 22 & $\begin{array}{l}\text { Though circumstances } \\
\text { change, we believe } \\
\text { that our supplier will } \\
\text { be ready and willing } \\
\text { to offer us assistance } \\
\text { and support. }\end{array}$ & 1 & 2 & 3 & 4 & 5 & 6 & 7 \\
\hline \multirow[t]{2}{*}{23} & $\begin{array}{l}\text { When making } \\
\text { important decisions, } \\
\text { our supplier is } \\
\text { concerned about our } \\
\text { welfare. }\end{array}$ & 1 & 2 & 3 & 4 & 5 & 6 & 7 \\
\hline & & $\begin{array}{l}\text { Strongly } \\
\text { Disagree }\end{array}$ & $\begin{array}{l}\text { Disagre } \\
\text { e }\end{array}$ & $\begin{array}{c}\text { Moderatel } \\
\mathbf{y} \\
\text { Disagree }\end{array}$ & $\begin{array}{c}\text { Neither } \\
\text { Agree nor } \\
\text { Disagree }\end{array}$ & $\begin{array}{c}\text { Moderately } \\
\text { Agree }\end{array}$ & Agree & $\begin{array}{c}\text { Strongly } \\
\text { Agree }\end{array}$ \\
\hline 24 & $\begin{array}{l}\text { When we share our } \\
\text { problems with our } \\
\text { supplier, we know that } \\
\text { it will respond with } \\
\text { understanding. }\end{array}$ & 1 & 2 & 3 & 4 & 5 & 6 & 7 \\
\hline 25 & $\begin{array}{l}\text { In the future, we can } \\
\text { count on our supplier } \\
\text { to consider how its } \\
\text { decisions and actions } \\
\text { will affect us. }\end{array}$ & 1 & 2 & 3 & 4 & 5 & 6 & 7 \\
\hline 26 & $\begin{array}{l}\text { When it comes to } \\
\text { things that are } \\
\text { important to us, we } \\
\text { can depend on our } \\
\text { supplier support. }\end{array}$ & 1 & 2 & 3 & 4 & 5 & 6 & 7 \\
\hline 27 & $\begin{array}{l}\text { I believe my supplier } \\
\text { is capable of } \\
\text { delivering products } \\
\text { that meet our needs. }\end{array}$ & 1 & 2 & 3 & 4 & 5 & 6 & 7 \\
\hline 28 & $\begin{array}{l}\text { I believe our supplier } \\
\text { is an expert in the } \\
\text { position that they } \\
\text { hold. }\end{array}$ & 1 & 2 & 3 & 4 & 5 & 6 & 7 \\
\hline 30 & $\begin{array}{l}\text { Generally speaking, } \\
\text { our supplier's } \\
\text { representatives are } \\
\text { poorly trained. }\end{array}$ & 1 & 2 & 3 & 4 & 5 & 6 & 7 \\
\hline 31 & $\begin{array}{l}\text { People with relevant } \\
\text { work experience are } \\
\text { employed by our } \\
\text { supplier. }\end{array}$ & 1 & 2 & 3 & 4 & 5 & 6 & 7 \\
\hline 32 & $\begin{array}{l}\text { Our supplier does } \\
\text { things competently. }\end{array}$ & 1 & 2 & 3 & 4 & 5 & 6 & 7 \\
\hline 33 & $\begin{array}{l}\text { Unfortunately, our } \\
\text { supplier does things } \\
\text { poorly. }\end{array}$ & 1 & 2 & 3 & 4 & 5 & 6 & 7 \\
\hline 34 & $\begin{array}{l}\text { Our supplier } \\
\text { employees perform } \\
\text { their tasks with skill. }\end{array}$ & 1 & 2 & 3 & 4 & 5 & 6 & 7 \\
\hline
\end{tabular}




\section{Appendix 1 (Continued)}

\begin{tabular}{|c|c|c|c|c|c|c|c|c|}
\hline 35 & $\begin{array}{l}\text { Our supplier does } \\
\text { things in a capable } \\
\text { manner. }\end{array}$ & 1 & 2 & 3 & 4 & 5 & 6 & 7 \\
\hline 36 & $\begin{array}{l}\text { Our supplier is a good } \\
\text { partner to deal with. }\end{array}$ & 1 & 2 & 3 & 4 & 5 & 6 & 7 \\
\hline 37 & $\begin{array}{l}\text { We are satisfied with } \\
\text { the products we get } \\
\text { from our supplier. }\end{array}$ & 1 & 2 & 3 & 4 & 5 & 6 & 7 \\
\hline 38 & $\begin{array}{l}\text { In general, we are } \\
\text { satisfied with our } \\
\text { dealings with our } \\
\text { supplier. }\end{array}$ & 1 & 2 & 3 & 4 & 5 & 6 & 7 \\
\hline 39 & $\begin{array}{l}\text { We will continue } \\
\text { having a relationship } \\
\text { with our supplier if we } \\
\text { can. }\end{array}$ & 1 & 2 & 3 & 4 & 5 & 6 & 7 \\
\hline \multirow[t]{2}{*}{40} & $\begin{array}{l}\text { We are satisfied with } \\
\text { the service we get } \\
\text { from our supplier. }\end{array}$ & 1 & 2 & 3 & 4 & 5 & 6 & 7 \\
\hline & & $\begin{array}{l}\text { Strongly } \\
\text { Disagree }\end{array}$ & $\begin{array}{c}\text { Disagre } \\
\mathrm{e}\end{array}$ & $\begin{array}{c}\text { Moderatel } \\
\mathbf{y} \\
\text { Disagree }\end{array}$ & $\begin{array}{c}\text { Neither } \\
\text { Agree nor } \\
\text { Disagree }\end{array}$ & $\begin{array}{c}\text { Moderately } \\
\text { Agree }\end{array}$ & Agree & $\begin{array}{c}\text { Strongly } \\
\text { Agree }\end{array}$ \\
\hline 41 & $\begin{array}{l}\text { Most of the } \\
\text { disagreements we } \\
\text { have had with our } \\
\text { supplier were settled } \\
\text { to our satisfaction. }\end{array}$ & 1 & 2 & 3 & 4 & 5 & 6 & 7 \\
\hline 42 & $\begin{array}{l}\text { Our supplier is very } \\
\text { interested in helping } \\
\text { us make our business } \\
\text { profitable. }\end{array}$ & 1 & 2 & 3 & 4 & 5 & 6 & 7 \\
\hline 43 & $\begin{array}{l}\text { We are satisfied with } \\
\text { the sales of our } \\
\text { supplier's products. }\end{array}$ & 1 & 2 & 3 & 4 & 5 & 6 & 7 \\
\hline 44 & $\begin{array}{l}\text { We are satisfied with } \\
\text { the performance of } \\
\text { our relationship with } \\
\text { our supplier. }\end{array}$ & 1 & 2 & 3 & 4 & 5 & 6 & 7 \\
\hline 45 & $\begin{array}{l}\text { We are satisfied with } \\
\text { the extent to which } \\
\text { our sales target has } \\
\text { been met. }\end{array}$ & 1 & 2 & 3 & 4 & 5 & 6 & 7 \\
\hline 46 & $\begin{array}{l}\text { Regarding the } \\
\text { economic aspect of } \\
\text { our relationship with } \\
\text { our supplier we are } \\
\text { pleased with its } \\
\text { performance. }\end{array}$ & 1 & 2 & 3 & 4 & 5 & 6 & 7 \\
\hline \multirow[t]{2}{*}{47} & $\begin{array}{l}\text { Regarding the } \\
\text { economic aspect of } \\
\text { our relationship with } \\
\text { our supplier we are } \\
\text { pleased with its } \\
\text { reliability. }\end{array}$ & 1 & 2 & 3 & 4 & 5 & 6 & 7 \\
\hline & $\begin{array}{l}\text { If for some reason } \\
\text { our supplier ended } \\
\text { its relationship with } \\
\text { us... }\end{array}$ & $\begin{array}{l}\text { Strongly } \\
\text { Disagree }\end{array}$ & $\begin{array}{c}\text { Disagre } \\
\text { e }\end{array}$ & $\begin{array}{c}\text { Moderatel } \\
\mathbf{y} \\
\text { Disagree }\end{array}$ & $\begin{array}{c}\text { Neither } \\
\text { Agree nor } \\
\text { Disagree }\end{array}$ & $\begin{array}{l}\text { Moderately } \\
\text { Agree }\end{array}$ & Agree & $\begin{array}{c}\text { Strongly } \\
\text { Agree }\end{array}$ \\
\hline
\end{tabular}


Appendix 1 (Continued

\begin{tabular}{|c|c|c|c|c|c|c|c|c|}
\hline 48 & $\begin{array}{l}\text { The loss would hurt } \\
\text { our sales of non- } \\
\text { supplier products as } \\
\text { well. }\end{array}$ & 1 & 2 & 3 & 4 & 5 & 6 & 7 \\
\hline 49 & $\begin{array}{l}\text { We could compensate } \\
\text { for it by switching our } \\
\text { efforts to other } \\
\text { supplier products we } \\
\text { carry. }\end{array}$ & 1 & 2 & 3 & 4 & 5 & 6 & 7 \\
\hline 50 & $\begin{array}{l}\text { It would be relatively } \\
\text { easy for us to develop } \\
\text { a relationship with a } \\
\text { different supplier. }\end{array}$ & 1 & 2 & 3 & 4 & 5 & 6 & 7 \\
\hline 51 & $\begin{array}{l}\text { We would suffer a } \\
\text { significant loss of } \\
\text { income despite our } \\
\text { best efforts to replace } \\
\text { the lost incomes. }\end{array}$ & 1 & 2 & 3 & 4 & 5 & 6 & 7 \\
\hline
\end{tabular}

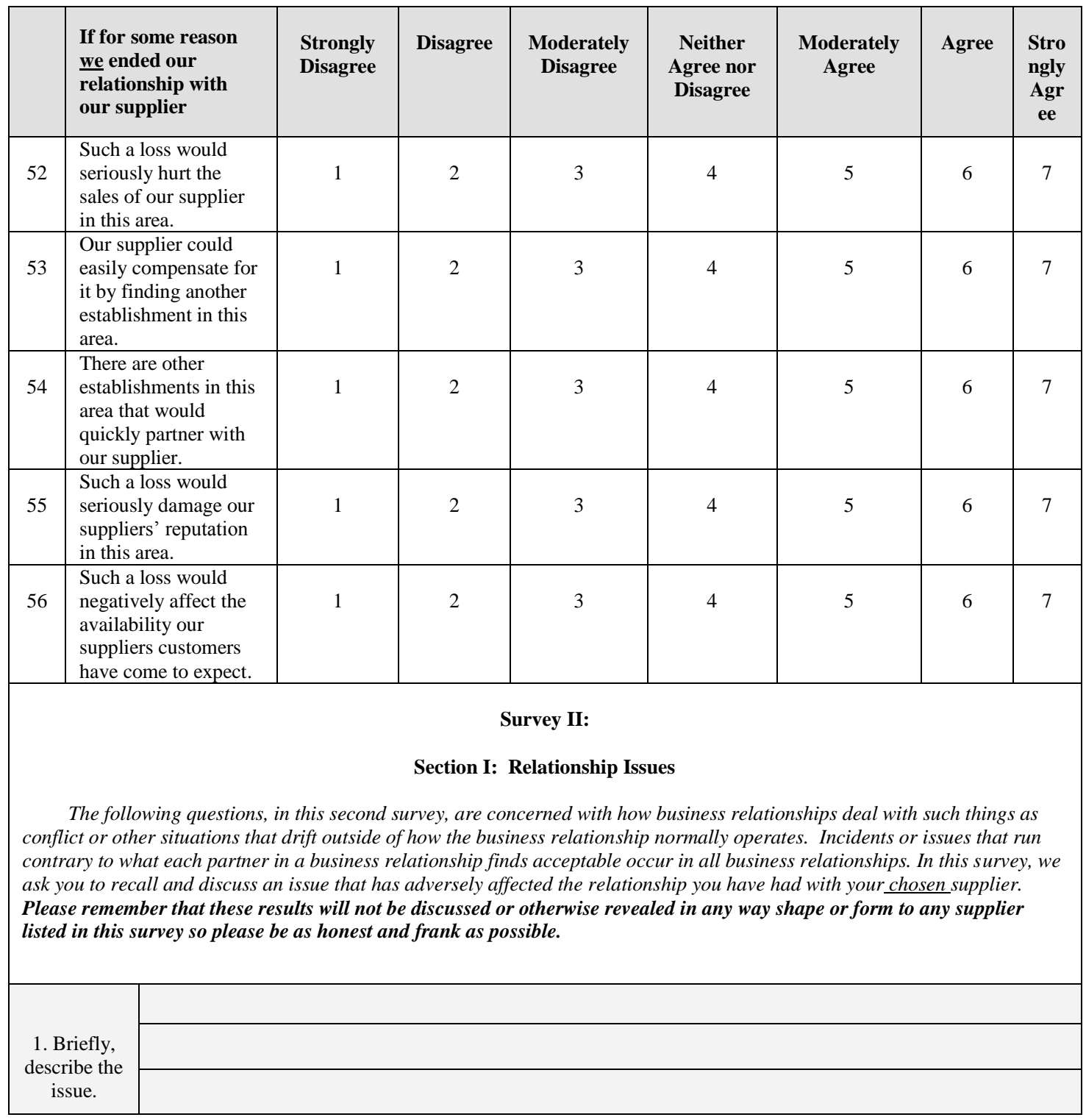


Appendix 1 (Continued)

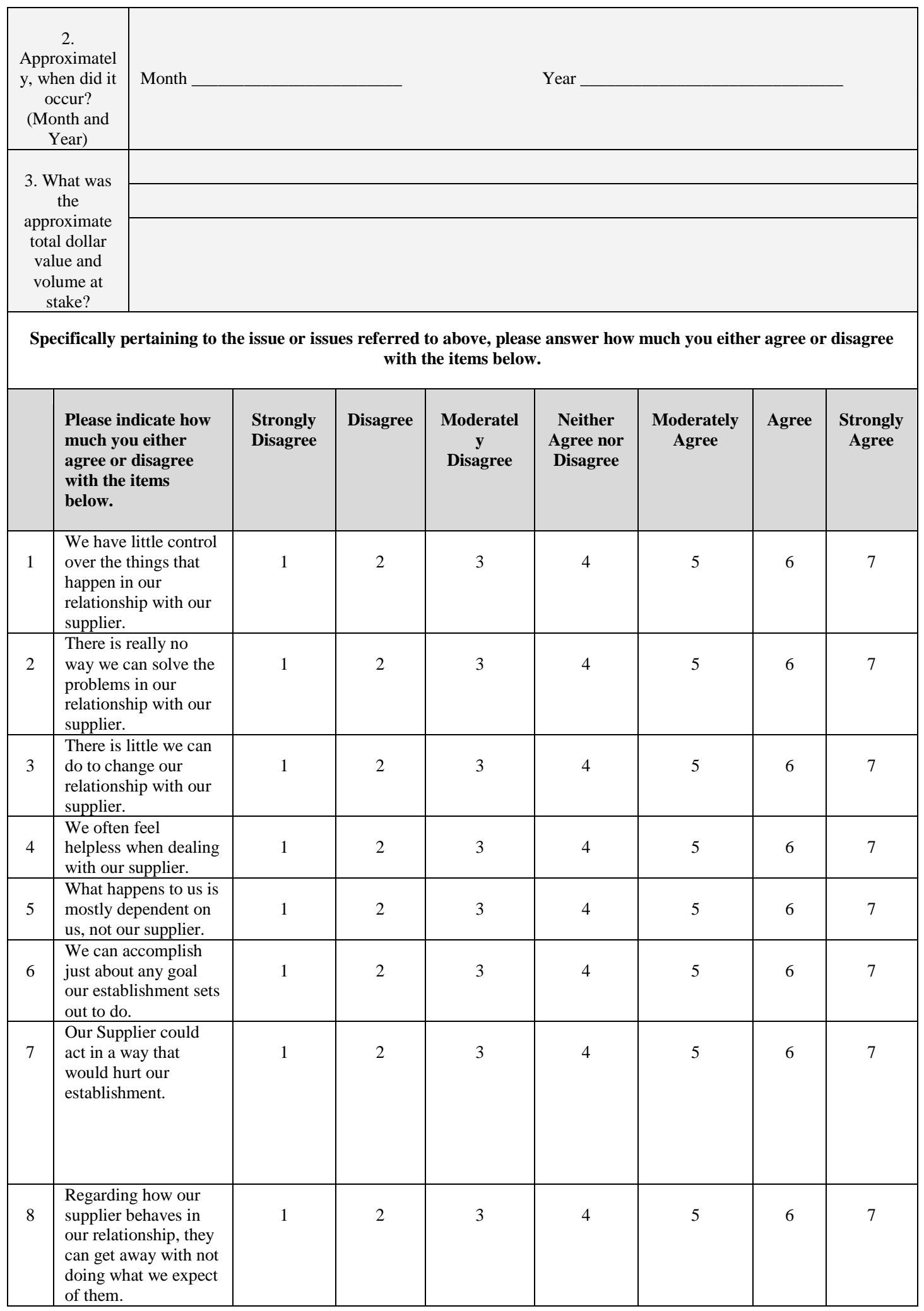




\section{Appendix 1 (Continued)}

\begin{tabular}{|c|c|c|c|c|c|c|c|c|}
\hline 9 & $\begin{array}{l}\text { We do not have the } \\
\text { ability to stop our } \\
\text { supplier's behavior, } \\
\text { even if it hurts our } \\
\text { establishment. }\end{array}$ & 1 & 2 & 3 & 4 & 5 & 6 & 7 \\
\hline & & $\begin{array}{l}\text { Strongly } \\
\text { Disagree }\end{array}$ & Disagree & $\begin{array}{c}\text { Moderatel } \\
\mathbf{y} \\
\text { Disagree }\end{array}$ & $\begin{array}{l}\text { Neither } \\
\text { Agree nor } \\
\text { Disagree }\end{array}$ & $\begin{array}{c}\text { Moderately } \\
\text { Agree }\end{array}$ & Agree & $\begin{array}{c}\text { Strongly } \\
\text { Agree }\end{array}$ \\
\hline 10 & $\begin{array}{l}\text { I do not believe our } \\
\text { supplier always } \\
\text { adheres to all } \\
\text { applicable laws and } \\
\text { regulations. }\end{array}$ & 1 & 2 & 3 & 4 & 5 & 6 & 7 \\
\hline 11 & $\begin{array}{l}\text { I do not believe our } \\
\text { supplier always } \\
\text { accurately represents } \\
\text { their credentials. }\end{array}$ & 1 & 2 & 3 & 4 & 5 & 6 & 7 \\
\hline 12 & $\begin{array}{l}\text { I do not believe our } \\
\text { supplier is always } \\
\text { honest in serving us } \\
\text { as a client. }\end{array}$ & 1 & 2 & 3 & 4 & 5 & 6 & 7 \\
\hline 13 & $\begin{array}{l}\text { I believe our supplier } \\
\text { would participate in a } \\
\text { conflict of interest } \\
\text { without prior notice } \\
\text { to all parties } \\
\text { involved. }\end{array}$ & 1 & 2 & 3 & 4 & 5 & 6 & 7 \\
\hline 14 & $\begin{array}{l}\text { I often feel as if our } \\
\text { supplier is not } \\
\text { completely truthful } \\
\text { with me. }\end{array}$ & 1 & 2 & 3 & 4 & 5 & 6 & 7 \\
\hline 15 & $\begin{array}{l}\text { Our supplier is } \\
\text { basically honest. }\end{array}$ & 1 & 2 & 3 & 4 & 5 & 6 & 7 \\
\hline 16 & $\begin{array}{l}\text { Our supplier seldom } \\
\text { lies to me. }\end{array}$ & 1 & 2 & 3 & 4 & 5 & 6 & 7 \\
\hline 17 & $\begin{array}{l}\text { Our supplier rarely } \\
\text { tells us what they are } \\
\text { thinking. }\end{array}$ & 1 & 2 & 3 & 4 & 5 & 6 & 7 \\
\hline 18 & $\begin{array}{l}\text { I do not believe our } \\
\text { supplier always } \\
\text { considers my } \\
\text { establishment's best } \\
\text { interest when acting. }\end{array}$ & 1 & 2 & 3 & 4 & 5 & 6 & 7 \\
\hline 19 & $\begin{array}{l}\text { I believe our supplier, } \\
\text { at times, acts in ways } \\
\text { that could be harmful } \\
\text { to our relationship. }\end{array}$ & 1 & 2 & 3 & 4 & 5 & 6 & 7 \\
\hline 20 & $\begin{array}{l}\text { I believe our supplier, } \\
\text { at times, acts in ways } \\
\text { that could be harmful } \\
\text { to my establishment. }\end{array}$ & 1 & 2 & 3 & 4 & 5 & 6 & 7 \\
\hline 21 & $\begin{array}{l}\text { I believe our supplier, } \\
\text { at times, takes our } \\
\text { relationship for } \\
\text { granted. }\end{array}$ & 1 & 2 & 3 & 4 & 5 & 6 & 7 \\
\hline 22 & $\begin{array}{l}\text { I believe our supplier, } \\
\text { at times, uses our } \\
\text { relationship against } \\
\text { us for their own gain. }\end{array}$ & 1 & 2 & 3 & 4 & 5 & 6 & 7 \\
\hline
\end{tabular}




\section{Appendix 1 (Continued)}

\section{Section II: Relationship Dynamics}

All relationships, including business relationships, change in some way over time. In this section we ask you to evaluate the relationship you have with your chosen supplier AS IT CURRENTLY IS. When making this evaluation we ask that you consider all the events and issues that have transpired over time that have helped form your opinion of this relationship as it is today.

\begin{tabular}{|c|c|c|c|c|c|c|c|c|}
\hline & $\begin{array}{l}\text { As compared to } \\
\text { other similar retail } \\
\text { establishments, our } \\
\text { performance is very } \\
\text { high in terms of: }\end{array}$ & $\begin{array}{l}\text { Strongly } \\
\text { Disagree }\end{array}$ & $\begin{array}{c}\text { Disagre } \\
\mathrm{e}\end{array}$ & $\begin{array}{c}\text { Moderatel } \\
\mathbf{y} \\
\text { Disagree }\end{array}$ & $\begin{array}{c}\text { Neither } \\
\text { Agree nor } \\
\text { Disagree }\end{array}$ & $\begin{array}{c}\text { Moderately } \\
\text { Agree }\end{array}$ & Agree & $\begin{array}{c}\text { Strongly } \\
\text { Agree }\end{array}$ \\
\hline 1 & Sales Growth & 1 & 2 & 3 & 4 & 5 & 6 & 7 \\
\hline 2 & Profit Growth & 1 & 2 & 3 & 4 & 5 & 6 & 7 \\
\hline 3 & Overall Profitability & 1 & 2 & 3 & 4 & 5 & 6 & 7 \\
\hline 4 & Labor Productivity & 1 & 2 & 3 & 4 & 5 & 6 & 7 \\
\hline 5 & Cash Flow & 1 & 2 & 3 & 4 & 5 & 6 & 7 \\
\hline & $\begin{array}{l}\text { Please indicate how } \\
\text { much you either } \\
\text { agree or disagree } \\
\text { with the items } \\
\text { below. }\end{array}$ & $\begin{array}{l}\text { Strongly } \\
\text { Disagree }\end{array}$ & $\begin{array}{c}\text { Disagre } \\
\mathrm{e}\end{array}$ & $\begin{array}{c}\text { Moderatel } \\
\mathbf{y} \\
\text { Disagree }\end{array}$ & $\begin{array}{c}\text { Neither } \\
\text { Agree nor } \\
\text { Disagree }\end{array}$ & $\begin{array}{c}\text { Moderately } \\
\text { Agree }\end{array}$ & Agree & $\begin{array}{c}\text { Strongly } \\
\text { Agree }\end{array}$ \\
\hline 6 & $\begin{array}{l}\text { Our supplier uses } \\
\text { flexible systems of } \\
\text { delivery that have } \\
\text { been adapted for our } \\
\text { establishment. }\end{array}$ & 1 & 2 & 3 & 4 & 5 & 6 & 7 \\
\hline 7 & $\begin{array}{l}\text { Our supplier has } \\
\text { available novel } \\
\text { distribution systems } \\
\text { (for example online } \\
\text { ordering) for my } \\
\text { establishment to use. }\end{array}$ & 1 & 2 & 3 & 4 & 5 & 6 & 7 \\
\hline 8 & $\begin{array}{l}\text { Our supplier offers } \\
\text { my establishment a } \\
\text { diversified product } \\
\text { range. }\end{array}$ & 1 & 2 & 3 & 4 & 5 & 6 & 7 \\
\hline 9 & $\begin{array}{l}\text { Our supplier uses } \\
\text { modern stock and } \\
\text { control systems when } \\
\text { doing business with } \\
\text { my establishment. }\end{array}$ & 1 & 2 & 3 & 4 & 5 & 6 & 7 \\
\hline 11 & $\begin{array}{l}\text { Our supplier has } \\
\text { offered our } \\
\text { establishment new } \\
\text { products since the } \\
\text { beginning of our } \\
\text { relationship with } \\
\text { them. }\end{array}$ & 1 & 2 & 3 & 4 & 5 & 6 & 7 \\
\hline
\end{tabular}




\section{Appendix 1 (Continued)}

\begin{tabular}{|c|c|c|c|c|c|c|c|c|}
\hline 12 & $\begin{array}{l}\text { Our supplier has } \\
\text { offered our } \\
\text { establishment new } \\
\text { services since the } \\
\text { beginning of our } \\
\text { relationship with } \\
\text { them. }\end{array}$ & 1 & 2 & 3 & 4 & 5 & 6 & 7 \\
\hline & & $\begin{array}{l}\text { Strongly } \\
\text { Disagree }\end{array}$ & $\begin{array}{c}\text { Disagre } \\
\text { e }\end{array}$ & $\begin{array}{c}\text { Moderatel } \\
\mathbf{y} \\
\text { Disagree }\end{array}$ & $\begin{array}{l}\text { Neither } \\
\text { Agree nor } \\
\text { Disagree }\end{array}$ & $\begin{array}{c}\text { Moderately } \\
\text { Agree }\end{array}$ & Agree & $\begin{array}{c}\text { Strongly } \\
\text { Agree }\end{array}$ \\
\hline 13 & $\begin{array}{l}\text { Our supplier has } \\
\text { offered our } \\
\text { establishment new or } \\
\text { updated delivery } \\
\text { methods since the } \\
\text { beginning of our } \\
\text { relationship with } \\
\text { them. }\end{array}$ & 1 & 2 & 3 & 4 & 5 & 6 & 7 \\
\hline 14 & $\begin{array}{l}\text { Our supplier has } \\
\text { offered our } \\
\text { establishment new or } \\
\text { updated ordering } \\
\text { methods since the } \\
\text { beginning of our } \\
\text { relationship with } \\
\text { them. }\end{array}$ & 1 & 2 & 3 & 4 & 5 & 6 & 7 \\
\hline 15 & $\begin{array}{l}\text { When it comes to our } \\
\text { relationships, we } \\
\text { prefer variety to } \\
\text { routine. }\end{array}$ & 1 & 2 & 3 & 4 & 5 & 6 & 7 \\
\hline 16 & $\begin{array}{l}\text { When it comes to our } \\
\text { relationships, we } \\
\text { prefer to stick with } \\
\text { things that we know. }\end{array}$ & 1 & 2 & 3 & 4 & 5 & 6 & 7 \\
\hline 17 & $\begin{array}{l}\text { When it comes to our } \\
\text { relationships, we } \\
\text { dislike change. }\end{array}$ & 1 & 2 & 3 & 4 & 5 & 6 & 7 \\
\hline 18 & $\begin{array}{l}\text { When it comes to } \\
\text { how our relationships } \\
\text { operate, we are } \\
\text { attached to } \\
\text { conventional ways of } \\
\text { doing things. }\end{array}$ & 1 & 2 & 3 & 4 & 5 & 6 & 7 \\
\hline 19 & $\begin{array}{l}\text { When it comes to our } \\
\text { relationship we often } \\
\text { find new ways of } \\
\text { doing things. }\end{array}$ & 1 & 2 & 3 & 4 & 5 & 6 & 7 \\
\hline 20 & $\begin{array}{l}\text { The relationship we } \\
\text { have with our } \\
\text { supplier lacks a long- } \\
\text { range perspective. }\end{array}$ & 1 & 2 & 3 & 4 & 5 & 6 & 7 \\
\hline 21 & $\begin{array}{l}\text { When it comes to the } \\
\text { relationship my } \\
\text { establishment has } \\
\text { with our supplier, } \\
\text { things normally } \\
\text { happen the same way } \\
\text { every time every } \\
\text { time. }\end{array}$ & 1 & 2 & 3 & 4 & 5 & 6 & 7 \\
\hline 22 & $\begin{array}{l}\text { Our supplier does not } \\
\text { waste time on change } \\
\text { initiatives. }\end{array}$ & 1 & 2 & 3 & 4 & 5 & 6 & 7 \\
\hline
\end{tabular}


Appendix 1 (Continued)

\begin{tabular}{|c|c|c|c|c|c|c|c|c|}
\hline 23 & $\begin{array}{l}\text { Our supplier does not } \\
\text { worry about the } \\
\text { future of our } \\
\text { relationship. }\end{array}$ & 1 & 2 & 3 & 4 & 5 & 6 & 7 \\
\hline 24 & $\begin{array}{l}\text { Our supplier does not } \\
\text { usually make any } \\
\text { changes. }\end{array}$ & 1 & 2 & 3 & 4 & 5 & 6 & 7 \\
\hline 25 & $\begin{array}{l}\text { Our supplier often } \\
\text { makes major } \\
\text { changes. }\end{array}$ & 1 & 2 & 3 & 4 & 5 & 6 & 7 \\
\hline \multirow[t]{2}{*}{26} & $\begin{array}{l}\text { Regarding our } \\
\text { relationship with our } \\
\text { supplier we do not } \\
\text { worry about future } \\
\text { trouble in the } \\
\text { relationship. }\end{array}$ & 1 & 2 & 3 & 4 & 5 & 6 & 7 \\
\hline & & $\begin{array}{l}\text { Strongly } \\
\text { Disagree }\end{array}$ & $\begin{array}{c}\text { Disagre } \\
\mathbf{e}\end{array}$ & $\begin{array}{c}\text { Moderatel } \\
\mathbf{y} \\
\text { Disagree }\end{array}$ & $\begin{array}{l}\text { Neither } \\
\text { Agree nor } \\
\text { Disagree }\end{array}$ & $\begin{array}{l}\text { Moderately } \\
\text { Agree }\end{array}$ & Agree & $\begin{array}{c}\text { Strongly } \\
\text { Agree }\end{array}$ \\
\hline 27 & $\begin{array}{l}\text { Regarding the } \\
\text { relationship we have } \\
\text { with our supplier, we } \\
\text { are planning to make } \\
\text { changes to how the } \\
\text { relationship works. }\end{array}$ & 1 & 2 & 3 & 4 & 5 & 6 & 7 \\
\hline 28 & $\begin{array}{l}\text { Regarding the } \\
\text { relationship we have } \\
\text { with our supplier, I } \\
\text { do not believe we } \\
\text { would recognize the } \\
\text { need to change } \\
\text { anything if the need } \\
\text { developed. }\end{array}$ & 1 & 2 & 3 & 4 & 5 & 6 & 7 \\
\hline 29 & $\begin{array}{l}\text { I do not believe my } \\
\text { establishment } \\
\text { continues to look for } \\
\text { other suppliers. }\end{array}$ & 1 & 2 & 3 & 4 & 5 & 6 & 7 \\
\hline \multirow[t]{2}{*}{30} & $\begin{array}{l}\text { I do not believe my } \\
\text { establishment would } \\
\text { recognize a better } \\
\text { supplier if one was } \\
\text { available. }\end{array}$ & 1 & 2 & 3 & 4 & 5 & 6 & 7 \\
\hline & $\begin{array}{l}\text { Please indicate how strong } \\
\text { or weak the relationship } \\
\text { you have with your } \\
\text { supplier is, as it pertain to } \\
\text { the questions below. }\end{array}$ & $\begin{array}{l}\text { Very } \\
\text { Weak }\end{array}$ & Weak & $\begin{array}{c}\text { Moderatel } \\
\mathbf{y} \\
\text { Weak }\end{array}$ & $\begin{array}{l}\text { Neither } \\
\text { Weak nor } \\
\text { Strong }\end{array}$ & $\begin{array}{c}\text { Moderately } \\
\text { Strong }\end{array}$ & $\begin{array}{c}\text { Stron } \\
\text { g }\end{array}$ & $\begin{array}{l}\text { Very } \\
\text { Strong }\end{array}$ \\
\hline 31 & $\begin{array}{l}\text { What is your overall } \\
\text { assessment of the } \\
\text { strength of your } \\
\text { relationship with } \\
\text { your supplier's sales } \\
\text { rep? }\end{array}$ & 1 & 2 & 3 & 4 & 5 & 6 & 7 \\
\hline 32 & $\begin{array}{l}\text { How strong would } \\
\text { you like the strength } \\
\text { of your relationship } \\
\text { with your supplier's } \\
\text { sales rep to be? }\end{array}$ & 1 & 2 & 3 & 4 & 5 & 6 & 7 \\
\hline
\end{tabular}




\section{Appendix 1 (Continued)}

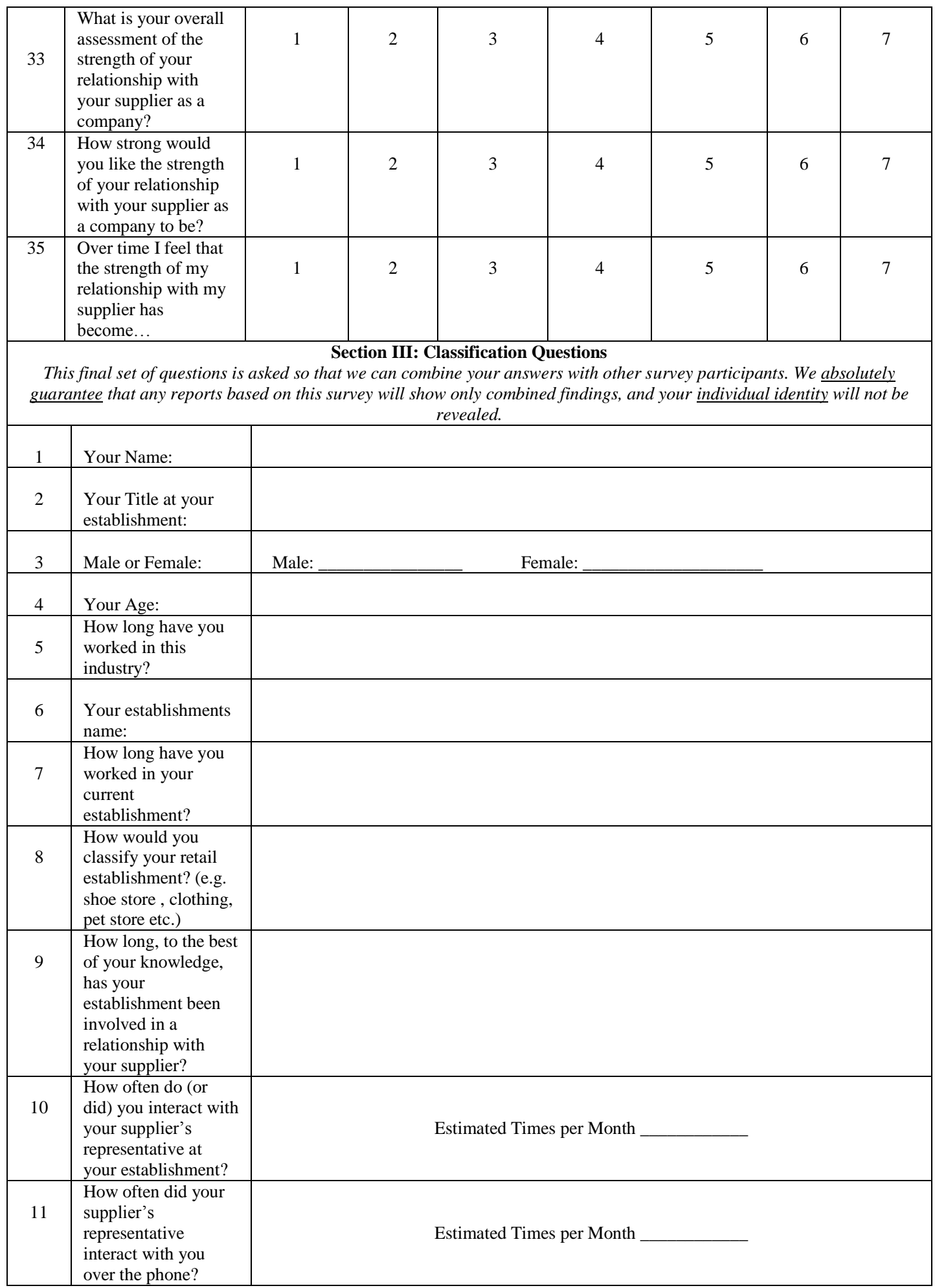


Appendix 1 (Continued)

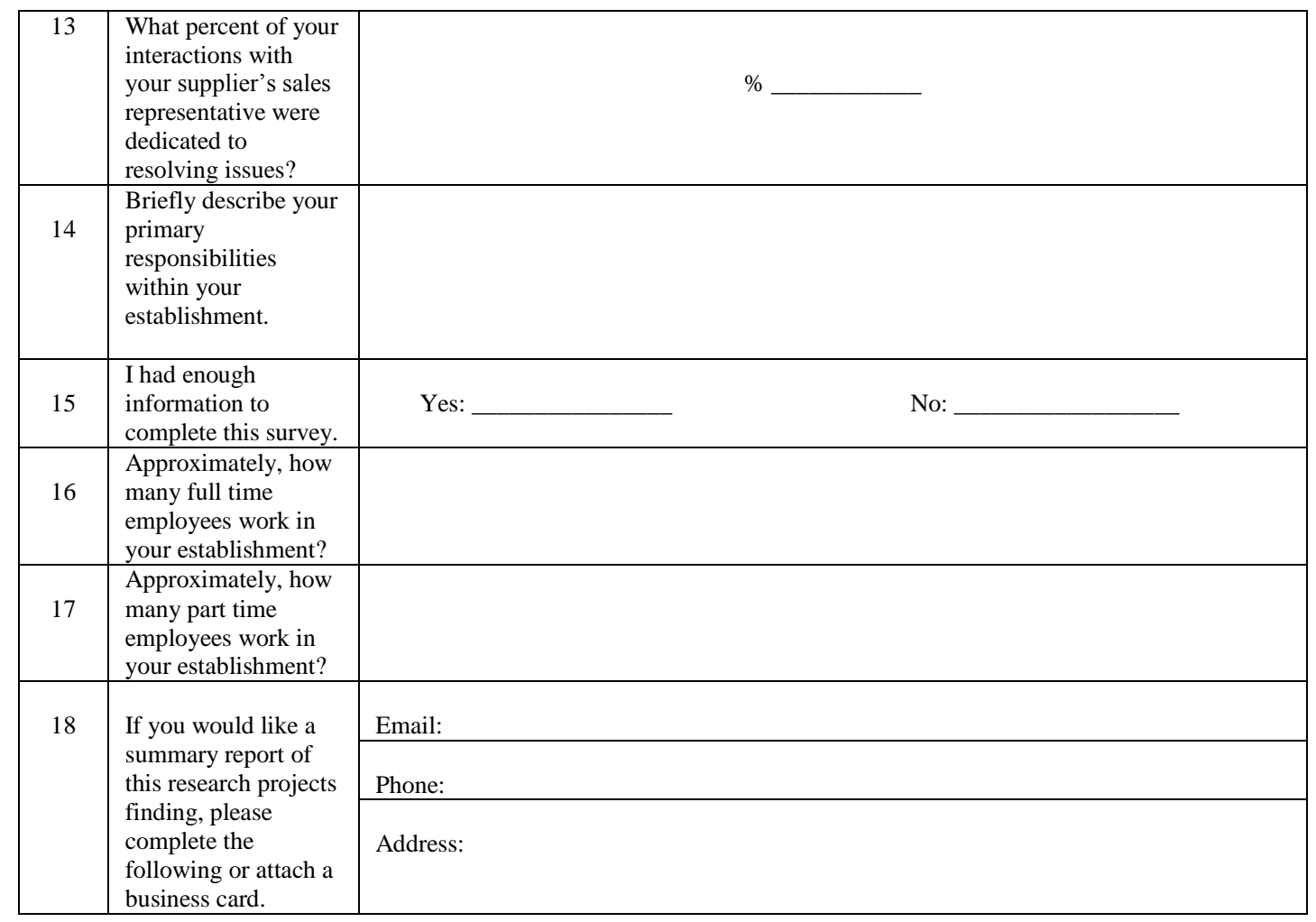


Appendix 2: Main Study Survey

\author{
University of South Florida
}

\title{
Business to Business Relationship Main Study Survey 2008 - 2009
}

\section{Dear Organizational Buyer:}

As someone who keeps in contact with your establishment's business to business relational partners you are in a unique position to gauge the quality of the relationship you and your establishment has with these partnering firms.

The following survey is for two research projects on business to business relationships. These studies are designed to gauge the quality of business to business relationships and how you and your relational partners handle issues of conflict. It is believed that the results of these surveys will provide a deeper understanding of how business to business relationships evolve and change over time and consequently provide a deeper understanding of how best to manage and govern these business relationships.

Your participation in this survey is completely voluntary and your individual responses will remain strictly confidential. No names will ever be revealed to any member of any partnering firm. All reports based on this survey will only present combined data. Also, please keep in mind that the authors of this survey are only affiliated with the University of South Florida and the University of Oklahoma and have no affiliation with any organization within the business community. Therefore, we have no reason to consult with any organization about the results of this study. So, please be completely honest and as frank as possible.

Thank you in advance for your cooperation.

P.S. These surveys should take about 20 - 25 minutes to complete.

\author{
Survey I: \\ Section I: Relationship with Focal Relationship Partner
}

This section seeks your opinion about the quality of the relationship you currently have with one of your main suppliers. For the purpose of this study, a main supplier is defined as a supplier with which your organization has conducted a significant amount of business, not necessarily your best or favorite business to business partner. Please review the following statement pertaining to the relationship you have with one of your main suppliers and provide your evaluations by checking or circling the appropriate box. All questions refer to the supplier you've identified and not the individual representatives of the supplier.

\begin{tabular}{|l|l|l|}
\hline & $\begin{array}{l}\text { Name of Relationship Partner (Optional) : } \\
\text { Please identify a } \\
\text { main supplier that } \\
\text { your organization } \\
\text { has conducted a } \\
\text { significant amount of } \\
\text { business with. }\end{array}$ & $\begin{array}{l}\text { (This question is asked for the purposes of calling to your attention a specific supplier } \\
\text { that your organization has conducted a significant amount of business with. } \\
\text { Answering this question is strictly voluntary and not critical for the completion of this } \\
\text { survey. However, please answer the following questions with the same supplier in } \\
\text { mind) }\end{array}$ \\
\hline
\end{tabular}




\section{Appendix 2 (Continued)}

\begin{tabular}{|c|c|c|c|c|c|c|c|c|}
\hline & $\begin{array}{l}\text { The below items } \\
\text { need to be answered } \\
\text { in } 2 \text { parts. Please } \\
\text { indicate the degree to } \\
\text { which you believe } \\
\text { that (1) your supplier } \\
\text { would agree with the } \\
\text { following statements, } \\
\text { and (2) you would } \\
\text { agree with the } \\
\text { following statements: }\end{array}$ & $\begin{array}{l}\text { Strongly } \\
\text { Disagree }\end{array}$ & Disagree & $\begin{array}{c}\text { Moderatel } \\
\mathbf{y} \\
\text { Disagree }\end{array}$ & $\begin{array}{c}\text { Neither } \\
\text { Agree nor } \\
\text { Disagree }\end{array}$ & $\begin{array}{c}\text { Moderately } \\
\text { Agree }\end{array}$ & Agree & $\begin{array}{c}\text { Strongly } \\
\text { Agree }\end{array}$ \\
\hline $1 \mathrm{a}$ & $\begin{array}{l}\text { Managers in this } \\
\text { business often engage } \\
\text { in behaviors that I } \\
\text { consider to be } \\
\text { unethical. (Suppliers } \\
\text { Response) }\end{array}$ & 1 & 2 & 3 & 4 & 5 & 6 & 7 \\
\hline $1 b$ & $\begin{array}{l}\text { Managers in this } \\
\text { business often engage } \\
\text { in behaviors that I } \\
\text { consider to be } \\
\text { unethical. (Your } \\
\text { Response) }\end{array}$ & 1 & 2 & 3 & 4 & 5 & 6 & 7 \\
\hline $2 \mathrm{a}$ & $\begin{array}{l}\text { In order to succeed in } \\
\text { this company, it is } \\
\text { often necessary to } \\
\text { compromise one's } \\
\text { ethics. (Suppliers } \\
\text { Response) }\end{array}$ & 1 & 2 & 3 & 4 & 5 & 6 & 7 \\
\hline $2 b$ & $\begin{array}{l}\text { In order to succeed in } \\
\text { this company, it is } \\
\text { often necessary to } \\
\text { compromise one's } \\
\text { ethics. (Your } \\
\text { Response) }\end{array}$ & 1 & 2 & 3 & 4 & 5 & 6 & 7 \\
\hline $3 a$ & $\begin{array}{l}\text { Top Management in } \\
\text { my company has let it } \\
\text { be known in no } \\
\text { uncertain terms that } \\
\text { unethical behavior } \\
\text { will not be tolerated. } \\
\text { (Suppliers Response) }\end{array}$ & 1 & 2 & 3 & 4 & 5 & 6 & 7 \\
\hline $3 b$ & $\begin{array}{l}\text { Top Management in } \\
\text { my company has let it } \\
\text { be known in no } \\
\text { uncertain terms that } \\
\text { unethical behavior } \\
\text { will not be tolerated. } \\
\text { (Your Response) }\end{array}$ & 1 & 2 & 3 & 4 & 5 & 6 & 7 \\
\hline
\end{tabular}


Appendix 2 (Continued)

\begin{tabular}{|c|c|c|c|c|c|c|c|c|}
\hline $4 a$ & $\begin{array}{l}\text { If a manager in my } \\
\text { company is discovered } \\
\text { to have engaged in } \\
\text { unethical behavior that } \\
\text { results primarily in } \\
\text { personal gain (rather } \\
\text { than corporate gain), } \\
\text { he or she will be } \\
\text { promptly } \\
\text { reprimanded. } \\
\text { (Suppliers Response) }\end{array}$ & 1 & 2 & 3 & 4 & 5 & 6 & 7 \\
\hline $4 \mathrm{~b}$ & $\begin{array}{l}\text { If a manager in my } \\
\text { company is discovered } \\
\text { to have engaged in } \\
\text { unethical behavior that } \\
\text { results primarily in } \\
\text { personal gain (rather } \\
\text { than corporate gain), } \\
\text { he or she will be } \\
\text { promptly } \\
\text { reprimanded. (Your } \\
\text { Response) }\end{array}$ & 1 & 2 & 3 & 4 & 5 & 6 & 7 \\
\hline $5 \mathrm{a}$ & $\begin{array}{l}\text { If a manager in my } \\
\text { company is discovered } \\
\text { to have engaged in } \\
\text { unethical behavior that } \\
\text { results primarily in } \\
\text { corporate gain (rather } \\
\text { than personal gain), he } \\
\text { or she will be } \\
\text { promptly } \\
\text { reprimanded. } \\
\text { (Suppliers Response) }\end{array}$ & 1 & 2 & 3 & 4 & 5 & 6 & 7 \\
\hline $5 b$ & $\begin{array}{l}\text { If a manager in my } \\
\text { company is discovered } \\
\text { to have engaged in } \\
\text { unethical behavior that } \\
\text { results primarily in } \\
\text { corporate gain (rather } \\
\text { than personal gain), he } \\
\text { or she will be } \\
\text { promptly } \\
\text { reprimanded. (Your } \\
\text { Response) }\end{array}$ & 1 & 2 & 3 & 4 & 5 & 6 & 7 \\
\hline & $\begin{array}{l}\text { Please indicate how } \\
\text { much you either } \\
\text { agree or disagree } \\
\text { with the items below. }\end{array}$ & $\begin{array}{l}\text { Strongly } \\
\text { Disagree }\end{array}$ & Disagree & $\begin{array}{c}\text { Moderatel } \\
\mathbf{y} \\
\text { Disagree }\end{array}$ & $\begin{array}{l}\text { Neither } \\
\text { Agree nor } \\
\text { Disagree }\end{array}$ & $\begin{array}{l}\text { Moderately } \\
\text { Agree }\end{array}$ & Agree & $\begin{array}{c}\text { Strongly } \\
\text { Agree }\end{array}$ \\
\hline 1 & $\begin{array}{l}\text { I would be very happy } \\
\text { to not ever have to } \\
\text { change our supplier }\end{array}$ & 1 & 2 & 3 & 4 & 5 & 6 & 7 \\
\hline 2 & $\begin{array}{l}\text { I think that I could } \\
\text { easily become as } \\
\text { attached to another } \\
\text { supplier as I am to this } \\
\text { one. }\end{array}$ & 1 & 2 & 3 & 4 & 5 & 6 & 7 \\
\hline 3 & $\begin{array}{l}\text { I do not feel like part } \\
\text { of the family with our } \\
\text { supplier. }\end{array}$ & 1 & 2 & 3 & 4 & 5 & 6 & 7 \\
\hline
\end{tabular}


Appendix 2 (Continued)

\begin{tabular}{|c|c|c|c|c|c|c|c|c|}
\hline 4 & $\begin{array}{l}\text { My supplier has a } \\
\text { great deal of personal } \\
\text { meaning for me. }\end{array}$ & 1 & 2 & 3 & 4 & 5 & 6 & 7 \\
\hline & $\begin{array}{l}\text { Please indicate how } \\
\text { much you either } \\
\text { agree or disagree } \\
\text { with the items below. }\end{array}$ & $\begin{array}{l}\text { Strongly } \\
\text { Disagree }\end{array}$ & Disagree & $\begin{array}{c}\text { Moderatel } \\
\mathbf{y} \\
\text { Disagree }\end{array}$ & $\begin{array}{l}\text { Neither } \\
\text { Agree nor } \\
\text { Disagree }\end{array}$ & $\begin{array}{c}\text { Moderately } \\
\text { Agree }\end{array}$ & Agree & $\begin{array}{c}\text { Strongly } \\
\text { Agree }\end{array}$ \\
\hline 5 & $\begin{array}{l}\text { I do not feel a strong } \\
\text { sense of belonging } \\
\text { with our supplier }\end{array}$ & 1 & 2 & 3 & 4 & 5 & 6 & 7 \\
\hline 6 & $\begin{array}{l}\text { I do not believe that } \\
\text { an establishment must } \\
\text { always be loyal to } \\
\text { their suppliers }\end{array}$ & 1 & 2 & 3 & 4 & 5 & 6 & 7 \\
\hline 7 & $\begin{array}{l}\text { Jumping from supplier } \\
\text { to supplier does not } \\
\text { seem unethical to me. }\end{array}$ & 1 & 2 & 3 & 4 & 5 & 6 & 7 \\
\hline 8 & $\begin{array}{l}\text { One of the major } \\
\text { reasons we continue to } \\
\text { have a relationship } \\
\text { with our supplier is } \\
\text { that loyalty is very } \\
\text { important and } \\
\text { therefore we feel a } \\
\text { sense of moral } \\
\text { obligation to remain in } \\
\text { the relationship. }\end{array}$ & 1 & 2 & 3 & 4 & 5 & 6 & 7 \\
\hline 9 & $\begin{array}{l}\text { If we got a better offer } \\
\text { from another supplier } \\
\text { we would not feel it } \\
\text { was right to leave our } \\
\text { current supplier }\end{array}$ & 1 & 2 & 3 & 4 & 5 & 6 & 7 \\
\hline 10 & $\begin{array}{l}\text { We believe in the } \\
\text { value of remaining } \\
\text { loyal to one supplier } \\
\text { when possible }\end{array}$ & 1 & 2 & 3 & 4 & 5 & 6 & 7 \\
\hline 11 & $\begin{array}{l}\text { Things were better in } \\
\text { the days when } \\
\text { establishments stayed } \\
\text { with only one supplier } \\
\text { at a time. }\end{array}$ & 1 & 2 & 3 & 4 & 5 & 6 & 7 \\
\hline 12 & $\begin{array}{l}\text { We do not feel that } \\
\text { remaining loyal to one } \\
\text { supplier is sensible } \\
\text { anymore. }\end{array}$ & 1 & 2 & 3 & 4 & 5 & 6 & 7 \\
\hline 13 & $\begin{array}{l}\text { Even when our } \\
\text { supplier gives us a } \\
\text { rather unlikely } \\
\text { explanation, we are } \\
\text { confident that they are } \\
\text { telling the truth. }\end{array}$ & 1 & 2 & 3 & 4 & 5 & 6 & 7 \\
\hline 14 & $\begin{array}{l}\text { Our supplier has often } \\
\text { provided us } \\
\text { information that has } \\
\text { later proven to be } \\
\text { inaccurate. }\end{array}$ & 1 & 2 & 3 & 4 & 5 & 6 & 7 \\
\hline
\end{tabular}


Appendix 2 (Continued)

\begin{tabular}{|c|c|c|c|c|c|c|c|c|}
\hline 15 & $\begin{array}{l}\text { Our supplier usually } \\
\text { keeps the promises } \\
\text { that it makes to our } \\
\text { establishment. }\end{array}$ & 1 & 2 & 3 & 4 & 5 & 6 & 7 \\
\hline & $\begin{array}{l}\text { Please indicate how } \\
\text { much you either } \\
\text { agree or disagree } \\
\text { with the items below. }\end{array}$ & $\begin{array}{l}\text { Strongly } \\
\text { Disagree }\end{array}$ & Disagree & $\begin{array}{c}\text { Moderatel } \\
\mathbf{y} \\
\text { Disagree }\end{array}$ & $\begin{array}{c}\text { Neither } \\
\text { Agree nor } \\
\text { Disagree }\end{array}$ & $\begin{array}{l}\text { Moderately } \\
\text { Agree }\end{array}$ & Agree & $\begin{array}{c}\text { Strongly } \\
\text { Agree }\end{array}$ \\
\hline 16 & $\begin{array}{l}\text { Whenever our } \\
\text { supplier gives us } \\
\text { advice on our business } \\
\text { operations, we know } \\
\text { that it is sharing its } \\
\text { best judgment. }\end{array}$ & 1 & 2 & 3 & 4 & 5 & 6 & 7 \\
\hline 17 & $\begin{array}{l}\text { Our establishment can } \\
\text { count on our supplier } \\
\text { to be sincere. }\end{array}$ & 1 & 2 & 3 & 4 & 5 & 6 & 7 \\
\hline 18 & $\begin{array}{l}\text { Though circumstances } \\
\text { change, we believe } \\
\text { that our supplier will } \\
\text { be ready and willing } \\
\text { to offer us assistance } \\
\text { and support. }\end{array}$ & 1 & 2 & 3 & 4 & 5 & 6 & 7 \\
\hline 19 & $\begin{array}{l}\text { When making } \\
\text { important decisions, } \\
\text { our supplier is } \\
\text { concerned about our } \\
\text { welfare. }\end{array}$ & 1 & 2 & 3 & 4 & 5 & 6 & 7 \\
\hline 20 & $\begin{array}{l}\text { When we share our } \\
\text { problems with our } \\
\text { supplier, we know that } \\
\text { it will respond with } \\
\text { understanding. }\end{array}$ & 1 & 2 & 3 & 4 & 5 & 6 & 7 \\
\hline 21 & $\begin{array}{l}\text { In the future, we can } \\
\text { count on our supplier } \\
\text { to consider how its } \\
\text { decisions and actions } \\
\text { will affect us. }\end{array}$ & 1 & 2 & 3 & 4 & 5 & 6 & 7 \\
\hline 22 & $\begin{array}{l}\text { When it comes to } \\
\text { things that are } \\
\text { important to us, we } \\
\text { can depend on our } \\
\text { supplier's support. }\end{array}$ & 1 & 2 & 3 & 4 & 5 & 6 & 7 \\
\hline 23 & $\begin{array}{l}\text { I believe our supplier } \\
\text { is an expert in the } \\
\text { position that they } \\
\text { hold. }\end{array}$ & 1 & 2 & 3 & 4 & 5 & 6 & 7 \\
\hline 24 & $\begin{array}{l}\text { Generally speaking, } \\
\text { our supplier's } \\
\text { representatives are } \\
\text { poorly trained. }\end{array}$ & 1 & 2 & 3 & 4 & 5 & 6 & 7 \\
\hline 25 & $\begin{array}{l}\text { Our supplier does } \\
\text { things competently. }\end{array}$ & 1 & 2 & 3 & 4 & 5 & 6 & 7 \\
\hline
\end{tabular}


Appendix 2 (Continued)

\begin{tabular}{|c|c|c|c|c|c|c|c|c|}
\hline 26 & $\begin{array}{l}\text { Unfortunately, our } \\
\text { supplier does things } \\
\text { poorly. }\end{array}$ & 1 & 2 & 3 & 4 & 5 & 6 & 7 \\
\hline 27 & $\begin{array}{l}\text { Our supplier does } \\
\text { things in a capable } \\
\text { manner. }\end{array}$ & 1 & 2 & 3 & 4 & 5 & 6 & 7 \\
\hline & $\begin{array}{l}\text { Please indicate how } \\
\text { much you either } \\
\text { agree or disagree } \\
\text { with the items below. }\end{array}$ & $\begin{array}{l}\text { Strongly } \\
\text { Disagree }\end{array}$ & Disagree & $\begin{array}{c}\text { Moderatel } \\
\mathbf{y} \\
\text { Disagree }\end{array}$ & $\begin{array}{c}\text { Neither } \\
\text { Agree nor } \\
\text { Disagree }\end{array}$ & $\begin{array}{l}\text { Moderately } \\
\text { Agree }\end{array}$ & Agree & $\begin{array}{c}\text { Strongly } \\
\text { Agree }\end{array}$ \\
\hline 28 & $\begin{array}{l}\text { Our supplier is a good } \\
\text { partner to deal with. }\end{array}$ & 1 & 2 & 3 & 4 & 5 & 6 & 7 \\
\hline 29 & $\begin{array}{l}\text { We are satisfied with } \\
\text { the products/service } \\
\text { we get from our } \\
\text { supplier }\end{array}$ & 1 & 2 & 3 & 4 & 5 & 6 & 7 \\
\hline 30 & $\begin{array}{l}\text { In general, we are } \\
\text { satisfied with our } \\
\text { dealings with our } \\
\text { supplier }\end{array}$ & 1 & 2 & 3 & 4 & 5 & 6 & 7 \\
\hline 31 & $\begin{array}{l}\text { We will continue } \\
\text { having a relationship } \\
\text { with our supplier if we } \\
\text { can. }\end{array}$ & 1 & 2 & 3 & 4 & 5 & 6 & 7 \\
\hline 32 & $\begin{array}{l}\text { We are satisfied with } \\
\text { the service we get } \\
\text { from our supplier }\end{array}$ & 1 & 2 & 3 & 4 & 5 & 6 & 7 \\
\hline 33 & $\begin{array}{l}\text { We are satisfied with } \\
\text { the performance of } \\
\text { our supplier's } \\
\text { products/service (e.g. } \\
\text { sales) }\end{array}$ & 1 & 2 & 3 & 4 & 5 & 6 & 7 \\
\hline 34 & $\begin{array}{l}\text { We are satisfied with } \\
\text { the performance of } \\
\text { our relationship with } \\
\text { our supplier }\end{array}$ & 1 & 2 & 3 & 4 & 5 & 6 & 7 \\
\hline 35 & $\begin{array}{l}\text { We are satisfied with } \\
\text { the extent to which } \\
\text { our sales target has } \\
\text { been met. }\end{array}$ & 1 & 2 & 3 & 4 & 5 & 6 & 7 \\
\hline 36 & $\begin{array}{l}\text { Regarding the } \\
\text { economic aspect of } \\
\text { our relationship with } \\
\text { our supplier we are } \\
\text { pleased with its } \\
\text { performance. }\end{array}$ & 1 & 2 & 3 & 4 & 5 & 6 & 7 \\
\hline 37 & $\begin{array}{l}\text { Regarding the } \\
\text { economic aspect of } \\
\text { our relationship with } \\
\text { our supplier we are } \\
\text { pleased with its } \\
\text { reliability. }\end{array}$ & 1 & 2 & 3 & 4 & 5 & 6 & 7 \\
\hline
\end{tabular}


Appendix 2 (Continued)

\begin{tabular}{|c|c|c|c|c|c|c|c|c|}
\hline & $\begin{array}{l}\text { If for some reason } \\
\text { our supplier ended } \\
\text { its relationship with } \\
\text { us }\end{array}$ & $\begin{array}{l}\text { Strongly } \\
\text { Disagree }\end{array}$ & Disagree & $\begin{array}{c}\text { Moderatel } \\
\mathbf{y} \\
\text { Disagree }\end{array}$ & $\begin{array}{l}\text { Neither } \\
\text { Agree nor } \\
\text { Disagree }\end{array}$ & $\begin{array}{c}\text { Moderately } \\
\text { Agree }\end{array}$ & Agree & $\begin{array}{c}\text { Strongly } \\
\text { Agree }\end{array}$ \\
\hline 38 & $\begin{array}{l}\text { The loss would hurt } \\
\text { our sales of other } \\
\text { supplier's products as } \\
\text { well. }\end{array}$ & 1 & 2 & 3 & 4 & 5 & 6 & 7 \\
\hline \multirow[t]{2}{*}{39} & $\begin{array}{l}\text { We could compensate } \\
\text { for it by switching our } \\
\text { efforts to other } \\
\text { supplier's products we } \\
\text { carry. }\end{array}$ & 1 & 2 & 3 & 4 & 5 & 6 & 7 \\
\hline & & $\begin{array}{l}\text { Strongly } \\
\text { Disagree }\end{array}$ & Disagree & $\begin{array}{c}\text { Moderatel } \\
\mathbf{y} \\
\text { Disagree }\end{array}$ & $\begin{array}{c}\text { Neither } \\
\text { Agree nor } \\
\text { Disagree }\end{array}$ & $\begin{array}{c}\text { Moderately } \\
\text { Agree }\end{array}$ & Agree & $\begin{array}{c}\text { Strongly } \\
\text { Agree }\end{array}$ \\
\hline 40 & $\begin{array}{l}\text { It would be relatively } \\
\text { easy for us to develop } \\
\text { a relationship with a } \\
\text { different supplier. }\end{array}$ & 1 & 2 & 3 & 4 & 5 & 6 & 7 \\
\hline \multirow[t]{2}{*}{41} & $\begin{array}{l}\text { We would suffer a } \\
\text { significant loss of } \\
\text { income despite our } \\
\text { best efforts to replace } \\
\text { the lost incomes. }\end{array}$ & 1 & 2 & 3 & 4 & 5 & 6 & 7 \\
\hline & $\begin{array}{l}\text { If for some reason } \\
\text { we ended our } \\
\text { relationship with our } \\
\text { supplier }\end{array}$ & $\begin{array}{l}\text { Strongly } \\
\text { Disagree }\end{array}$ & Disagree & $\begin{array}{c}\text { Moderatel } \\
\mathbf{y} \\
\text { Disagree }\end{array}$ & $\begin{array}{c}\text { Neither } \\
\text { Agree nor } \\
\text { Disagree }\end{array}$ & $\begin{array}{c}\text { Moderately } \\
\text { Agree }\end{array}$ & Agree & $\begin{array}{c}\text { Strongly } \\
\text { Agree }\end{array}$ \\
\hline 42 & $\begin{array}{l}\text { Such a loss would } \\
\text { seriously hurt the sales } \\
\text { of our supplier in this } \\
\text { area. }\end{array}$ & 1 & 2 & 3 & 4 & 5 & 6 & 7 \\
\hline 43 & $\begin{array}{l}\text { Our supplier could } \\
\text { easily compensate for } \\
\text { it by finding another } \\
\text { establishment in this } \\
\text { area. }\end{array}$ & 1 & 2 & 3 & 4 & 5 & 6 & 7 \\
\hline 44 & $\begin{array}{l}\text { There are other } \\
\text { establishments in this } \\
\text { area that would } \\
\text { quickly partner with } \\
\text { our supplier. }\end{array}$ & 1 & 2 & 3 & 4 & 5 & 6 & 7 \\
\hline 45 & $\begin{array}{l}\text { Such a loss would } \\
\text { seriously damage our } \\
\text { supplier's reputation } \\
\text { in this area. }\end{array}$ & 1 & 2 & 3 & 4 & 5 & 6 & 7 \\
\hline 46 & $\begin{array}{l}\text { Such a loss would } \\
\text { negatively affect the } \\
\text { availability our } \\
\text { supplier's customers } \\
\text { have come to expect. }\end{array}$ & 1 & 2 & 3 & 4 & 5 & 6 & 7 \\
\hline
\end{tabular}




\section{Appendix 2 (Continued)}

\section{Survey II:}

\section{Section I: Relationship Issues}

The following questions, in this second survey, are concerned with how business relationships deal with such things as conflict or other situations that drift outside of how the business relationship normally operates. Incidents or issues that run contrary to what each partner in a business relationship finds acceptable occur in all business relationships. In this survey, we ask you to recall and discuss an issue that has adversely affected the relationship you have had with your chosen main supplier. Please remember that these results will not be discussed or otherwise revealed in any way shape or form to any supplier listed in this survey so please be as honest and frank as possible.

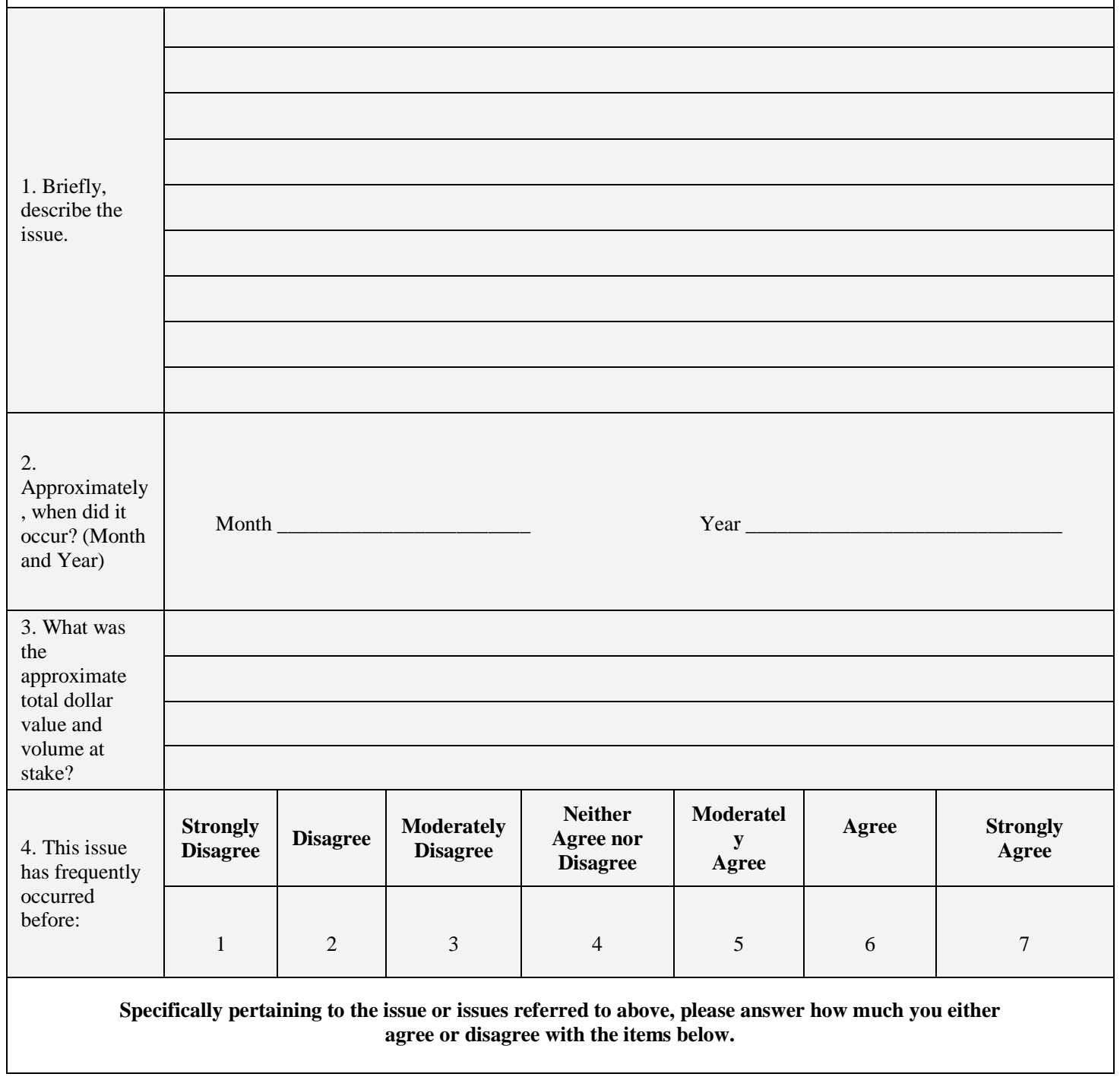


Appendix 2 (Continued)

\begin{tabular}{|c|c|c|c|c|c|c|c|c|}
\hline & $\begin{array}{l}\text { Please indicate how } \\
\text { much you either } \\
\text { agree or disagree } \\
\text { with the items } \\
\text { below. }\end{array}$ & $\begin{array}{l}\text { Strongly } \\
\text { Disagree }\end{array}$ & Disagree & $\begin{array}{c}\text { Moderatel } \\
\mathbf{y} \\
\text { Disagree }\end{array}$ & $\begin{array}{c}\text { Neither } \\
\text { Agree nor } \\
\text { Disagree }\end{array}$ & $\begin{array}{c}\text { Moderately } \\
\text { Agree }\end{array}$ & Agree & $\begin{array}{c}\text { Strongly } \\
\text { Agree }\end{array}$ \\
\hline 1 & $\begin{array}{l}\text { We have little control } \\
\text { over the things that } \\
\text { happen in our } \\
\text { relationship with our } \\
\text { supplier }\end{array}$ & 1 & 2 & 3 & 4 & 5 & 6 & 7 \\
\hline 2 & $\begin{array}{l}\text { There is really no } \\
\text { way we can solve the } \\
\text { problems in our } \\
\text { relationship with our } \\
\text { supplier. }\end{array}$ & 1 & 2 & 3 & 4 & 5 & 6 & 7 \\
\hline 3 & $\begin{array}{l}\text { There is little we can } \\
\text { do to change our } \\
\text { relationship with our } \\
\text { supplier. }\end{array}$ & 1 & 2 & 3 & 4 & 5 & 6 & 7 \\
\hline 4 & $\begin{array}{l}\text { We often feel } \\
\text { helpless when } \\
\text { dealing with our } \\
\text { supplier. }\end{array}$ & 1 & 2 & 3 & 4 & 5 & 6 & 7 \\
\hline & & $\begin{array}{l}\text { Strongly } \\
\text { Disagree }\end{array}$ & Disagree & $\begin{array}{c}\text { Moderatel } \\
\mathbf{y} \\
\text { Disagree }\end{array}$ & $\begin{array}{c}\text { Neither } \\
\text { Agree nor } \\
\text { Disagree }\end{array}$ & $\begin{array}{c}\text { Moderately } \\
\text { Agree }\end{array}$ & Agree & $\begin{array}{c}\text { Strongly } \\
\text { Agree }\end{array}$ \\
\hline 5 & $\begin{array}{l}\text { Regarding how our } \\
\text { supplier behaves in } \\
\text { our relationship, they } \\
\text { can get away with not } \\
\text { doing what we expect } \\
\text { of them. }\end{array}$ & 1 & 2 & 3 & 4 & 5 & 6 & 7 \\
\hline 6 & $\begin{array}{l}\text { We do not have the } \\
\text { ability to stop our } \\
\text { supplier's behavior, } \\
\text { even if it hurts our } \\
\text { establishment. }\end{array}$ & 1 & 2 & 3 & 4 & 5 & 6 & 7 \\
\hline 7 & $\begin{array}{l}\text { I do not believe our } \\
\text { supplier is always } \\
\text { honest in serving us } \\
\text { as a client. }\end{array}$ & 1 & 2 & 3 & 4 & 5 & 6 & 7 \\
\hline 8 & $\begin{array}{l}\text { I believe our supplier } \\
\text { would participate in a } \\
\text { conflict of interest } \\
\text { without prior notice } \\
\text { to all parties } \\
\text { involved. }\end{array}$ & 1 & 2 & 3 & 4 & 5 & 6 & 7 \\
\hline 9 & $\begin{array}{l}\text { I do not believe our } \\
\text { supplier always } \\
\text { considers my } \\
\text { establishment's best } \\
\text { interest when acting. }\end{array}$ & 1 & 2 & 3 & 4 & 5 & 6 & 7 \\
\hline
\end{tabular}




\section{Appendix 2 (Continued)}

\begin{tabular}{|c|c|c|c|c|c|c|c|c|}
\hline 10 & $\begin{array}{l}\text { I believe our supplier, } \\
\text { at times, acts in ways } \\
\text { that could be harmful } \\
\text { to our relationship. }\end{array}$ & 1 & 2 & 3 & 4 & 5 & 6 & 7 \\
\hline 11 & $\begin{array}{l}\text { I believe our supplier, } \\
\text { at times, acts in ways } \\
\text { that could be harmful } \\
\text { to my establishment. }\end{array}$ & 1 & 2 & 3 & 4 & 5 & 6 & 7 \\
\hline 12 & $\begin{array}{l}\text { I believe our supplier, } \\
\text { at times, takes our } \\
\text { relationship for } \\
\text { granted. }\end{array}$ & 1 & 2 & 3 & 4 & 5 & 6 & 7 \\
\hline 13 & $\begin{array}{l}\text { I believe our supplier, } \\
\text { at times, uses our } \\
\text { relationship against } \\
\text { us for their own gain. }\end{array}$ & 1 & 2 & 3 & 4 & 5 & 6 & 7 \\
\hline \multicolumn{9}{|c|}{ Section II: Relationship Dynamics } \\
\hline & $\begin{array}{l}\text { As compared to } \\
\text { other similar } \\
\text { organizations, our } \\
\text { performance is very } \\
\text { high in terms of: }\end{array}$ & $\begin{array}{l}\text { Strongly } \\
\text { Disagree }\end{array}$ & Disagree & $\begin{array}{c}\text { Moderatel } \\
\mathbf{y} \\
\text { Disagree }\end{array}$ & $\begin{array}{l}\text { Neither } \\
\text { Agree nor } \\
\text { Disagree }\end{array}$ & $\begin{array}{c}\text { Moderately } \\
\text { Agree }\end{array}$ & Agree & $\begin{array}{c}\text { Strongly } \\
\text { Agree }\end{array}$ \\
\hline 1 & Sales Growth & 1 & 2 & 3 & 4 & 5 & 6 & 7 \\
\hline 2 & Profit Growth & 1 & 2 & 3 & 4 & 5 & 6 & 7 \\
\hline 3 & Overall Profitability & 1 & 2 & 3 & 4 & 5 & 6 & 7 \\
\hline 4 & Labor Productivity & 1 & 2 & 3 & 4 & 5 & 6 & 7 \\
\hline \multirow[t]{2}{*}{5} & Cash Flow & 1 & 2 & 3 & 4 & 5 & 6 & 7 \\
\hline & $\begin{array}{l}\text { Please indicate how } \\
\text { much you either } \\
\text { agree or disagree } \\
\text { with the items } \\
\text { below. }\end{array}$ & $\begin{array}{l}\text { Strongly } \\
\text { Disagree }\end{array}$ & Disagree & $\begin{array}{c}\text { Moderatel } \\
\mathbf{y} \\
\text { Disagree }\end{array}$ & $\begin{array}{l}\text { Neither } \\
\text { Agree nor } \\
\text { Disagree }\end{array}$ & $\begin{array}{c}\text { Moderately } \\
\text { Agree }\end{array}$ & Agree & $\begin{array}{c}\text { Strongly } \\
\text { Agree }\end{array}$ \\
\hline
\end{tabular}


Appendix 2 (Continued)

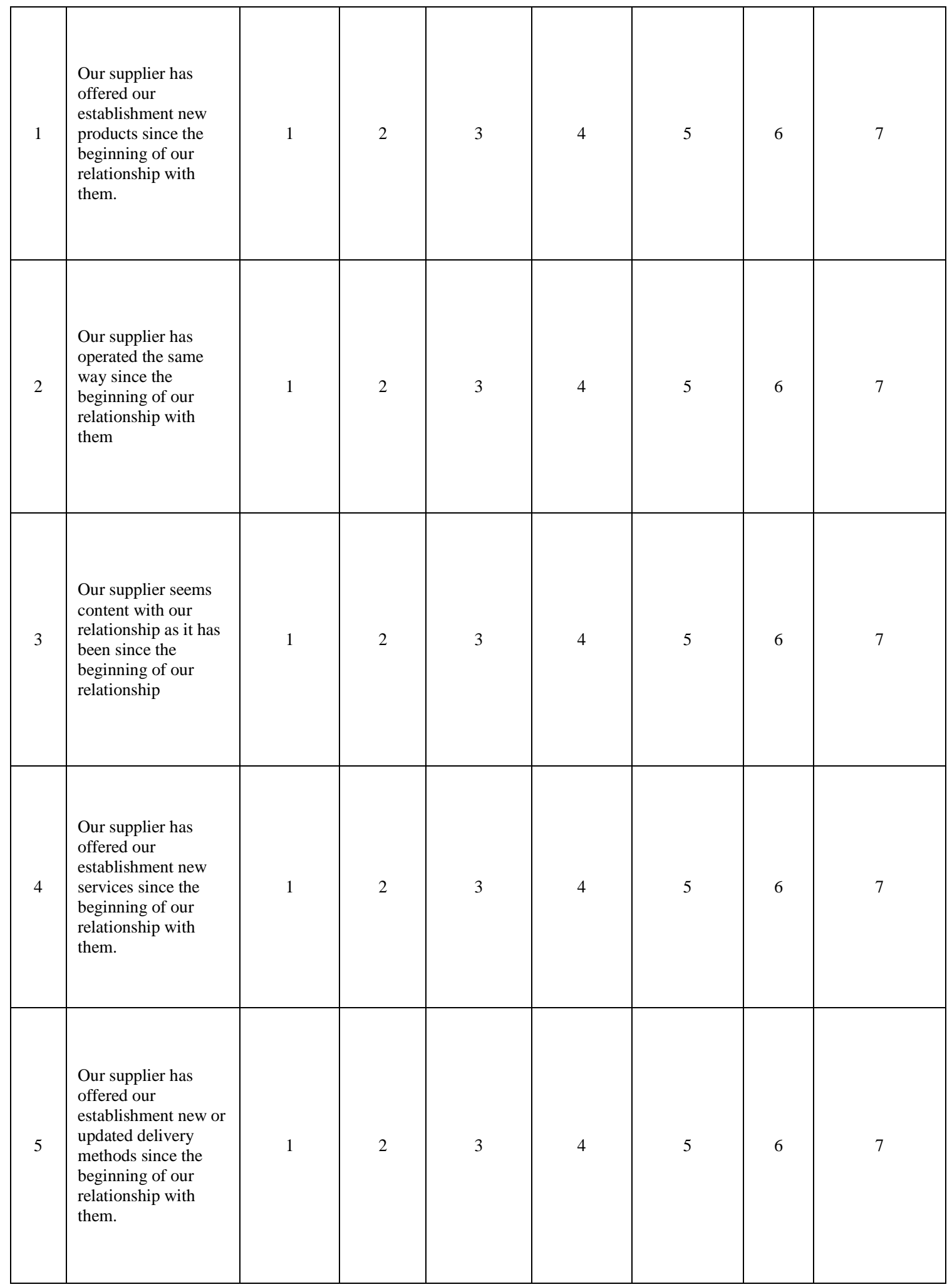


Appendix 2 (Continued)

\begin{tabular}{|c|c|c|c|c|c|c|c|c|}
\hline & & $\begin{array}{l}\text { Strongly } \\
\text { Disagree }\end{array}$ & $\begin{array}{l}\text { Disagre } \\
\text { e }\end{array}$ & $\begin{array}{c}\text { Moderatel } \\
\mathbf{y} \\
\text { Disagree }\end{array}$ & $\begin{array}{l}\text { Neither } \\
\text { Agree nor } \\
\text { Disagree }\end{array}$ & $\begin{array}{c}\text { Moderately } \\
\text { Agree }\end{array}$ & Agree & $\begin{array}{c}\text { Strongly } \\
\text { Agree }\end{array}$ \\
\hline 6 & $\begin{array}{l}\text { Our supplier has } \\
\text { offered our } \\
\text { establishment new or } \\
\text { updated ordering } \\
\text { methods since the } \\
\text { beginning of our } \\
\text { relationship with } \\
\text { them. }\end{array}$ & 1 & 2 & 3 & 4 & 5 & 6 & 7 \\
\hline 7 & $\begin{array}{l}\text { When it comes to our } \\
\text { relationships, we } \\
\text { prefer to stick with } \\
\text { things that we know. }\end{array}$ & 1 & 2 & 3 & 4 & 5 & 6 & 7 \\
\hline 8 & $\begin{array}{l}\text { When it comes to our } \\
\text { relationships, we } \\
\text { dislike change. }\end{array}$ & 1 & 2 & 3 & 4 & 5 & 6 & 7 \\
\hline 9 & $\begin{array}{l}\text { When it comes to } \\
\text { how our } \\
\text { relationships operate, } \\
\text { we are attached to } \\
\text { conventional ways of } \\
\text { doing things. }\end{array}$ & 1 & 2 & 3 & 4 & 5 & 6 & 7 \\
\hline 10 & $\begin{array}{l}\text { When it comes to our } \\
\text { relationship we often } \\
\text { find new ways of } \\
\text { doing things. }\end{array}$ & 1 & 2 & 3 & 4 & 5 & 6 & 7 \\
\hline
\end{tabular}


Appendix 2 (Continued)

\begin{tabular}{|c|c|c|c|c|c|c|c|c|}
\hline 11 & $\begin{array}{l}\text { When it comes to our } \\
\text { relationship, we do } \\
\text { not keep looking for } \\
\text { different suppliers } \\
\text { after we have } \\
\text { developed } \\
\text { relationships with the } \\
\text { ones we have }\end{array}$ & 1 & 2 & 3 & 4 & 5 & 6 & 7 \\
\hline 12 & $\begin{array}{l}\text { When it comes to our } \\
\text { relationship, we } \\
\text { prefer not to change } \\
\text { things that have } \\
\text { proven to work }\end{array}$ & 1 & 2 & 3 & 4 & 5 & 6 & 7 \\
\hline & $\begin{array}{l}\text { Please indicate how } \\
\text { strong or weak the } \\
\text { relationship you } \\
\text { have with your } \\
\text { supplier is, as it } \\
\text { pertains to the } \\
\text { questions below. }\end{array}$ & $\begin{array}{c}\text { Very } \\
\text { Weak }\end{array}$ & Weak & $\begin{array}{c}\text { Moderatel } \\
\text { y } \\
\text { Weak }\end{array}$ & $\begin{array}{l}\text { Neither } \\
\text { Weak nor } \\
\text { Strong }\end{array}$ & $\begin{array}{c}\text { Moderately } \\
\text { Strong }\end{array}$ & $\begin{array}{c}\text { Stron } \\
\mathbf{g}\end{array}$ & $\begin{array}{l}\text { Very } \\
\text { Strong }\end{array}$ \\
\hline 13 & $\begin{array}{l}\text { What is your overall } \\
\text { assessment of the } \\
\text { strength of your } \\
\text { relationship with } \\
\text { your supplier's sales } \\
\text { rep? }\end{array}$ & 1 & 2 & 3 & 4 & 5 & 6 & 7 \\
\hline 14 & $\begin{array}{l}\text { How strong would } \\
\text { you like the strength } \\
\text { of your relationship } \\
\text { with your supplier's } \\
\text { sales rep to be? }\end{array}$ & 1 & 2 & 3 & 4 & 5 & 6 & 7 \\
\hline & $\begin{array}{l}\text { Please indicate how } \\
\text { strong or weak the } \\
\text { relationship you } \\
\text { have with your } \\
\text { supplier is, as it } \\
\text { pertains to the } \\
\text { questions below. }\end{array}$ & $\begin{array}{l}\text { Very } \\
\text { Weak }\end{array}$ & Weak & $\begin{array}{c}\text { Moderatel } \\
\text { y } \\
\text { Weak }\end{array}$ & $\begin{array}{l}\text { Neither } \\
\text { Weak nor } \\
\text { Strong }\end{array}$ & $\begin{array}{c}\text { Moderately } \\
\text { Strong }\end{array}$ & $\begin{array}{c}\text { Stron } \\
\mathbf{g}\end{array}$ & $\begin{array}{l}\text { Very } \\
\text { Strong }\end{array}$ \\
\hline
\end{tabular}


Appendix 2 (Continued)

\begin{tabular}{|c|c|c|c|c|c|c|c|c|}
\hline 11 & $\begin{array}{l}\text { What is your overall } \\
\text { assessment of the } \\
\text { strength of your } \\
\text { relationship with } \\
\text { your supplier as a } \\
\text { company? }\end{array}$ & 1 & 2 & 3 & 4 & 5 & 6 & 7 \\
\hline 12 & $\begin{array}{l}\text { How strong would } \\
\text { you like the strength } \\
\text { of your relationship } \\
\text { with your supplier as } \\
\text { a company to be? }\end{array}$ & 1 & 2 & 3 & 4 & 5 & 6 & 7 \\
\hline 13 & $\begin{array}{l}\text { Over time I feel that } \\
\text { the strength of my } \\
\text { relationship with my } \\
\text { supplier has } \\
\text { become... }\end{array}$ & 1 & 2 & 3 & 4 & 5 & 6 & 7 \\
\hline \multicolumn{9}{|c|}{$\begin{array}{l}\text { Section III: Classification Questions } \\
\text { This final set of questions is asked so that we can combine your answers with other survey participants. } \\
\text { We absolutely guarantee that any reports based on this survey will show only combined findings, and } \\
\text { your individual identity will not be revealed. }\end{array}$} \\
\hline 1 & Your Name: & & & & & & & \\
\hline 2 & $\begin{array}{l}\text { Your Title at your } \\
\text { establishment: }\end{array}$ & & & & & & & \\
\hline 3 & Male or Female: & & Male & & & & & \\
\hline 4 & Your Age: & & & & & & & \\
\hline
\end{tabular}


Appendix 2 (Continued)

\begin{tabular}{|c|c|c|}
\hline 5 & $\begin{array}{l}\text { How long have you } \\
\text { worked in this } \\
\text { industry? }\end{array}$ & \\
\hline 6 & $\begin{array}{l}\text { Your establishments } \\
\text { name: }\end{array}$ & \\
\hline 7 & $\begin{array}{l}\text { How long have you } \\
\text { worked in your } \\
\text { current } \\
\text { establishment? }\end{array}$ & \\
\hline 8 & $\begin{array}{l}\text { How would you } \\
\text { classify your retail } \\
\text { establishment? (e.g. } \\
\text { shoe store, clothing, } \\
\text { pet store etc.) }\end{array}$ & \\
\hline 9 & $\begin{array}{l}\text { How long, to the best } \\
\text { of your knowledge, } \\
\text { has your } \\
\text { establishment been } \\
\text { involved in a } \\
\text { relationship with } \\
\text { your main supplier? }\end{array}$ & \\
\hline 10 & $\begin{array}{l}\text { How often do (or } \\
\text { did) you interact } \\
\text { with your main } \\
\text { supplier's } \\
\text { representative at } \\
\text { your establishment? }\end{array}$ & Estimated Times per Month \\
\hline 11 & $\begin{array}{l}\text { How often did your } \\
\text { main supplier's } \\
\text { representative } \\
\text { interact with you } \\
\text { over the phone? }\end{array}$ & Estimated Times per Month \\
\hline
\end{tabular}




\section{Appendix 2 (Continued)}

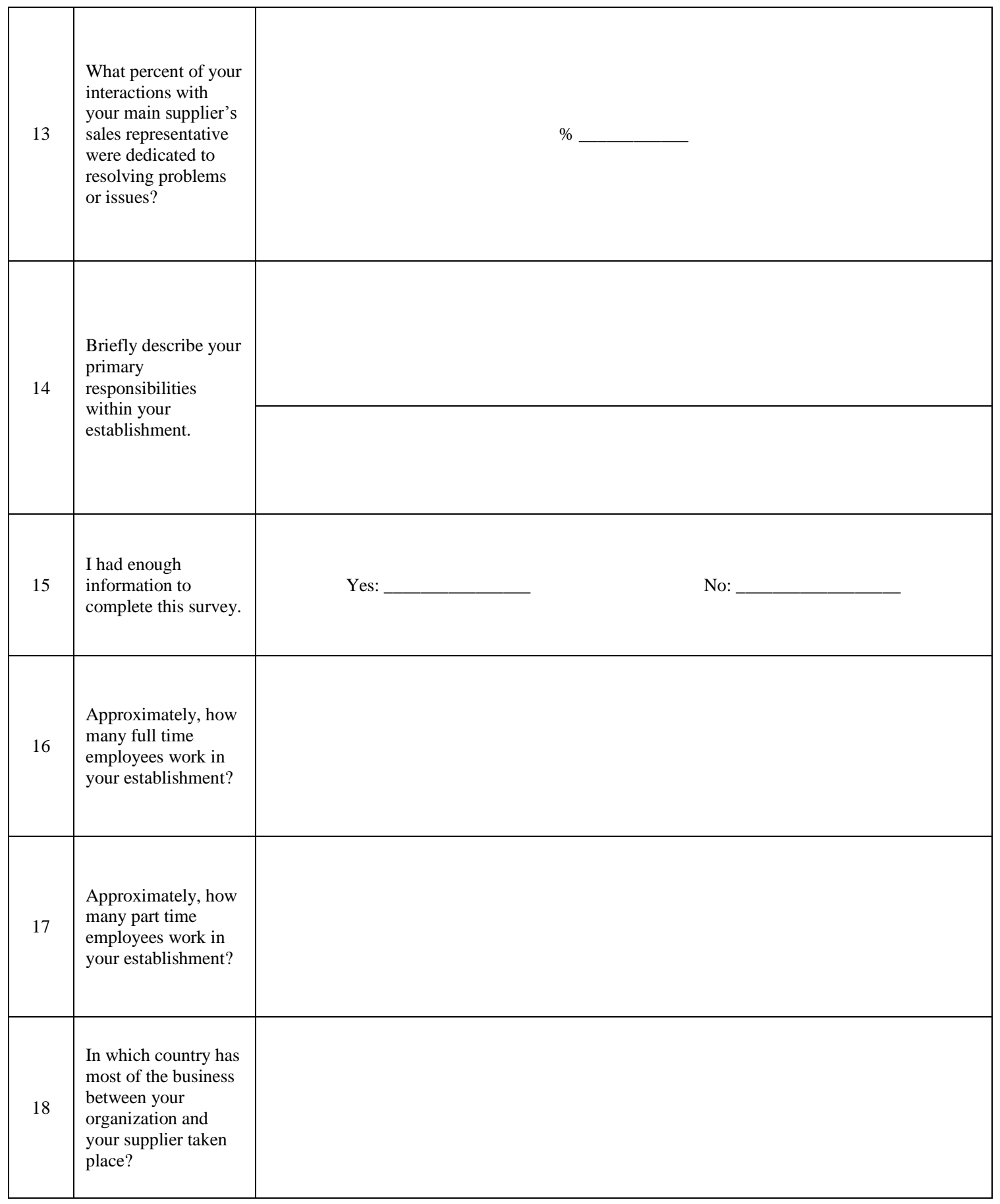


Appendix 2 (Continued)

\begin{tabular}{|c|c|c|}
\hline \multirow{3}{*}{18} & \multirow{3}{*}{$\begin{array}{l}\text { If you would like a } \\
\text { summary report of } \\
\text { this research projects } \\
\text { finding, please } \\
\text { complete the } \\
\text { following or attach a } \\
\text { business card. }\end{array}$} & Email: \\
\hline & & Phone: \\
\hline & & Address: \\
\hline
\end{tabular}


December 8, 2008

Dear Organizational Buyer,

My name is Brent Baker and I am a Ph.D. Candidate in the Marketing Department, at the University of South Florida. I am currently collecting data for my dissertation. The dissertation is the final yet most significant portion of the Marketing Ph.D. program. I elected to study business to business relationships and how they change over time for my dissertation topic. This dissertation is being conducted under the guidance of Dr. Rajiv P. Dant of the University of Oklahoma and Dr. James R. Stock of the University of South Florida. The working hypothesis of this dissertation is that as business relationships age attitudes and behaviors within the relationship will also change.

Attached to this letter is a survey asking about your establishment and the relationship it has with one of your key suppliers.

It is important to note that the attached survey is completely a University of South Florida research project. IT IS NOT IN ANYWAY AFFILIATED OR OTHERWISE ASSOCIATED WITH ANY COMMERCIAL SUPPLIER OR VENDOR. Your participation in this survey is completely voluntary and your individual answers will remain confidential. No names will ever be revealed to any vendor or supplier. The authors of this survey have no reason to consult with any vendor or supplier about the results of this study.

The attached survey should take approximately 20-25 minutes to complete. If there are any questions or concerns regarding the survey and your participation please feel free to contact me. My contact information is listed below. I thank you in advance for your time and support in completing this significant research project.

Sincerely,

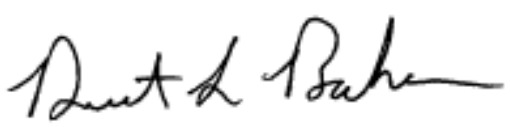

Brent L. Baker

Department of Marketing/College of Business

University of South Florida

4202 East Fowler Avenue, BSN 3403

Tampa, FL 33620-5500

813-974-6239

bbaker@coba.usf.edu 


\begin{abstract}
About the Author
Brent Lynn Baker received his undergraduate degree in Finance, his MBA with concentrations in International Business, Marketing Strategy, and Management, and his Ph.D. in Marketing, all from the University of South Florida. He served five years in the United States Navy where he flew in the S-3B Viking aircraft as an Aviation Warfare Systems Operator. During his time in the military he was able to travel extensively throughout the Middle East and Southern Europe. After completing his undergraduate degree he went to work for a large insurance company as a financial analyst. He worked for this company for approximately three years before deciding to enter the doctoral program. His primary research areas are relationship marketing and business to business marketing.
\end{abstract}

